\title{
INFLUÊNCIA DA UMIDADE NAS PROPRIEDADES DE RESISTÊNCIA E RIGIDEZ DA MADEIRA
}

Norman Barros Logsdon

Tese apresentada à Escola de Engenharia de São Carlos, da Universidade de São Paulo, como parte dos requisitos para obtenção do título de Doutor em Engenharia de Estruturas

ORIENTADOR: Prof. Tit. Carlito Calil Júnior

São Carlos

1998 
Gass. TCSE-EESC

Cutt.

Tombo

13102

$\infty 9$

\section{0}

Ficha catalográfica preparada pela Seção de Tratamento da Informação do Serviço de Biblioteca - EESC/USP

\section{Logsdon, Norman Barros}

L832i Influência da umidade nas propriedades de resistência e rigidez da madeira / Norman Barros Logsdon. -- São Carlos, 1998.

Tese (Doutorado) -- Escola de Engenharia de São Carlos-Universidade de São Paulo, 1998.

Área: Engenharia de Estruturas.

Orientador: Prof. Dr. Carlito Calil Júnior.

1. Madeira. 2. Teor de umidade. 3. Resistência. 4. Rigidez. I. Título. 


\section{FOLHA DE APROVACÃO}

Candidato: Engenheiro NORMAN BARROS LOGSDON

Tese defendida e aprovada em 16.12 .1998

pela Comissão Julgadora:

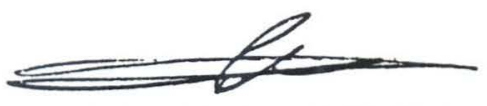

Prof. Tit. CARLITO CALIL JUNIOR (Orientador)

(Escola de Engenharia de São Carlos - Universidade de São Paulo)

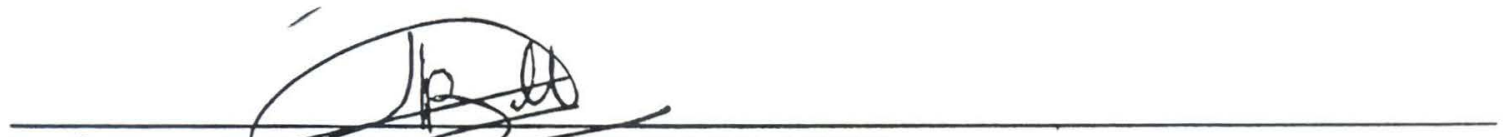

\section{Prof. Dr A RI AGGER BALLARIN}

(UNESP - Campus de Botucatu)

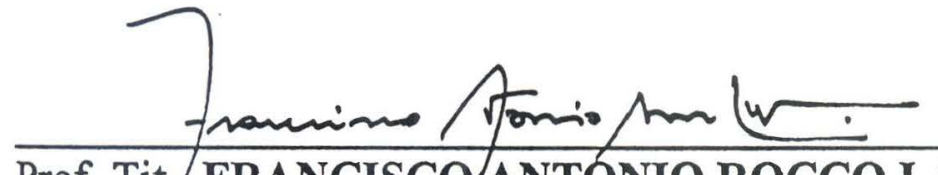

Prof. Tit. FRANCISCO ANTONIO ROCCO LAHR

(Escola/de Engenharia de São Carlos - Universidade de São Paulo)

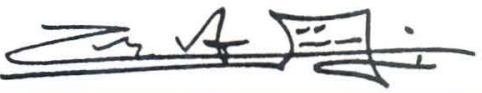

\section{Prof. Dr. CARLOS ALBERTO SZÜCS}

(Universidade Federal de Santa Catarina)

\section{Prof. Dr. ELOY FERRAZ MACHADO JUNIOR}

(Escola de Engenharia de São Carlos - Universidade de São Paulo)

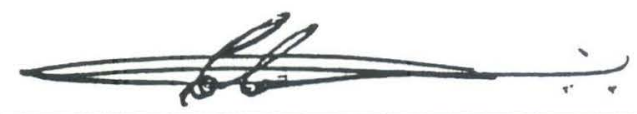

Prof. Titular CARLITO CALIL JUNIOR

Coordenador da Área de Engenharia de Estruturas

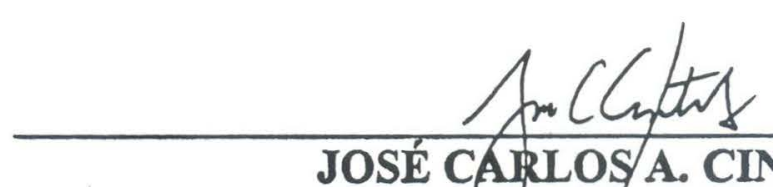

\section{JOSÉ CARLOSA. CINTRA}

Presidente da Comissão de Pós-Graduação da EESC 
Ao passado, em memória de meus pais Norman e Zilah e de meus tios Svinte e Jandira, pela sólida base acadêmica que permitiu o assentamento dos novos conhecimentos adquiridos no desenvolvimento deste trabalho.

Ao presente, na dedicação e carinho de minha esposa Noemia e no apoio de minha tia Noemia, pela disposição e criatividade.

Ao futuro, representado por minhas filhas Lauren e Louise, pela esperança de que o trabalho desenvolvido frutifique. 


\section{AGRADECIMENTOS}

A Deus, pela saúde e vitalidade.

Ao Professor Carlito Calil Júnior, pela excelente orientação fornecida e pela amizade demonstrada durante a elaboração deste trabalho.

À Coordenadoria de Aperfeiçoamento de Pessoal de Nível Superior - CAPES, pela bolsa de estudo concedida.

Ao Instituto Florestal, da Prefeitura Municipal de Itirapina, por fornecer a madeira necessária para a elaboração deste trabalho.

Aos colegas da Universidade Federal de Mato Grosso, José Holanda Campelo Júnior, Marco Antônio Araújo Pinto e Zenesio Finger, pelo incentivo e apoio na viabilização de meu afastamento para a realização deste trabalho. Um agradecimento especial ao Professor Zenesio Finger pela identificação da madeira utilizada neste trabalho.

Aos alunos do Curso de Engenharia Florestal da Faculdade de Engenharia Florestal, Universidade Federal de Mato Grosso, representados pela aluna Mariza Misturini e pelo exaluno Antônio de Arruda Tsukamoto Júnior, pela compreensão e pelo sacrifício em cursar, durante meu afastamento, a disciplina Estruturas de Madeira no período de férias.

A todos os colegas, professores e funcionários do Departamento de Engenharia de Estruturas da Escola de Engenharia de São Carlos, Universidade de São Paulo , pelo carinho, pelos ensinamentos e pela colaboração. Um agradecimento especial ao funcionário José Francisco do Nascimento, pela alegria e disposição demonstrada durante a realização dos ensaios. 


\section{SUMÁRIO}

LISTA DE FIGURAS viii

LISTA DE TABELAS $\quad \mathrm{xV}$

LISTA DE ABREVIATURAS E SIGLAS xxi

LISTA DE SÍMBOLOS xxii

RESUMO XXV

ABSTRACT xxvi

1. INTRODUÇÃO 1

2. OBJETIVOS 7

3. JUSTIFICATIVA 8

4. REVISÃO BIBLIOGRÁFICA 11

4.1. GENERALIDADES 11

4.2. SOBRE O PROCEDIMENTO DE SECAGEM 20

4.3. RETRAÇÃO E INCHAMENTO 25

4.4. DENSIDADE APARENTE 27

4.5. COMPRESSÃO PARALELA ÀS FIBRAS 28

4.6. TRAÇÃO PARALELA ÀS FIBRAS 34

4.7. CISALHAMENTO PARALELO ÀS FIBRAS 35

4.8. FLEXÃO ESTÁTICA 37

4.9. MÓDULO DE ELASTICIDADE 42

4.10. OUTRAS PROPRIEDADES 46

4.11. ALGUMAS EXPRESSÕES UTILIZADAS PARA DEFINIR O EFEITO DO TEOR DE UMIDADE SOBRE UMA DETERMINADA PROPRIEDADE DA MADEIRA 55

4.12. COMENTÁRIOS SOBRE A REVISÃO BIBLIOGRÁFICA REALIZADA 64

5. MATERIAL E MÉTODOS 69

5.1. SELEÇÃO DAS ESPÉCIES

5.2. MADEIRA E CORPOS DE PROVA NECESSÁRIOS 69 
5.3. OBTENÇÃO E IDENTIFICAÇÃO DA MADEIRA NECESSÁRIA 72

5.4. BREVE DESCRIÇÃO DAS ESPÉCIES UTILIZADAS 73

5.4.1. PINUS BAHAMENSIS $\quad 73$

$\begin{array}{ll}\text { 5.4.2. PINUS ELLIOTTII } & 74\end{array}$

$\begin{array}{ll}\text { 5.4.3. PINUS TAEDA } & 75\end{array}$

5.4.4. EUCALIPTO GRANDIS 75

5.4.5. CUPIÚBA 76

5.4.6. EUCALIPTO CITRIODORA 76

5.4.7. ЈАТОВÁ 77

5.5. PROCEDIMENTO DE SECAGEM E CONTROLE DO TEOR DE $\begin{array}{ll}\text { UMIDADE } & 77\end{array}$

5.6. ENSAIO DE COMPRESSÃO PARALELA ÀS FIBRAS 80

5.7. ENSAIO DE TRAÇÃO PARALELA ÀS FIBRAS 81

5.8. ENSAIO DE CISALHAMENTO 82

5.9. ANÁLISE ESTATÍSTICA 83

6. RESULTADOS E DISCUSSÃO 86

6.1. ENSAIOS DE COMPRESSÃO PARALELA 86

6.1.1. PINUS BAHAMENSIS 86

6.1.2. PINUS ELLIOTTII 92

6.1.3. PINUS TAEDA 93

6.1.4. EUCALIPTO GRANDIS 95

6.1.5. CUPIÚBA 96

6.1.6. EUCALIPTO CITRIODORA 97

6.1.7. JATOBÁ 98

6.2. ENSAIOS DE TRAÇÃO PARALELA ÀS FIBRAS 100

6.2.1. PINUS BAHAMENSIS 100

6.2.2. PINUS ELLIOTTII 101

6.2.3. PINUS TAEDA 102

6.2.4. EUCALIPTO GRANDIS 102

6.2.5. CUPIÚBA 103

6.2.6. EUCALIPTO CITRIODORA 103

6.2.7. JATOBÁ 103

6.3. ENSAIOS DE CISALHAMENTO 104

6.3.1. PINUS BAHAMENSIS 104

6.3.2. PINUS ELLIOTTII 105 
6.3.3. PINUS TAEDA

106

6.3.4. EUCALIPTO GRANDIS 107

6.3.5. CUPIÚBA 108

6.3.6. EUCALIPTO CITRIODORA 109

6.3.7. JATOBÁ 110

6.4. REGRESSÕES PARA OBTENÇÃO DAS RELAÇÕES ENTRE O

TEOR DE UMIDADE E CADA PROPRIEDADE DA MADEIRA 111

6.4.1. PINUS BAHAMENSIS 111

6.4.2. PINUS ELLIOTTII 114

6.4.3. PINUS TAEDA 118

6.4.4. EUCALIPTO GRANDIS 121

6.4.5. CUPIÚBA 124

6.4.6. EUCALIPTO CITRIODORA 127

6.4.7. JATOBÁ 130

6.4.8. RESUMO DOS RESULTADOS 133

6.5. VERIFICAÇÃO DA POSSIBILIDADE DE APLICAÇÃO DE ALGUNS MODELOS PARA CORREÇÃO DE DETERMINADA PROPRIEDADE AO TEOR DE UMIDADE DE REFERÊNCIA 134 6.5.1. PINUS BAHAMENSIS 134

6.5.2. PINUS ELLIOTTII 146

6.5.3. PINUS TAEDA 149

6.5.4. EUCALIPTO GRANDIS 152

6.5.5. CUPIÚBA 154

6.5.6. EUCALIPTO CITRIODORA 157

6.5.7. JATOBÁ 160

6.5.8. RESUMO DOS TESTES DE TUKEY 163

7. CONCLUSÕES 167

8. REFERÊNCIAS BIBLIOGRÁFICAS 170 


\section{LISTA DE FIGURAS}

FIGURA 01 - Variação da resistência à compressão paralela às fibras com o teor de umidade. Exemplo obtido para a PEROBA ROSA, Aspidosperma peroba.

FIGURA. 02 - Curvas de tensão-deformação obtidas em ensaios de compressão normal às fibras, em "Douglas-Fir", a diferentes teores de umidade.

FIGURA 03 - Relações entre propriedades de compressão paralela às fibras e o teor de umidade em corpos de prova de "Douglas-Fir".

FIGURA 04 - Variação do módulo de elasticidade transversal de "Scarlet Oak" com o teor de umidade.

FIGURA 05 - Resistência à tração normal às fibras de Califórnia "Black Oak" em função do teor de umidade.

FIGURA 06 - Relações entre propriedades mecânicas e o teor de umidade de corpos de provas, pequenos e isentos de defeitos, de "Stika Spruce".

FIGURA 07 - Variação da resistência com o teor de umidade, para a tração e compressão paralela às fibras de "Spruce-Pine-Fir". O comportamento das duas propriedades são totalmente diferentes.

FIGURA 08 - Gradiente de umidade observado em uma peça de "Douglas Fir". As regiões mais escuras representam, proporcionalmente, teores de umidade mais elevados. Os valores representam teores de umidade em \%.

FIGURA 09 - Efeito da severidade do processo de secagem sobre a resistência à flexão.

FIGURA 10 - Teor de umidade de equilíbrio da madeira em vários ambientes. A figura varia um pouco com a espécie e o diagrama mostra apenas valores médios.

FIGURA 11 - Comparação entre os métodos de Secagem ao Ar e de Equilíbrio (Condicionamento em câmara de climatização).

FIGURA 12 - Comparação entre os métodos de Secagem ao Ar e de Exposição (exposição às intempéries por três meses, seguido de secagem ao ar). 
FIGURA 13 - Inchamento volumétrico como uma função do teor de umidade para diferentes espécies de madeira.

FIGURA 14 - Diagramas de inchamentos para a Itaúba, Mezilaurus itauba (Meissn) Taubert ex Mez.

FIGURA 15 - Diagramas de Retrações para a Itaúba, Mezilaurus itauba (Meissn) Taubert ex Mez.

FIGURA 16 - Inchamento volumétrico por $1 \%$ de aumento no teor de umidade relacionado à densidade aparente seca.

FIGURA 17 - Diagrama de Kollmann, que representa a variação da densidade aparente com o teor de umidade.

FIGURA 18 - Relação entre a resistência à compressão paralela às fibras e o teor de umidade.

FIGURA 19 - Efeitos do teor de umidade sobre a resistência à compressão paralela às fibras para algumas espécies de madeira.

FIGURA 20 - Influência da umidade sobre a resistência à compressão paralela às fibras para o Eucalyptus puntacta.

FIGURA 21 - Variação da resistência à compressão paralela às fibras com o teor de umidade do Eucalyptus saligna.

FIGURA 22 - Influência da umidade e da densidade sobre a resistência à compressão paralela às fibras do Eucalipto Citriodora.

FIGURA 23 - Variação da resistência à compressão paralela às fibras com a umidade do Eucalipto Citriodora.

FIGURA 24 - Variação da resistência à compressão paralela às fibras com o teor de umidade em "Southern pine".

FIGURA 25 - Variação da resistência à tração paralela às fibras com o teor de umidade em "Southern pine".

FIGURA 26 - Efeito do teor de umidade sobre a resistência ao cisalhamento (corpo de prova com um plano de cisalhamento) para "pine".

FIGURA 27 - Variação da resistência ao cisalhamento paralelo às fibras com o teor de umidade em "Southern pine".

FIGURA 28 - Variação da resistência ao cisalhamento paralelo às fibras com o teor de umidade em Eucalyptus saligna.

FIGURA 29 - Variação da resistência ao cisalhamento paralelo às fibras com o teor de umidade em "Hem-Fir" e "Southern-Pine-Fir" (S-P-F). O comportamento dos dois grupos de espécies é muito diferente. 
FIGURA 30 - Influência da umidade e da densidade sobre a resistência à flexão para o Jatobá.

FIGURA 31 - Efeito do teor de umidade sobre a resistência à flexão: de a) "ash" e "pine", b) "beech".

FIGURA 32 - Variação da resistência à flexão com o teor de umidade em "Southern pine".

FIGURA 33 - Variação da resistência à flexão com o teor de umidade em Eucalyptus saligna.

FIGURA 34 - Modelo Analítico do efeito do teor de umidade sobre a resistência à flexão.

FIGURA 35 - Efeitos do teor de umidade sobre a resistência à flexão de peças comerciais, de seção 2" x 4" (5 cm x $10 \mathrm{~cm})$, classe "Select Structural", aos níveis percentuais de $5,10,25,50,75,90$ e 95 .

FIGURA 36 - Variação da resistência à flexão com o teor de umidade.

FIGURA 37 - Efeito do teor de umidade sobre o módulo de elasticidade longitudinal de "Stika spruce". O módulo de elasticidade longitudinal foi determinado dinamicamente.

FIGURA 38 - Efeito do teor de umidade sobre o módulo de elasticidade na direção paralela às fibras de "spruce".

FIGURA 39 - Variação do módulo de elasticidade, obtido no ensaio de flexão, com o teor de umidade em Eucalyptus saligna.

FIGURA 40 - Efeitos do teor de umidade sobre o módulo de elasticidade, obtido no ensaio de flexão, de peças comerciais, de seção 2" x 4" $(5 \mathrm{~cm}$ x 10 $\mathrm{cm})$, classe "Select Structural", aos níveis percentuais de 5, 10, 25, 50, 75,90 e 95.

FIGURA 41 - Efeitos do teor de umidade sobre o módulo de elasticidade, obtido no ensaio de flexão, em peças de "Douglas Fir".

FIGURA 42 - Variação da resistência à tração normal às fibras com o teor de umidade da madeira de Eucalyptus saligna.

FIGURA 43 - Variação da resistência à tração normal às fibras com o teor de umidade em "Southern pine".

FIGURA 44 - Variação da resistência à compressão normal às fibras com o teor de umidade em "Southern pine".

FIGURA 45 - Efeito do teor de umidade sobre as constantes elásticas de "Stika spuce". 
FIGURA 46 - Efeito do teor de umidade sobre o módulo de elasticidade transversal de "Stika spruce". O módulo de elasticidade transversal foi determinado dinamicamente.

FIGURA 47 - Variação do módulo de elasticidade longitudinal, na direção tangencial, com o teor de umidade e com a temperatura.

FIGURA 48 - Efeito do teor de umidade sobre a dureza, Método Brinell, de "pine".

FIGURA 49 - Diagramas carga-deformação para ensaios de flexão estática em madeiras a diferentes teores de umidade: a) madeira seca em estufa; b) madeira seca ao ar; c) madeira verde.

FIGURA. 50 - Efeito do teor de umidade na deformação por impacto e no trabalho de impacto para "beechwood".

FIGURA 51 - Variação do momento resistente com o teor de umidade. A capacidade de resistir ao momento diminui, a medida em que a madeira seca, para material com uma resistência menor que $35 \mathrm{MPa}$.

FIGURA 52 - Variação do produto de rigidez (E.I) com o teor de umidade. O produto de rigidez praticamente não é afetado pelas alterações do teor de umidade.

FIGURA 53 - Curvas típicas utilizadas para representar a influência do teor de umidade sobre as propriedades de resistência e rigidez.

FIGURA 54 - Uma amostra, refletindo a enorme variabilidade da madeira, pode causar um erro de especificação no modelo da relação resistênciaumidade. O comportamento depende do indivíduo.

FIGURA 55 - Posição da retirada das barras e orientação de seus anéis de crescimento.

FIGURA 56 - Madeira de Pinus caribea Morelet var bahamensis (Griseb) Barret et Golfari

FIGURA 57 - Madeira de Pinus elliottii Engelm

FIGURA 58 - Madeira de Pinus taeda L.

FIGURA 59 - Madeira de Eucalyptus grandis (Hill) Maiden. 75

FIGURA 60 - Madeira de Goupia glabra Aubl. 76

FIGURA 61 - Madeira de Eucalyptus citriodora Hook.

FIGURA 62 - Madeira de Hymenaeae stilbocarpa Hayne. 77

FIGURA 63 - Ensaio de compressão paralela: a) máquina universal, b) corpo de prova e c) instalação para o ensaio. 
FIGURA 64 - Ensaio de tração paralela: a) máquina universal, b) corpo de prova e c) instalação para o ensaio.

FIGURA 65 - Ensaio de cisalhamento: a) máquina universal, b) corpo de prova e c) instalação para o ensaio.

FIGURA 66 - Planilha para acompanhamento do ensaio de compressão paralela às fibras.

FIGURA 67 - Diagrama tensão x deformação específica para o corpo de prova, cuja folha de ensaio é apresentada na figura 66.

FIGURA 68 - Diagrama de desvios

FIGURA 69 - Planilha para acompanhamento do ensaio de tração paralela às fibras.

FIGURA 70 - Planilha para acompanhamento do ensaio de cisalhamento.

FIGURA 71 - Influência do teor de umidade sobre a resistência à compressão paralela às fibras, para o Pinus caribaea var. bahamensis.

FIGURA 72 - Influência do teor de umidade sobre a resistência à tração paralela às fibras, para o Pinus caribaea var. bahamensis.

FIGURA 73 - Influência do teor de umidade sobre a resistência cisalhamento, para o Pinus caribaea var. bahamensis.

FIGURA 74 - Influência do teor de umidade sobre o módulo de elasticidade longitudinal, para o Pinus caribaea var. bahamensis.

FIGURA 75 - Influência do teor de umidade sobre a densidade aparente, para o Pinus caribaea var. bahamensis.

FIGURA 76 - Influência do teor de umidade sobre a resistência à compressão paralela às fibras, para o Pinus elliottii.

FIGURA 77 - Influência do teor de umidade sobre a resistência à tração paralela às fibras, para o Pinus elliottii.

FIGURA 78 - Influência do teor de umidade sobre a resistência cisalhamento, para o Pinus elliottii.

FIGURA 79 - Influência do teor de umidade sobre o módulo de elasticidade longitudinal, para o Pinus elliottii.

FIGURA 80 - Influência do teor de umidade sobre a densidade aparente, para o Pinus elliottii.

FIGURA 81 - Influência do teor de umidade sobre a resistência à compressão paralela às fibras, para o Pinus taeda.

FIGURA 82 - Influência do teor de umidade sobre a resistência à tração paralela às fibras, para o Pinus taeda. 
FIGURA 83 - Influência do teor de umidade sobre a resistência cisalhamento, para o Pinus taeda.

FIGURA 84 - Influência do teor de umidade sobre o módulo de elasticidade longitudinal, para o Pinus taeda.

FIGURA 85 - Influência do teor de umidade sobre a densidade aparente, para o Pinus taeda.

FIGURA 86 - Influência do teor de umidade sobre a resistência à compressão paralela às fibras, para o Eucalyptus grandis.

FIGURA 87 - Influência do teor de umidade sobre a resistência à tração paralela às fibras, para o Eucalyptus grandis.

FIGURA 88 - Influência do teor de umidade sobre a resistência cisalhamento, para o Eucalyptus grandis.

FIGURA 89 - Influência do teor de umidade sobre o módulo de elasticidade longitudinal, para o Eucalyptus grandis.

FIGURA 90 - Influência do teor de umidade sobre a densidade aparente, para o $E u$ calyptus grandis.

FIGURA 91 - Influência do teor de umidade sobre a resistência à compressão paralela às fibras, para a Goupia glabra.

FIGURA 92 - Influência do teor de umidade sobre a resistência à tração paralela às fibras, para a Goupia glabra.

FIGURA 93 - Influência do teor de umidade sobre a resistência cisalhamento, para a Goupia glabra.

FIGURA 94 - Influência do teor de umidade sobre o módulo de elasticidade longitudinal, para a Goupia glabra.

FIGURA 95 - Influência do teor de umidade sobre a densidade aparente, para a Goupia glabra.

FIGURA 96 - Influência do teor de umidade sobre a resistência à compressão paralela às fibras, para o Eucalyptus citriodora.

FIGURA 97 - Influência do teor de umidade sobre a resistência à tração paralela às fibras, para o Eucalyptus citriodora.

FIGURA 98 - Influência do teor de umidade sobre a resistência cisalhamento, para o Eucalyptus citriodora.

FIGURA 99 - Influência do teor de umidade sobre o módulo de elasticidade longitudinal, para o Eucalyptus citriodora. 
FIGURA 100 - Influência do teor de umidade sobre a densidade aparente, para o $E u$ calyptus citriodora.

FIGURA 101 - Influência do teor de umidade sobre a resistência à compressão paralela às fibras, para o Hymenaea stilbocarpa.

FIGURA 102 - Influência do teor de umidade sobre a resistência à tração paralela às fibras, para o Hymenaea stilbocarpa.

FIGURA 103 - Influência do teor de umidade sobre a resistência cisalhamento, para o Hymenaea stilbocarpa.

FIGURA 104 - Influência do teor de umidade sobre o módulo de elasticidade longitudinal, para o Hymenaea stilbocarpa.

FIGURA 105 - Influência do teor de umidade sobre a densidade aparente, para o $\mathrm{Hy}$ menaea stilbocarpa. 


\section{LISTA DE TABELAS}

TABELA 01 - Classes de umidade 2

TABELA 02 - Valores de $\mathrm{k}_{\text {mod.2 }}$

TABELA 03 - Classes de carregamento 3

TABELA 04 - Valores de $\mathrm{k}_{\text {mod.1 }}$

TABELA 05 - Valores de $\mathrm{k}_{\text {mod.3 }}$

TABELA 06 - Coeficientes de ponderação das resistências 5

TABELA 07 - Incremento médio nas propriedades mecânicas para um decréscimo de $1 \%$ no teor de umidade abaixo do ponto de saturação das fibras 18

$\begin{array}{ll}\text { TABELA } 08 \text { - Valores do coeficiente } \alpha & 19\end{array}$

$\begin{array}{ll}\text { TABELA } 09 \text { - Seleção das espécies } & 70\end{array}$

$\begin{array}{ll}\text { TABELA } 10 \text { - Quantidade de corpos de prova, ou de ensaios, prevista } & 72\end{array}$

TABELA 11 - Espécies utilizadas 73

TABELA 12 - Estatística e resumo dos resultados da regressão linear $\sigma=\mathrm{A}+\mathrm{B} . \varepsilon$, para o corpo de prova BAH-16. 88

TABELA 13 - Análise de variância da regressão linear $\sigma=\mathrm{A}+$ B.e , para o corpo de prova BAH-16.

TABELA 14 - Coeficientes obtidos para a regressão linear $\sigma=\mathrm{A}+\mathrm{B} . \varepsilon$, do corpo de prova BAH-16.

TABELA 15 - Resultados obtidos nos ensaios de compressão paralela às fibras em Pinus caribaea var. bahamensis

TABELA 16 - Resultados obtidos nos ensaios de compressão paralela às fibras em Pinus elliottii

TABELA 17 - Resultados obtidos nos ensaios de compressão paralela às fibras em Pinus taeda

TABELA 18 - Resultados obtidos nos ensaios de compressão paralela às fibras em Eucalyptus grandis 
TABELA 19 - Resultados obtidos nos ensaios de compressão paralela às fibras em Goupia glabra

TABELA 20 - Resultados obtidos nos ensaios de compressão paralela às fibras em Eucalyptus citriodora

TABELA 21 - Resultados obtidos nos ensaios de compressão paralela às fibras em Hymenaea stilbocarpa

TABELA 22 - Resultados obtidos nos ensaios de tração paralela às fibras em Pinus caribaea var. bahamensis

TABELA 23 - Resultados obtidos nos ensaios de tração paralela às fibras em Pinus elliottii

TABELA 24 - Resultados obtidos nos ensaios de tração paralela às fibras em Pinus taeda

TABELA 25 - Resultados obtidos nos ensaios de tração paralela às fibras em $E u$ calyptus grandis

TABELA 26 - Resultados obtidos nos ensaios de tração paralela às fibras em Goupia glabra

TABELA 27 - Resultados obtidos nos ensaios de tração paralela às fibras em Eucalyptus citriodora

TABELA 28 - Resultados obtidos nos ensaios de tração paralela às fibras em Hymenaea stilbocarpa

TABELA 29 - Resultados obtidos nos ensaios de cisalhamento em Pinus caribaea var. bahamensis

TABELA 30 - Resultados obtidos nos ensaios de cisalhamento em Pinus elliottii

TABELA 31 - Resultados obtidos nos ensaios de cisalhamento em Pinus taeda

TABELA 32 - Resultados obtidos nos ensaios de cisalhamento em Eucalyptus grandis

TABELA 33 - Resultados obtidos nos ensaios de cisalhamento em Goupia glabra

TABELA 34 - Resultados obtidos nos ensaios de cisalhamento em Eucalyptus citriodora

TABELA 35 - Resultados obtidos nos ensaios de cisalhamento em Hymenaea stilbocarpa

TABELA 36 - Resumo dos resultados das regressões para as propriedades de resistência do Pinus caribaea var. bahamensis.

TABELA 37 - Resumo dos resultados da regressão para a rigidez do Pinus caribaea var. bahamensis. 
TABELA 38 - Resumo dos resultados da regressão para a densidade aparente do $P i$ nus caribaea var. bahamensis.

TABELA 39 - Resumo dos resultados das regressões para as propriedades de resistência do Pinus elliottii.

TABELA 40 - Resumo dos resultados da regressão para a rigidez do Pinus elliottii.

TABELA 41 - Resumo dos resultados da regressão para a densidade aparente do Pinus elliottii.

TABELA 42 - Resumo dos resultados das regressões para as propriedades de resistência do Pinus taeda.

TABELA 43 - Resumo dos resultados da regressão para a rigidez do Pinus taeda.

TABELA 44 - Resumo dos resultados da regressão para a densidade aparente do $\mathrm{Pi}$ nus taeda.

TABELA 45 - Resumo dos resultados das regressões para as propriedades de resistência do Eucalyptus grandis.

TABELA 46 - Resumo dos resultados da regressão para a rigidez do Eucalyptus grandis.

TABELA 47 - Resumo dos resultados da regressão para a densidade aparente do $E u$ calyptus grandis.

TABELA 48 - Resumo dos resultados das regressões para as propriedades de resistência da Goupia glabra.

TABELA 49 - Resumo dos resultados da regressão para a rigidez da Goupia glabra.

TABELA 50 - Resumo dos resultados da regressão para a densidade aparente da Goupia glabra.

TABELA 51 - Resumo dos resultados das regressões para as propriedades de resistência do Eucalyptus citriodora.

TABELA 52 - Resumo dos resultados da regressão para a rigidez do Eucalyptus citriodora.

TABELA 53 - Resumo dos resultados da regressão para a densidade aparente do Eucalyptus citriodora.

TABELA 54 - Resumo dos resultados das regressões para as propriedades de resistência do Hymenaea stilbocarpa.

TABELA 55 - Resumo dos resultados da regressão para a rigidez do Hymenaea stilbocarpa.

TABELA 56 - Resumo dos resultados da regressão para a densidade aparente do $H y$ menaea stilbocarpa. 
TABELA 57 - Resumo dos resultados das regressões.

TABELA 58 - Tratamentos utilizados no teste de Tukey para o estudo de cada propriedade de resistência.

TABELA 59 - Teste de Tukey - Análise de variância (Resistência à compressão paralela, $\mathrm{f}_{\mathrm{c} 0}$ em MPa - Pinus caribaea var. bahamensis)

TABELA 60 - Teste de Tukey - Tabela de médias (Resistência à compressão paralela, $\mathrm{f}_{\mathrm{c} 0}$ em MPa - Pinus caribaea var. bahamensis)

TABELA 61 - Teste de Tukey - Grupos de médias homogêneas (Resistência à compressão paralela, $\mathrm{f}_{\mathrm{c} 0} \mathrm{em} \mathrm{MPa} \mathrm{-} \mathrm{Pinus} \mathrm{caribaea} \mathrm{var.} \mathrm{bahamensis)}$

TABELA 62 - Teste de Tukey - Grupos de médias homogêneas (Resistência à tração paralela, $\mathrm{f}_{\mathrm{t} 0}$ em $\mathrm{MPa}$ - Pinus caribaea var. bahamensis)

TABELA 63 - Teste de Tukey - Grupos de médias homogêneas (Resistência ao cisalhamento, $\mathrm{f}_{\mathrm{v} 0}$ em MPa - Pinus caribaea var. bahamensis)

TABELA 64 - Tratamentos utilizados no teste de Tukey para o estudo do módulo de elasticidade longitudinal.

TABELA 65 - Teste de Tukey - Grupos de médias homogêneas (Módulo de elasticidade longitudinal, $\mathrm{E}_{\mathrm{c} 0}$ em MPa - Pinus caribaea var. bahamensis)

TABELA 66 - Tratamentos utilizados no teste de Tukey para o estudo da densidade aparente.

TABELA 67 - Teste de Tukey - Grupos de médias homogêneas (Densidade aparente, $\rho \mathrm{em} \mathrm{g} / \mathrm{cm}^{3}$ - Pinus caribaea var. bahamensis)

TABELA 68 - Teste de Tukey - Grupos de médias homogêneas (Resistência à compressão paralela, $\mathrm{f}_{\mathrm{c} 0} \mathrm{em} \mathrm{MPa} \mathrm{-} \mathrm{Pinus} \mathrm{elliottii)}$

TABELA 69 - Teste de Tukey - Grupos de médias homogêneas (Resistência à tração paralela, $\mathrm{f}_{\mathrm{t} 0}$ em MPa - Pinus elliottii)

TABELA 70 - Teste de Tukey - Grupos de médias homogêneas (Resistência ao cisalhamento, $\mathrm{f}_{\mathrm{v} 0} \mathrm{em} \mathrm{MPa} \mathrm{-} \mathrm{Pinus} \mathrm{elliottii)}$

TABELA 71 - Teste de Tukey - Grupos de médias homogêneas (Módulo de elasticidade longitudinal, $\mathrm{E}_{\mathrm{c} 0}$ em MPa - Pinus elliottii)

TABELA 72 - Teste de Tukey - Grupos de médias homogêneas (Densidade aparente, $\rho \mathrm{em} \mathrm{g} / \mathrm{cm}^{3}$ - Pinus elliottii)

TABELA 73 - Teste de Tukey - Grupos de médias homogêneas (Resistência à compressão paralela, $\mathrm{f}_{\mathrm{c} 0}$ em $\mathrm{MPa}$ - Pinus taeda)

TABELA 74 - Teste de Tukey - Grupos de médias homogêneas (Resistência à tração paralela, $\mathrm{f}_{\mathrm{t} 0}$ em MPa - Pinus taeda) 
TABELA 75 - Teste de Tukey - Grupos de médias homogêneas (Resistência ao cisalhamento, $\mathrm{f}_{\mathrm{v} 0}$ em MPa - Pinus taeda)

TABELA 76 - Teste de Tukey - Grupos de médias homogêneas (Módulo de elasticidade longitudinal, $\mathrm{E}_{\mathrm{c} 0}$ em MPa - Pinus taeda)

TABELA 77 - Teste de Tukey - Grupos de médias homogêneas (Densidade aparente, $\rho \mathrm{em} \mathrm{g} / \mathrm{cm}^{3}-$ Pinus taeda)

TABELA 78 - Teste de Tukey - Grupos de médias homogêneas (Resistência à compressão paralela, $\mathrm{f}_{\mathrm{c} 0} \mathrm{em} \mathrm{MPa-Eucalyptus} \mathrm{grandis)}$

TABELA 79 - Teste de Tukey - Grupos de médias homogêneas (Resistência à tração paralela, $\mathrm{f}_{\mathrm{t} 0} \mathrm{em} \mathrm{MPa} \mathrm{-} \mathrm{Eucalyptus} \mathrm{grandis)}$

TABELA 80 - Teste de Tukey - Grupos de médias homogêneas (Resistência ao cisalhamento, $\mathrm{f}_{\mathrm{v} 0}$ em MPa - Eucalyptus grandis)

TABELA 81 - Teste de Tukey - Grupos de médias homogêneas (Módulo de elasticidade longitudinal, $\mathrm{E}_{\mathrm{c} 0}$ em MPa - Eucalyptus grandis)

TABELA 82 - Teste de Tukey - Grupos de médias homogêneas (Densidade aparente, $\rho \mathrm{em} \mathrm{g} / \mathrm{cm}^{3}$ - Eucalyptus grandis)

TABELA 83 - Teste de Tukey - Grupos de médias homogêneas (Resistência à compressão paralela, $\mathrm{f}_{\mathrm{c} 0} \mathrm{em} \mathrm{MPa} \mathrm{-} \mathrm{Goupia} \mathrm{glabra)}$

TABELA 84 - Teste de Tukey - Grupos de médias homogêneas (Resistência à tração paralela, $\mathrm{f}_{\mathrm{t} 0} \mathrm{em} \mathrm{MPa} \mathrm{-} \mathrm{Goupia} \mathrm{glabra)}$

TABELA 85 - Teste de Tukey - Grupos de médias homogêneas (Resistência ao cisalhamento, $\mathrm{f}_{\mathrm{v} 0} \mathrm{em} \mathrm{MPa} \mathrm{-} \mathrm{Goupia} \mathrm{glabra)}$

TABELA 86 - Teste de Tukey - Grupos de médias homogêneas (Módulo de elasticidade longitudinal, $\mathrm{E}_{\mathrm{c} 0}$ em MPa - Goupia glabra)

TABELA 87 - Teste de Tukey - Grupos de médias homogêneas (Densidade aparente, $\rho \mathrm{em} \mathrm{g} / \mathrm{cm}^{3}$ - Goupia glabra)

TABELA 88 - Teste de Tukey - Grupos de médias homogêneas (Resistência à compressão paralela, $\mathrm{f}_{\mathrm{c} 0} \mathrm{em} \mathrm{MPa-Eucalyptus} \mathrm{citriodora)}$

TABELA 89 - Teste de Tukey - Grupos de médias homogêneas (Resistência à tração paralela, $\mathrm{f}_{\mathrm{t} 0} \mathrm{em} \mathrm{MPa}$ - Eucalyptus citriodora)

TABELA 90 - Teste de Tukey - Grupos de médias homogêneas (Resistência ao cisalhamento, $\mathrm{f}_{\mathrm{v} 0}$ em MPa - Eucalyptus citriodora)

TABELA 91 - Teste de Tukey - Grupos de médias homogêneas (Módulo de elasticidade longitudinal, $\mathrm{E}_{\mathrm{c} 0}$ em MPa - Eucalyptus citriodora) 
TABELA 92 - Teste de Tukey - Grupos de médias homogêneas (Densidade aparente, $\rho \mathrm{em} \mathrm{g} / \mathrm{cm}^{3}$ - Eucalyptus citriodora)

TABELA 93 - Teste de Tukey - Grupos de médias homogêneas (Resistência à compressão paralela, $\mathrm{f}_{\mathrm{c} 0}$ em MPa - Hymenaea stilbocarpa)

TABELA 94 - Teste de Tukey - Grupos de médias homogêneas (Resistência à tração paralela, $\mathrm{f}_{\mathrm{t} 0} \mathrm{em} \mathrm{MPa} \mathrm{-} \mathrm{Hymenaea} \mathrm{stilbocarpa)}$

TABELA 95 - Teste de Tukey - Grupos de médias homogêneas (Resistência ao cisalhamento, $\mathrm{f}_{\mathrm{v} 0}$ em MPa - Hymenaea stilbocarpa)

TABELA 96 - Teste de Tukey - Grupos de médias homogêneas (Módulo de elasticidade longitudinal, $\mathrm{E}_{\mathrm{c} 0}$ em MPa - Hymenaea stilbocarpa)

TABELA 97 - Teste de Tukey - Grupos de médias homogêneas (Densidade aparente, $\rho \mathrm{em} \mathrm{g} / \mathrm{cm}^{3}$ - Hymenaea stilbocarpa)

TABELA 98 - Tratamentos estatisticamente equivalentes aos resultados experimentais (Densidade aparente)

TABELA 99 - Tratamentos estatisticamente equivalentes aos resultados experimentais (Módulo de elasticidade longitudinal)

TABELA 100 - Tratamentos estatisticamente equivalentes aos resultados experimentais (Propriedades de resistência)

TABELA 101 - Valores do coeficiente de correção, $\alpha$ 


\title{
LISTA DE ABREVIATURAS E SIGLAS
}

\author{
ABNT - Associação Brasileira de Normas Técnicas \\ BAH - Pinus bahamensis (para denominar corpos de prova desta espécie) \\ CEN - Comitê Europeu de Normalização \\ CIT - Eucalipto citriodora (para denominar corpos de prova desta espécie) \\ C. P. - Corpo de prova \\ CSA - Canadian Standards Association (Associação Canadense de Normalização) \\ CUP - Cupiúba (para denominar corpos de prova desta espécie) \\ ELL - Pinus elliottii (para denominar corpos de prova desta espécie) \\ FPL - Forest Products Laboratory \\ GRD - Eucalipto grandis (para denominar corpos de prova desta espécie) \\ JAT - Jatobá (para denominar corpos de prova desta espécie) \\ MB - Método Brasileiro \\ NBR - Norma Brasileira Registrada \\ PSF - Ponto de Saturação das Fibras \\ TDA - Pinus taeda (para denominar corpos de prova desta espécie) \\ var. - variedade
}




\section{LISTA DE SÍMBOLOS}
A, B - constantes (coeficientes da regressão);
$\mathrm{A}_{\mathrm{a}} \quad$ - Trabalho após a ruptura (notação utilizada exclusivamente na figura 49);
$A_{b} \quad-$ Trabalho antes da ruptura (notação utilizada exclusivamente na figura 49);
d - desvios (variável estudada, no teste de "pairing");
$\overline{\mathrm{d}} \quad$ - estimativa da média dos desvios;
$\mathrm{E}_{12} \quad$ - rigidez (módulo de elasticidade longitudinal) da madeira a um teor de umidade de $12 \%$;
$\mathrm{E}_{\mathrm{c} 0} \quad$ - módulo de elasticidade longitudinal;
$\mathrm{E}_{\mathrm{c} 0 \text {,NBR }}$ - módulo de elasticidade longitudinal, obtido pela expressão fornecida pela NBR 7190, da ABNT (1997);

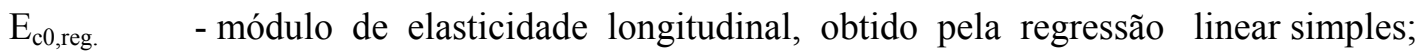
$\mathrm{E}_{\mathrm{U} \%} \quad$ - rigidez (módulo de elasticidade longitudinal) da madeira a um teor de umidade de U\%;
$\mathrm{f}_{1}$ e $\mathrm{f}_{2} \quad$ - valores de uma particular propriedade de resistência, respectivamente, para os teores de umidade $\mathrm{U}_{1}$ e $\mathrm{U}_{2}$ (em \%);
$\mathrm{f}_{12} \quad-$ resistência, à determinada solicitação, a um teor de umidade de $12 \%$;
$\mathrm{f}_{15} \quad-$ resistência a um teor de umidade de $15 \%$;
$\mathrm{f}_{\mathrm{ar}} \quad$ - resistência (ou outra propriedade mecânica), da madeira seca ao ar;
$\mathrm{f}_{\mathrm{c} 0} \quad$ - resistência à compressão paralela às fibras;
$\mathrm{f}_{\mathrm{c} 0,12 \%} \quad$ - resistência da madeira, à compressão paralela às fibras, ao teor de umidade de referência de $12 \%$;
$\mathrm{f}_{\mathrm{c} 0, \mathrm{k}} \quad$ - resistência característica à compressão paralela às fibras;
$\mathrm{f}_{\mathrm{c} 0, \mathrm{~m}} \quad$ - resistência média à compressão paralela às fibras;
$\mathrm{f}_{\mathrm{c} 0, \mathrm{U} \%} \quad$ - resistência da madeira, à compressão paralela às fibras, ao teor de umidade $\mathrm{U} \%$;
$\mathrm{f}_{\text {ensaio }} \quad$ - resistência (ou outra propriedade mecânica), obtida no ensaio;
$\mathrm{f}_{\mathrm{t} 0} \quad$ - resistência à tração paralela às fibras; 


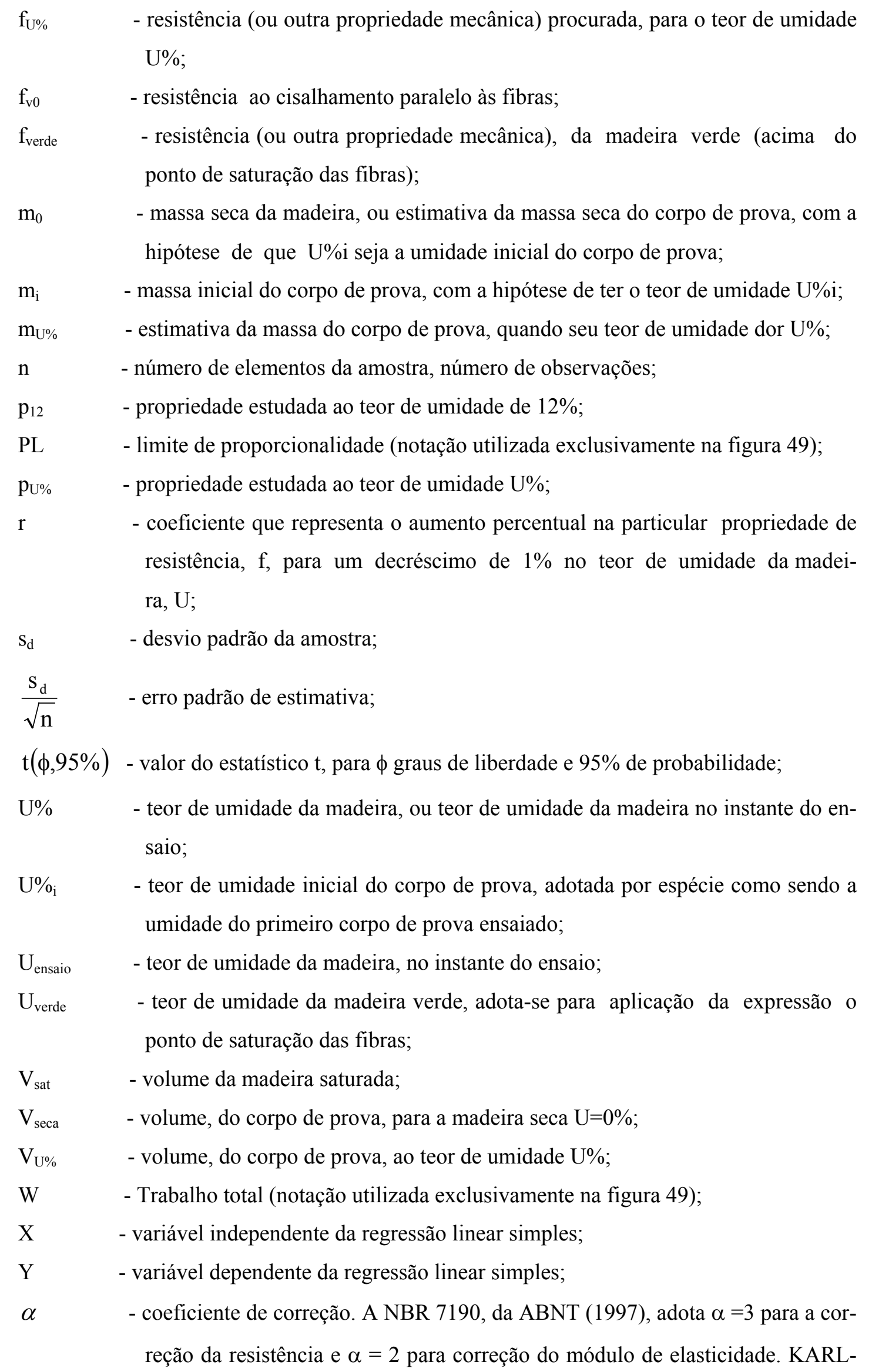


SEN et al (1967) utiliza os valores da tabela 08. No estudo de MATEUS (1962), para o Pinho Bravo, $\alpha$ assume o valor aproximado de 25 $\mathrm{kgf} / \mathrm{cm}^{2}$, para relacionar a resistência à compressão paralela às fibras ao teor de umidade. Neste trabalho, foram obtidos valores médios apresentados na tabela 57, e na conclusão se propõe os valores da tabela 101. Ângulo da linha reta no limite elástico (notação utilizada exclusivamente na figura 49). Coeficiente angular da regressão linear simples;

$\beta_{0} \ldots \beta_{4} \quad$ - constantes (coeficientes da regressão);

$\delta_{\mathrm{V}} \quad$ - coeficiente de retratibilidade volumétrica;

$\Delta \mathrm{V} \quad$ - retração volumétrica, para a variação de umidade entre $\mathrm{U} \%$ e $0 \%$;

$\phi \quad$ - número de graus de liberdade;

$\mu_{\mathrm{d}} \quad-$ média dos desvios;

$\rho \quad$ - densidade aparente;

$\rho_{12} \quad$ - densidade aparente, ao teor de umidade $12 \%$;

$\rho_{\text {bas }} \quad$ - densidade básica, e

$\rho_{\mathrm{U} \%} \quad$ - densidade aparente, ao teor de umidade $\mathrm{U} \%$. 


\section{RESUMO}

LOGSDON, N. B. (1998). Influência da umidade nas propriedades de resistência e rigidez da madeira. São Carlos, 1998. 174p. Tese (Doutorado) - Escola de Engenharia de São Carlos - Universidade de São Paulo.

A norma brasileira para o projeto de estruturas de madeira foi alterada, recentemente, abandonando o método determinista das Tensões Admissíveis e adotando o método probabilista dos Estados Limites. Seguindo tendência mundial, a atual norma brasileira, estabelece um teor de umidade de referência de $12 \%$, no qual devem ser reportados os resultados dos ensaios.

Dificilmente se conseguirá condicionar, a madeira para o ensaio, com um teor de umidade de exatamente $12 \%$, portanto, será necessário corrigir os resultados do ensaio para este teor de umidade. A atual norma brasileira propõe expressões, para fazer esta correção nas propriedades de resistência e de rigidez da madeira, baseando-se em poucos resultados de ensaios.

O objetivo deste trabalho é aferir as expressões propostas pela norma brasileira, sugerindo as alterações necessárias. Uma proposta para a correção da densidade aparente, não prevista na norma brasileira, também será estudada.

Para garantir uma base experimental adequada, estuda-se a influência do teor de umidade sobre as propriedades de resistência à compressão paralela às fibras, tração paralela às fibras, cisalhamento paralelo às fibras (no plano radial-longitudinal), bem como sobre o módulo de elasticidade longitudinal e a densidade aparente, em sete diferentes espécies de madeira, correspondentes às sete classes de resistência adotadas pela atual norma brasileira.

Conclui-se o trabalho apresentando uma proposta para correção das propriedades de resistência e rigidez ao teor de umidade de $12 \%$. Apresenta-se também uma proposta para a correção da densidade aparente.

Palavras-chave: madeira; teor de umidade; resistência; rigidez. 


\begin{abstract}
LOGSDON, N. B. (1998). Influence of moisture content on strength and stiffness of wood. São Carlos, 1998. 174p. PHD Thesis. Escola de Engenharia de São Carlos - Universidade de São Paulo.
\end{abstract}

The Brazilian Code, NBR 7190/97 - Design of timber structures, was revisited, recently, abandoning the Allowable Stress Method and adopting the States Limits Design Method. Following world tendency, the current Brazilian Code, establishes a reference moisture content of $12 \%$, in which the test's results should be registered.

It is not possible to keep the specimen, for testing, with exactly $12 \%$ moisture content, therefore, it will be necessary to correct the results for this moisture content level. The current Brazilian Code proposes expressions, to do this correction in the strength and stiffness properties of wood, based on few test's results.

The objective of this work is to judge the expressions proposed by the Brazilian Code, proposing the necessary alterations. A proposal for the correction of the specific gravity, not presented in the Brazilian Code, it will also be studied.

To this purpose, the influence of moisture content on the strength in compression and tension parallel to grain, shear parallel to grain (in the radial-longitudinal plane), as well as on the stiffness (modulus of elasticity) and specific gravity, in seven different wood species, corresponding to the seven Brazilian Code strength classes were studied.

The conclusions presents a proposal for correction of the strength, stiffness properties and specific gravity, to the $12 \%$ moisture content level.

Keywords: wood; moisture content; strength; stiffness. 


\section{INTRODUÇÃO}

Há muito tempo sabe-se que a resistência da madeira varia com seu teor de umidade. Com o aumento do teor de umidade da madeira observa-se uma diminuição em sua resistência mecânica, esta variação na resistência é mais sensível para baixos teores de umidade, e é praticamente desprezível para elevados teores de umidade.

Decorre deste fato, que para comparar a resistência de duas espécies, ou peças, a uma determinada solicitação, é necessário estabelecer-se um teor de umidade de referência, pois uma espécie de menor resistência, com baixo teor de umidade, pode aparentar maior resistência que uma espécie sabidamente mais resistente, porém com elevado teor de umidade.

A antiga norma brasileira, NBR 7190 - Cálculo e Execução de Estruturas de Madeira, da Associação Brasileira de Normas Técnicas - ABNT (1982), baseada no método determinista das tensões admissíveis, simplificava este problema ao recomendar que durante o projeto se considerasse a madeira verde, com umidade acima do ponto de saturação das fibras, situação em que a resistência fica praticamente constante. Com essa postura o dimensionamento subestimava a resistência da madeira, pois uma estrutura de madeira raramente estará em serviço com a madeira verde à exceção de estruturas submersas. No início da construção a madeira pode até estar verde, mas ela secará ao longo da construção, e em serviço terá um teor de umidade muito inferior ao da madeira verde, e portanto uma resistência bem superior.

A nova versão da norma brasileira, NBR 7190 - Projeto de Estruturas de Madeira, da ABNT (1997), baseada no método probabilista dos estados limites, a exemplo da maioria das normas internacionais, adota a umidade de referência de $12 \%$. Uma espécie, ou peça, é dita mais resistente que outra, a uma determinada solicitação, se sua resistência, ao teor de umidade de referência de $12 \%$, for superior.

A fixação da umidade de referência acrescenta duas novas questões ao cálculo de estruturas de madeira.

A primeira diz respeito a umidade da madeira em serviço, ou seja, se as condições ambientais acarretarem um teor de umidade da madeira diferente da umidade de referência o que se deve fazer? 
Para responder a esta questão a atual norma brasileira, estabelece classes de umidade com a finalidade de ajustar as propriedades de resistência e rigidez da madeira em função das condições ambientais em que permanecerá a estrutura. Na tabela 01 são apresentadas as classes de umidade.

TABELA 01 - Classes de umidade

\begin{tabular}{ccc}
\hline $\begin{array}{c}\text { CLASSES DE } \\
\text { UMIDADE }\end{array}$ & $\begin{array}{c}\text { UMIDADE RELATIVA } \\
\text { DO AMBIENTE } \mathbf{U}_{\mathrm{amb}}\end{array}$ & $\begin{array}{c}\text { UMIDADE DE EQUILÍBRIO } \\
\text { DA MADEIRA }\end{array}$ \\
\hline 1 & $\leq 65 \%$ & $12 \%$ \\
2 & $65 \%<\mathrm{U}_{\mathrm{amb}} \leq 75 \%$ & $15 \%$ \\
3 & $75 \%<\mathrm{U}_{\mathrm{amb}} \leq 85 \%$ & $18 \%$ \\
4 & $\mathrm{U}_{\mathrm{amb}}>85 \%$ durante longos períodos & $\geq 25 \%$
\end{tabular}

Fonte: ABNT (1997)

Conhecida a classe de umidade, em que se supõe a madeira em serviço, pode-se corrigir o valor de cálculo, da resistência ou da rigidez, utilizando o coeficiente parcial de modificação $\mathrm{k}_{\text {mod.2, }}$ que considera o teor de umidade da madeira em serviço e o tipo de material empregado. Na tabela 02 são apresentados os valores deste coeficiente.

TABELA 02 - Valores de $\mathrm{k}_{\text {mod.2 }}$

\begin{tabular}{ccc}
\hline CLASSES DE & MADEIRA SERRADA & MADEIRA RECOMPOSTA \\
UMIDADE & MADEIRA LAMINADA E COLADA & \\
& MADEIRA COMPENSADA & 1,0 \\
\hline$(1)$ e (2) & 1,0 & 0,9 \\
(3) e (4) & 0,8 &
\end{tabular}

OBS.: Para madeira submersa, utiliza-se $\mathrm{k}_{\text {mod.2 }}=0,65$. Fonte: ABNT (1997)

Outros dois coeficientes parciais de modificação também são utilizados pela atual norma brasileira. $\mathrm{O} \mathrm{k}_{\text {mod.1 }}$, que considera a classe de carregamento e o tipo de material empregado e o $\mathrm{k}_{\text {mod.3, }}$ que considera a categoria da madeira. Na tabela 03 são estabelecidas as classes de carregamento, na tabela 04 são apresentados os valores de $\mathrm{k}_{\text {mod.1 }}$ e na tabela 05 os de $\mathrm{k}_{\text {mod.3. }}$. 
TABELA 03 - Classes de carregamento

\begin{tabular}{lc}
\hline \multicolumn{1}{c}{ CLASSE DE } & ORDEM DE GRANDEZA DA DURAÇÃO ACUMULADA \\
CARREGAMENTO & DA AÇÃO CARACTERÍSTICA \\
\hline Permanente & Vida útil da construção \\
Longa duração & Mais de 6 meses \\
Média duração & Uma semana a seis meses \\
Curta duração & Menos de uma semana \\
Duração instantânea & Muito curta \\
\hline
\end{tabular}

Fonte: ABNT (1997)

TABELA 04 - Valores de $\mathrm{k}_{\text {mod.1 }}$

\begin{tabular}{lcc}
\hline \multirow{2}{*}{ CLASSES DE } & \multicolumn{2}{c}{ TIPOS DE MADEIRA } \\
\cline { 2 - 3 } CARREGAMENTO & \multicolumn{2}{c}{ MADEIRA SERRADA } \\
& $\begin{array}{c}\text { MADEIRA } \\
\text { MADEIRA LAMINADA E COLADA }\end{array}$ & RECOMPOSTA \\
& MADEIRA COMPENSADA & \\
\hline Permanente & 0,60 & 0,30 \\
Longa duração & 0,70 & 0,45 \\
Média duração & 0,85 & 0,65 \\
Curta duração & 1,00 & 1,00 \\
Instantânea & 1,10 & 1,10 \\
\hline
\end{tabular}

Fonte: ABNT (1997)

É oportuno salientar que, da mesma forma que faz o EUROCODE 5 - Design of timber structures - Part 1-1: General rules and rules for buildings, do European Committee for Standardization - CEN (1993), foram adotados valores únicos para a madeira serrada, madeira laminada e colada, e madeira compensada. Nestes três tipos de madeira é mantida a orientação das fibras em suas direções preferenciais. Para a madeira recomposta, na qual se perde a orientação preferencial para as fibras da madeira, os valores adotados são diferentes e menores que os anteriores.

Os valores prescritos para $\mathrm{k}_{\text {mod.1 }}$ e $\mathrm{k}_{\text {mod.2 }}$ são praticamente os mesmos adotados pelo EUROCODE 5, do CEN (1993). A diferença está em que o EUROCODE 5 apresenta tabelas de valores do produto $\mathrm{k}_{\text {mod.1. }} \cdot \mathrm{k}_{\text {mod.2. }}$. Uma análise desses valores mostra que os coeficientes podem ser individualizados, como foi feito na NBR 7190 da ABNT (1997). 
TABELA 05 - Valores de $\mathrm{k}_{\text {mod.3 }}$

\begin{tabular}{|c|c|c|}
\hline \multicolumn{2}{|r|}{ CATEGORIA DA MADEIRA } & \multirow{2}{*}{$\mathbf{K}_{\text {mod. } 3}$} \\
\hline CATEGORIA & DEFINIÇÃO & \\
\hline Primeira & $\begin{array}{l}\text { Todas as peças são classificadas como isentas de defeitos, por } \\
\text { meio de um método visual normalizado, e submetidas à classifi- } \\
\text { cação mecânica que garanta a homogeneidade da rigidez das pe- } \\
\text { ças que compõem o lote. }\end{array}$ & 1,00 \\
\hline Segunda & $\begin{array}{l}\text { Madeira não classificada ou de classificação inferior a descrita } \\
\text { para madeira de primeira categoria. }\end{array}$ & 0,8 \\
\hline
\end{tabular}

OBS.: A fim de considerar o risco da presença de nós não detectáveis pela inspeção visual, para coníferas, na forma de peças estruturais maciças de madeira serrada, deve-se utilizar $\mathrm{k}_{\text {mod.3 }}=0,8$. Fonte: ABNT (1997).

A aplicação dos coeficientes parciais de modificação, apresentados nas tabelas 02 , 04 e 05, aliados aos coeficientes de ponderação das resistências, nas expressões (01) e (02), fornecem a resistência de cálculo, a determinada solicitação, e o módulo de elasticidade efetivo na direção paralela às fibras. Os coeficientes de ponderação das resistências são coeficientes de minoração das propriedades de resistência da madeira, os quais são apresentados na tabela 06.

$$
\begin{aligned}
& \mathrm{X}_{\mathrm{d}}=\mathrm{k}_{\bmod } \cdot \frac{\mathrm{X}_{\mathrm{k}}}{\gamma_{\mathrm{w}}} \Rightarrow \mathrm{X}_{\mathrm{d}}=\mathrm{k}_{\bmod .1} \cdot \mathrm{k}_{\bmod .2} \cdot \mathrm{k}_{\bmod .3} \cdot \frac{\mathrm{X}_{\mathrm{k}}}{\gamma_{\mathrm{w}}} \\
& \mathrm{E}_{\mathrm{c} 0, \mathrm{ef}}=\mathrm{k}_{\mathrm{mod}} \cdot \mathrm{E}_{\mathrm{c} 0, \mathrm{~m}} \Rightarrow \mathrm{E}_{\mathrm{co}, \mathrm{ef}}=\mathrm{k}_{\mathrm{mod} .1} \cdot \mathrm{k}_{\mathrm{mod} .2} \cdot \mathrm{k}_{\mathrm{mod} .3} \cdot \mathrm{E}_{\mathrm{c} 0, \mathrm{~m}}
\end{aligned}
$$

Nas quais:

$\mathrm{X}_{\mathrm{d}}=$ valor de cálculo de uma determinada propriedade de resistência da madeira;

$\mathrm{X}_{\mathrm{k}}=$ valor característico desta propriedade de resistência;

$\mathrm{k}_{\text {mod }}=$ coeficiente de modificação, composto pelos coeficientes parciais de modificação: $\mathrm{k}_{\text {mod.1 }}, \mathrm{k}_{\text {mod.2 }}$ e $\mathrm{k}_{\text {mod.3 }}$ (ver tabelas 02,04 e 05);

$\gamma_{\mathrm{w}}=$ coeficiente de ponderação da resistência (ver tabela 06);

$\mathrm{E}_{\mathrm{c} 0 \text {,ef }}=$ módulo de elasticidade efetivo na direção paralela às fibras e

$\mathrm{E}_{\mathrm{c} 0, \mathrm{~m}}=$ módulo de elasticidade médio na direção paralela às fibras. 
TABELA 06 - Coeficientes de ponderação das resistências.

\begin{tabular}{lcc}
\hline PROPRIEDADE & \multicolumn{2}{c}{ COEFICIENTE DE PONDERAÇÃO } \\
\cline { 2 - 3 } DE RESISTENCIA & ESTADOS LIMITES & ESTADOS LIMITES \\
& ÚLTIMOS & DE UTILIZAÇÃO \\
\hline Compressão paralela às fibras & $\gamma_{\mathrm{wc}}=1,4$ & $\gamma_{\mathrm{w}}=1,0$ \\
Tração paralela às fibras & $\gamma_{\mathrm{wt}}=1,8$ & $\gamma_{\mathrm{w}}=1,0$ \\
Cisalhamento paralelo às fibras & $\gamma_{\mathrm{wv}}=1,8$ & $\gamma_{\mathrm{w}}=1,0$ \\
\hline
\end{tabular}

Fonte: ABNT (1997)

A segunda questão, que se acrescenta com a fixação da umidade de referência, diz respeito ao teor de umidade no instante do ensaio. Ou seja, se durante o ensaio o teor de umidade do corpo-de-prova não for de exatamente $12 \%$, o que se deve fazer?

Para corrigir os valores de resistência e rigidez, obtidos em um ensaio, para o teor de umidade de referência, a atual norma brasileira adota, para teores de umidade entre $10 \% \mathrm{e}$ $20 \%$, as seguintes expressões:

$$
\begin{aligned}
& \mathrm{f}_{12}=\mathrm{f}_{\mathrm{U} \%} \cdot\left[1+3 \cdot\left(\frac{\mathrm{U} \%-12}{100}\right)\right] \\
& \mathrm{E}_{12}=\mathrm{E}_{\mathrm{U} \%} \cdot\left[1+2 \cdot\left(\frac{\mathrm{U} \%-12}{100}\right)\right]
\end{aligned}
$$

Nas quais:

$\mathrm{f}_{12}$ = resistência da madeira, à solicitação considerada, ao teor de umidade de referência de $12 \%$;

$\mathrm{f}_{\mathrm{U} \%}=$ resistência da madeira, à solicitação considerada, ao teor de umidade $\mathrm{U} \%$;

$\mathrm{U} \%=$ teor de umidade da madeira no instante do ensaio, em \%;

$\mathrm{E}_{12}=$ módulo de elasticidade longitudinal, à compressão paralela às fibras, ao teor de umidade de referência de $12 \%$, e

$\mathrm{E}_{\mathrm{U} \%}=$ módulo de elasticidade longitudinal, à compressão paralela às fibras, ao teor de umidade $\mathrm{U} \%$. 
Para teores de umidade acima de 20\% a NBR 7190, da ABNT (1997), considera que a resistência e a rigidez da madeira sofrem apenas pequenas variações.

Quanto à densidade aparente, outra propriedade que precisa ser fornecida para o teor de umidade de referência, a NBR 7190/97 é omissa a respeito de sua correção. 


\section{OBJETIVOS}

O objetivo deste trabalho, é o estudo, teórico e experimental, da influência da umidade da madeira em suas propriedades de resistência e rigidez, com a finalidade principal de aferir, experimentalmente, a validade do modelo teórico proposto pela nova NBR 7190 da ABNT (1997) e, se for o caso, indicar expressões mais adequadas. O estudo, teórico e experimental, da influência da umidade da madeira sobre sua densidade aparente, bem como a determinação de um modelo para reportá-la ao teor de umidade de $12 \%$, não definido pela atual NBR 7190/97, também é objetivo deste trabalho. O estudo envolverá às principais características de resistência e rigidez e a densidade aparente, com destaque à compressão paralela às fibras, pois esta é a característica adotada pela atual norma brasileira para classificar as espécies em classes de resistência. 


\section{JUSTIFICATIVA}

Ao se preparar um ensaio, com o objetivo de determinar a resistência de um determinado corpo-de-prova a determinada solicitação, não se conhece o teor de umidade deste corpo-de-prova. Pode-se, é verdade, condicionar o corpo-de-prova a um teor de umidade próximo à umidade de referência, bastando para isso mantê-lo em uma câmara, ou sala, de climatização na qual se mantém a temperatura e a umidade relativa do ar em níveis preestabelecidos.

Assim, torna-se necessário corrigir os resultados, obtidos nos ensaios, para a umidade de referência de $12 \%$. A atual norma brasileira, parte do diagrama apresentado na figura 01, que relaciona a resistência à compressão paralela com o teor de umidade, obtido experimentalmente para a PEROBA ROSA, Aspidosperma peroba, e adota, admitindo validade no intervalo de umidade entre $10 \%$ e $20 \%$, a seguinte expressão:

$$
\mathrm{f}_{\mathrm{c} 0,12 \%}=\mathrm{f}_{\mathrm{c} 0, \mathrm{U} \%} \cdot\left[1+3 \cdot\left(\frac{\mathrm{U} \%-12}{100}\right)\right]
$$

Onde:

$\mathrm{f}_{\mathrm{c} 0,12 \%}=$ resistência da madeira, à compressão paralela às fibras, ao teor de umidade de referência de $12 \%$;

$\mathrm{f}_{\mathrm{c} 0, \mathrm{U} \%}=$ resistência da madeira, à compressão paralela às fibras, ao teor de umidade $\mathrm{U} \%$;

$\mathrm{U} \%=$ teor de umidade da madeira no instante do ensaio

Admitida, com base experimental, a existência de relação entre a resistência da madeira a determinada solicitação com sua resistência à compressão paralela, a atual norma brasileira adota de maneira geral, para correção da resistência da madeira, qualquer que seja a solicitação, a eq. (03), apresentada anteriormente. 


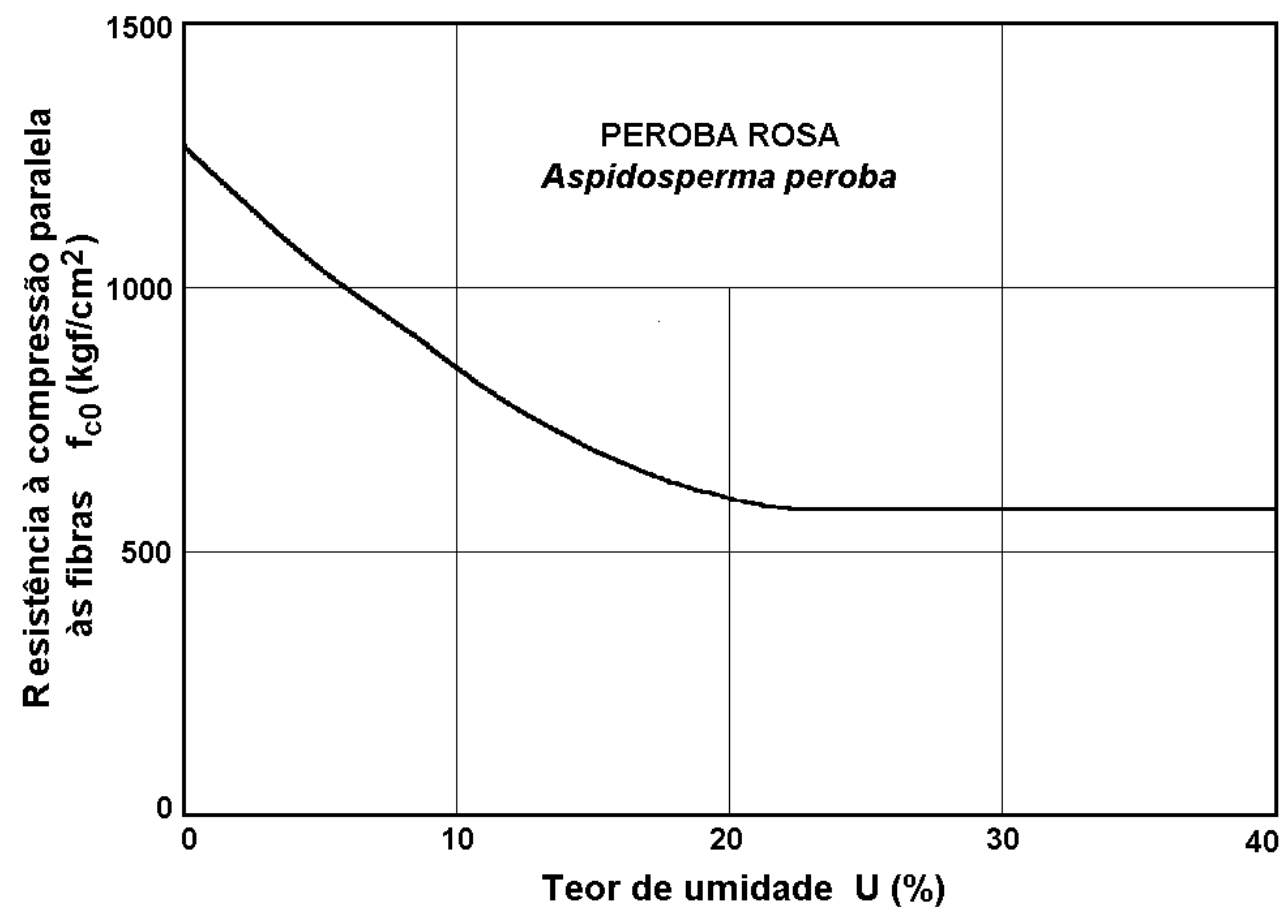

FIGURA 01 - Variação da resistência à compressão paralela às fibras com o teor de umidade $\left(1 \mathrm{kgf} / \mathrm{cm}^{2} \cong 0,1 \mathrm{MPa}\right)$. Exemplo obtido para a PEROBA ROSA, Aspidosperma peroba. Fonte: ASSOCIAÇÃO BRASILEIRA DE NORMAS TÉCNICAS - ABNT (1980)

Apoiando-se em ensaios complementares e na existência de relação entre a rigidez e a resistência da madeira, mas também partindo do diagrama anteriormente citado, obtido experimentalmente para a PEROBA ROSA, Aspidosperma peroba, a atual norma brasileira adota, para correção da rigidez a eq. (04) apresentada anteriormente.

Expressões como as eq. (03) e (04) são de extrema utilidade na homogeneização dos resultados de ensaio, entretanto deve-se ter em mente que os resultados experimentais, obtidos para a PEROBA ROSA, Aspidosperma peroba, podem não ser extensíveis à outras espécies ou outras classes de resistência. Além disto é temerário assumir, sem base experimental específica, que o comportamento da rigidez é basicamente o mesmo observado para a resistência.

Outra característica importante que deve ser corrigida para a umidade de referência é a densidade aparente, entretanto a nova versão da norma brasileira é omissa quanto a esta correção.

Justifica-se, dessa forma, a necessidade de aferição das expressões apresentadas pela NBR 7190/97 em outras espécies, ou classes de resistência, e em outras propriedades. Além 
disso é necessário estabelecer uma forma de corrigir a densidade aparente, para o teor de umidade de referência, se possível tão simples quanto as propostas para resistência e rigidez. 


\section{REVISÃO BIBLIOGRÁFICA}

\subsection{GENERALIDADES}

A madeira é um material orgânico, de origem vegetal, produzido pela árvore. Na árvore, a madeira é formada em um ambiente saturado em água. As células ativas do alburno fazem parte do sistema vascular, afirmam ZIMMERMAN \& BROWN ${ }^{1}$ apud SKAAR (1984), que conduz água e soluções aquosas das raízes até as folhas através de uma rede contínua de células saturadas em água. Tão logo a árvore é derrubada e retirada do solo, a madeira começa a perder a maior parte de sua umidade. Desta forma, a madeira é um material higroscópico, e sua massa, dimensões e densidade, bem como suas propriedades mecânicas, elásticas, elétricas, térmicas e de movimento são afetadas por seu teor de umidade. Em serviço o teor de umidade e as propriedades da madeira (que dependem dele) variam com alterações nas condições ambientais, particularmente com a umidade relativa.

WIANDY \& ROWELL (1984) afirmam que a resistência da madeira está relacionada à quantidade de água na parede da célula da fibra. Acima do ponto de saturação das fibras a água se acumula nas cavidades das células da madeira (água livre), e não se verifica efeito sensível sobre a resistência da madeira associado à variação do teor de umidade neste intervalo. Para teores de umidade entre $0 \%$ (madeira seca em estufa) até o ponto de saturação das fibras a água se acumula nas paredes das células da madeira (água de impregnação), e afeta sensivelmente a resistência da madeira, pois o aumento da quantidade de água reduz as ligações por pontes de hidrogênio, entre os polímeros orgânicos das paredes das células, diminuindo a resistência da madeira.

Uma indicação de como as propriedades mecânicas da madeira são influenciadas pela umidade, apresentada por BODIG \& JAYNE (1992), pode ser observada nas curvas de tensão-deformação da figura 02. Estes dados, obtidos de ensaios de compressão normal às fibras em "Douglas-Fir", refletem as variações no módulo de elasticidade, na resistência, na

${ }^{1}$ ZIMMERMAN, M. H.; BROWN, C. L. (1971). Trees-Structure and Function. SpringerVerlag: New York apud SKAAR, C. (1984). Wood-Water Relationships. In: The Chemistry of Solid Wood. Washington, DC. American Chemical Society. 
energia de deformação, e na fragilidade. A ordenada máxima, alcançada por cada curva, mostra as alterações na resistência; a inclinação, de cada gráfico, mostra as variações no módulo de elasticidade; a energia de deformação é obtida da área sob cada curva; e a fragilidade se reflete nas características das curvas na região de ruptura. Pode-se notar que, em geral, as propriedades mecânicas da madeira, inclusive a fragilidade, tendem a aumentar para baixos teores de umidade.

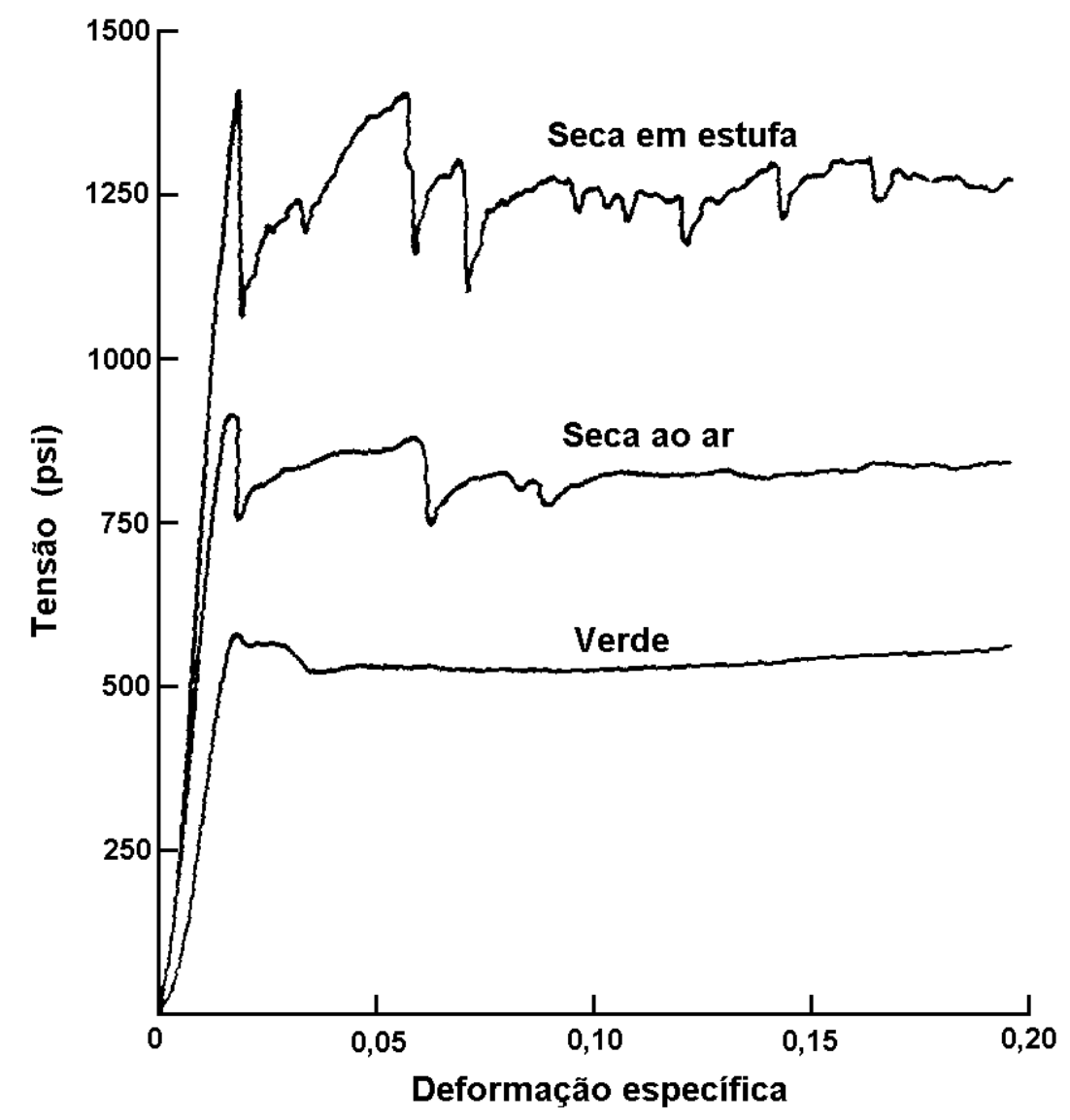

FIGURA. 02 - Curvas de tensão-deformação obtidas em ensaios de compressão normal às fibras, em "Douglas-Fir", a diferentes teores de umidade $(1 \mathrm{psi} \cong 0,006895$ MPa). Fonte: BODIG ${ }^{2}$ apud BODIG \& JAYNE (1992)

Um conjunto de corpos-de-prova muito semelhantes, mas cada um a um diferente teor de umidade, quando ensaiados a compressão paralela às fibras, segundo BODIG \& JAYNE (1992), fornecem dados como os apresentados na figura 03. Para um intervalo, no

${ }^{2}$ BODIG, J. (1966). Stress-strain relationship of wood in transverse compression. J. Mat. 1 (3). p.645-666. apud BODIG, J.; JAYNE, B. A. (1992). Mechanics of Wood and Wood Composites. New York. Van Nostrand Reinhold Company Inc. 
teor de umidade, de $0 \%$ até pouco acima de $20 \%$, tanto a resistência, quanto o limite de proporcionalidade, a compressão paralela às fibras, apresentam um declínio a medida que o teor de umidade cresce. Acima deste teor de umidade não existe alteração significativa destas propriedades.

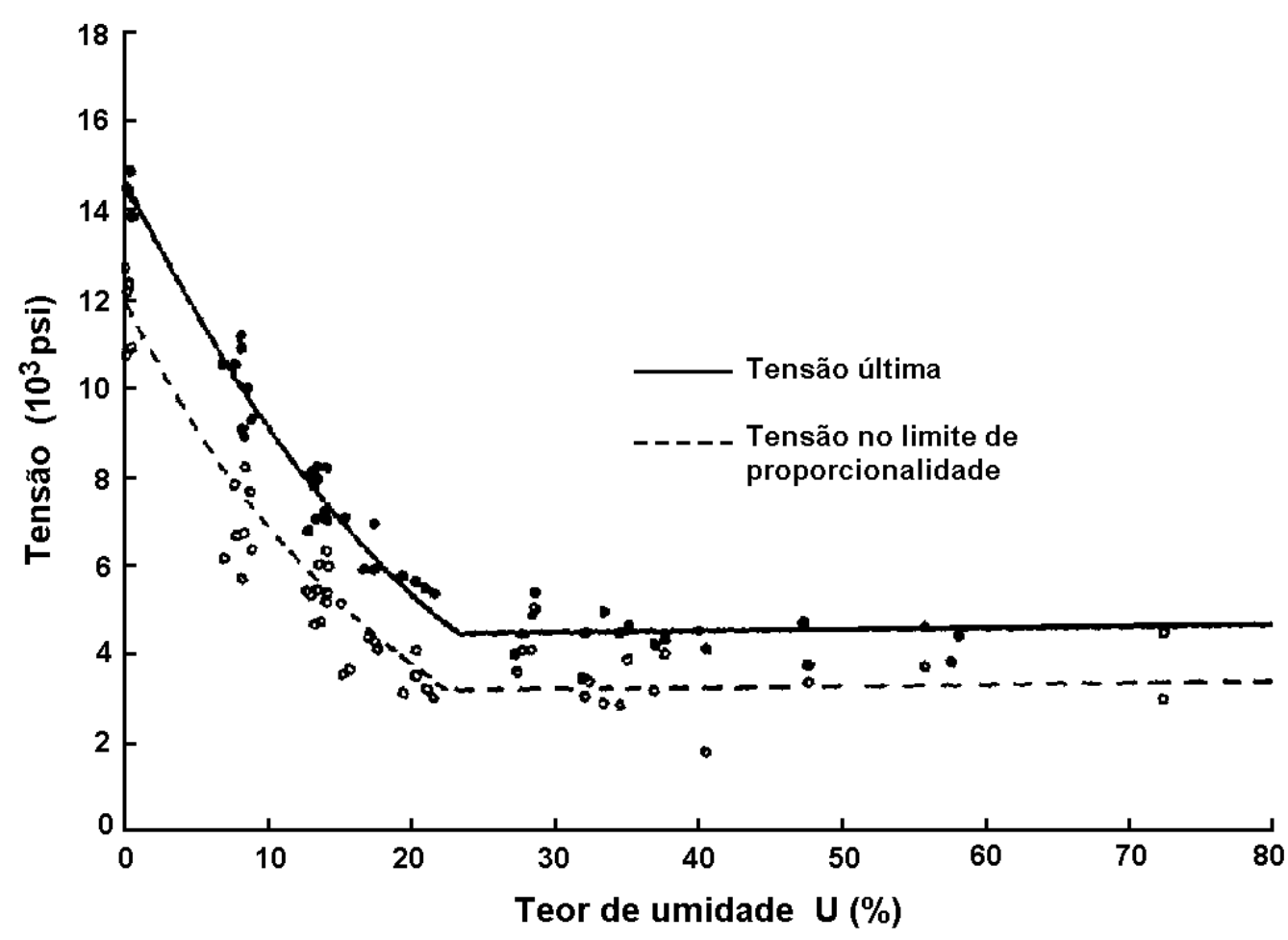

FIGURA 03 - Relações entre propriedades de compressão paralela às fibras e o teor de umidade em corpos-de-prova de "Douglas-Fir" (1 psi $\cong 0,006895 \mathrm{MPa})$. Fonte: BODIG \& JAYNE (1992)

A curva apresentada pela resistência com a variação do teor de umidade sugere, segundo BODIG \& JAYNE (1992), uma função exponencial negativa para representar os dados com teor de umidade entre zero e o ponto de saturação das fibras e uma constante para os dados com umidade acima dele. A interseção destas duas curvas é um dos métodos para determinação do ponto de saturação das fibras.

A variação das propriedades mecânicas ao longo de uma exponencial negativa parece não ser uma regra universal. Pode-se notar, por exemplo, a relação linear apresentada na figura 04 e a curva invertida apresentada na figura 05 . 


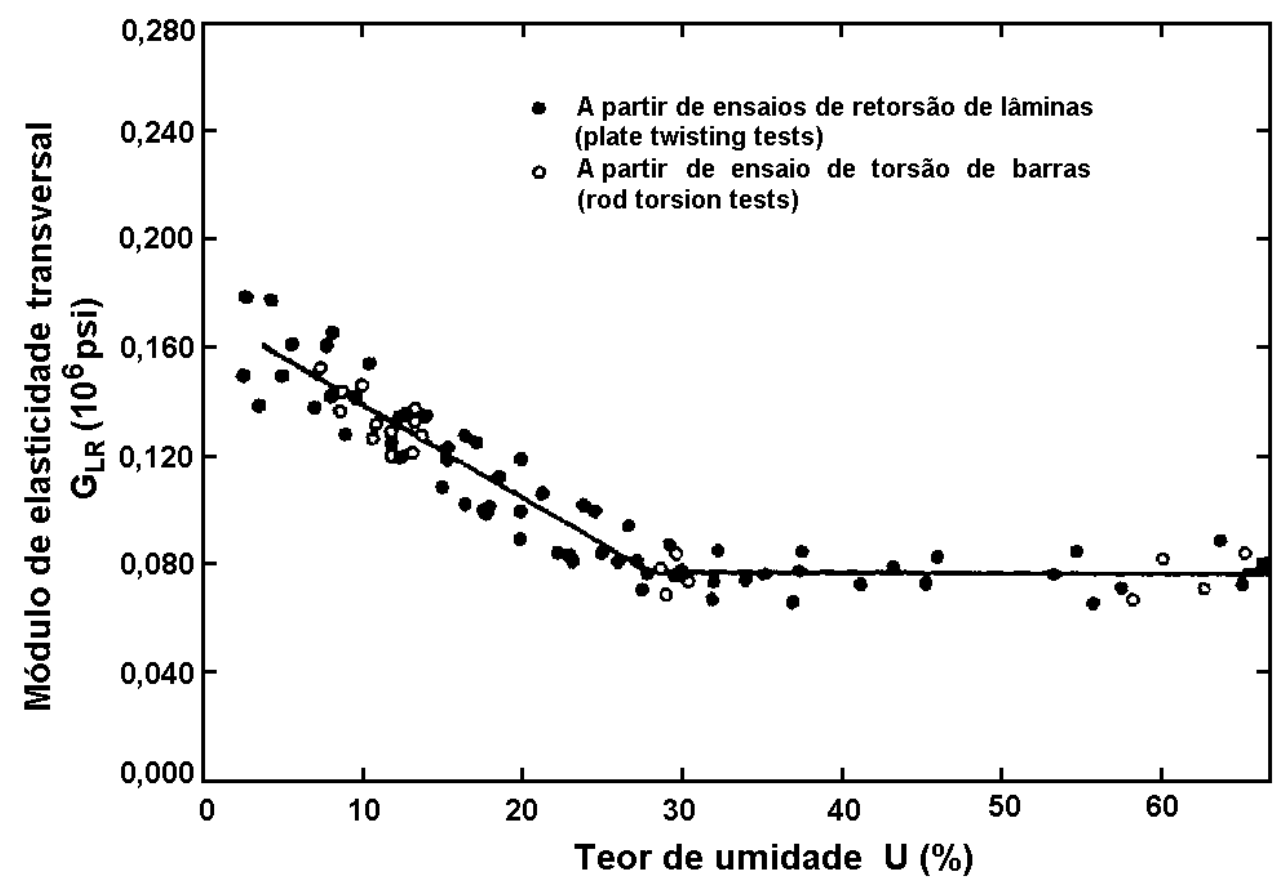

FIGURA 04 - Variação do módulo de elasticidade transversal de "Scarlet Oak" com o teor de umidade $(1 \mathrm{psi} \cong 0,006895 \mathrm{MPa})$. Fonte: MATEJAK \& STARECKA ${ }^{3}$ apud BODIG \& JAYNE (1992).

Desenhando-se, em uma mesma figura, relações resistência-umidade para diferentes propriedades, como se apresenta na figura 06, pode-se constatar a existência de inclinações diferentes para diferentes propriedades mecânicas da madeira.

MADSEN (1992), estudando a influência do teor de umidade sobre a resistência da madeira do grupo de espécies "Spruce-Pine-Fir" (S-P-F), obteve jogos de curvas, de comportamento muito diferente, para tração e compressão paralela às fibras (ver figura 07).

\footnotetext{
${ }^{3}$ MATEJAK, M.; STARECKA, D. (1971). Effect of freezing of wood on its compression strength. (In German.) Holztechnol. 12 (3). p.144-146. apud BODIG, J.; JAYNE, B. A. (1992). Mechanics of Wood and Wood Composites. New York. Van Nostrand Reinhold Company Inc.
} 


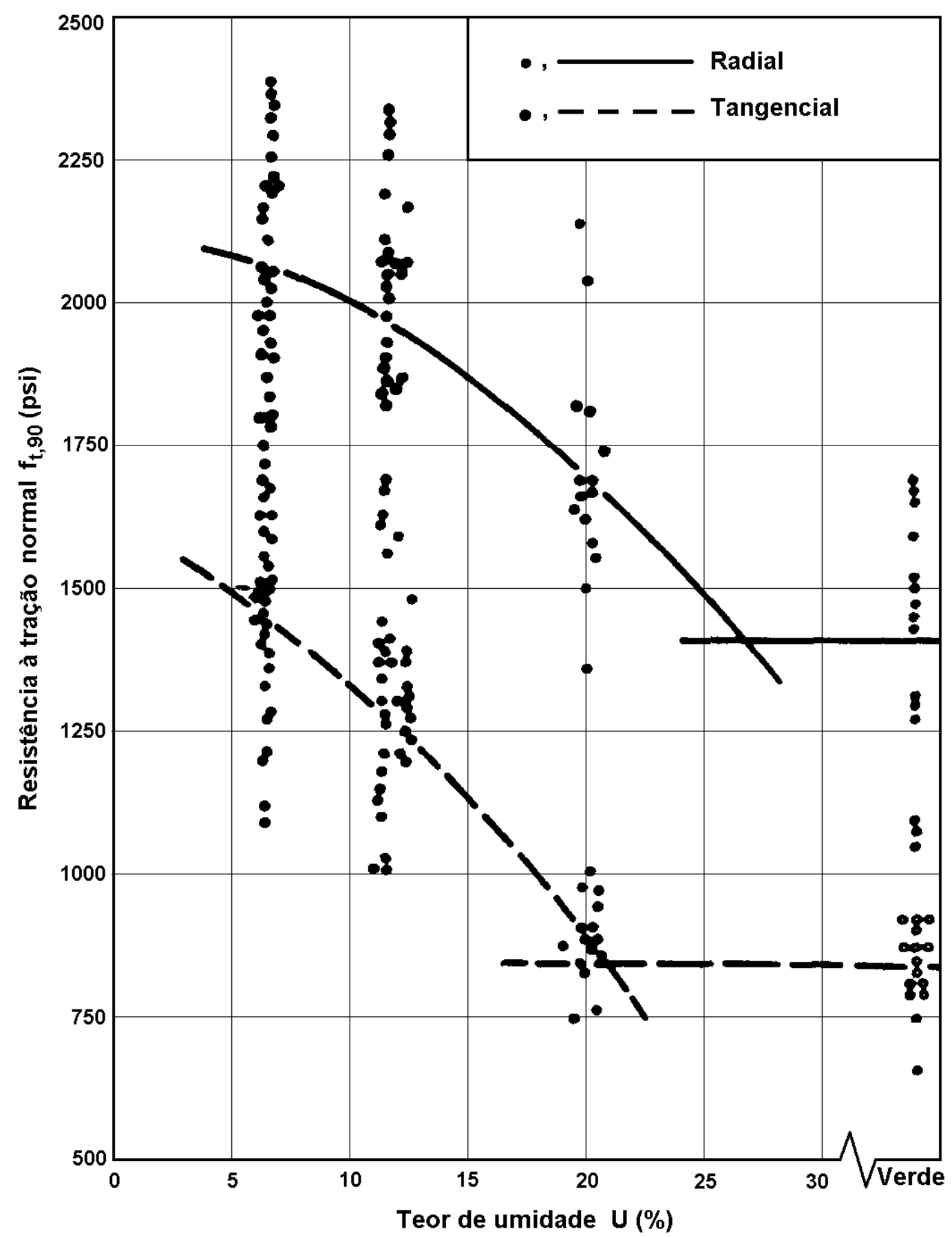

FIGURA 05 - Resistência à tração normal às fibras de Califórnia "Black Oak" em função do teor de umidade $(1 \mathrm{psi} \cong 0,006895 \mathrm{MPa})$. Fonte: SCHNIEWIND $^{4}$ apud BODIG \& JAYNE (1992).

${ }^{4}$ SCHNIEWIND, A. P. (1962). Tensile strength, perpendicular to grain as a function of moisture content in California black oak. For. Prod. J. 12 (5). p.249-252. apud BODIG, J.; JAYNE, B. A. (1992). Mechanics of Wood and Wood Composites. New York. Van Nostrand Reinhold Company Inc. 


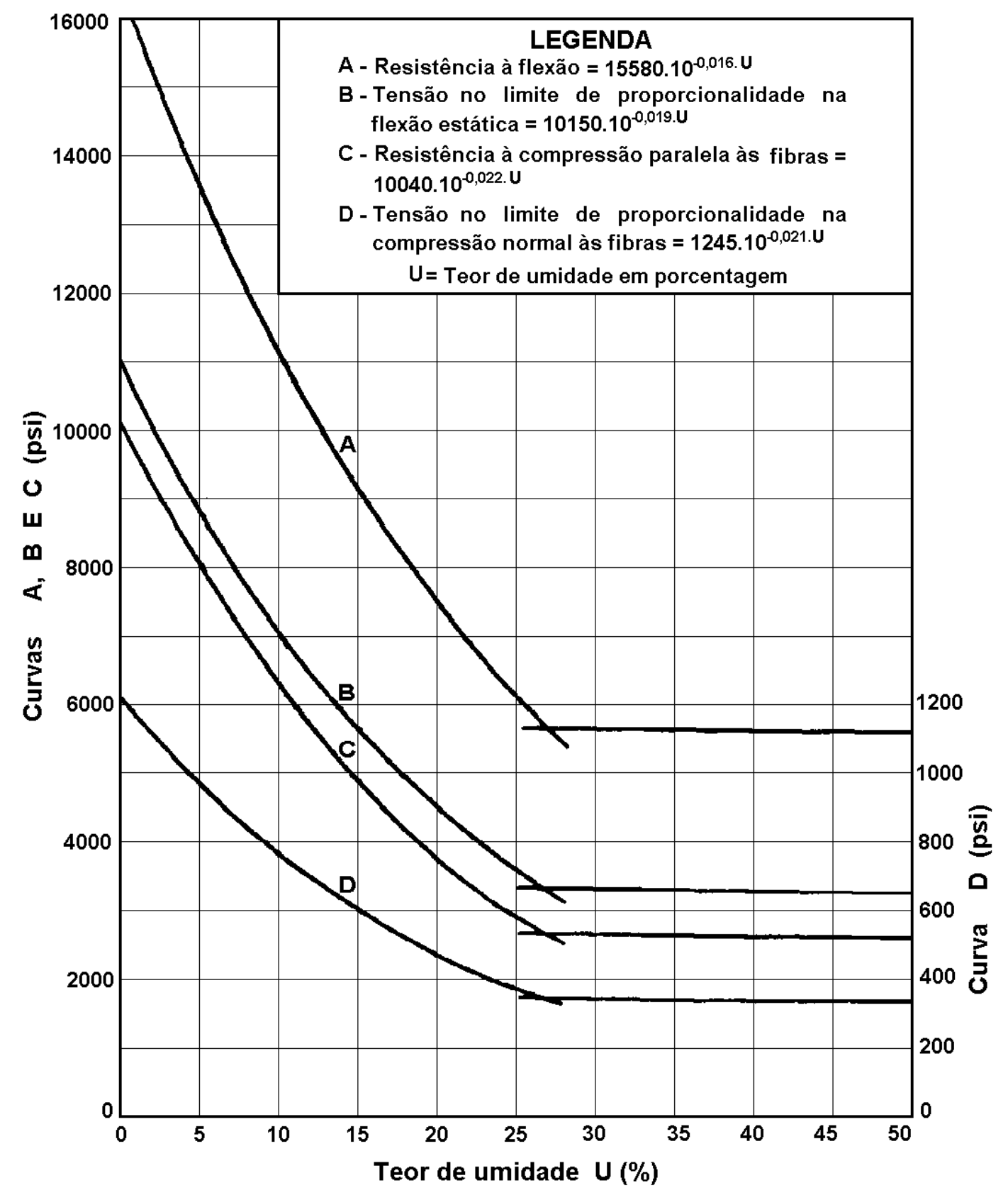

FIGURA 06 - Relações entre propriedades mecânicas e o teor de umidade de corpos-deprova, pequenos e isentos de defeitos, de "Stika Spruce" ( 1 psi $\cong 0,006895$ MPa). Fonte: MARKWARDT \& WILSON ${ }^{5}$ apud BODIG \& JAYNE (1992).

${ }^{5}$ MARKWARDT, L. J.; WILSON, T. R. C. (1935). Strength and related properties of woods grown in the United States. USDA Tech. Bull. No. 479. Washington, DC. apud 


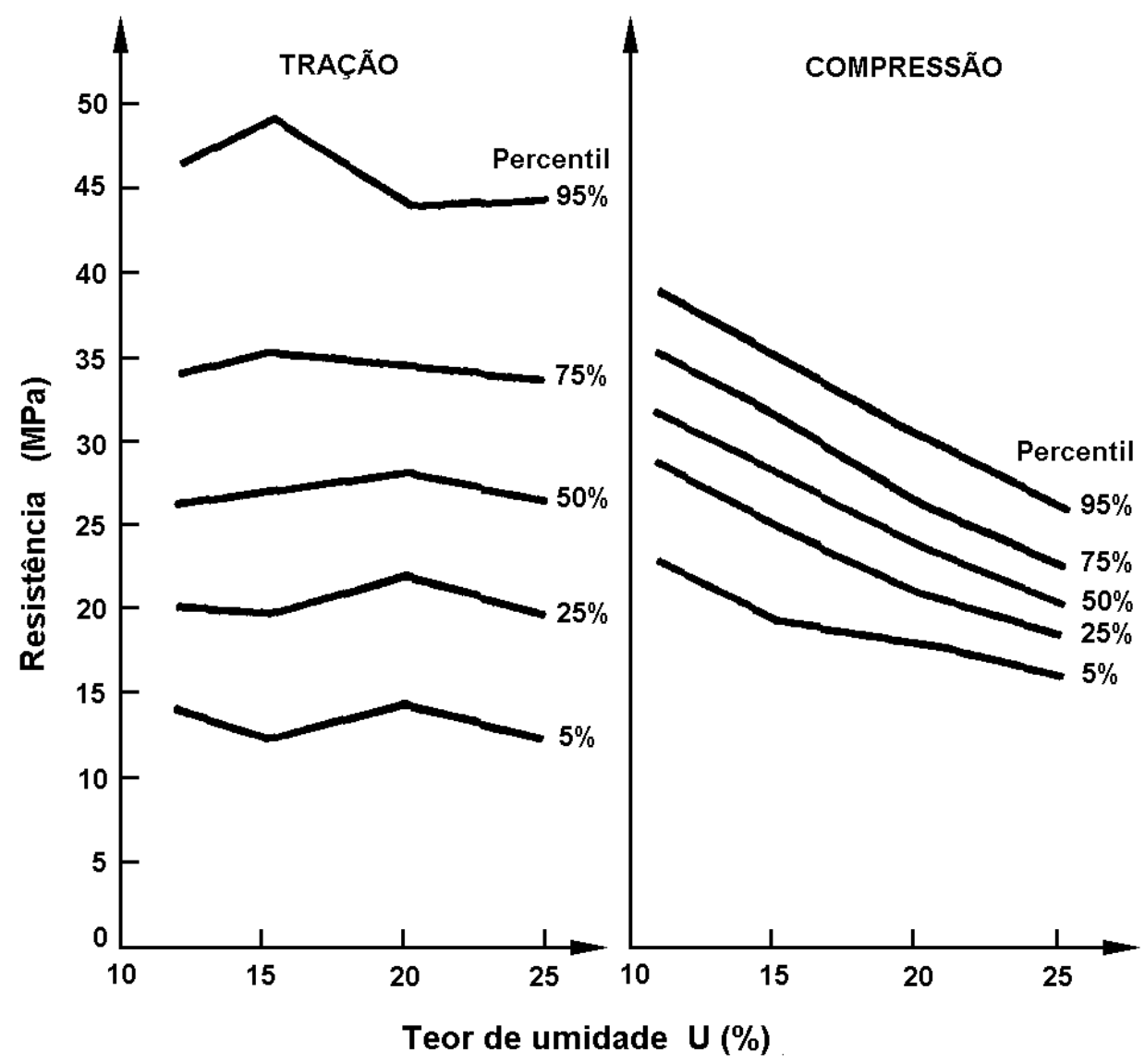

FIGURA 07 - Variação da resistência com o teor de umidade, para a tração e compressão paralela às fibras de "Spruce-Pine-Fir". O comportamento das duas propriedades são totalmente diferentes. Fonte: MADSEN (1992)

Devido a moderada curvatura no diagrama resistência-umidade, podem ser feitas correções, razoavelmente precisas, assumindo a linearidade, para um limitado intervalo de umidade (BODIG \& JAYNE,1992). A linearização às vezes também é utilizada, mesmo para uma variação de umidade desde a condição seca em estufa até o ponto de saturação das fibras. Nestes casos, porém os erros podem chegar a 10 ou 20\%. Assim, a hipótese de linearidade do diagrama resistência-umidade só é recomendável para pequenos intervalos de umidade. Na tabela 07 são apresentadas as variações nas propriedades mecânicas para uma variação de $1 \%$ no teor de umidade, abaixo de ponto de saturação das fibras.

A norma francesa, segundo BROCHARD (1960), considerava, para uma variação unitária no teor de umidade, as seguintes variações: $4 \%$ na compressão paralela às fibras; $2 \%$ na flexão estática; e superestimava em $4 \%$ para as outras solicitações.

BODIG, J.; JAYNE, B. A. (1992). Mechanics of Wood and Wood Composites. New York. Van Nostrand Reinhold Company Inc. 
TABELA 07 - Incremento médio nas propriedades mecânicas para um decréscimo de 1\% no teor de umidade abaixo do ponto de saturação das fibras

\begin{tabular}{lc}
\hline PROPRIEDADE & VARIAÇ̃̃O, \% \\
\hline Flexão estática & 5 \\
Tensão no limite de proporcionalidade & 4 \\
Resistência (MOR) & 2 \\
Módulo de elasticidade & 8 \\
Energia de deformação até o limite de proporcionalidade & 0,5 \\
Energia de deformação até a carga última & \\
\hline
\end{tabular}

Flexão dinâmica (impacto, tenacidade)

$\begin{array}{ll}\text { Altura de queda para causar a ruptura } & 0,5\end{array}$

Compressão paralela às fibras

Tensão no limite de proporcionalidade 5

Resistência (tensão última) 6

Compressão normal às fibras

Tensão no limite de proporcionalidade $\quad 5,5$

Cisalhamento paralelo às fibras

Resistência (tensão última) 3

Tração normal às fibras

Resistência (tensão última) $\quad 1,5$

Dureza

Topo 4

Lateral 2,5

Fonte: MARKWARDT \& WILSON ${ }^{6}$ apud BODIG \& JAYNE (1992).

BENDTSEN \& CALLIGAN ${ }^{7}$ apud TANAAMI (1986), estudando quatro espécies de coníferas, concluíram que quando a madeira seca, desde a condição verde até a situação de

${ }^{6}$ MARKWARDT, L. J.; WILSON, T. R. C. (1935). Strength and related properties of woods grown in the United States. USDA Tech. Bull. No. 479. Washington, DC. apud BODIG, J.; JAYNE, B. A. (1992). Mechanics of Wood and Wood Composites. New York Van Nostrand Reinhold Company Inc.

${ }^{7}$ BENTDTSEN, A.; GALLIGAN, W. L. (1967). Deriving allowable properties of lumber: a practical guide for interpretation of ASTM standards. Mad., Wis., USDA - FS - FPL, s.d. (General Technical Report, FPL 20). apud TANAAMI, R. G. (1986). Influência da 
equilíbrio ao ar, podem ser considerados os seguintes acréscimos na resistência: $75 \%$ na compressão paralela às fibras; $35 \%$ na tração paralela às fibras; $35 \%$ na flexão estática e $13 \%$ no cisalhamento paralelo.

KARLSEN et al. (1967) também utilizam uma correção linear para a resistência, mas indicam coeficientes diferentes para diferentes solicitações e espécies, como se apresenta na tabela 08. A expressão utilizada por KARLSEN et al. (1967), que corrige a resistência para o teor de umidade de $15 \%$, tem validade no intervalo de umidade de $8 \%$ a $23 \%$, e é dada por:

$$
\mathrm{f}_{15}=\mathrm{f}_{\mathrm{U} \%} \cdot[1+\alpha \cdot(\mathrm{U} \%-15)]
$$

Onde:

$\mathrm{f}_{15}=$ resistência a um teor de umidade de $15 \%$;

$\mathrm{f}_{\mathrm{U} \%}=$ resistência a um teor de umidade de $\mathrm{U} \%$;

$\mathrm{U} \%=$ teor de umidade da madeira, em \%, e

$\alpha=$ coeficiente de correção obtido da tabela 08 .

TABELA 08 - Valores do coeficiente $\alpha$

PROPRIEDADE DE RESISTÊNCIA "Redwood e larch" "White-wood, fir e oak"

\begin{tabular}{lll}
\hline Compressão paralela às fibras & 0,05 & 0,04 \\
Flexão estática & 0,04 & 0,04 \\
Cisalhamento paralelo às fibras & 0,03 & 0,03 \\
\hline
\end{tabular}

Fonte: KARLSEN et al. (1967)

Alguns dados sugerem, segundo BODIG \& JAYNE (1992), que algumas propriedades mecânicas podem atingir um valor máximo para um teor de umidade de aproximadamente $5 \%$ e decrescer para níveis menores de umidade. Outros dados não revelam ponto de máximo, ao contrario, as propriedades de resistência continuam aumentando até toda a umidade ser removida. Alguns investigadores acreditam que um declínio na resistência para teores de umidade abaixo de $5 \%$ pode estar relacionada a microfissuras provenientes do processo de secagem. O fenômeno é complexo e não foi resolvido até o momento.

umidade e da densidade na resistência à flexão de peças de madeira. In: Encontro Brasileiro em Madeiras e Estruturas de Madeira ,2.,São Carlos, 1986. Anais. São Paulo, USP-EESC-SET-LaMEM. Características. p.126-152. 
Outro aspecto interessante a ressaltar foi abordado por ANDREWS ${ }^{8}$ apud TANAAMI (1986), em um texto genérico, e diz respeito à constatação de que o acréscimo de resistência, devido a redução do teor de umidade, é mais significativo em pequenos corpos-deprova do que em peças de dimensões estruturais.

\subsection{SOBRE O PROCEDIMENTO DE SECAGEM}

MADSEN (1992) considera ser intrínseco à madeira a existência de um gradiente de umidade. Para comprovar este fato avalia a umidade, utilizando medidores elétricos de umidade (baseados na resistência elétrica), em uma malha com vários pontos, de uma peça de "Douglas Fir", de seção 38 mm x 184 mm, ao longo de um processo de secagem. Os resultados mostraram que apesar de variar muito de um instante a outro, ao longo da secagem, sempre são observados teores de umidade diferentes em diferentes pontos da peça. A figura 08 apresenta linhas de mesmo teor de umidade, em um instante do ensaio de MADSEN (1992).

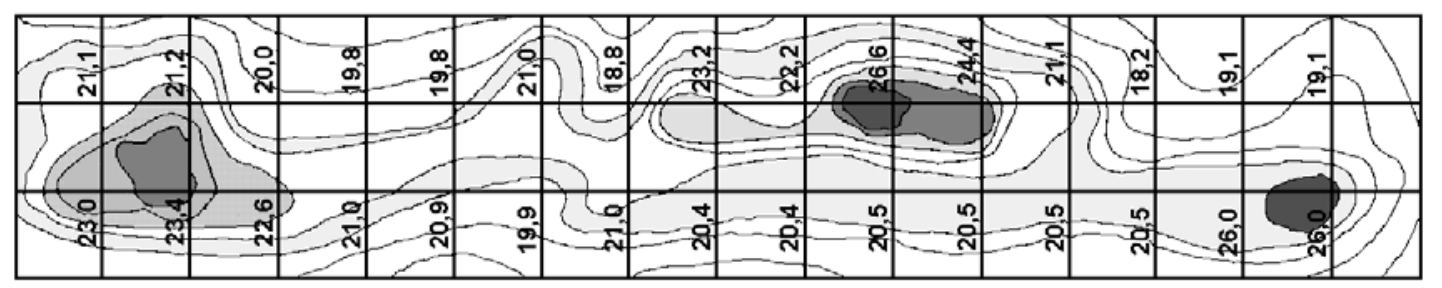

FIGURA 08 - Gradiente de umidade observado em uma peça de "Douglas Fir". As regiões mais escuras representam, proporcionalmente, teores de umidade mais elevados. Os valores representam teores de umidade em \%. Fonte: MADSEN (1992)

Feita esta constatação, MADSEN (1992) indaga: como considerar o teor de umidade da madeira no estudo da influência do teor de umidade sobre a resistência? O teor de umidade médio da peça? Ou o teor de umidade na posição onde ocorreu a ruptura?

MADSEN (1992) faz a opção pelo teor de umidade médio da peça, basicamente pelo fato da ruptura estar relacionada à porção mais fraca do corpo-de-prova, em geral correspon-

${ }^{8}$ ANDREWS, H. J. (1967). An introduction to timber engineering. Oxford, Pergamon. apud TANAAMI, R. G. (1986). Influência da umidade e da densidade na resistência à flexão de peças de madeira. In: Encontro Brasileiro em Madeiras e Estruturas de Madeira, 2., São Carlos, 1986. Anais. São Paulo, USP-EESC-SET-LaMEM. Características. p.126152. 
dente à existência de fibras retorcidas, de nós, e outros pequenos defeitos imperceptíveis a olho nu. Em geral estes defeitos causam a exposição das extremidades das fibras facilitando a saída da umidade e assim a umidade na posição de ruptura será diferente do resto da peça.

GREEN \& PELLERIN (1991) consideram que a severidade no processo de secagem afeta a qualidade final da madeira e assim afeta a forma da curva resistência-umidade.

De fato, segundo BETTS ${ }^{9}$ apud KOLLMANN \& COTÉ (1984), a resistência à flexão de madeiras cuja secagem foi acelerada, normalmente, é muito mais alto que o obtido com uma secagem que garanta distribuição uniforme do teor de umidade (ver figura 09). A razão é evidente: devido ao elevado gradiente de umidade, do interior para o exterior, as camadas mais externas da madeira estão mais secas e assim mais resistentes, afetando sensivelmente a resistência a flexão.

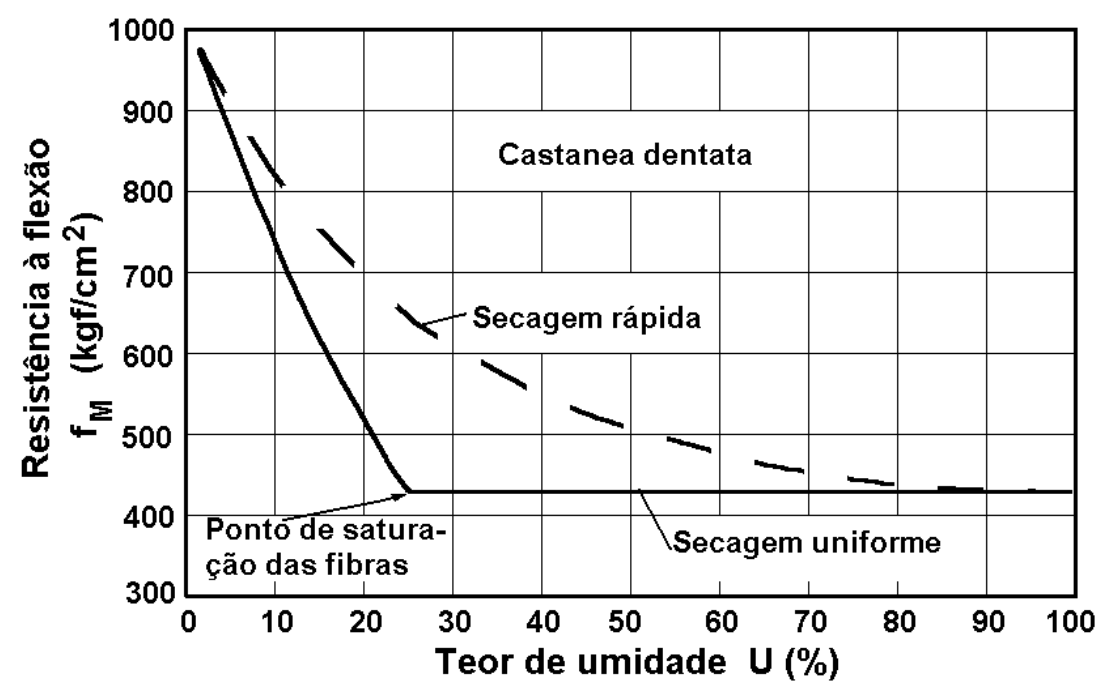

FIGURA 09 - Efeito da severidade do processo de secagem sobre a resistência à flexão $(1 \mathrm{kgf} / \mathrm{cm} 2 \cong 0,10 \mathrm{MPa})$. Fonte: BETTS $^{9}$ apud KOLLMANN \& COTÉ (1984)

Durante a secagem em estufa, segundo MADSEN (1992), grandes gradientes de umidade são criados pelas condições extremas do ar ambiente, mas isto não acontece quando a secagem é realizada ao ar.

DINWOODIE (1981) apresenta a figura 10, na qual se observa que a secagem ao ar permite o equilíbrio da madeira a um teor de umidade de aproximadamente $17 \%$, desejando

${ }^{9}$ BETTS, H. S. (1919). Timber, its strength, seasoning and grading. New York, p.31 apud KOLLMANN, F. F. P. \& CÔTÉ, W. A. (1984). Principles of wood science and technology. Vol I Solid Wood. Reprint Berlin, Heidelberg, New York, Tokyo. SpringerVerlag. 1968-1984. 
uma umidade de equilíbrio menor é necessário o uso de estufa. A direita, na figura 10 , são apresentados os teores para a umidade de equilíbrio em diversas situações de uso da madeira.



FIGURA 10 - Teor de umidade de equilíbrio da madeira em vários ambientes. A figura varia um pouco com a espécie e o diagrama mostra apenas valores médios. Fonte: DINWOODIE (1981)

MADSEN (1992) comparou três métodos de secagem, durante um estudo do efeito do teor de umidade sobre a resistência à flexão. Os métodos utilizados foram:

a) Secagem ao Ar: o material, inicialmente molhado, foi submetido a secagem, protegido da chuva para simular sua utilização no interior de uma construção onde o edifício é rapidamente fechado. Isto era feito deixando o material secar sob as condições gerais do laboratório.

b) Exposição: o material, inicialmente molhado, foi colocado do lado de fora por três meses, sujeito à chuva e ao sol, para simular um local de construção onde o traba- 
1ho, por uma razão ou outra, parou antes que o edifício tenha sido terminado. Em seguida, o material foi trazido para o laboratório e seco ao ar.

c) Equilíbrio: o material, inicialmente molhado, foi colocado em câmaras, na qual o corpo-de-prova foi condicionado lentamente até o equilíbrio a um teor de umidade específico em uma atmosfera controlada.

Obtidos os resultados dos ensaios, inicialmente MADSEN (1992) ajustou distribuições tri-paramétricas de Weibull a cada conjunto de dados, assinalando nas abscissas a freqüência acumulada e nas ordenadas a resistência à flexão.

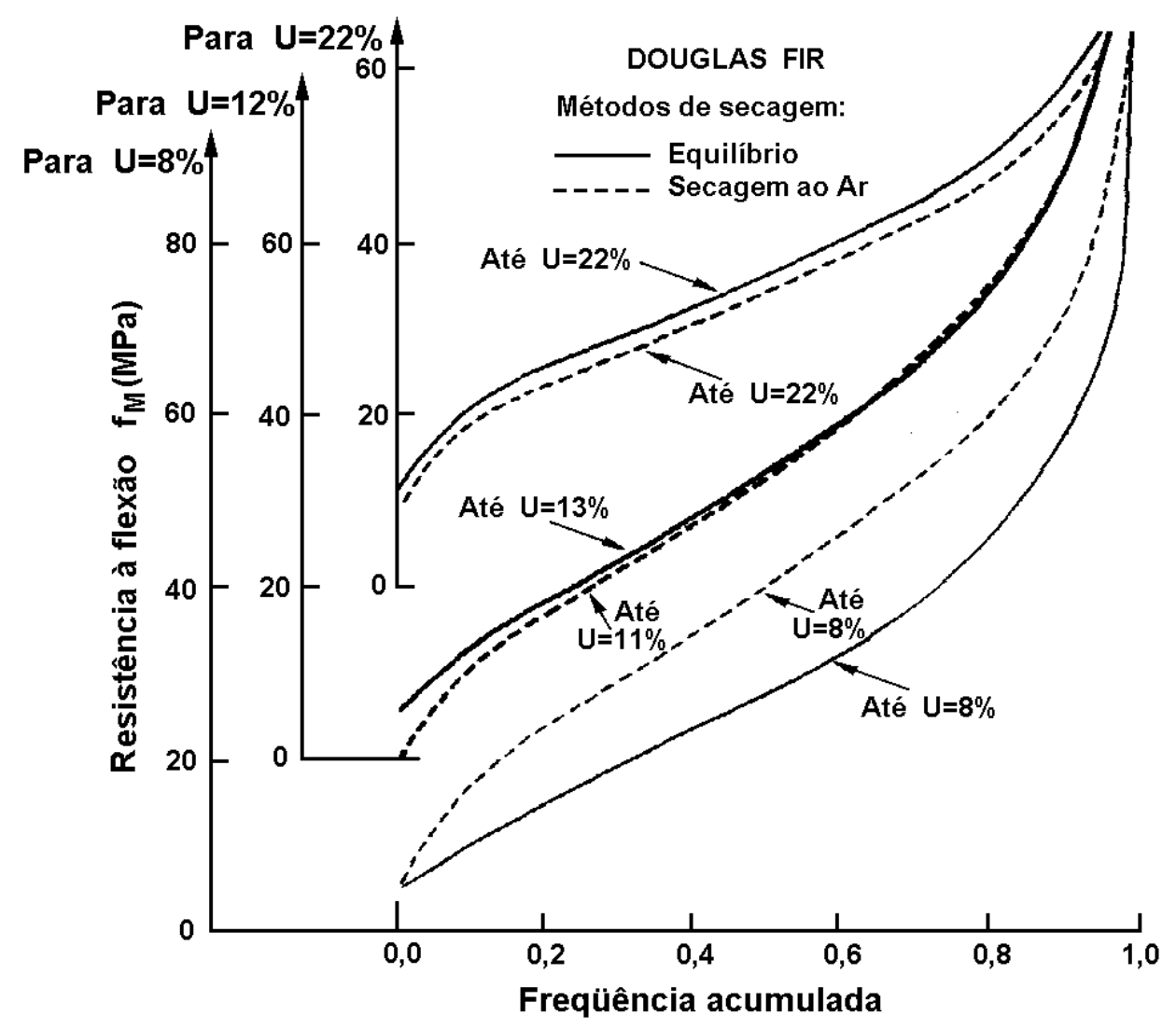

FIGURA 11 - Comparação entre os métodos de Secagem ao Ar e de Equilíbrio (Condicionamento em câmara de climatização). Fonte: MADSEN (1992)

Utilizando estas distribuições, MADSEN (1992) comparou o efeito dos métodos de secagem nos resultados. Na figura 11 apresenta-se a comparação entre os métodos de Secagem ao Ar e de Equilíbrio para o "Douglas Fir" nos diferentes teores de umidade, resultados semelhantes foram obtidos para as outras espécies estudadas. Na figura 12 apresenta-se a comparação entre os métodos de Secagem ao Ar e de Exposição para as diferentes espécies, 
ou grupos de espécies, estudadas. Nestas duas figuras a ordenada foi compensada para condensar os desenhos; consequentemente existem três eixos para as ordenadas.

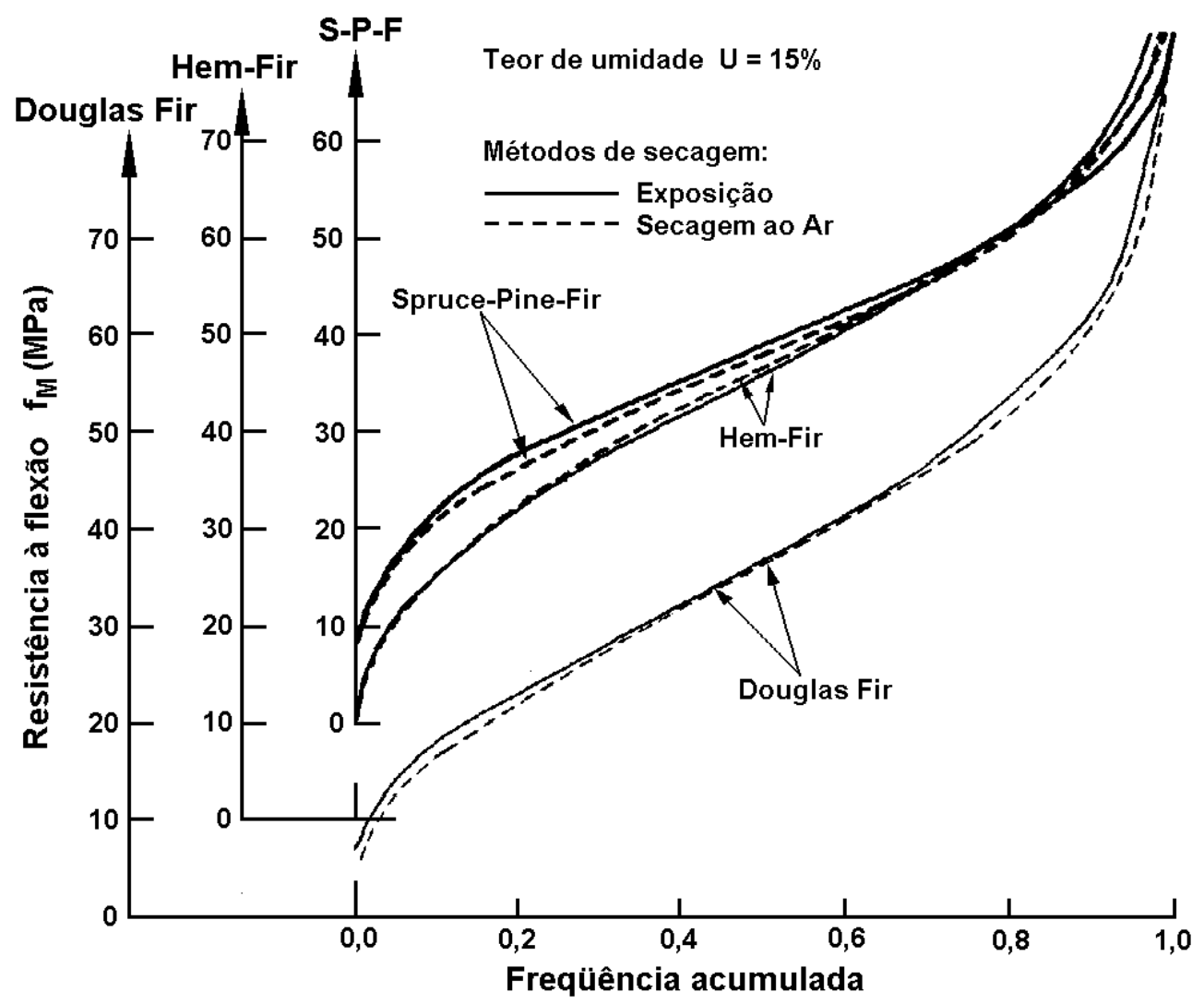

FIGURA 12 - Comparação entre os métodos de Secagem ao Ar e de Exposição (exposição às intempéries por três meses, seguido de secagem ao ar). Fonte: MADSEN (1992)

$\mathrm{Na}$ figura. 11 nota-se que os dois métodos de secagem se aproximam muito para os dados ao teor de umidade de $11 \%$ e de $22 \%$, enquanto que para o teor de umidade de $8 \%$ as curvas se afastam. MADSEN (1992) especula que a falta de ajuste, também observada nos ensaios com os grupos de espécies "Hem-Fir" e "Spruce-Pine-Fir" (S-P-F), pode ter sido causada pelo fato das tábuas terem sido submetidas por muito tempo, nos testes de equilíbrio, a condições muito secas, e isto, associado ao calor, pode ter gerado alguma deterioração da resistência.

Na figura 12 , que compara os métodos de Exposição e de Secagem ao Ar, fixado o teor de umidade de $15 \%$, para os três grupos de espécies, as curvas coincidem e indicam que as diferenças, se existirem, nos métodos de secagem são desprezíveis. 
Assim, conclui MADSEN (1992), o método de secagem, exceção feita ao nível com teor de umidade de $8 \%$, não afetou as distribuições de resistência.

\subsection{RETRAÇÃO E INCHAMENTO}

A mais sensível influência do teor de umidade sobre as propriedades da madeira se dá sobre sua estabilidade dimensional. As dimensões da madeira se alteram substancialmente com a variação da umidade, no intervalo de $0 \%$ até o ponto de saturação das fibras. Neste intervalo, conhecido como intervalo higroscópico, ao aumentar o teor de umidade as dimensões da madeira aumentam (inchamento) e ao diminuir o teor de umidade as dimensões diminuem (retração).

KOLLMANN \& COTÉ (1984) mostram que o inchamento volumétrico tem uma variação linear para variações de umidade abaixo do ponto de saturação das fibras e é praticamente constante acima dele (figura 13).

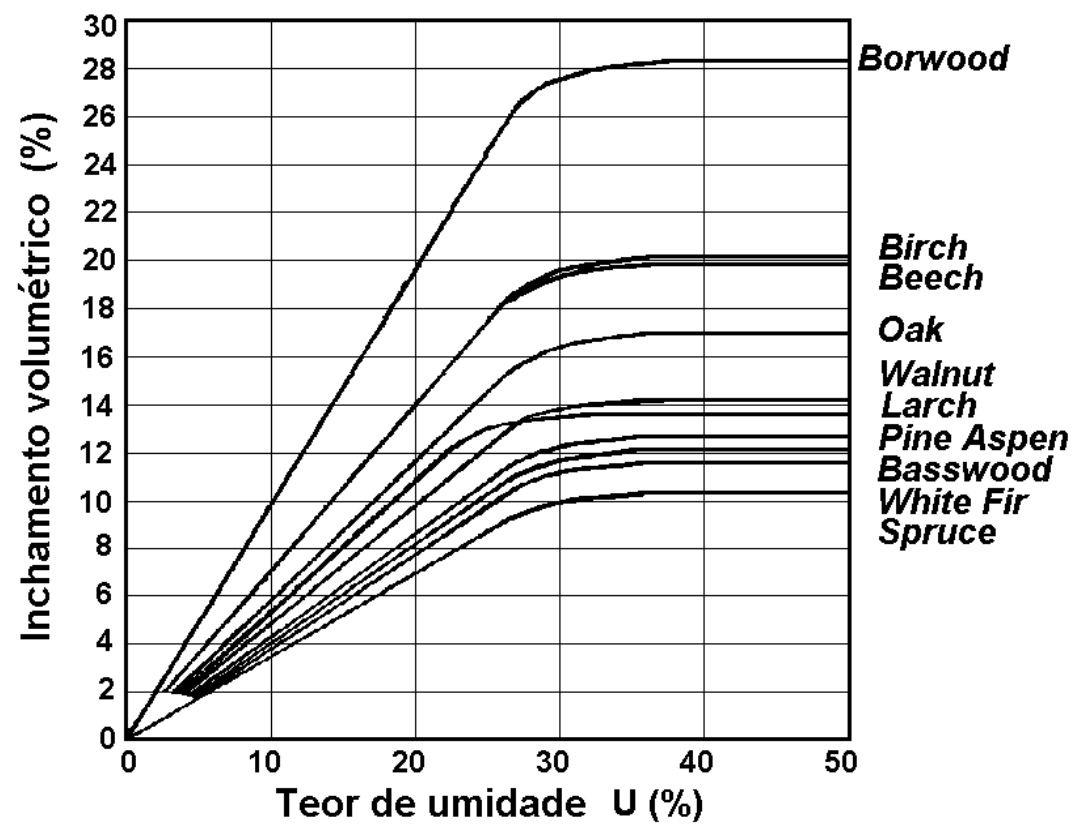

FIGURA 13 - Inchamento volumétrico como uma função do teor de umidade para diferentes espécies de madeira. Fonte: KOLLMANN \& COTÉ (1984)

LOGSDON (1998) estudando madeiras brasileiras obtém diagramas semelhantes aos de KOLLMANN \& COTÉ (1984) mesmo para os inchamentos lineares (ver figura 14), já para as retrações os diagramas, usualmente admitidos semelhantes aos de inchamento, são bastante diferentes (ver figura 15). 


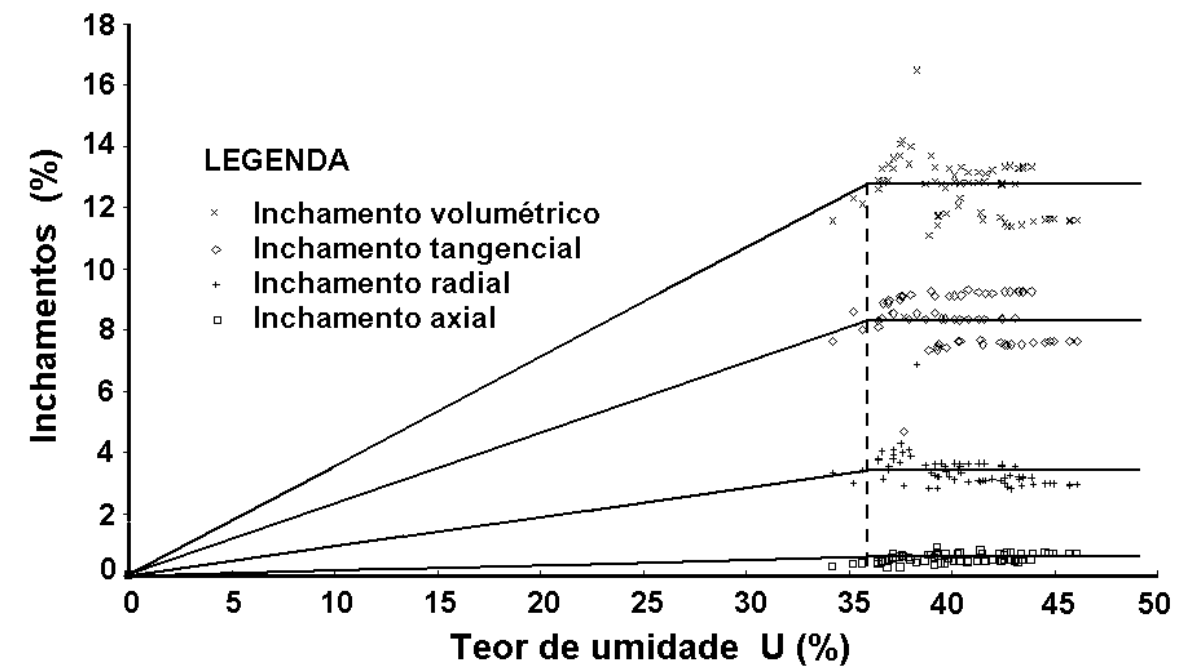

FIGURA 14 - Diagramas de inchamentos para a Itaúba, Mezilaurus itauba (Meissn) Taubert ex Mez. Fonte: LOGSDON (1998)

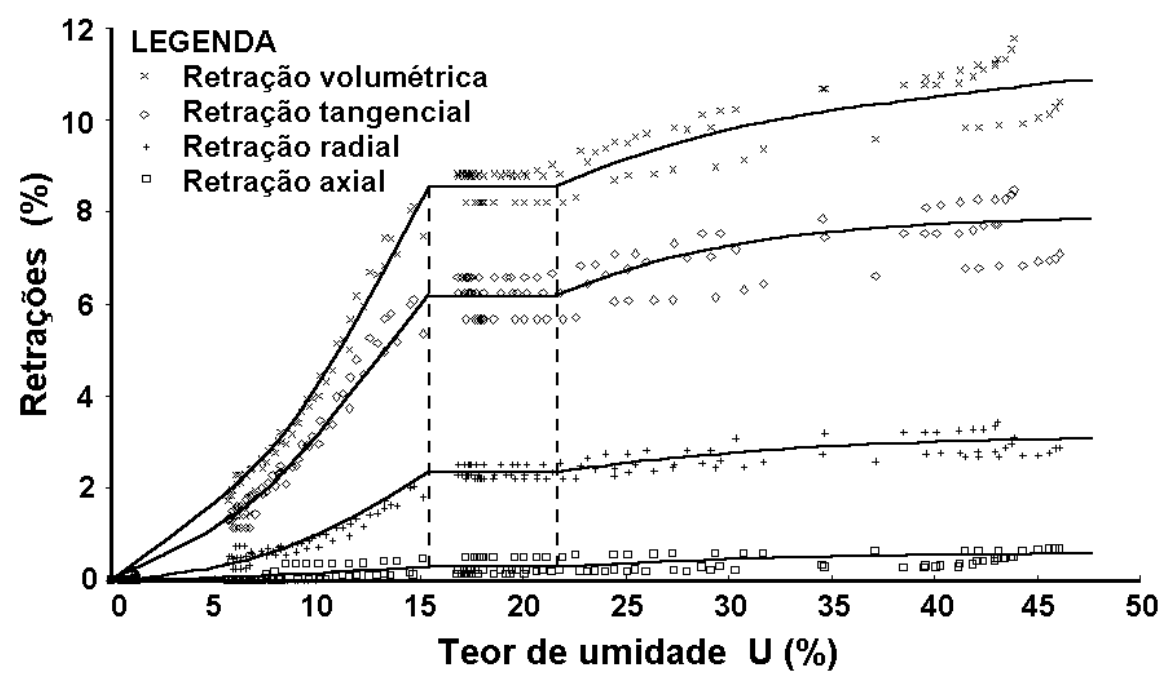

FIGURA 15 - Diagramas de Retrações para a Itaúba, Mezilaurus itauba (Meissn) Taubert ex Mez. Fonte: LOGSDON (1998)

Alguns autores, como SCHMIDT (1995), consideram retração ou inchamento a variação dimensional entre um determinado teor de umidade e $0 \%$. A variação dimensional entre dois teores de umidade, no intervalo higroscópico, é denominada movimento. 


\subsection{DENSIDADE APARENTE}

A densidade aparente da madeira depende de seu teor de umidade, de modo que é inútil referir-se a densidade de uma madeira sem, simultaneamente, fornecer o correspondente teor de umidade.

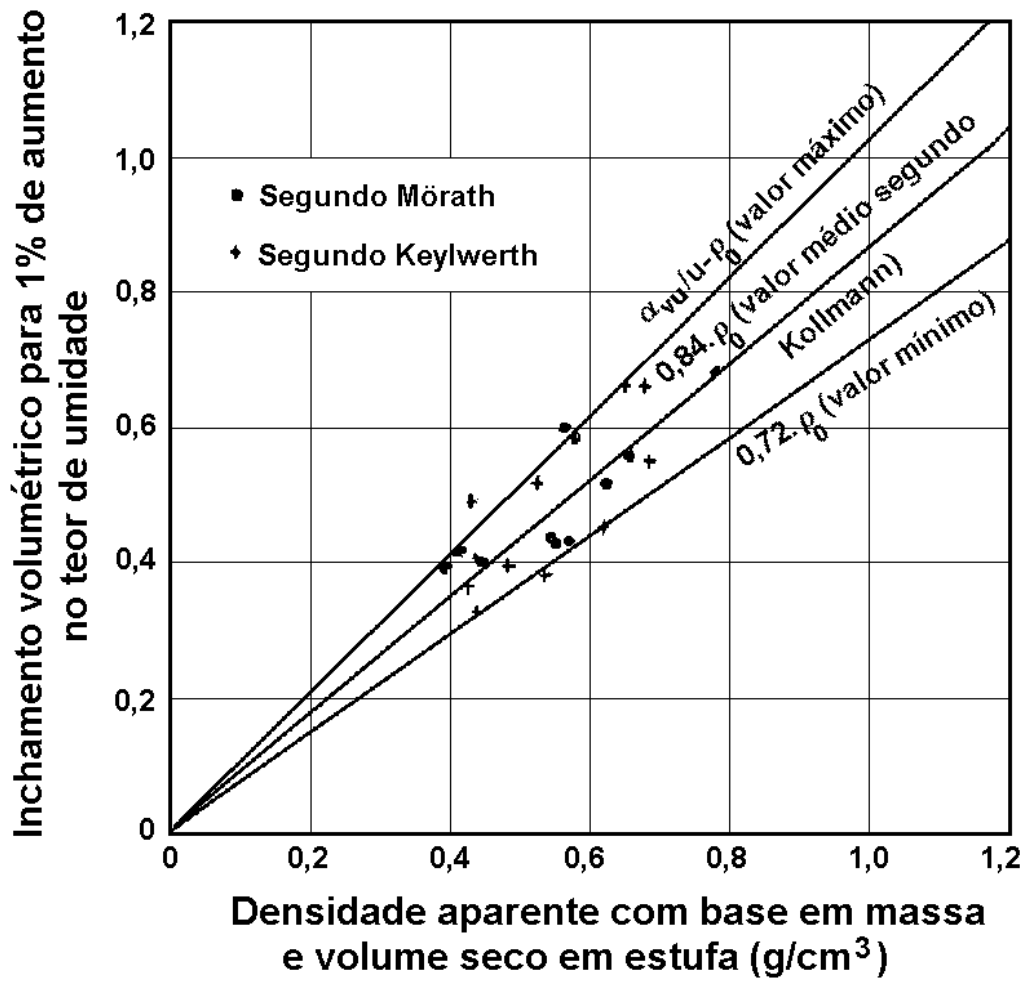

FIGURA 16 - Inchamento volumétrico por $1 \%$ de aumento no teor de umidade relacionado à densidade aparente seca. Fonte: KOLLMANN \& COTÉ (1984)

KOLLMANN ${ }^{10}$ apud KOLLMANN \& COTÉ (1984), a fim de estudar a variação da densidade aparente com o teor de umidade, associou, inicialmente, a densidade aparente seca à variação do inchamento volumétrico por unidade de variação da umidade (ver figura 16), com a média do resultado obtido e admitindo $28 \%$ para o ponto de saturação das fibras, construiu um diagrama, atualmente conhecido como Diagrama de Kollmann, para representar a variação da densidade aparente com a umidade (ver figura 17).

${ }^{10}$ KOLLMANN, F. (1934). Holzgewicht und Feuchtigkeit. Z. VDI 78: 1399 apud KOLLMANN, F. F. P. \& CÔTÉ, W. A. (1984). Principles of wood science and technology. Vol I Solid Wood. Reprint Berlin, Heidelberg, New York, Tokyo. Springer-Verlag. 1968-1984. 


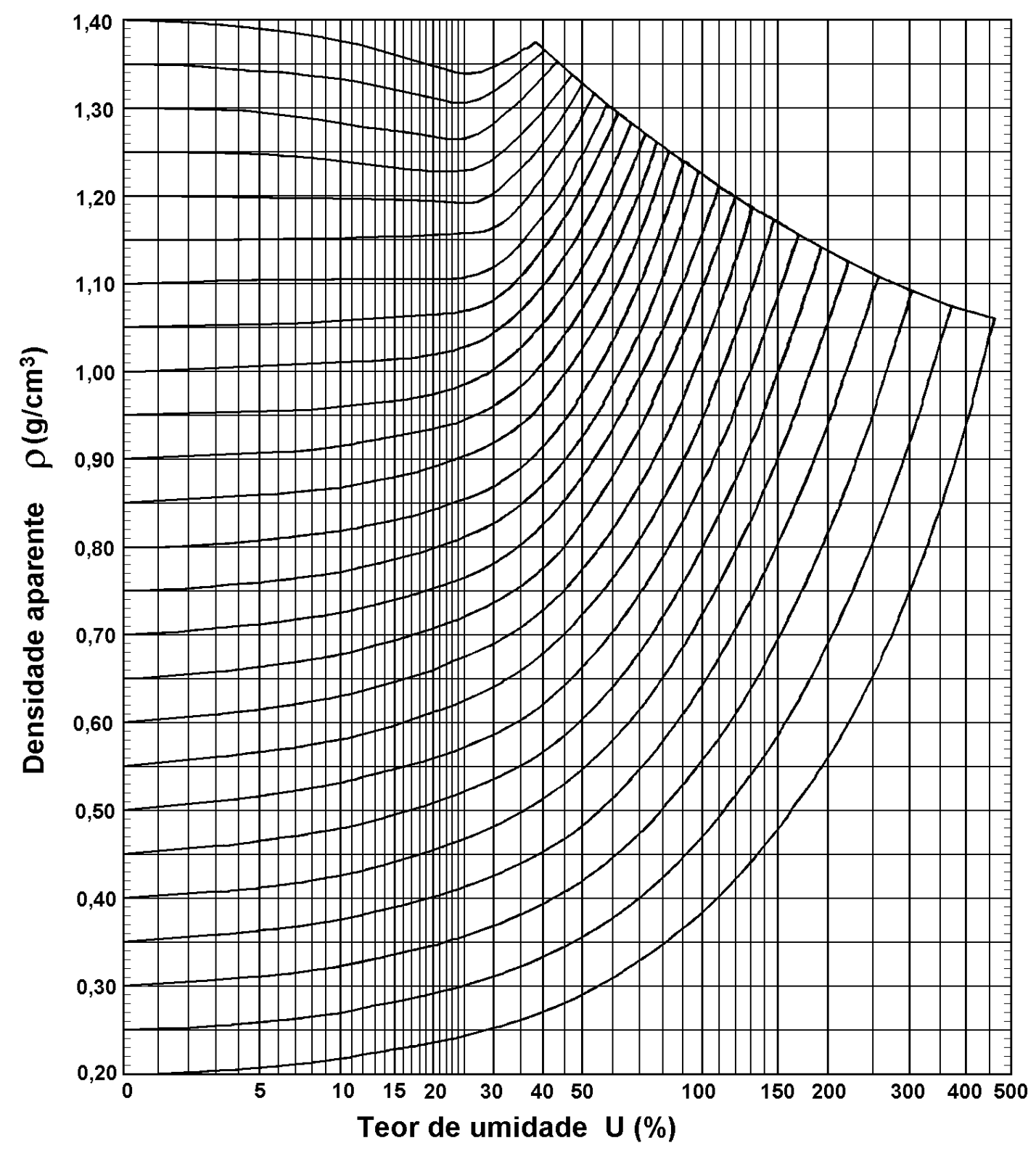

FIGURA 17 - Diagrama de Kollmann, que representa a variação da densidade aparente com o teor de umidade. Fonte: KOLLMANN \& COTÉ (1984)

\subsection{COMPRESSÃO PARALELA ÀS FIBRAS}

MATEUS (1962) separou dez lotes de Pinho Bravo (Pinus pinaster Ait), condicionou-os em diferentes teores de umidade, ensaiou os corpos-de-prova de cada lote à compressão axial, e traçou uma curva resistência-umidade unindo os pontos médios de cada lote (ver figura 18). 


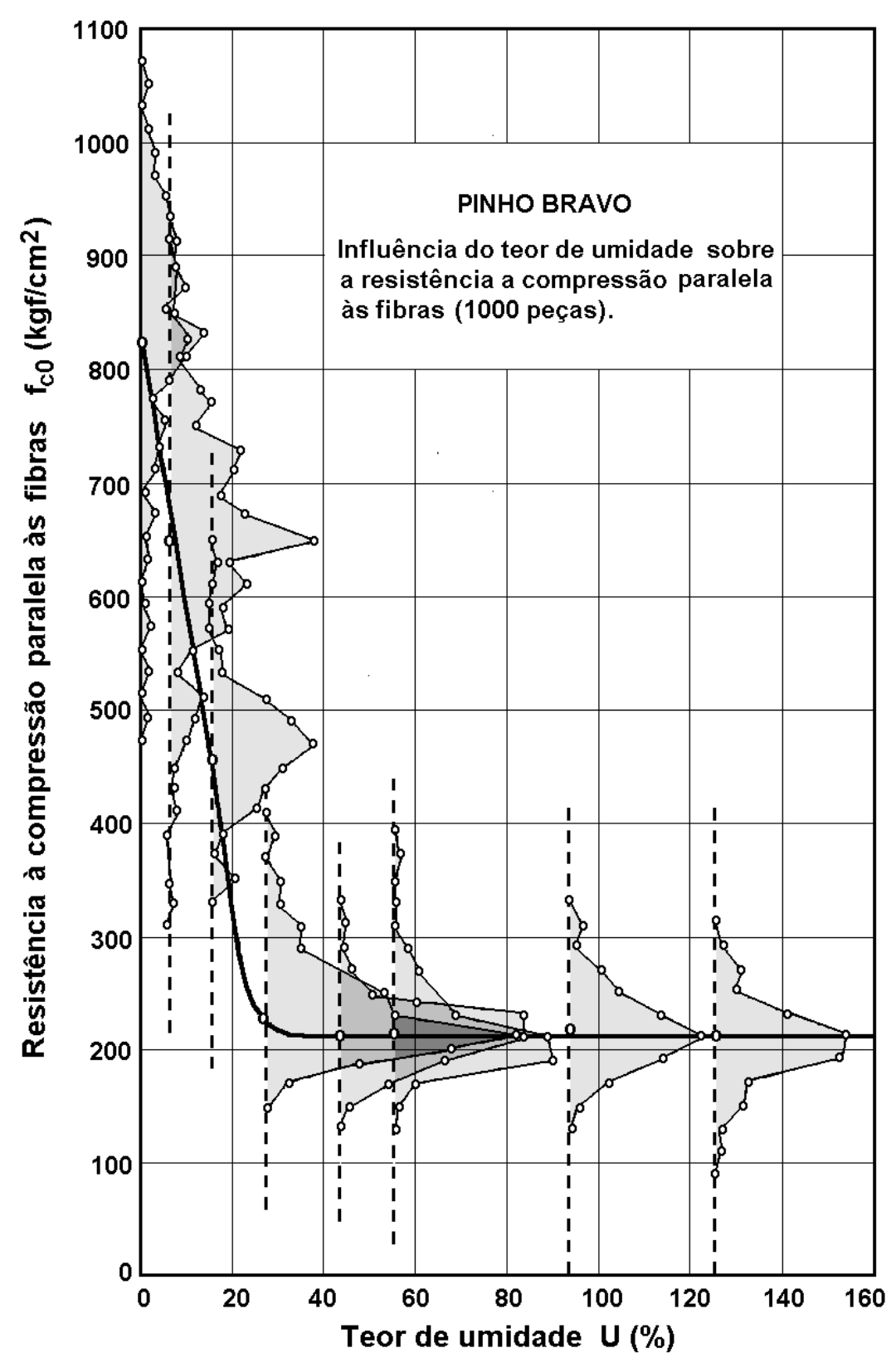

FIGURA 18 - Relação entre a resistência à compressão paralela às fibras e o teor de umidade $\left(1 \mathrm{kgf} / \mathrm{cm}^{2} \cong 0,10 \mathrm{MPa}\right)$. Fonte: MATEUS (1962)

KOLLMANN $^{11}$ apud KOLLMANN \& COTÉ (1984) estudou o efeito do teor de umidade sobre a compressão paralela em quatro espécies diferentes (ver figura 19) e conside-

${ }^{11}$ KOLLMANN, F. (1951). Technologie des Holzes und der Holzwerkstoffe, Vol. I, 2.ed. Berlin - Göttingen - Heidelberg. Springer-Verlag. apud KOLLMANN, F. F. P. \& CÔTÉ, W. A. (1984). Principles of wood science and technology. Vol I Solid Wood. Reprint Berlin, Heidelberg, New York, Tokyo. Springer-Verlag. 1968-1984. 
rou que as curvas são suaves e, para um teor de umidade entre 8 e $18 \%$, podem ser substituídas por linhas retas.

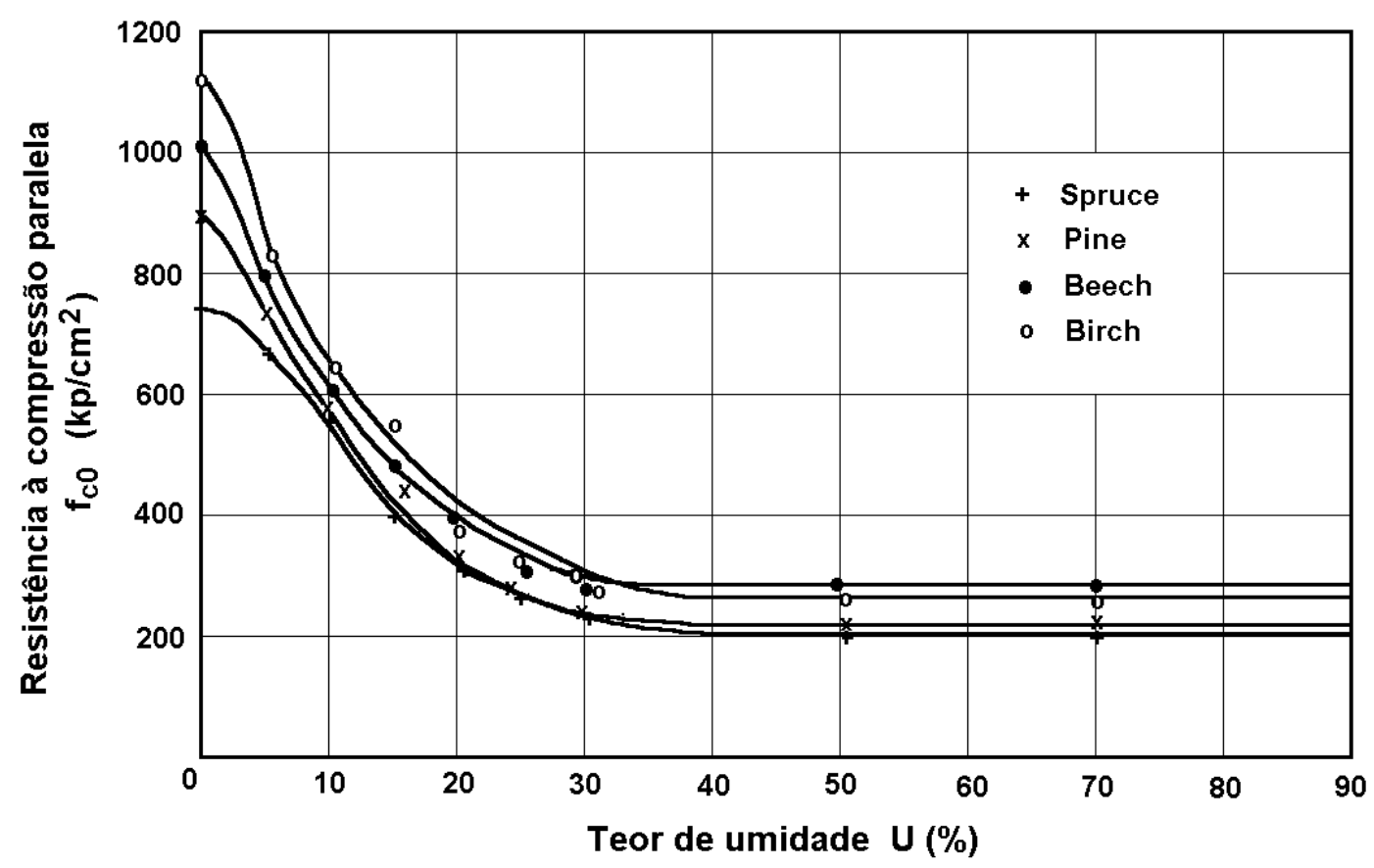

FIGURA 19 - Efeitos do teor de umidade sobre a resistência à compressão paralela às fibras para algumas espécies de madeira. Fonte: KOLLMANN ${ }^{11}$ apud KOLLMANN \& COTÉ (1984)

HELLMEISTER (1983), com o intuito de obter corpos-de-prova semelhantes, utilizou uma barra para estudar a influência da umidade sobre a resistência à compressão paralela às fibras (ver figura 20).

LOGSDON (1995), estudando a variação da resistência ao cisalhamento com a posição do corpo-de-prova no tronco, conclui que: "ao longo do comprimento esta variação é tão pequena que pode ser desprezada e a tensão resistente admitida como constante", constatando assim o acerto da decisão de HELLMEISTER (1983). 


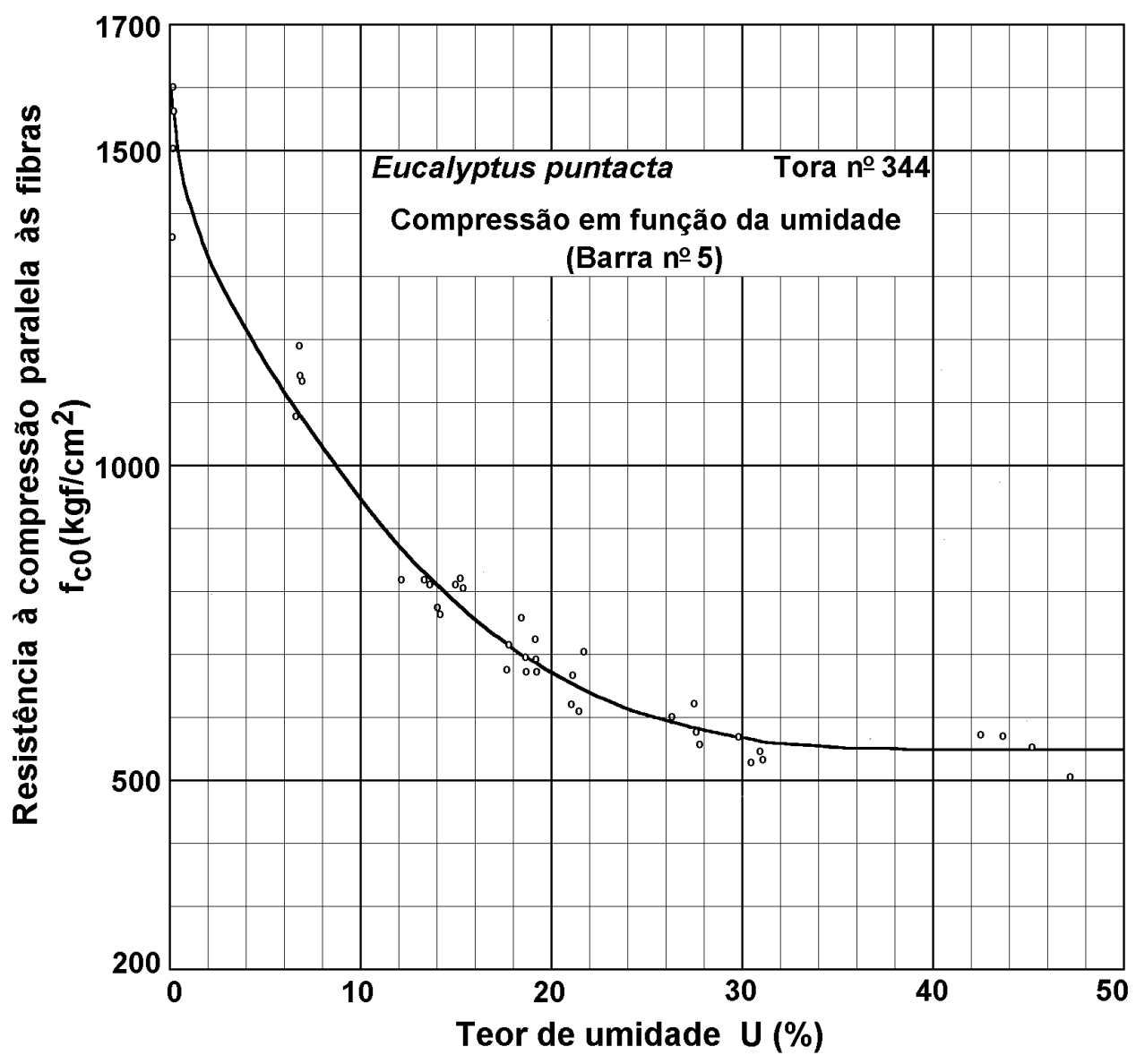

FIGURA 20 - Influência da umidade sobre a resistência à compressão paralela às fibras para o Eucalyptus puntacta $\left(1 \mathrm{kgf} / \mathrm{cm}^{2} \cong 0,10 \mathrm{MPa}\right)$. Fonte: HELLMEISTER (1983)

LIMA et al. (1986), utilizando corpos-de-prova retirados de uma única árvore, na região do cerne, imediatamente abaixo do alburno, estudaram o efeito do teor de umidade sobre a resistência à compressão paralela às fibras e obtiveram os resultados apresentados na figura 21. Ainda chamaram a atenção para a possibilidade de escrever a expressão obtida (ver figura 21) sob a forma:

$$
f_{c 0}=\frac{90,89}{(1+0,03)^{\mathrm{U} \%}}
$$

Onde:

$\mathrm{f}_{\mathrm{c} 0}=$ resistência à compressão paralela às fibras ao teor de umidade $\mathrm{U} \%$, em $\mathrm{MPa}$, e $\mathrm{U} \%=$ teor de umidade da madeira, em \%. 
O valor 0,03 na eq. (07), pode ser interpretado, segundo LIMA et al. (1986), como a resistência à compressão para cada $1 \%$ de aumento no teor de umidade.

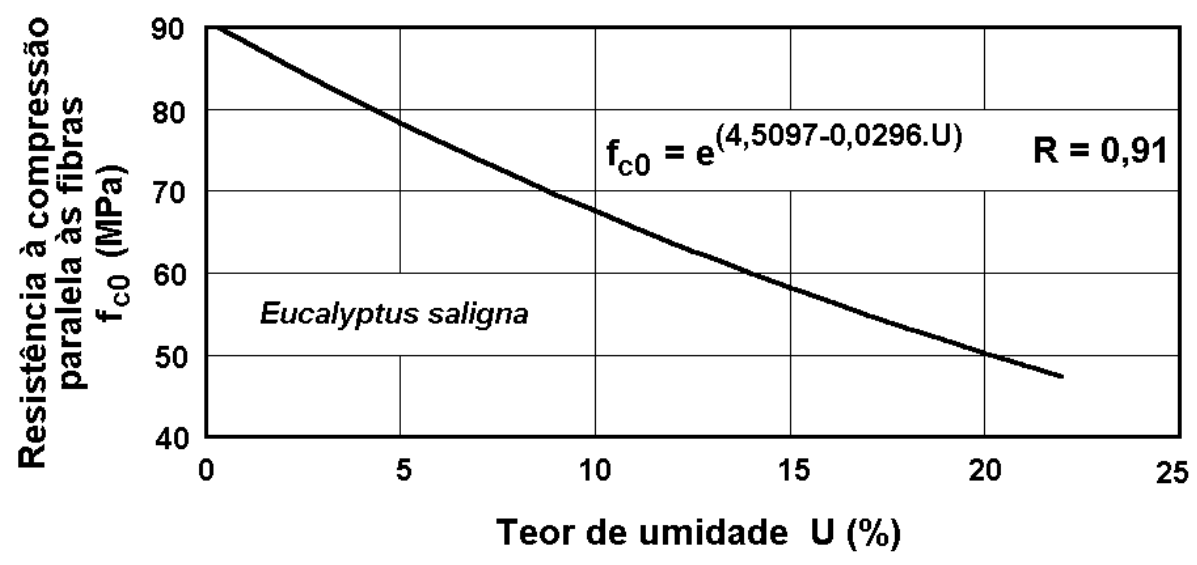

FIGURA 21 - Variação da resistência à compressão paralela às fibras com o teor de umidade do Eucalyptus saligna. Fonte: LIMA et al. (1996)

PIGOZZO (1982), estudando a influência da umidade e da densidade na resistência à compressão paralela, obtém curvas dependentes da densidade e da umidade (ver figura 22).

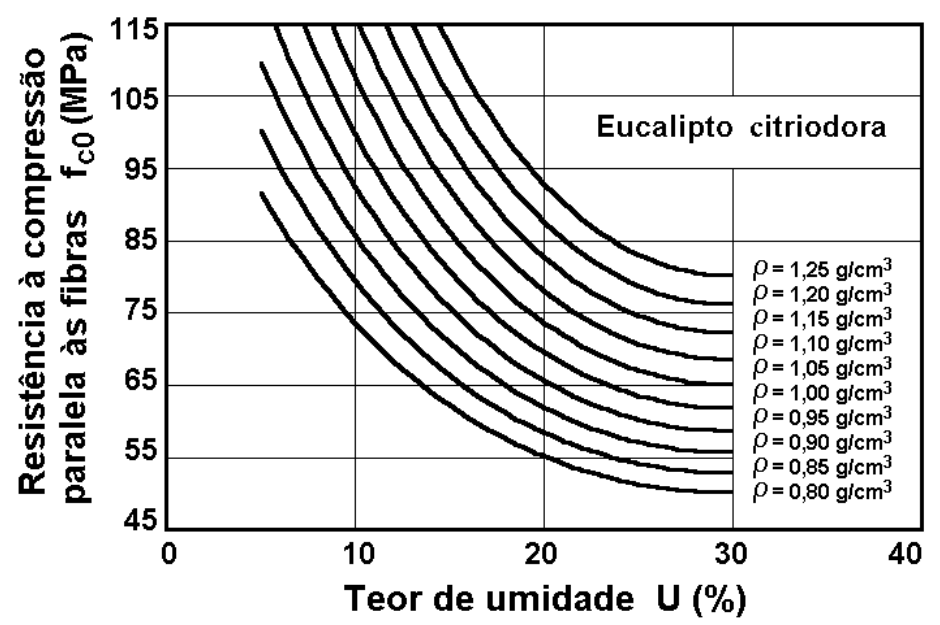

FIGURA 22 - Influência da umidade e da densidade sobre a resistência à compressão paralela às fibras do Eucalipto citriodora. Fonte : PIGOZZO (1982)

BALLARIN \& RIBEIRO (1998) obtêm duas retas para representar a variação da resistência à compressão paralela às fibras com a umidade do Eucalipto citriodora (ver figura 23). O coeficiente angular da reta, que representa a variação da resistência, para teor de umidade acima do ponto de saturação das fibras é muito baixo tornando a reta praticamente 
constante. BALLARIN \& RIBEIRO (1998) verificam seus resultados na expressão proposta pela NBR 7190/97 e concluem pela validade daquela proposta.

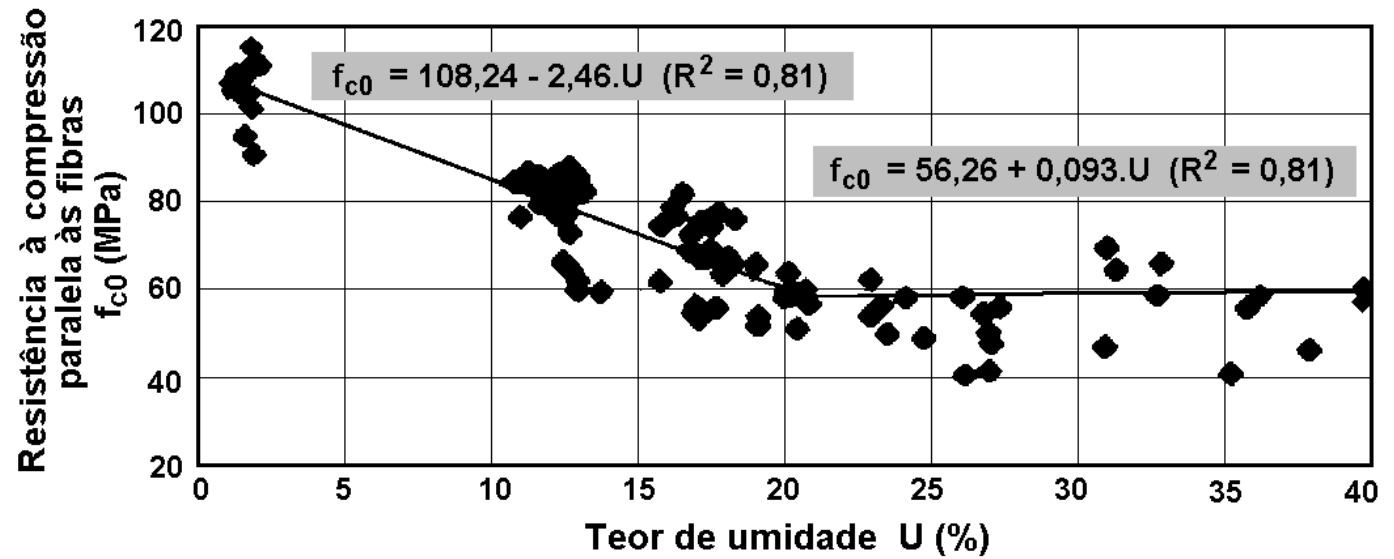

FIGURA 23 - Variação da resistência à compressão paralela às fibras com a umidade do Eucalipto citriodora. Fonte: BALLARIN \& RIBEIRO (1998)

KRETSHMANN \& GREEN (1994) estudando a influência de baixos teores de umidade sobre a resistência, de peças comerciais de "Southern pine" (Pinus echinata ou Pinus taeda), também obtiveram uma variação linear para a compressão paralela às fibras (ver figura 24).

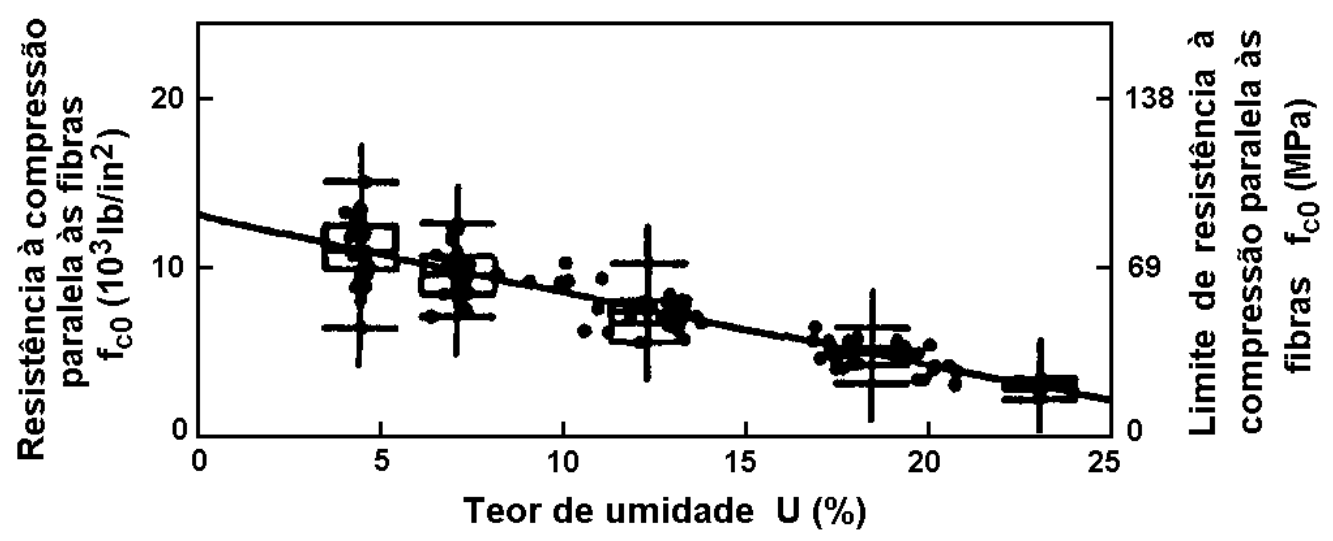

FIGURA 24 - Variação da resistência à compressão paralela às fibras com o teor de umidade em "Southern pine" $\left(1 \mathrm{lb} / \mathrm{in}^{2} \cong 0,00689 \mathrm{MPa}\right)$. Fonte: KRETSHMANN \& GREEN (1994) 


\subsection{TRAÇÃO PARALELA ÀS FIBRAS}

A resistência à tração ao longo das fibras, segundo KOLLMANN \& COTÉ (1984), aumenta a medida em que a madeira seca abaixo do ponto de saturação das fibras. Poucos ensaios de tração paralela foram realizados, ainda assim SCHYLYTER \& WINBERG ${ }^{12}$ apud KOLLMANN \& COTÉ (1984) informaram que a partir dos $10 \%$ de teor de umidade até o ponto de saturação das fibras há uma diminuição linear de resistência à tração, que de acordo com o U.S. Forest Products Laboratory é de 3\% para cada 1\% de aumento no teor de umidade.

Investigações de $\mathrm{KÜCH}^{13}$ apud KOLLMANN \& COTÉ (1984) trouxeram evidências de que há um pico de resistência à tração para um teor de umidade entre 8 e $10 \%$. As razões físicas para este ponto de máximo ainda não estão claras.

KRETSHMANN \& GREEN (1994) estudando a influência de baixos teores de umidade sobre a resistência, de peças comerciais de "Southern pine" (Pinus echinata ou Pinus taeda), obtiveram na tração paralela um ponto de máximo a um teor de umidade de 12,6 $\%$ (ver figura 25).

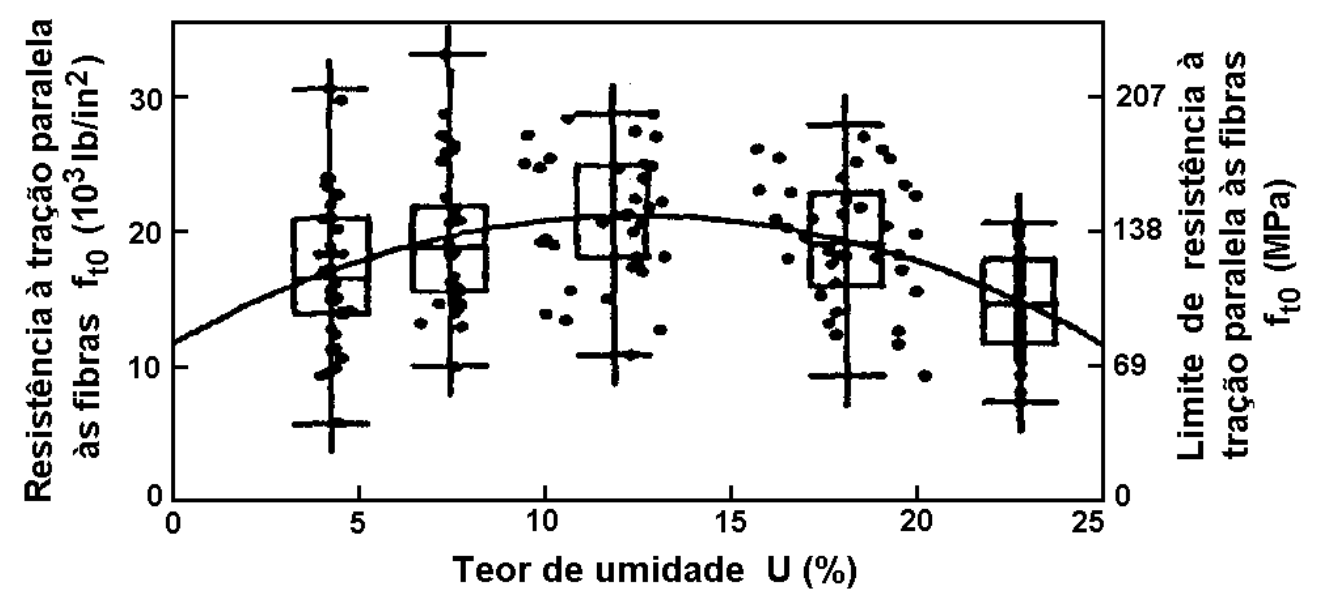

FIGURA 25 - Variação da resistência à tração paralela às fibras com o teor de umidade em "Southern pine" (1 lb/in² $\cong 0,00689 \mathrm{MPa})$. Fonte: KRETSHMANN \& GREEN (1994)

${ }^{12}$ SCHLYTER, R.; WINBERG, G. (1929). Svenskt furuvirkes háafasthetsegenskaper och deras beroende av fuktighetahalt och volymvikt. Stat. Provningsanst. Medd. 42. Stockholm. apud KOLLMANN, F. F. P. \& CÔTÉ, W. A. (1984). Principles of wood science and technology. Vol I Solid Wood. Reprint Berlin, Heidelberg, New York, Tokyo. Springer-Verlag. 1968-1984.

${ }^{13}$ KÜCH, W. (1943). Der Einflu $\beta$ des Feuchtigkeisgehalts auf die Festigkeit von Voll und Schichtholz. Holz als Roh und Werkstoff, 6. p.157-161 apud KOLLMANN, F. F. P. \& CÔTÉ, W. A. (1984). Principles of wood science and technology. Vol I Solid Wood. Reprint Berlin, Heidelberg, New York, Tokyo. Springer-Verlag. 1968-1984. 


\subsection{CISALHAMENTO PARALELO ÀS FIBRAS}

$\mathrm{O}$ aumento médio da resistência ao cisalhamento paralelo às fibras, no intervalo higroscópico, para uma diminuição do teor de umidade é menor que o que ocorre na flexão ou compressão paralela. Por outro lado, a orientação entre o plano de ruptura e as forças transversais é de suma importância. Para algumas orientações das fibras praticamente não existe efeito do teor de umidade sobre a resistência ao cisalhamento (KOLLMANN \& COTÉ,1984). Na figura 26 é apresentada a influência do teor de umidade sobre a resistência ao cisalhamento para diversas orientações das fibras.

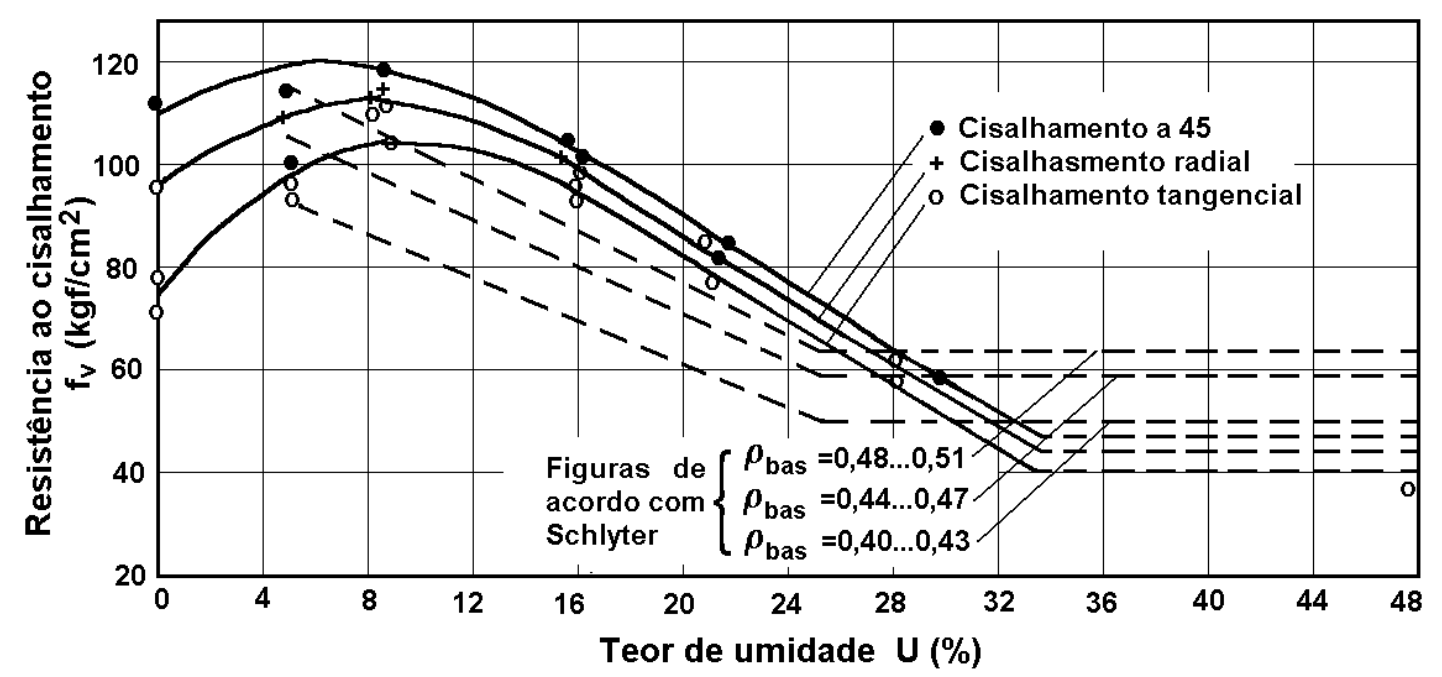

FIGURA 26 - Efeito do teor de umidade sobre a resistência ao cisalhamento (corpo-de-prova com um plano de cisalhamento) para "pine" $\left(1 \mathrm{kgf} / \mathrm{cm}^{2} \cong 0,10 \mathrm{MPa}\right)$. Fonte: SCHYLTER \& WINBERG ${ }^{14}$ apud KOLLMANN \& COTÉ (1984)

KRETSHMANN \& GREEN (1994) estudando a influência de baixos teores de umidade sobre a resistência ao cisalhamento paralelo, de peças comerciais de "Southern pine" (Pinus echinata ou Pinus taeda), obtiveram um ponto de máximo a um teor de umidade de $1,2 \%$ (ver figura 27 ).

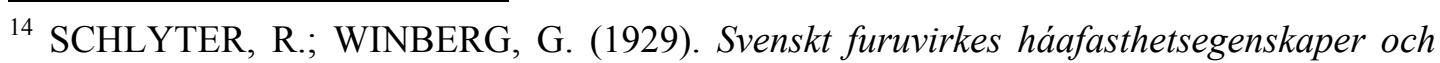
deras beroende av fuktighetahalt och volymvikt. Stat. Provningsanst. Medd. 42. Stockholm. apud KOLLMANN, F. F. P. \& CÔTÉ, W. A. (1984). Principles of wood science and technology. Vol I Solid Wood. Reprint Berlin, Heidelberg, New York, Tokyo. Springer-Verlag. 1968-1984. 


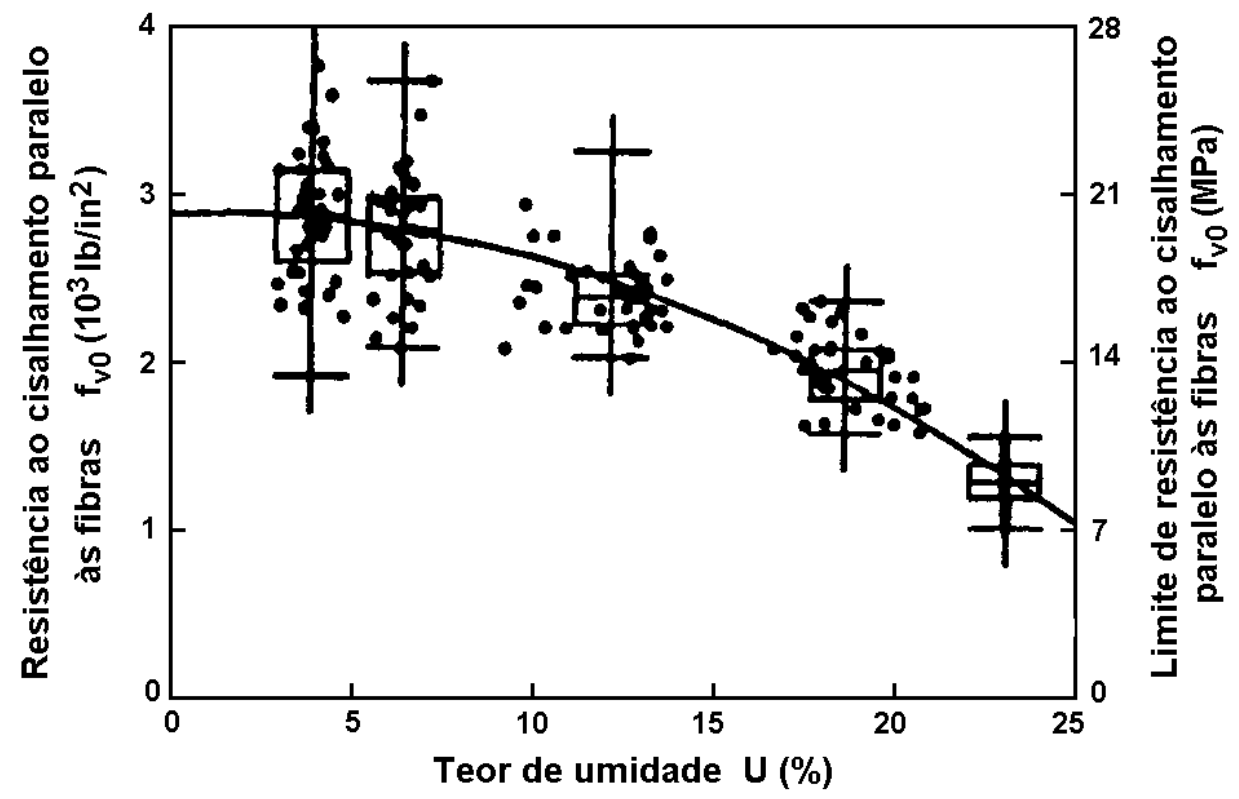

FIGURA 27 - Variação da resistência ao cisalhamento paralelo às fibras com o teor de umidade em "Southern pine" ( $\left.1 \mathrm{lb} / \mathrm{in}^{2} \cong 0,00689 \mathrm{MPa}\right)$. Fonte: KRETSHMANN \& GREEN (1994)

Resultado semelhante, apresentado na figura 28, foi obtido por LIMA et al. (1986), entretanto, sem obter um ponto de máximo. É importante ressaltar que a metodologia utilizada, por LIMA et al. (1986), foi a descrita no antigo método brasileiro MB-26, NBR-6230 da ABNT (1980), no qual a orientação do plano de cisalhamento não é claramente definida.

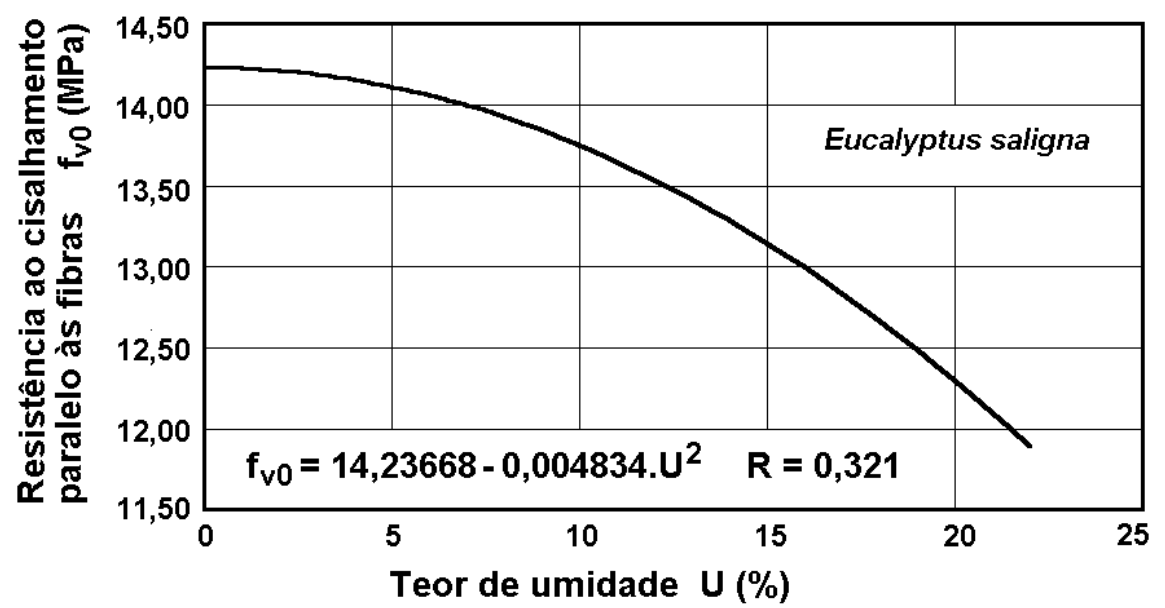

FIGURA 28 - Variação da resistência ao cisalhamento paralelo às fibras com o teor de umidade em Eucalyptus saligna. Fonte: LIMA et al. (1986) 
MADSEN (1992), ao estudar o efeito do teor de umidade sobre a resistência ao cisalhamento em peças comerciais, obteve comportamento diferente para grupos de espécies diferentes (ver figura 29).

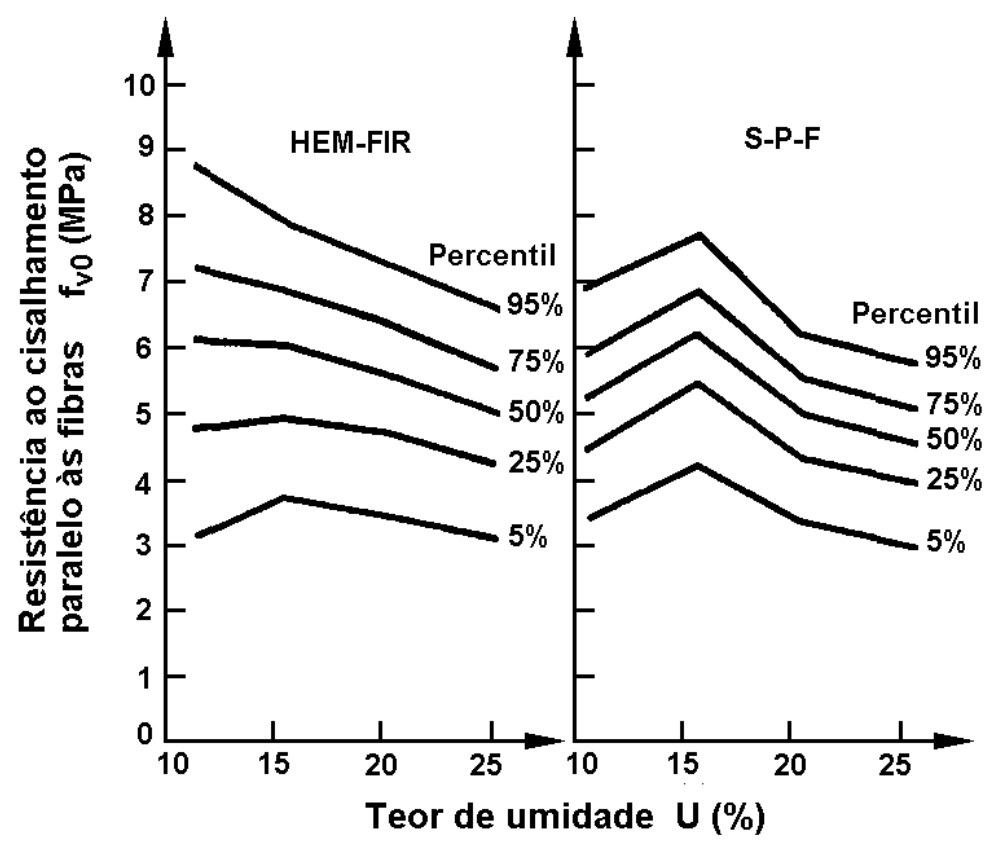

FIGURA 29 - Variação da resistência ao cisalhamento paralelo às fibras com o teor de umidade em "Hem-Fir" e "Southern-Pine-Fir" (S-P-F). O comportamento dos dois grupos de espécies é muito diferente. Fonte: MADSEN (1992)

\subsection{FLEX̃̃O ESTÁTICA}

TANAAMI (1986), estudando a influência da umidade e da densidade sobre a resistência à flexão, obtém um jogo de curvas, nas quais a resistência aumenta a medida que a madeira seca (ver figura 30). Estas curvas, dependentes da densidade e da umidade, indicam que a relação resistência-umidade também varia com a qualidade da madeira.

KÜCH ${ }^{15}$ apud KOLLMANN \& COTÉ (1984) mostrou que a relação entre a resistência à flexão (de "ash" e "beechwood") e o teor de umidade é caracterizado por um pico a um teor de umidade de aproximadamente $5 \%$ (ver figura 31 ). No intervalo de teor de umidade entre 8 e $15 \%$ uma relação linear é aceitável.

${ }^{15}$ KÜCH, W. (1943). Der Einfluß des Feuchtigkeisgehalts auf die Festigkeit von Voll und Schichtholz. Holz als Roh und Werkstoff, 6. p.157-161 apud KOLLMANN, F. F. P. \& CÔTÉ, W. A. (1984). Principles of wood science and technology. Vol I Solid Wood. Reprint Berlin, Heidelberg, New York, Tokyo. Springer-Verlag. 1968-1984. 


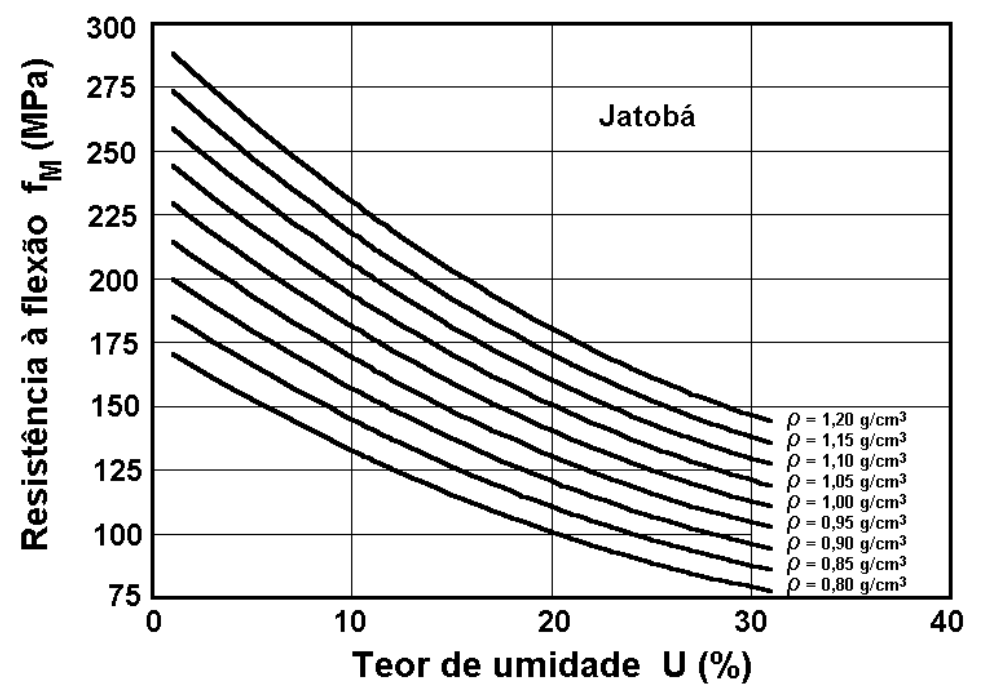

FIGURA 30 - Influência da umidade e da densidade sobre a resistência à flexão para o Jatobá. Fonte : TANAAMI (1986)

Já KRETSHMANN \& GREEN (1994) estudando a influência de baixos teores de umidade sobre a resistência, de peças comerciais de "Southern pine" (Pinus echinata ou Pinus taeda), não obteve para a flexão um ponto de máximo (ver figura 32). Resultado bastante semelhante, apresentado na figura 33, foi obtido por LIMA et al. (1986).

MCLAIN et al. ${ }^{16}$ apud GREEN \& PELLERIN (1991) apresentam um modelo analítico para representar o efeito do teor de umidade sobre a resistência à flexão, no qual a forma da curva resistência-umidade é função da qualidade da madeira (ver figura 34).

GREEN \& PELLERIN (1991), estudando a variação das propriedades de flexão com o teor de umidade em sete diferentes espécies, observam que a variação da resistência à flexão é dependente da espécie e da qualidade da madeira em uma mesma espécie (percentil de resistência). Isto pode ser constatado através da figura 35 .

\footnotetext{
${ }^{16}$ MCLAIN, T.E.; DEBONIS, A. L.; GREEN, D. W.; WILSON, F. J.; LINK, C. (1986). The Influence of Moisture Content on the Flexural! Properties of Southern Pine Dimension Lumber. Res. Pap. FPL-447, Madison, WI. U.S. Department of Agriculture, Forest Service, Forest Products Laboratory apud GREEN, D. W., EVANS, J. W. \& PELLERIN, R. (1991). Moisture content and the flexural properties of lumber: species differences. In: International Timber Engineering Conference London. Anais. London, England.
} 


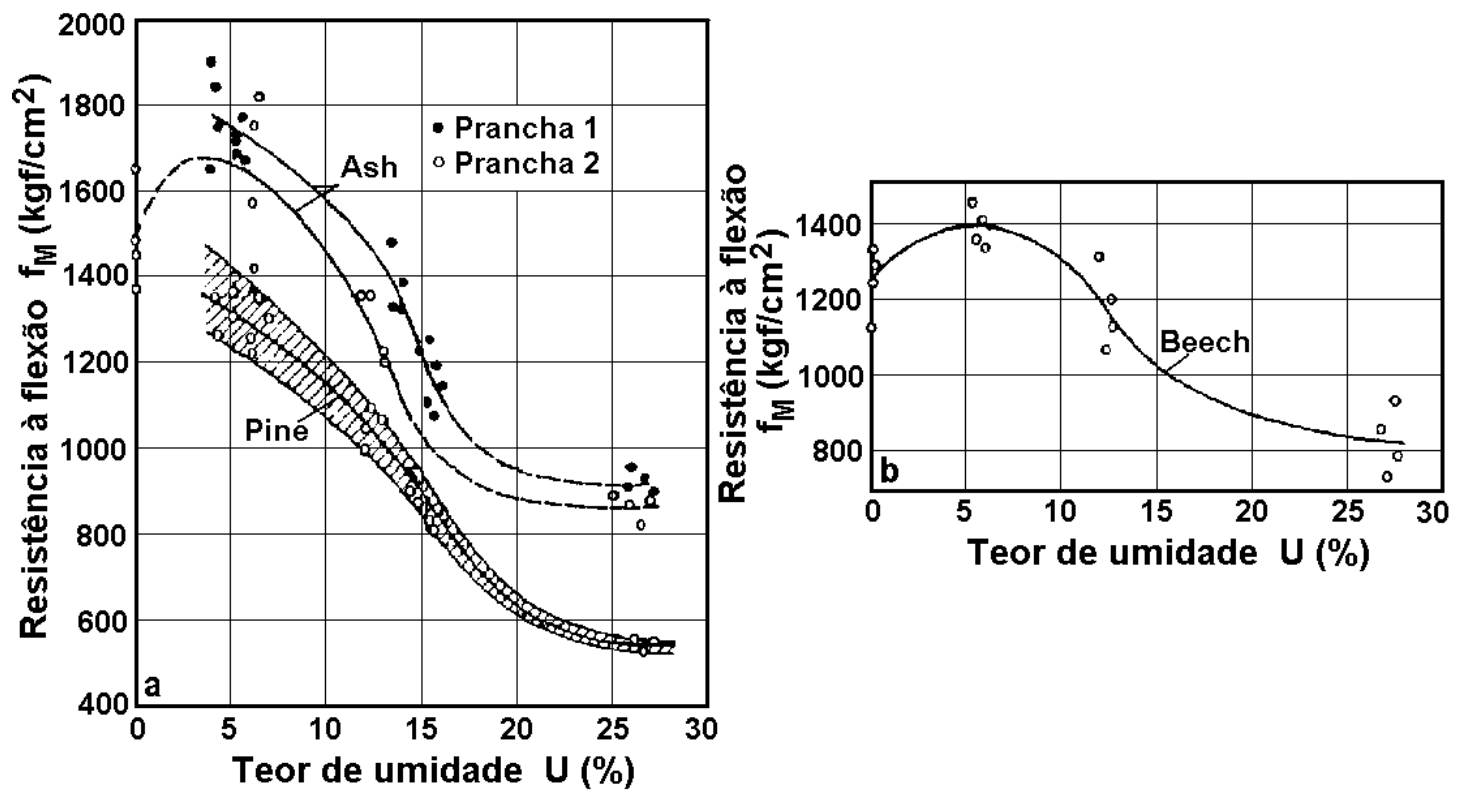

FIGURA 31 - Efeito do teor de umidade sobre a resistência à flexão: de a) "ash" e "pine", b) "beech" (1 kgf/cm² $\cong 0,10 \mathrm{MPa})$. Fonte: $\mathrm{KÜCH}^{17}$ apud KOLLMANN \& COTÉ (1984)

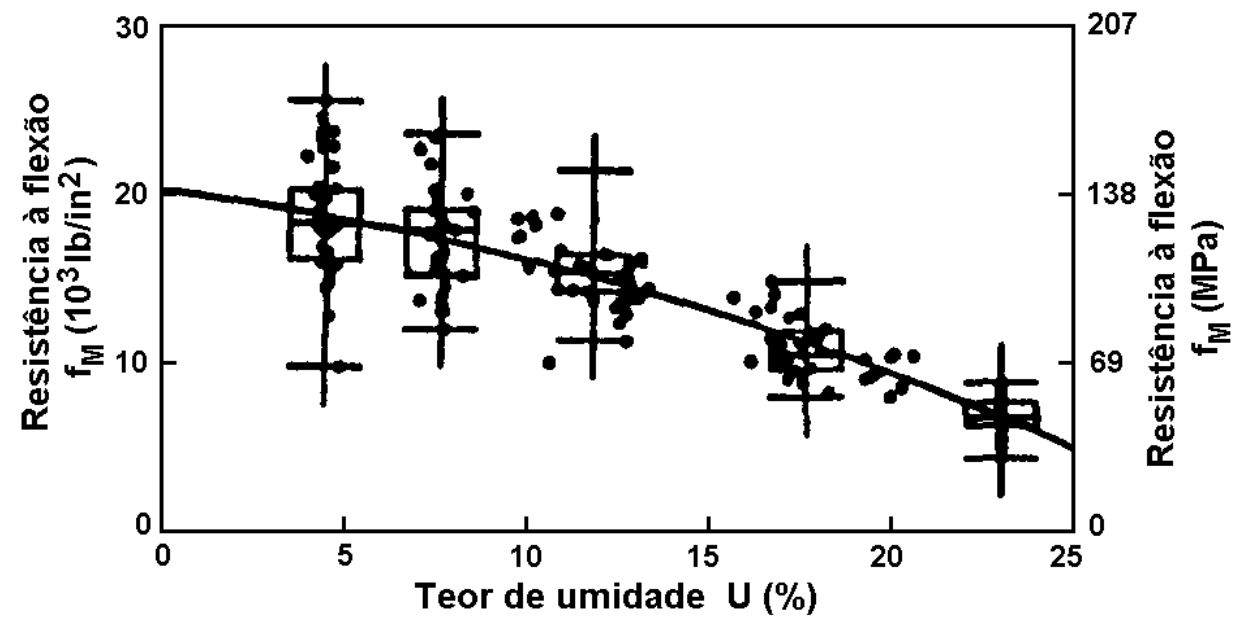

FIGURA 32 - Variação da resistência à flexão com o teor de umidade em "Southern pine" ( $1 \mathrm{lb} / \mathrm{in} 2 \cong 0,00689 \mathrm{MPa})$. Fonte: KRETSHMANN \& GREEN (1994)

${ }^{17}$ KÜCH, W. (1943). Der Einflu $\beta$ des Feuchtigkeisgehalts auf die Festigkeit von Voll und Schichtholz. Holz als Roh und Werkstoff, 6. p.157-161 apud KOLLMANN, F. F. P. \& CÔTÉ, W. A. (1984). Principles of wood science and technology. Vol I Solid Wood. Reprint Berlin, Heidelberg, New York, Tokyo. Springer-Verlag. 1968-1984. 


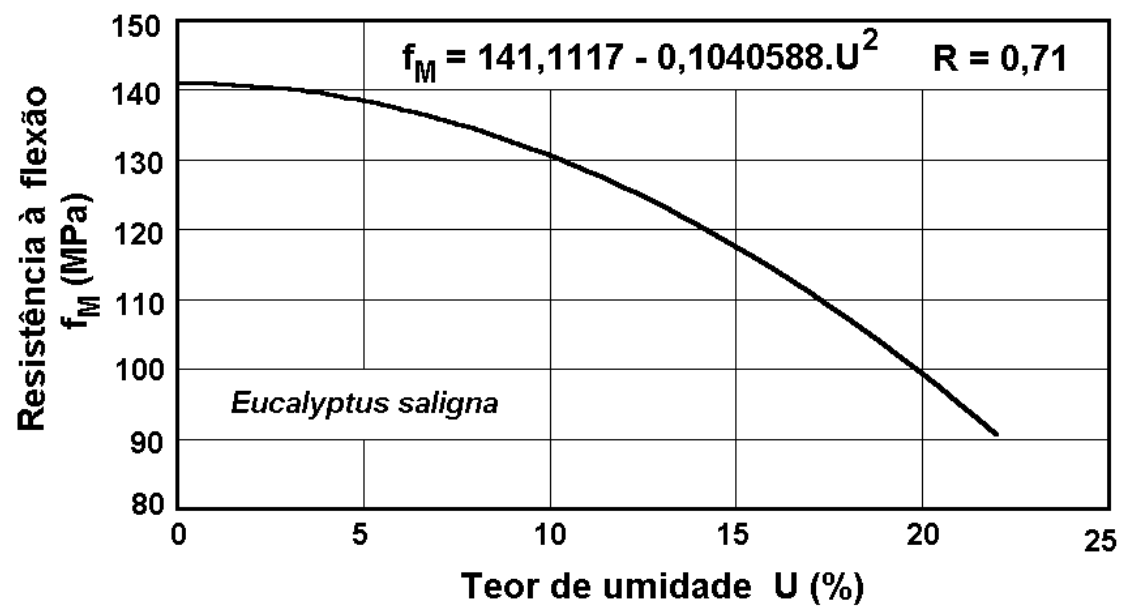

FIGURA 33 - Variação da resistência à flexão com o teor de umidade em Eucalyptus saligna. Fonte: LIMA et al. (1986)

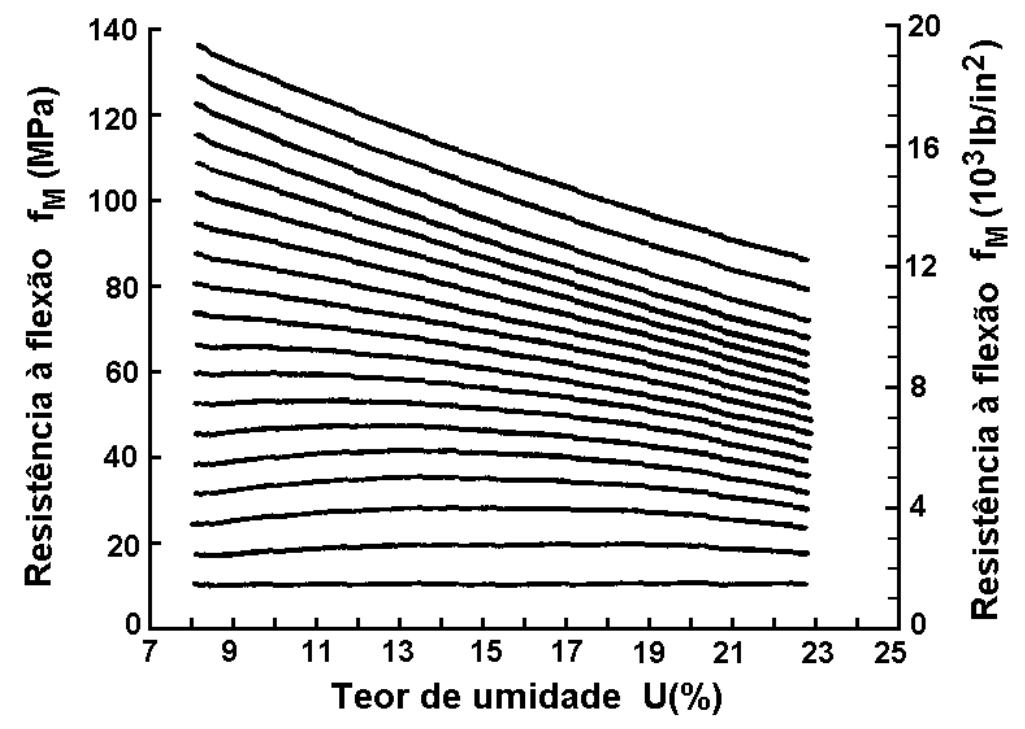

FIGURA 34 - Modelo Analítico do efeito do teor de umidade sobre a resistência à flexão $\left(1 \mathrm{lb} / \mathrm{in}^{2} \cong 0,00689 \mathrm{MPa}\right)$. Fonte: MCLAIN et al. ${ }^{18}$ apud GREEN \& PELLERIN (1991)

${ }^{18}$ MCLAIN, T.E.; DEBONIS, A. L.; GREEN, D. W.; WILSON, F. J.; LINK, C. (1986). The Influence of Moisture Content on the Flexural! Properties of Southern Pine Dimension Lumber. Res. Pap. FPL-447, Madison, WI. U.S. Department of Agriculture, Forest Service, Forest Products Laboratory apud GREEN, D. W., EVANS, J. W. \& PELLERIN, R. (1991). Moisture content and the flexural properties of lumber: species differences. In: International Timber Engineering Conference London. Anais. London, England. 

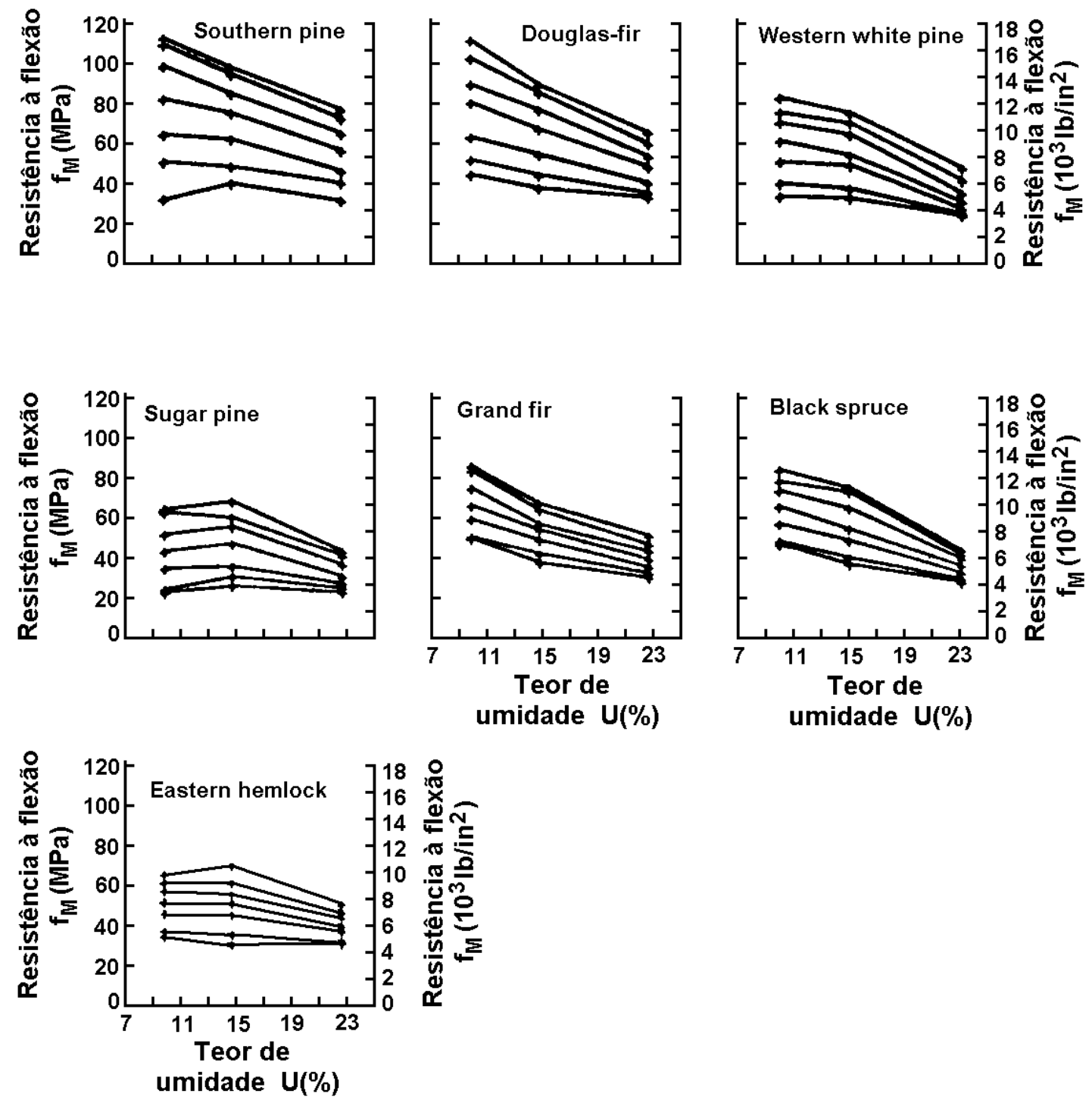

FIGURA 35 - Efeitos do teor de umidade sobre a resistência à flexão de peças comerciais, de seção 2" x 4" (5 cm x $10 \mathrm{~cm})$, classe "Select Structural", aos níveis percentuais de 5, 10, 25, 50, 75, 90 e $95\left(1 \mathrm{lb} / \mathrm{in}^{2} \cong 0,00689 \mathrm{MPa}\right)$. Fonte: GREEN \& PELLERIN (1991)

Resultados muito semelhantes foram obtidos por MADSEN (1992), para o "Douglas Fir" (ver figura 36). 


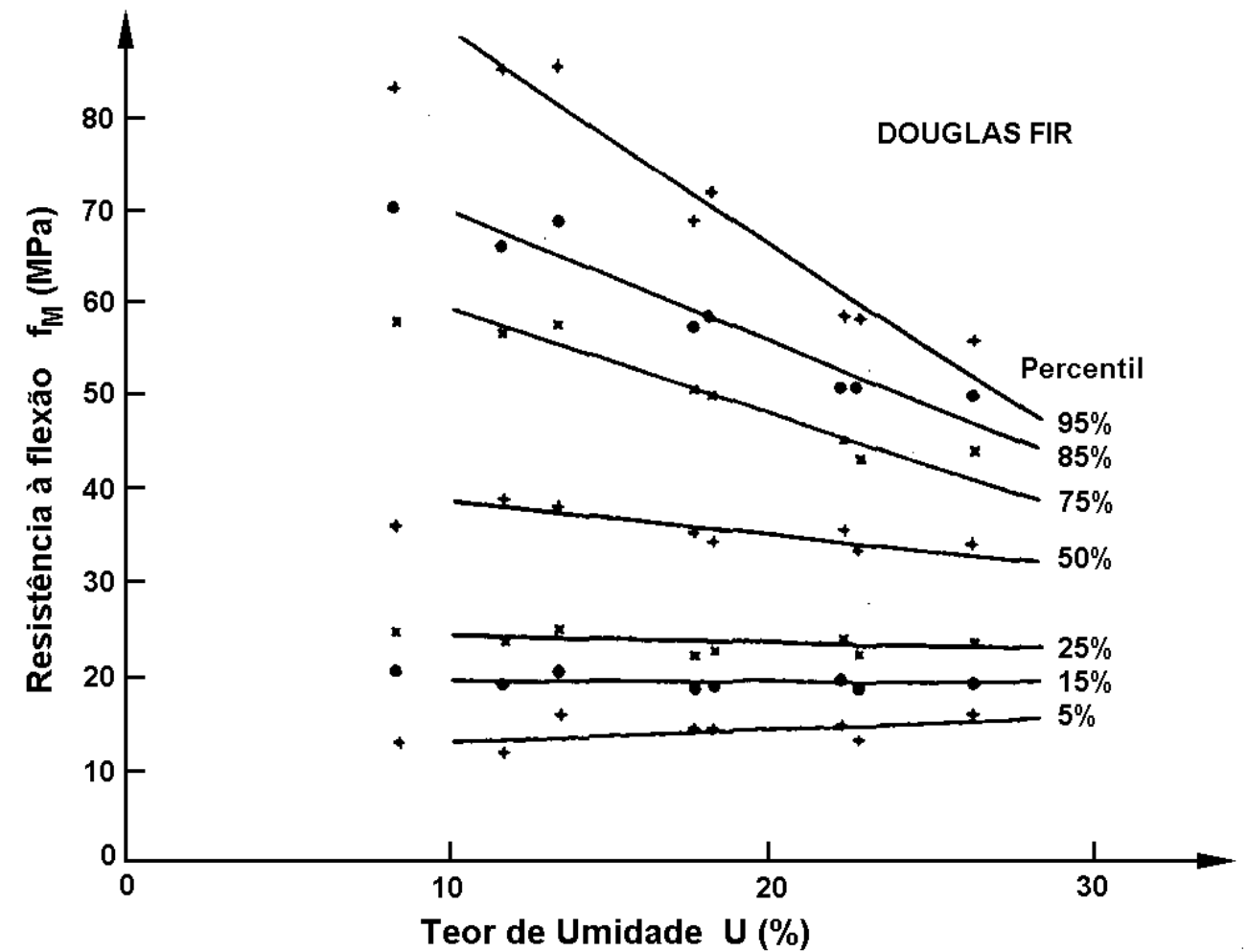

FIGURA 36 - Variação da resistência à flexão com o teor de umidade. Fonte: MADSEN (1992)

\subsection{MÓDULO DE ELASTICIDADE}

Tomando-se medidas de freqüência de vibração, em intervalos regulares, ao longo da secagem, de peças de "Stika spruce", a partir de um teor de umidade de $70 \%$ até a completa secagem, obtém-se, segundo DINWOODIE (1981), um diagrama, como o apresentado na figura 37, para representar a variação do módulo de elasticidade longitudinal com o teor de umidade.

O aumento no valor do módulo de elasticidade, a medida em que a madeira seca, também foi verificado, por HAYGREEN \& BOWER ${ }^{19}$ apud SMITH (1998), que ensaiaram à flexão peças de "Black spruce", Picea mariana (Mill.) B. S. P., e obtiveram para madeira verde $1,38 \cdot 10^{6} \mathrm{psi}(\cong 9515 \mathrm{MPa})$ e para madeira seca ao ar $1,61 \cdot 10^{6} \mathrm{psi}(\cong 11100 \mathrm{MPa})$.

${ }^{19}$ HAYGREEN, J. G.; BOWER, J. L. (1982). Forest products and wood science. Iowa State University. Press: Ames. apud SMITH, P. (1998). Black spruce, Picea mariana (Mill.) B. S. P. http://forestry.auburn.edu/coops/sfnmc/class/bspruce.html (22/06/98) 


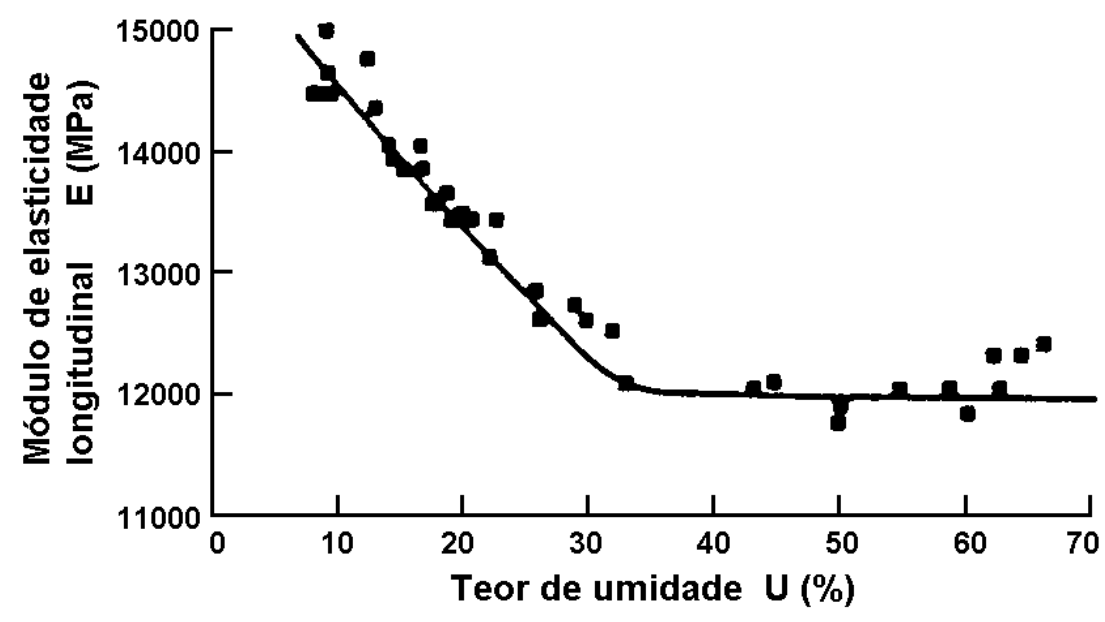

FIGURA 37 - Efeito do teor de umidade sobre o módulo de elasticidade longitudinal de "Stika spruce". O módulo de elasticidade longitudinal foi determinado dinamicamente. Fonte: DINWOODIE (1981)

KOLLMANN ${ }^{20}$ \& KRECH apud KOLLMANN \& COTÉ (1984), baseando-se em ensaios de vibração, obtêm diagramas como o da figura 38 e admitem a possibilidade, para teor de umidade entre 8 e $22 \%$, de aproximar as curvas a linhas retas.

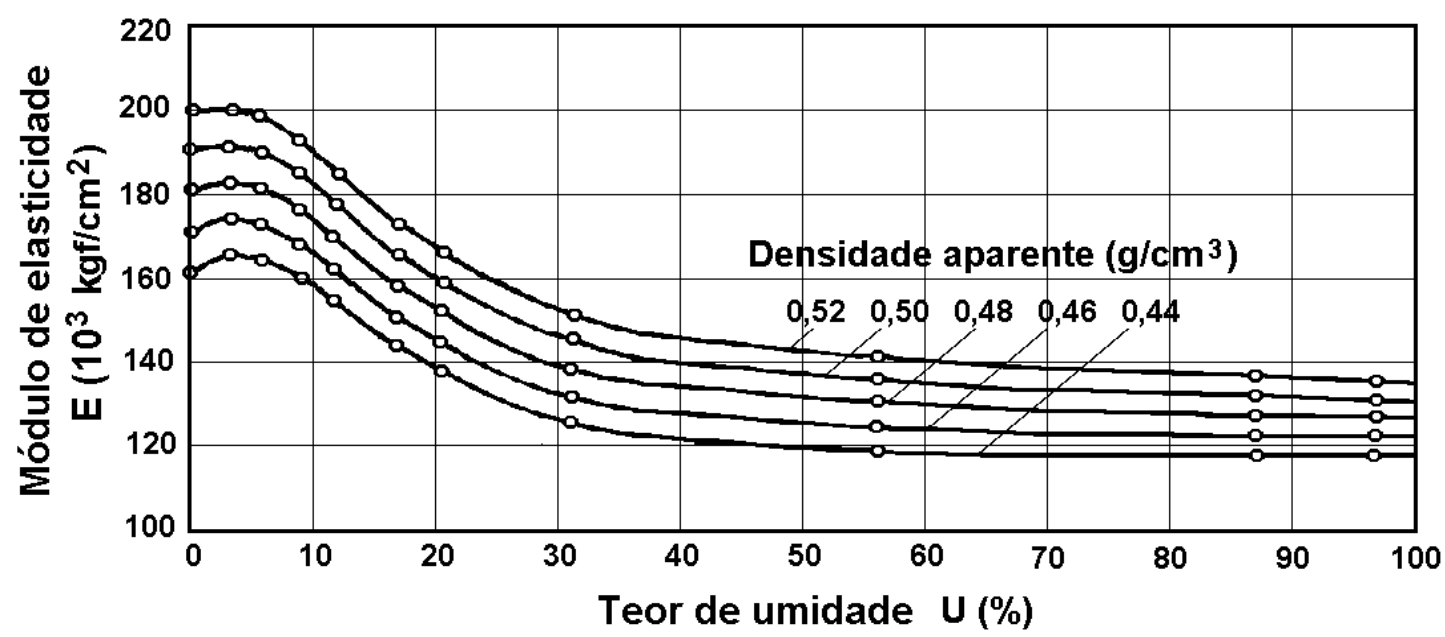

FIGURA 38 - Efeito do teor de umidade sobre o módulo de elasticidade na direção paralela às fibras de "spruce" $\left(1 \mathrm{kgf} / \mathrm{cm}^{2} \cong 0,10 \mathrm{MPa}\right)$. Fonte: KOLLMANN \& KRE$\mathrm{CH}^{20}$ apud KOLLMANN \& COTÉ (1984)

${ }^{20}$ KOLLMANN, F. and KRECH, H. (1960). Dynamische Messungen der elastischen Holzeigenschaften und der Dämpfung. Holz als Roh und Werkstoff. 18: 41-54 apud KOLLMANN, F. F. P. \& CÔTÉ, W. A. (1984). Principles of wood science and technology. Vol. I Solid Wood. Reprint Berlin, Heidelberg, New York, Tokyo. SpringerVerlag. 1968-1984. 
KOLLMANN \& COTÉ (1984) consideram que, em relação as demais constantes elásticas da madeira, o módulo de elasticidade na direção paralela às fibras é, aparentemente, o menos sensível ao teor de umidade.

LIMA et al. (1986), através de ensaios de flexão, obtiveram a relação, apresentada na figura 39, para representar a variação do módulo de elasticidade com o teor de umidade. É importante ressaltar que a metodologia utilizada, por LIMA et al. (1986), foi a descrita na NBR 6230, da ABNT (1980), e, segundo LAHR (1983), este método fornece um módulo de elasticidade aparente, pois desconsidera a deformação por força cortante, que é importante para a relação entre as dimensões do corpo-de-prova adotado no ensaio.

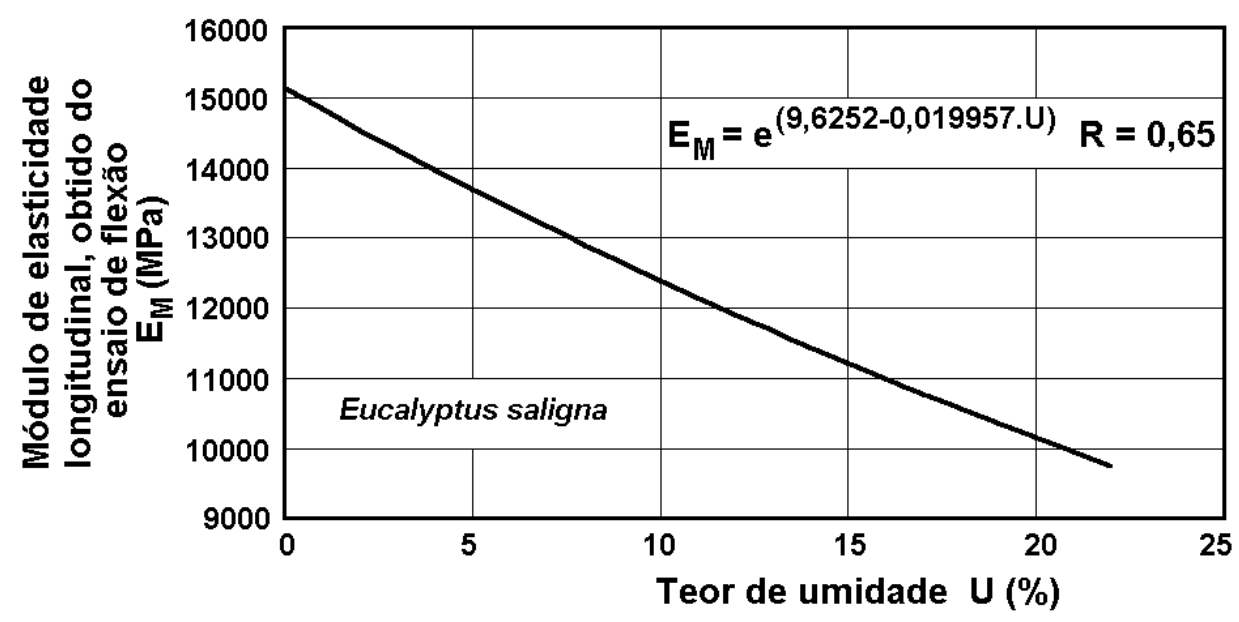

FIGURA 39 - Variação do módulo de elasticidade, obtido no ensaio de flexão, com o teor de umidade em Eucalyptus saligna. Fonte: LIMA et al. (1986)

Utilizando-se de ensaios de flexão, GREEN \& PELLERIN (1991) concluem que a variação do módulo de elasticidade com o teor de umidade é dependente da espécie e da qualidade da madeira em uma mesma espécie (percentil de resistência). Isto pode ser constatado através da figura 40 .

MADSEN (1992), utilizando um número maior de níveis para o teor de umidade, obtém um jogo de curvas semelhantes às de GREEN \& PELLERIN (1991). Estas curvas são apresentadas na figura 41 .

COVINGTON \& FEWELL ${ }^{21}$ apud TANAAMI (1986) chamam a atenção para o fato de que a variação no teor de umidade além de provocar alterações na rigidez (módulo de e-

${ }^{21}$ COVINGTON, S. A.; FEWELL, A. R. (1975). The effect of change in moisture content on the geometrical properties, modulus of elasticity and stiffness of timber. Garston, Building Research Establishment Department of the Environment, Feb. 1975 (Current Paper 
lasticidade) também altera suas características geométricas (momento de inércia) e, consequentemente, o produto de rigidez.
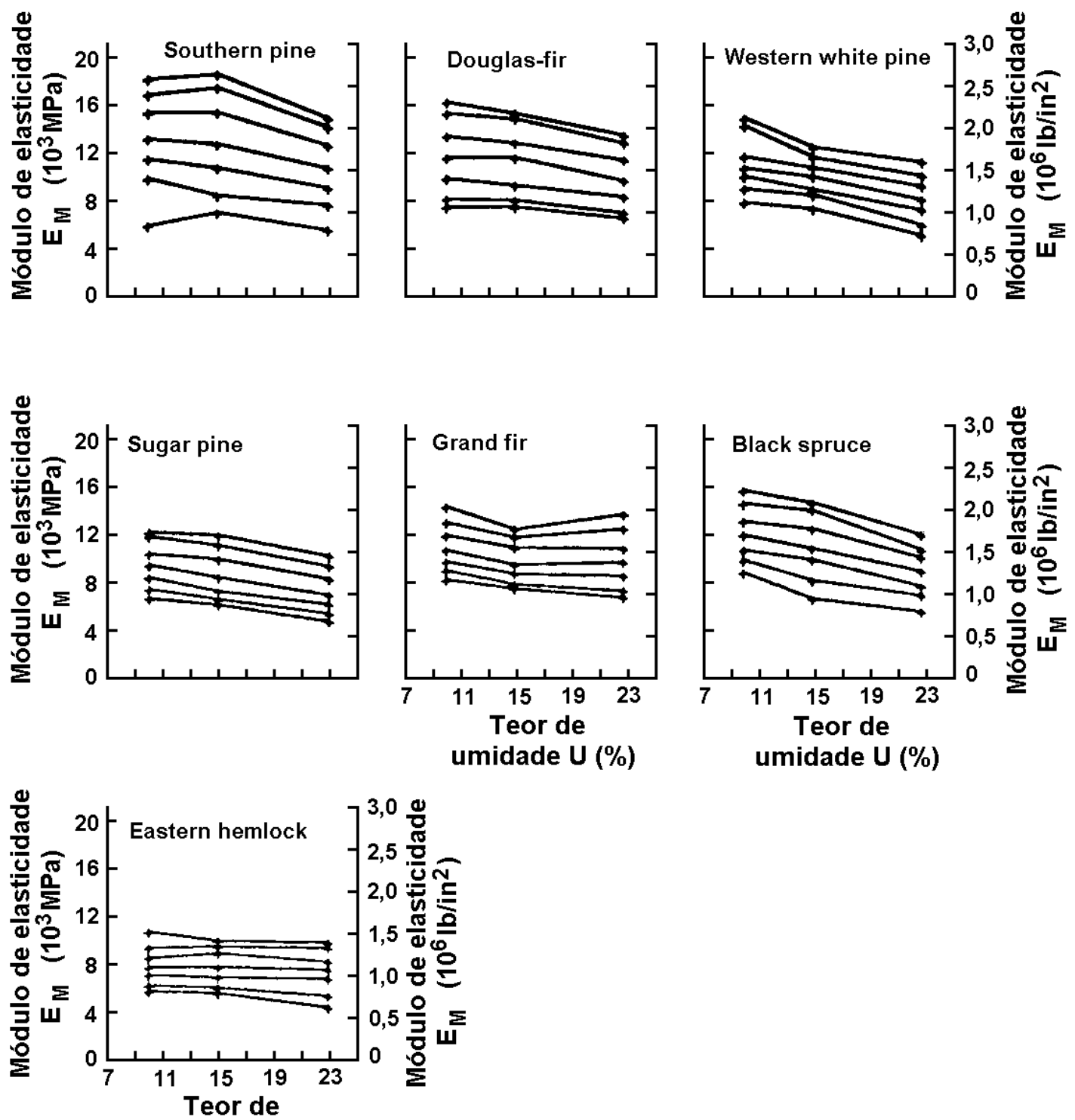

umidade $\mathrm{U}(\%)$

FIGURA 40 - Efeitos do teor de umidade sobre o módulo de elasticidade, obtido no ensaio de flexão, de peças comerciais, de seção 2" x 4" (5 cm x $10 \mathrm{~cm})$, classe "Select Structural", aos níveis percentuais de 5, 10, 25, 50, 75, 90 e $95\left(1 \mathrm{lb} / \mathrm{in}^{2} \cong\right.$ 0,00689 MPa). Fonte: GREEN \& PELLERIN (1991)

21/75). apud TANAAMI, R. G. (1986). Influência da umidade e da densidade na resistência à flexão de peças de madeira. In: Encontro Brasileiro em Madeiras e Estruturas de Madeira ,2.,São Carlos, 1986. Anais. São Paulo, USP-EESC-SET-LaMEM. Características. p.126-152. 


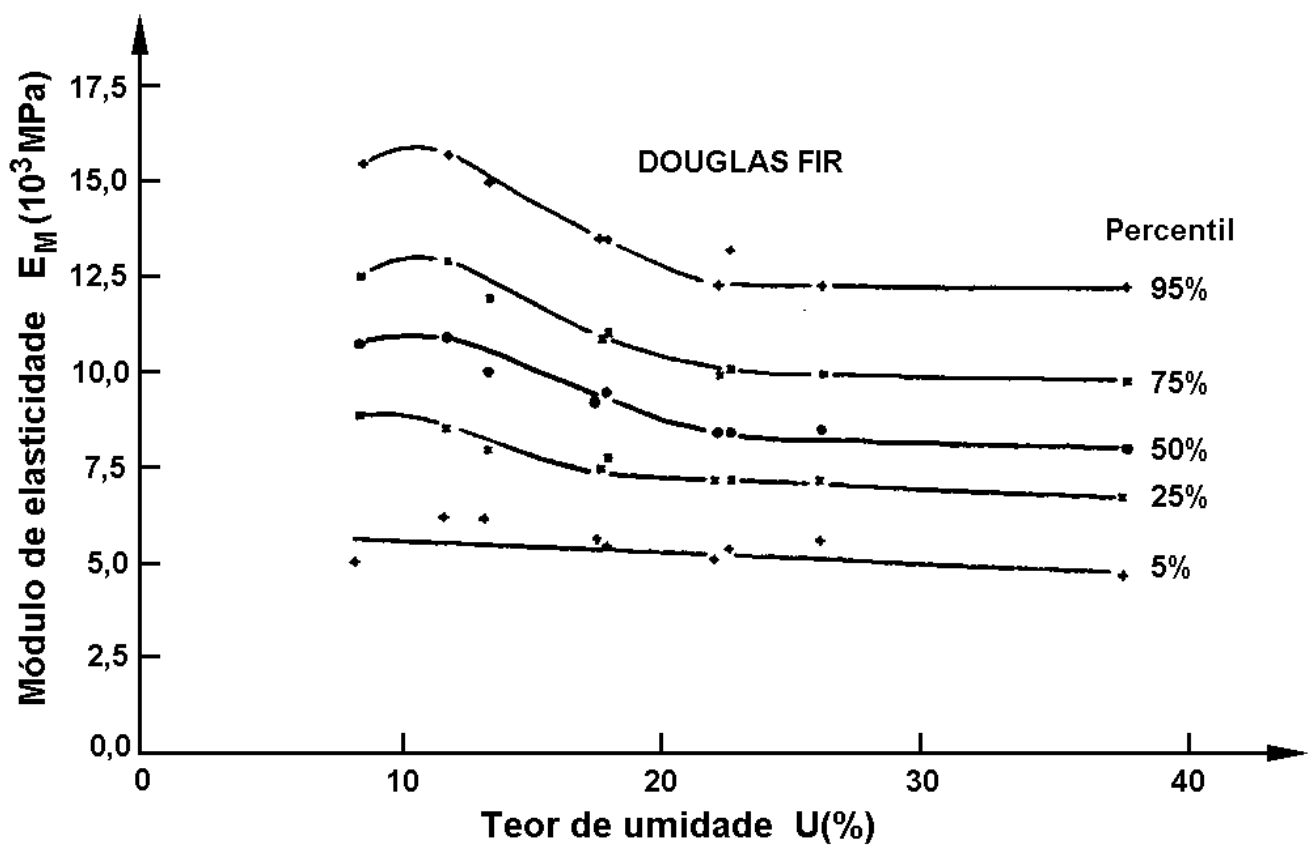

FIGURA 41 - Efeitos do teor de umidade sobre o módulo de elasticidade, obtido no ensaio de flexão, em peças de "Douglas Fir". Fonte: MADSEN (1992)

\subsection{OUTRAS PROPRIEDADES}

LIMA et al. (1986), estudando a influência do teor de umidade sobre as propriedades da madeira de Eucalyptus saligna, concluem que "a resistência à tração normal da madeira de Eucalyptus saligna parece ser constante e independente do teor de umidade" (ver figura $42)$.



FIGURA 42 - Variação da resistência à tração normal às fibras com o teor de umidade da madeira de Eucalyptus saligna. Fonte: LIMA et al. (1986) 
Estudando a influência de baixos teores de umidade sobre a resistência, de peças comerciais de "Southern pine" (Pinus echinata ou Pinus taeda), KRETSHMANN \& GREEN (1994) obtiveram, na tração normal, um ponto de máximo a um teor de umidade de 10,2\% (ver figura 43).

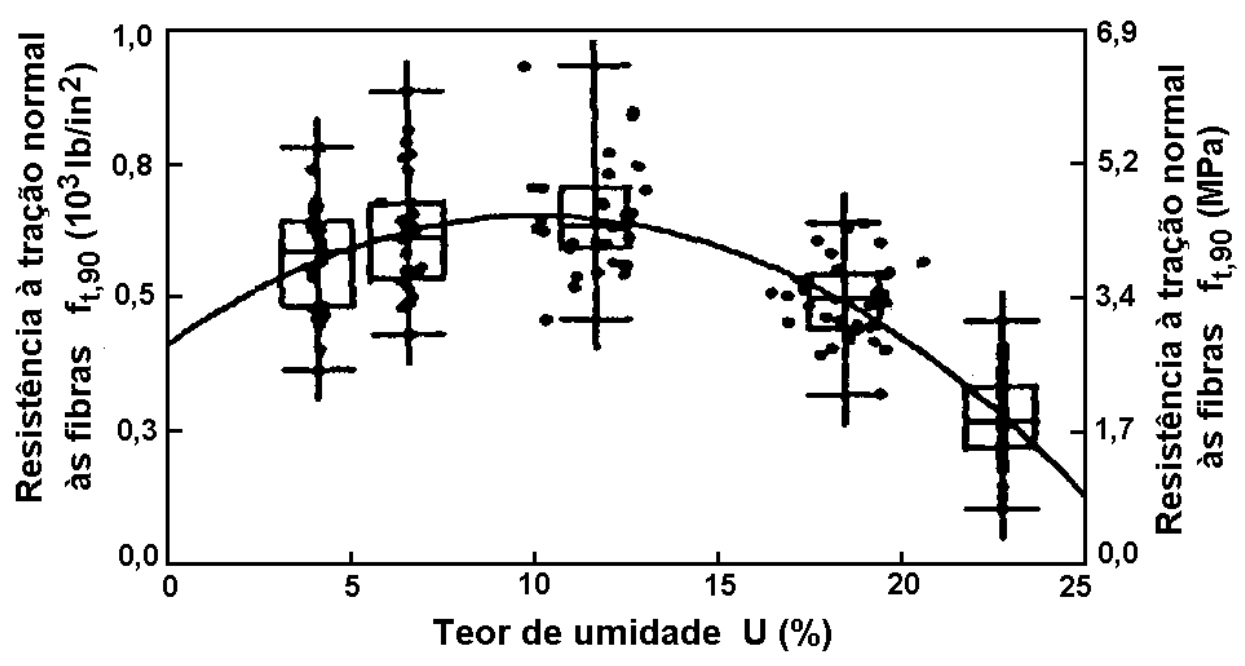

FIGURA 43 - Variação da resistência à tração normal às fibras com o teor de umidade em "Southern pine" $\left(1 \mathrm{lb} / \mathrm{in}^{2} \cong 0,00689 \mathrm{MPa}\right)$. Fonte: KRETSHMANN \& GREEN (1994)

Já para a compressão normal às fibras, KRETSHMANN \& GREEN (1994), obtiveram uma variação linear (ver figura 44).

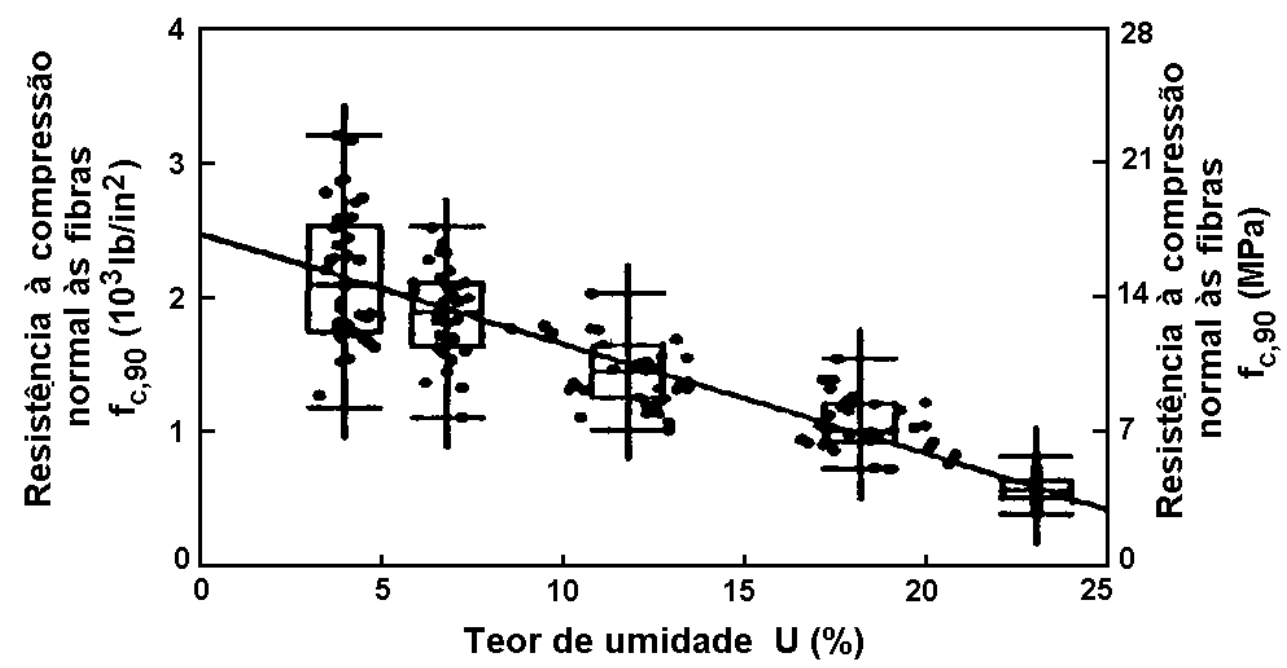

FIGURA 44 - Variação da resistência à compressão normal às fibras com o teor de umidade em "Southern pine" ( $\left.1 \mathrm{lb} / \mathrm{in}^{2} \cong 0,00689 \mathrm{MPa}\right)$. Fonte: KRETSHMANN \& GREEN (1994) 
MADSEN (1992), estudando o efeito do teor de umidade sobre a resistência da madeira, concluiu que as resistências à tração e à compressão normal às fibras são altamente sensíveis a alteração do teor de umidade.

CARRINGTON $^{22}$ apud DINWOODIE (1981) avaliou a variação de algumas constantes elásticas da madeira obtendo os resultados apresentados na figura 45. Destes resultados pode-se observar que o módulo de elasticidade transversal tem comportamento semelhante ao do módulo de elasticidade longitudinal e diminui com o aumento da umidade, o que é confirmado pelo autor, usando métodos dinâmicos (ver figura 46). O coeficiente de Poisson, exceto para o plano radial-longitudinal, tem um comportamento contrário e aumenta com o aumento da umidade.

SIIMES $^{23}$ apud SVENSSON (1998) estudou, para a madeira de "Scots pine", a variação do módulo de elasticidade longitudinal, na direção tangencial, e concluiu que ele diminui com o acréscimo do teor de umidade e da temperatura (ver figura 47). Outra observação interessante, nesta figura, é a diminuição do ponto de saturação das fibras com o aumento da temperatura.

KOLLMANN ${ }^{24}$ apud KOLLMAN \& COTÉ (1984) avaliou o efeito da umidade sobre a dureza, utilizando o Método Brinell, e obteve curvas semelhantes às observadas para outras propriedades mecânicas (ver figura 48).

${ }^{22}$ CARRINGTON, H. (1922). The elastic constants of spruce as affected by moisture content. Aeronautical Journal, 26, 462. apud DINWOODIE, J. M. (1981). Timber its nature and behavior. Princes Risborough Laboratory. Building Research Establishment. New York. USA. Van Nostrand Reinhold Company Ltd.

${ }^{23}$ SIIMES, F. E. (1967). The effects of specific gravity, moisture content, temperature and heating time on the tension and compression strength and elasticity properties perpendicular to the grain of Finnish pine, spruce and birch wood and the significance of these factors on the checking of timber at kiln drying. VTT Report 84, Helsinki apud SVENSSON, S. (1998). Internal Stresses in Wood Caused by Climate Variations. Lecture Hall V. A. School of Civil Engineering. Lund University. $15^{\text {th }}$ January 1998 (PHD. Thesis). http://thse.kstr.lhtse/ staffan/thesis.htm (28/05/98)

${ }^{24}$ KOLLMANN, F. (1951). Technologie des Holzes und der Holzwerkstoffe, Vol. I, 2nd ed., Springer-Verlag, Berlin - Göttingen - Heidelberg. apud KOLLMANN, F. F. P. \& CÔTÉ, W. A. (1984). Principles of wood science and technology. Vol I Solid Wood. Reprint Berlin, Heidelberg, New York, Tokyo. Springer-Verlag. 1968-1984. 

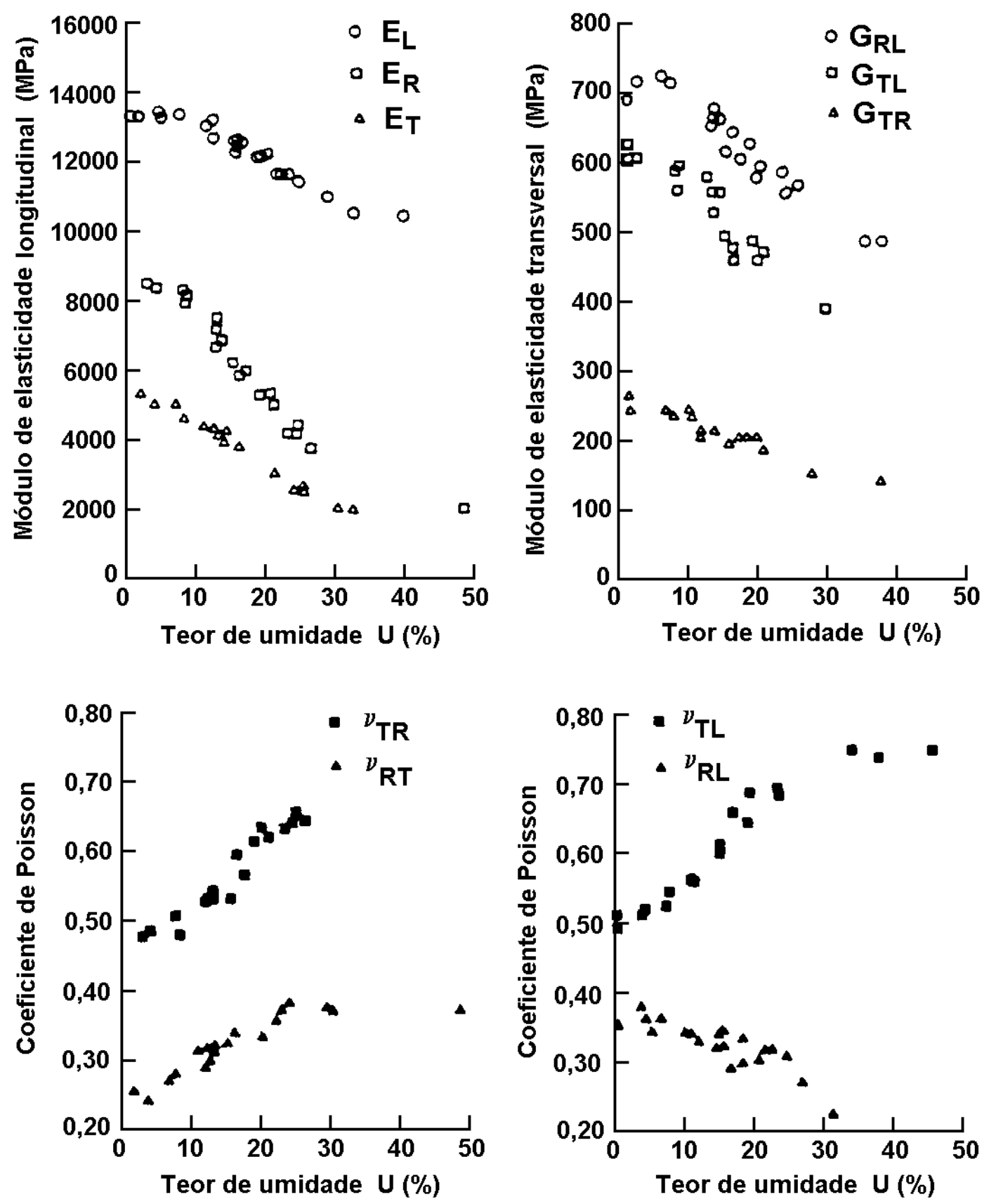

FIGURA 45 - Efeito do teor de umidade sobre as constantes elásticas de "Stika spuce". Fonte: CARRINGTON ${ }^{25}$ apud DINWOODIE (1981)

${ }^{25}$ CARRINGTON, H. (1922). The elastic constants of spruce as affected by moisture content. Aeronautical Journal, 26, 462. apud DINWOODIE, J. M. (1981). Timber its nature and behavior. Princes Risborough Laboratory. Building Research Establishment. New York. USA. Van Nostrand Reinhold Company Ltd. 


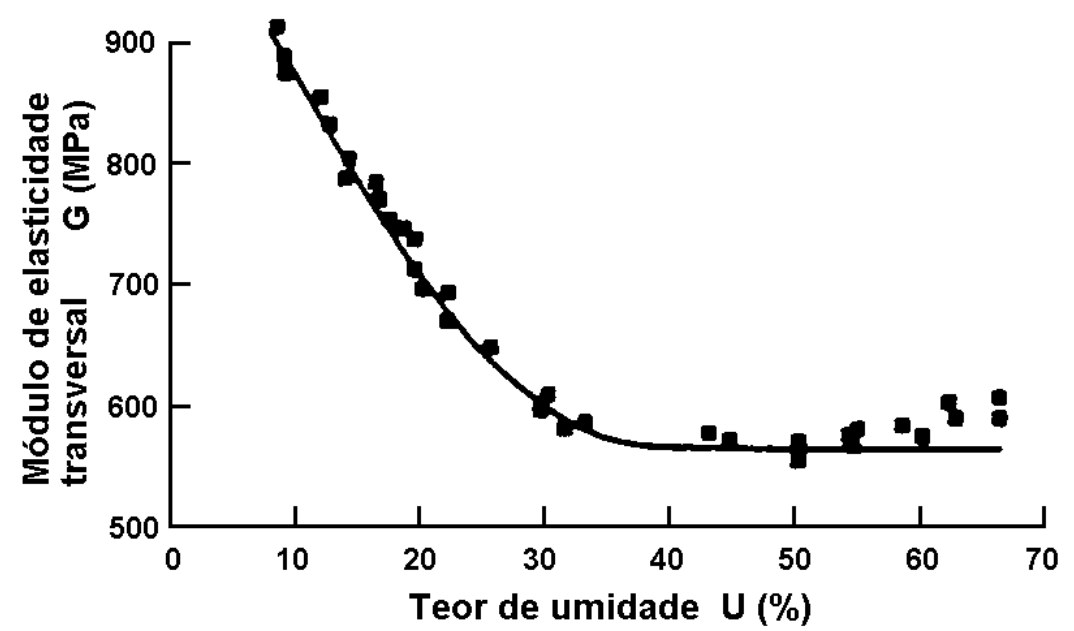

FIGURA 46 - Efeito do teor de umidade sobre o módulo de elasticidade transversal de "Stika spruce". O módulo de elasticidade transversal foi determinado dinamicamente. Fonte: DINWOODIE (1981)

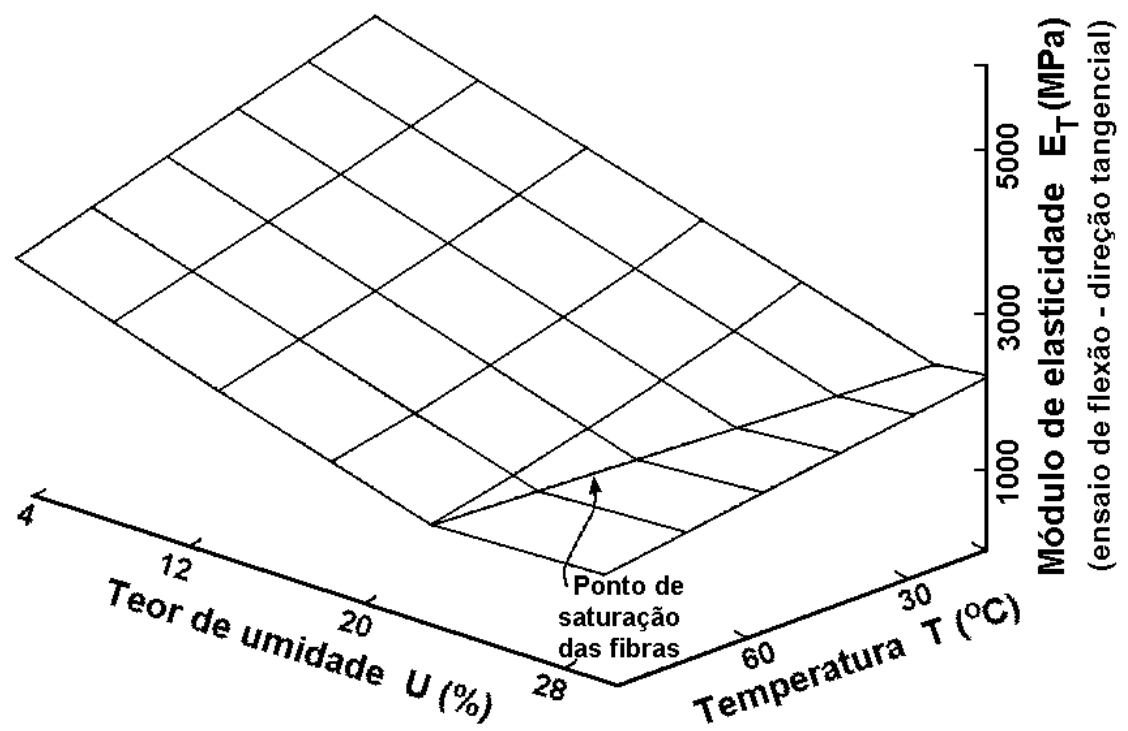

FIGURA 47 - Variação do módulo de elasticidade longitudinal, na direção tangencial, com o teor de umidade e com a temperatura. Fonte: SIIMES ${ }^{26}$ apud SVENSSON (1998)

${ }^{26}$ SIIMES, F. E. (1967). The effects of specific gravity, moisture content, temperature and heating time on the tension and compression strength and elasticity properties perpendicular to the grain of Finnish pine, spruce and birch wood and the significance of these factors on the checking of timber at kiln drying. VTT Report 84, Helsinki apud SVENSSON, S. (1998). Internal Stresses in Wood Caused by Climate Variations. Lecture Hall V. A. School of Civil Engineering. Lund University. $15^{\text {th }}$ January 1998 (PHD. Thesis). http://thse.kstr.lhtse/ staffan/thesis.htm (28/05/98) 


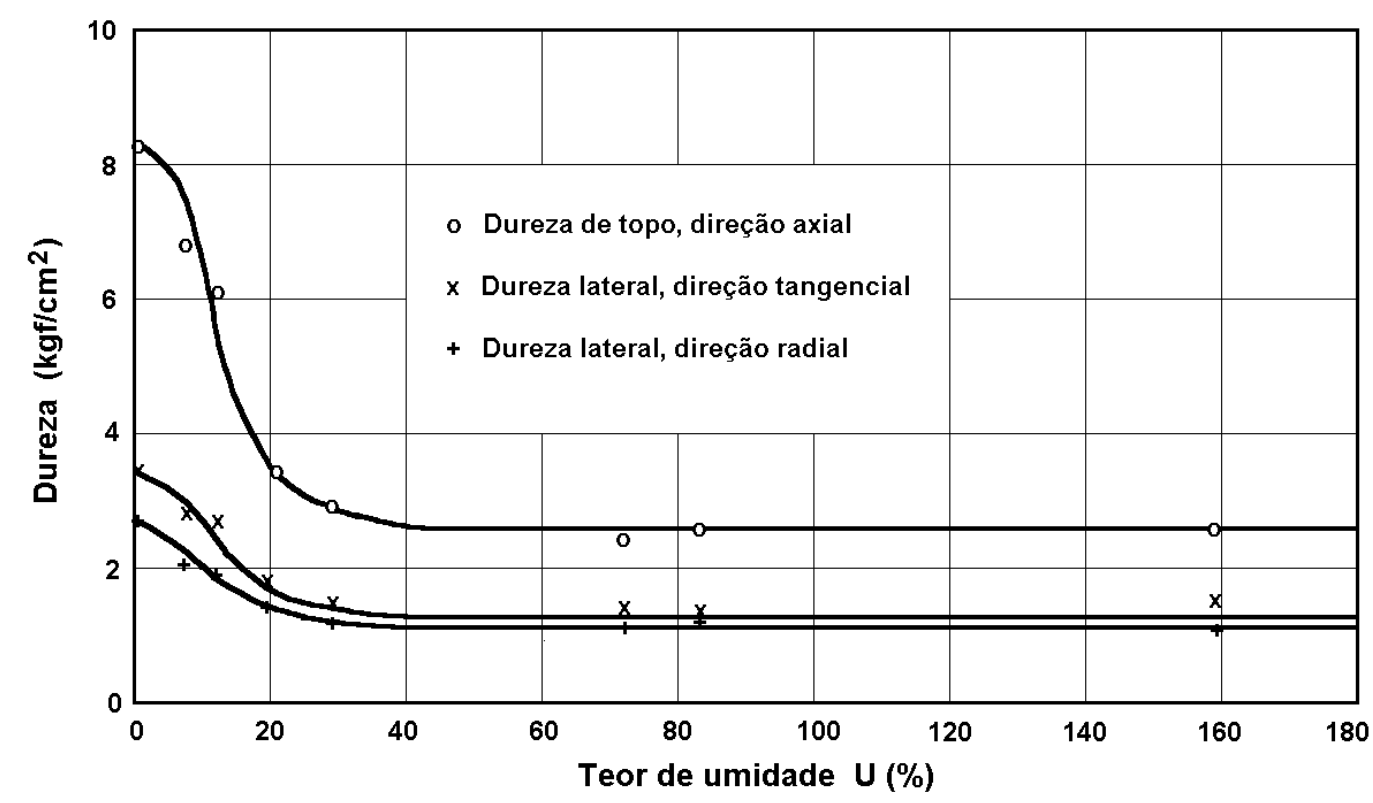

FIGURA 48 - Efeito do teor de umidade sobre a dureza, Método Brinell, de "pine" $\left(1 \mathrm{kgf} / \mathrm{mm}^{2} \cong 0,001 \mathrm{MPa}\right)$. Fonte: KOLLMANN ${ }^{27}$ apud KOLLMANN \& COTÉ (1984)

Nos itens precedentes foram observados aumentos na resistência estática da madeira a medida que a madeira seca abaixo do ponto de saturação das fibras. Esta afirmativa, segundo KOLLMANN \& COTÉ (1984), não se aplica à propriedade de flexão dinâmica, ou resistência ao choque. A madeira seca não é tão flexível quanto a madeira verde. Este fato é ilustrado na figura 49. As áreas sob as curvas carga-deslocamento até a completa ruptura, proporcional ao trabalho total, praticamente não são influenciadas pelo teor de umidade.

O desempenho da madeira sob condições de carregamento dinâmico, segundo WIANDY \& ROWELL (1984), é uma função de dois fatores: da resistência do material, que diminui com o aumento no teor de umidade; e da flexibilidade do material, que aumenta com o aumento no teor de umidade. As alterações na resistência e na flexibilidade compensam uma a outra e, então, as propriedades mecânicas, que respondem pelos carregamentos dinâmicos, normalmente não são afetadas por variações no teor de umidade.

MARKWARDT \& WILSON ${ }^{28}$ apud KOLLMANN \& COTÉ (1984) chegaram a conclusão, avaliando ensaios de flexão dinâmica, que o teor de umidade pode ser negligenciado.

${ }^{27}$ KOLLMANN, F. (1951). Technologie des Holzes und der Holzwerkstoffe, Vol. I, 2nd ed., Springer-Verlag, Berlin - Göttingen - Heidelberg. apud KOLLMANN, F. F. P. \& CÔTÉ, W. A. (1984). Principles of wood science and technology. Vol I Solid Wood. Reprint Berlin, Heidelberg, New York, Tokyo. Springer-Verlag. 1968-1984. 


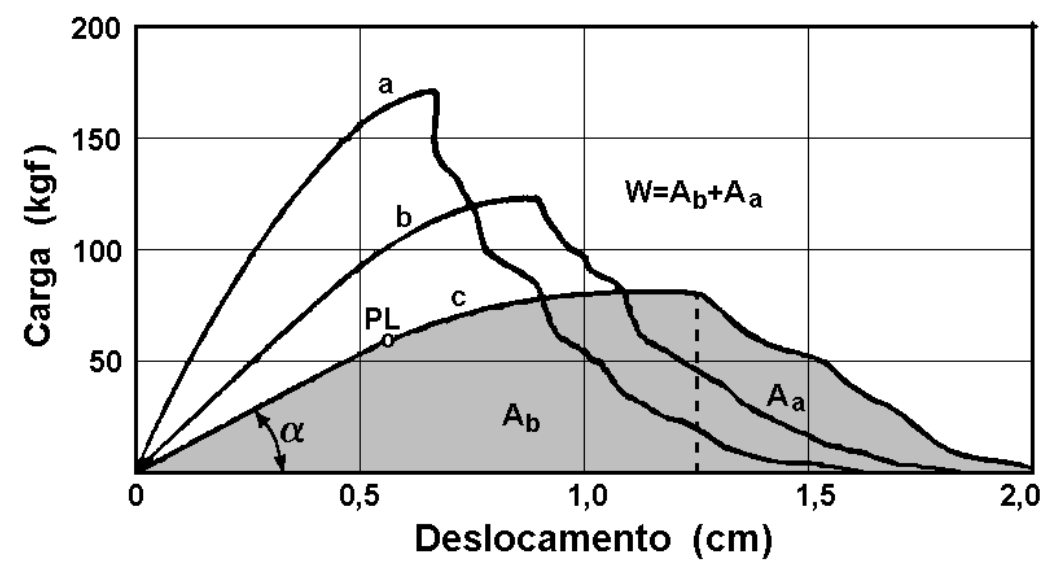

FIGURA 49 - Diagramas carga-deslocamento para ensaios de flexão estática em madeiras a diferentes teores de umidade: a) madeira seca em estufa; b) madeira seca ao ar; c) madeira verde $(1 \mathrm{kgf} \cong 10 \mathrm{~N}) . \mathrm{W}=$ trabalho total, $\mathrm{A}_{\mathrm{b}}=$ trabalho antes da ruptura, $A_{a}=$ trabalho após a ruptura, $\alpha=$ ângulo da linha reta no limite elástico, $\mathrm{PL}=$ limite de proporcionalidade. Fonte: $\mathrm{MONNIN}^{29}$ apud KOLLMANN \& COTÉ (1984).

De fato, resultados, obtidos por $\mathrm{KRECH}^{30}$ apud KOLLMANN \& COTÉ (1984), mostraram que para "beechwood", no intervalo higroscópico, o trabalho na flexão dinâmica independe do teor de umidade. Aumentando o teor de umidade do meio, é claro, aumenta a deformação (ver figura 50).

${ }^{28}$ MARWARDT, L. J. \& WILSON, T. R. C. (1935). Strength and related properties of woods grown in the United States. U. S. Dep. Agr. Tech. Bull. Washington, D.C., No. 479, p.67 apud KOLLMANN, F. F. P. \& CÔTÉ, W. A. (1984). Principles of wood science and technology. Vol I Solid Wood. Reprint Berlin, Heidelberg, New York, Tokyo. Springer-Verlag. 1968-1984.

${ }^{29}$ MONNIN, M. (1932). L'essai des bois. Kongreßbuch Zürich Int. Verb. Materialprüfung. p.85 apud KOLLMANN, F. F. P. \& CÔTÉ, W. A. (1984). Principles of wood science and technology. Vol I Solid Wood. Reprint Berlin, Heidelberg, New York, Tokyo. Springer-Verlag. 1968-1984.

${ }^{30}$ KRECH, H. (1960). Größe und zeitlicher Ablauf von Kraft und Durchbiegung beim Schlagbiegeversuch na Holz und ihr Zusammenhang mit der Bruchschlagarbeit. apud KOLLMANN, F. F. P. \& CÔTÉ, W. A. (1984). Principles of wood science and technology. Vol I Solid Wood. Reprint Berlin, Heidelberg, New York, Tokyo. SpringerVerlag. 1968-1984. 


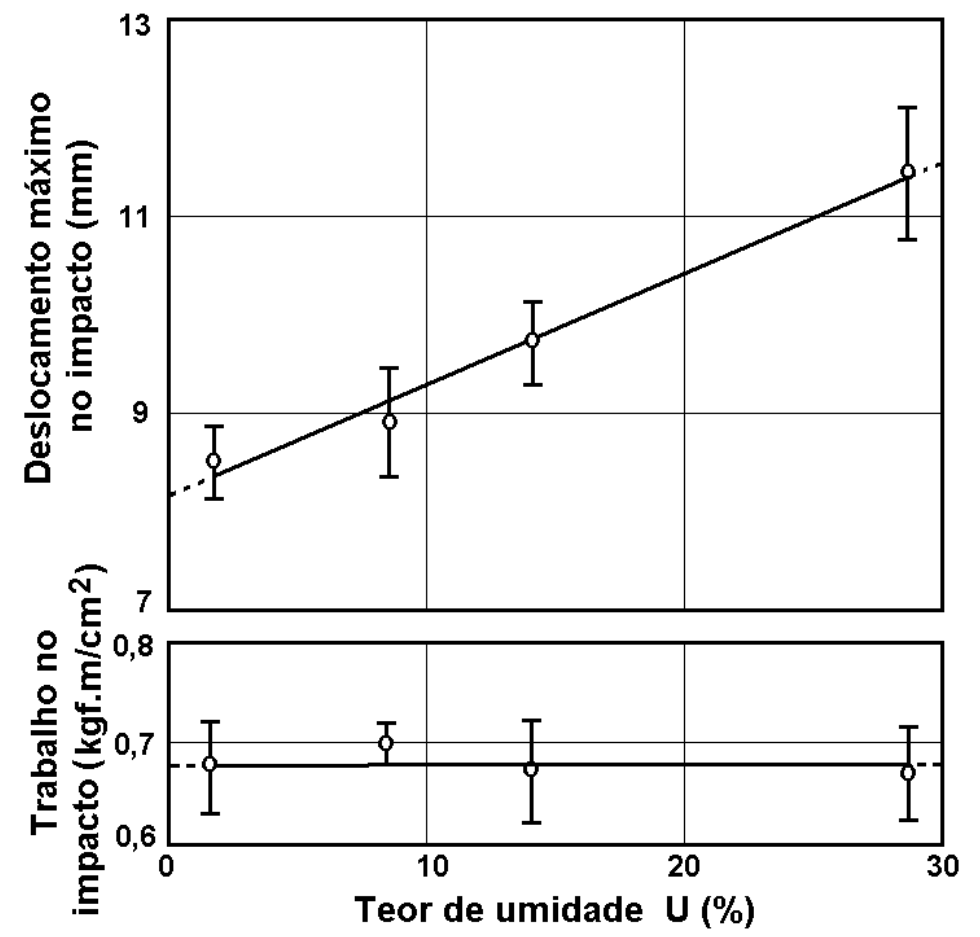

FIGURA. 50 - Efeito do teor de umidade no deslocamento por impacto e no trabalho de impacto para "beechwood" (1 kgf.m/ $\left.\mathrm{cm}^{2} \cong 0,10 \mathrm{~N} \cdot \mathrm{m} / \mathrm{mm}^{2}\right)$. As linhas verticais representam os intervalos de confiança estatística com $99 \%$ de probabilidade. Fonte: KRECH ${ }^{31}$ apud KOLLMANN \& COTÉ (1984).

Preocupado com a alteração na metodologia de cálculo do Método das Tensões Admissíveis para o Método dos Estados Limites, MADSEN (1992) considera interessante avaliar o efeito do teor de umidade na capacidade de resistir ao momento (momento resistente). Seus resultados são apresentados na figura. 51.

Para o produto de rigidez, definido como o produto do módulo de elasticidade pelo momento de inércia, MADSEN (1992) obteve os resultados apresentados na figura 52, na qual as linhas são quase horizontais e mostram pequena ou nenhuma alteração no produto de rigidez com a diminuição do teor de umidade. Este comportamento é causado pelo aumento no valor do módulo de elasticidade, que é cancelado pela diminuição correspondente no momento de inércia, devido à retração, durante a secagem.

${ }^{31}$ KRECH, H. (1960). Größe und zeitlicher Ablauf von Kraft und Durchbiegung beim Schlagbiegeversuch na Holz und ihr Zusammenhang mit der Bruchschlagarbeit. apud KOLLMANN, F. F. P. \& CÔTÉ, W. A. (1984). Principles of wood science and technology. Vol I Solid Wood. Reprint Berlin, Heidelberg, New York, Tokyo. SpringerVerlag. 1968-1984. 


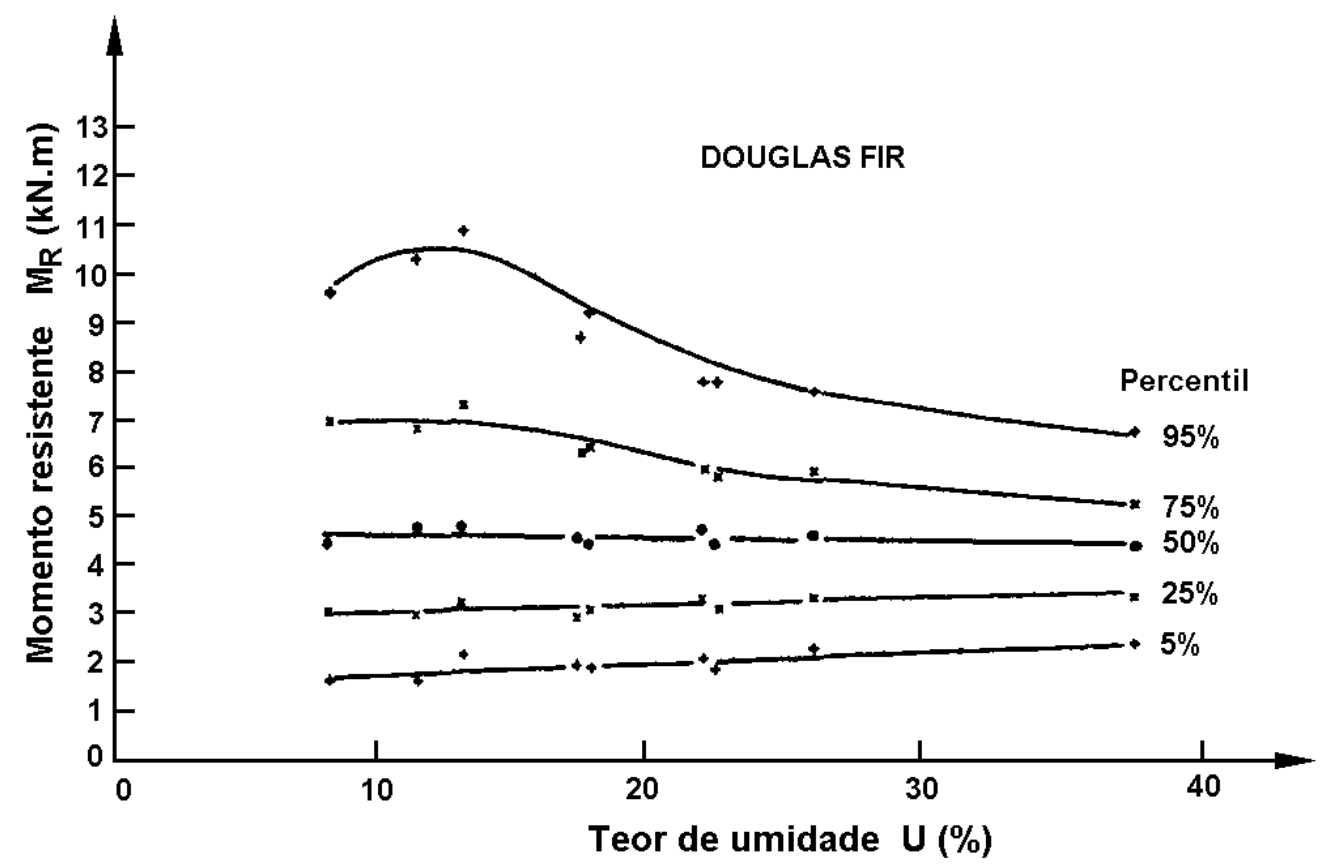

FIGURA 51 - Variação do momento resistente com o teor de umidade. Para material com uma resistência menor que $35 \mathrm{MPa}$, parcela significativa do material (ver figura 36), a capacidade de resistir ao momento diminui a medida em que a madeira seca. Fonte: MADSEN (1992)

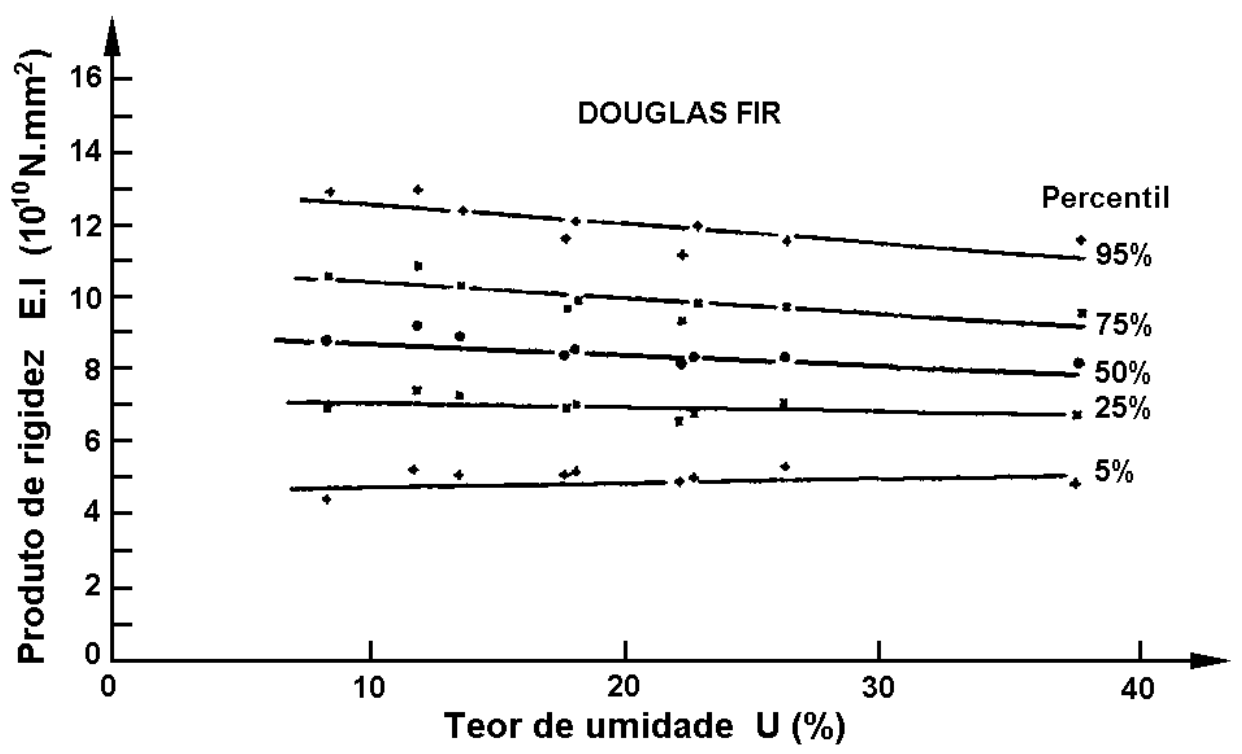

FIGURA 52 - Variação do produto de rigidez (E.I) com o teor de umidade. O produto de rigidez praticamente não é afetado pelas alterações do teor de umidade. Fonte: MADSEN (1992) 


\subsection{ALGUMAS EXPRESSÕES UTILIZADAS PARA DEFINIR O EFEITO DO TEOR DE UMIDADE SOBRE UMA PROPRIEDADE DA MADEI-} RA

LOGSDON (1992) fez um estudo sobre a maneira de corrigir a densidade aparente para o teor de umidade de 12\%. Deste estudo, LOGSDON (1992), concluiu que para corrigir a densidade aparente para o teor de umidade de $12 \%$, pode-se adotar os seguintes critérios:

a) Traçar o diagrama $\rho$ x U a partir de resultados experimentais e deste diagrama obter $\rho_{12}$;

b) A partir de um instante do ensaio, na proximidade de $\mathrm{U}=12 \%$, corrigir o valor da densidade aparente com o auxílio do Diagrama de Kollmann (figura 17);

c) A partir de dois instantes do ensaio, ambos na proximidade de $U=12 \%$, obter $\rho_{12}$ por interpolação linear;

d) A partir de um instante do ensaio, no intervalo higroscópico, aplicar a seguinte expressão:

$$
\rho_{12}=\rho_{\mathrm{U} \%}+\rho_{\mathrm{U} \%} \cdot\left[\left(1-\delta_{\mathrm{V}}\right) \cdot \frac{(12-\mathrm{U} \%)}{100}\right]
$$

Na qual,

$$
\delta_{\mathrm{V}}=\frac{\Delta \mathrm{V}}{\mathrm{U} \%}
$$

e

$$
\Delta \mathrm{V}=\frac{\mathrm{V}_{\mathrm{U} \%}-\mathrm{V}_{\text {seca }}}{\mathrm{V}_{\text {sec a }}} .100 \%
$$

Onde:

$\rho_{12}=$ densidade aparente, $\mathrm{em} \mathrm{g} / \mathrm{cm}^{3}$, ao teor de umidade $12 \%$;

$\rho_{\mathrm{U} \%}=$ densidade aparente, $\mathrm{em} \mathrm{g} / \mathrm{cm}^{3}$, ao teor de umidade $\mathrm{U} \%$;

$\mathrm{U} \%=$ teor de umidade, em \%;

$\delta_{\mathrm{V}}=$ coeficiente de retratibilidade volumétrica;

$\Delta \mathrm{V}=$ retração volumétrica, para a variação de umidade entre $\mathrm{U} \%$ e $0 \%$, em \%; 
$\mathrm{V}_{\mathrm{U} \%}=$ volume, do corpo-de-prova, ao teor de umidade $\mathrm{U} \%$, e

$\mathrm{V}_{\text {seca }}=$ volume, do corpo-de-prova, para a madeira seca $\mathrm{U}=0 \%$.

A norma francesa, segundo BROCHARD (1960), permitia a aplicação de uma expressão simplificada para corrigir a densidade aparente ao teor de umidade de referência, adotado como 15\%. Aplicando esta expressão, para o teor de umidade de referência de $12 \%$, obtém-se:

$$
\rho_{12}=\rho_{\mathrm{U} \%} \cdot \frac{(1+12 / 100)}{(1+\mathrm{U} \% / 100)}
$$

Onde:

$\rho_{12}=$ densidade aparente ao teor de umidade de $12 \%$;

$\rho_{\mathrm{U} \%}=$ densidade aparente ao teor de umidade $\mathrm{U} \%$, e

$\mathrm{U} \%=$ teor de umidade da madeira, no instante do ensaio, em $\%$.

Melhores resultados eram obtidos, segundo DESLANDES \& VANDERBERGHE (1959), com a aplicação da expressão (já adaptada para a umidade de referência de 12\%):

$$
\rho_{12}=\rho_{\mathrm{U} \%} \cdot\left[1-\frac{\left(1-\delta_{\mathrm{V}}\right) . .(\mathrm{U} \%-12)}{100}\right]
$$

Onde:

$\delta_{\mathrm{V}}=$ coeficiente de retratibilidade volumétrica, definido na eq, (09));

$\rho_{\mathrm{U} \%}=$ densidade aparente obtida no ensaio com $\mathrm{U} \%$ de umidade;

$\rho_{12}=$ densidade aparente ao teor de umidade $12 \%$, e

$\mathrm{U} \%=$ teor de umidade da madeira, no instante do ensaio, em \%.

Pode-se notar a perfeita coincidência entre as expressões (08) e (12).

Para correção das propriedades mecânicas, abaixo do ponto de saturação das fibras, segundo BODIG \& JAYNE (1992), uma simples relação exponencial negativa ajusta razoavelmente bem os dados:

$$
\mathrm{f}_{\mathrm{u} \%}=\mathrm{A} \cdot \mathrm{e}^{-\mathrm{B} \cdot \mathrm{U} \%}
$$


Onde:

$\mathrm{f}_{\mathrm{U} \%}=$ resistência (ou outra propriedade mecânica), ao teor de umidade U\%;

$\mathrm{U} \%$ = teor de umidade da madeira, $\mathrm{e}$

$\mathrm{A}, \mathrm{B}=$ constantes (coeficientes da regressão).

Uma transformação logarítmica da eq. (13) fornece:

$\ln \mathrm{f}_{\mathrm{U} \%}=\ln \mathrm{A}-\mathrm{B} . \mathrm{U} \%$

Partindo da eq. (14), BODIG \& JAYNE (1992) mostram que se pode obter, com algumas operações algébricas, uma equação para correção da resistência usando quatro pontos da curva: madeira seca ao ar ( $f_{a r}$ e $U_{a r}$ ), madeira verde ( $f_{\text {verde }}$ e $U_{\text {verde }}$ ), madeira a uma determinada umidade durante o ensaio ( $f_{\text {ensaio }}$ e $U_{\text {ensaio }}$ ) e madeira a uma umidade qualquer (resistência procurada - $\mathrm{f}_{\mathrm{U} \%}$ e U\%). E obtêm:

$$
\ln \mathrm{f}_{\mathrm{U} \%}=\ln \mathrm{f}_{\text {ensaio }}+\frac{\mathrm{U}_{\text {ensaio }}-\mathrm{U} \%}{\mathrm{U}_{\text {verde }}-\mathrm{U}_{\text {ar }}} \cdot \ln \frac{\mathrm{f}_{\text {ar }}}{\mathrm{f}_{\text {verde }}}
$$

Onde:

$\mathrm{f}_{\mathrm{U} \%} \quad=$ resistência (ou outra propriedade mecânica) procurada, para o teor de umidade U\%;

$\mathrm{f}_{\text {ensaio }}=$ resistência (ou outra propriedade mecânica), obtida no ensaio;

$\mathrm{f}_{\mathrm{ar}}=$ resistência (ou outra propriedade mecânica), da madeira seca ao ar;

$\mathrm{f}_{\mathrm{verde}}=$ resistência (ou outra propriedade mecânica), da madeira verde (acima do ponto de saturação das fibras);

$\mathrm{U} \%=$ teor de umidade da madeira;

$\mathrm{U}_{\text {ensaio }}=$ teor de umidade da madeira, no instante do ensaio;

$\mathrm{U}_{\text {verde }}=$ teor de umidade da madeira verde, adota-se para aplicação da expressão o ponto de saturação das fibras;

Na eq. (15), segundo BODIG \& JAYNE (1992), em geral, são adotadas: para madeira seca ao ar, o teor de umidade $\mathrm{U}_{\mathrm{ar}}=12 \%$; para madeira verde, o teor de umidade correspondente ao ponto de saturação das fibras $\mathrm{U}_{\text {verde }}=\mathrm{PSF} \cong 28 \%$, resultando: 


$$
\ln \mathrm{f}_{12}=\ln \mathrm{f}_{\mathrm{U} \%}+\frac{\mathrm{U} \%-12}{28-12} \cdot \ln \frac{\mathrm{f}_{\mathrm{ar}}}{\mathrm{f}_{\text {verde }}}
$$

Onde:

$\mathrm{f}_{\mathrm{U} \%} \quad=$ resistência (ou outra propriedade mecânica) procurada, para o teor de umidade $\mathrm{U} \%$;

$\mathrm{f}_{12}=$ resistência (ou outra propriedade mecânica) procurada, para o teor de umidade $12 \%$;

$\mathrm{f}_{\mathrm{ar}}=$ resistência (ou outra propriedade mecânica), da madeira seca ao ar;

$\mathrm{f}_{\text {verde }}=$ resistência (ou outra propriedade mecânica), da madeira verde (acima do ponto de saturação das fibras), e

$\mathrm{U} \%=$ teor de umidade da madeira, em \%.

Para a aplicação da equação (16), na correção dos resultados do ensaio ( $U$ \% e $\left.f_{U \%}\right)$ para o teor de umidade $\mathrm{U}=12 \%$, é necessário tabelar resultados da relação entre as resistências da madeira seca ao ar e verde $\left(f_{\mathrm{ar}} / \mathrm{f}_{\text {verde }}\right)$. Segundo BODIG \& JAYNE (1992), no Canadá e Estados Unidos esta prática é usual.

Esta mesma expressão, eq. (16), é apresentada por TSOUMIS (1991) sob a seguinte forma:

$$
\mathrm{f}_{\mathrm{U} \%}=\mathrm{f}_{12} \cdot\left(\frac{\mathrm{f}_{12}}{\mathrm{f}_{\text {verde }}}\right)^{-\left(\frac{\mathrm{U} \%-12}{\mathrm{PSF}-12}\right)}
$$

Onde:

$\mathrm{f}_{\mathrm{U} \%}=$ resistência (ou outra propriedade mecânica), obtida no ensaio;

$\mathrm{f}_{12}=$ resistência (ou outra propriedade mecânica), para o teor de umidade de $12 \%$;

$\mathrm{f}_{\text {verde }}=$ resistência (ou outra propriedade mecânica), da madeira verde (acima do ponto de saturação das fibras);

$\mathrm{U} \%$ = teor de umidade da madeira, no instante do ensaio, em \%;

PSF = ponto de saturação das fibras, aceito como sendo o teor de umidade $U \cong 28 \%$. 
Muitas outras expressões, em geral empíricas, são utilizadas. PEIRCE ${ }^{32}$ apud LIMA et al. (1986), trabalhando apenas com fibras têxteis, sugere o modelo:

$$
\mathrm{f}_{\mathrm{U} \%}=\mathrm{f}_{0} \cdot \mathrm{e}^{-\mathrm{A} \cdot \mathrm{U} \%}
$$

onde:

$\mathrm{f}_{\mathrm{U} \%}=$ resistência (ou outra propriedade mecânica), para o teor de umidade U\%;

$\mathrm{f}_{0}=$ resistência (ou outra propriedade mecânica) da madeira seca $(\mathrm{U} \%=0 \%$ );

$\mathrm{U} \%=$ teor de umidade da madeira, $\mathrm{e}$

A $=$ constante (coeficiente da regressão).

WILSON $^{33}$ apud LIMA et al. (1986) descreveu a relação propriedade mecânicaumidade, usando o modelo:

$$
\mathrm{f}_{\mathrm{U} \%}=\mathrm{f}_{\text {verde }} \cdot 10^{\mathrm{A} .(\mathrm{PSF}-\mathrm{U} \%)}
$$

Onde:

$\mathrm{f}_{\mathrm{U} \%}=$ resistência (ou outra propriedade mecânica), para o teor de umidade U\%;

$\mathrm{f}_{\text {verde }}=$ resistência (ou outra propriedade mecânica) da madeira verde, teor de umidade acima do ponto de saturação das fibras;

$\mathrm{U} \%=$ teor de umidade da madeira, em \%;

$\mathrm{PSF}=$ ponto de saturação das fibras, geralmente aceito como sendo o teor de umidade $\mathrm{U} \cong 28 \%$, e

A $=$ constante (coeficiente da regressão).

LIMA et al. (1986) chamaram a atenção, ao estudarem o efeito da umidade sobre a resistência à compressão paralela às fibras de Eucalyptus saligna, para o seguinte modelo:

${ }^{32}$ PEIRCE, F. T. (1929). A two-phase theory of the absorption of water vapour by cotton cellulose. Journal of Textile, 20. p. 133-150 apud LIMA, J. T.; DELLA LUCIA, R. M.; VITAL, B. R. (1986). Influência do teor de umidade nas propriedades mecânicas de Eucalyptus saligna. Revista Árvore, vol. 10, n. 1, p. 27.43.

${ }^{33}$ WILSON, T. R. C. (1932). Strenght-moisture relations for wood. U. S. Dep. Agr. Tech. Bull. Washington, D.C., No. 282, 88 p. apud LIMA, J. T.; DELLA LUCIA, R. M.; VITAL, B. R. (1986). Influência do teor de umidade nas propriedades mecânicas de Eucalyptus saligna. Revista Árvore, vol. 10, n. 1, p. 27.43. 


$$
\mathrm{f}_{\mathrm{U} \%}=\frac{\mathrm{A}}{(1+\alpha)^{\mathrm{U} \%}}
$$

Onde:

$\mathrm{f}_{\mathrm{U} \%}=$ resistência (ou outra propriedade mecânica), para o teor de umidade U\%;

$\alpha$ = coeficiente interpretado, segundo LIMA et al. (1986), como a variação da resistência para cada $1 \%$ de aumento no teor de umidade;

$\mathrm{U} \%=$ teor de umidade da madeira, $\mathrm{e}$

A = constante (coeficiente da regressão).

O FOREST PRODUCTS LABORATORY ${ }^{34}$ apud SKAAR (1984) apresenta, para exprimir a variação da resistência com o teor de umidade da madeira, abaixo do ponto de saturação das fibras, a seguinte expressão:

$$
\mathrm{f}_{2} / \mathrm{f}_{1}=\exp \left[-(\mathrm{r} / 100) \cdot\left(\mathrm{U}_{2}-\mathrm{U}_{1}\right)\right]
$$

Onde:

$\mathrm{f}_{1}$ e $\mathrm{f}_{2}=$ valores de uma particular propriedade de resistência, respectivamente, para os teores de umidade $\mathrm{U}_{1}$ e $\mathrm{U}_{2}$ (em \%), e

$\mathrm{r}=$ coeficiente que representa o aumento percentual na particular propriedade de resistência, f, para um decréscimo de $1 \%$ no teor de umidade da madeira, $\mathrm{U}$.

KRPAN $^{35}$ apud TSOUMIS (1991) utilizou, no estudo do efeito da umidade sobre a resistência à compressão paralela às fibras de "Scots pine", o seguinte modelo:

$$
\log \mathrm{f}_{\mathrm{U} \%}=\beta_{0}+\beta_{1} \cdot \mathrm{U} \%+\beta_{2} \cdot \mathrm{U} \%{ }^{2}
$$

\footnotetext{
${ }^{34}$ FOREST PRODUCTS LABORATORY. (1974). Wood Handbook. USDA Handbook. No. 72 , rev., Washington. DC. apud SKAAR, C. (1984). Wood-Water Relationships. In: The Chemistry of Solid Wood. Washington, DC. American Chemical Society.

${ }^{35}$ KRPAN, J. (1954). Untersuchungen über den Fasersättigungspunkt des Buchen. Eichen. Tannen und Fichtenholzes. Holz Roh Werkst. 12(3): 84-91. apud TSOUMIS, G. (1991). Science and technology of wood - Structure, properties, utilization. New York. Van Nostrand Reinhold.
} 
Onde:

$\mathrm{f}_{\mathrm{U} \%} \quad=$ resistência (ou outra propriedade mecânica), para o teor de umidade $\mathrm{U} \%$;

$\mathrm{U} \% \quad=$ teor de umidade da madeira, e

$\beta_{0}, \beta_{1}$, e $\beta_{2}=$ constantes (coeficientes da regressão).

GERHARDS $^{36}$ apud LIMA et al. (1986) descreveu a influência do teor de umidade, no intervalo higroscópico, em várias propriedades mecânicas, usando o modelo:

$$
\mathrm{f}_{\mathrm{U} \%}=\beta_{0}+\beta_{1} \cdot \mathrm{U} \%+\beta_{2} \cdot \mathrm{U}^{2}
$$

Onde:

$\mathrm{f}_{\mathrm{U} \%} \quad=$ resistência (ou outra propriedade mecânica), para o teor de umidade $\mathrm{U} \%$;

$\mathrm{U} \% \quad=$ teor de umidade da madeira, $\mathrm{e}$

$\beta_{0}, \beta_{1}$, e $\beta_{2}=$ constantes (coeficientes da regressão).

BALLARIN \& RIBEIRO (1998) utilizaram, no estudo da influência da umidade sobre a resistência à compressão paralela às fibras de Eucalipto citriodora, o modelo:

$$
\mathrm{f}_{\mathrm{U} \%}=\mathrm{A}+\mathrm{B} \cdot \mathrm{U} \%
$$

Onde:

$\mathrm{f}_{\mathrm{U} \%}=$ resistência (ou outra propriedade mecânica), para o teor de umidade U\%;

$\mathrm{U} \%$ = teor de umidade da madeira, $\mathrm{e}$

A e B $=$ constantes (coeficientes da regressão).

MATEUS (1962) recomendou uma expressão, para ajustar a resistência à compressão axial ao teor de umidade de $12 \%$, baseada no seguinte modelo:

${ }^{36}$ GEHARDS, C. C. (1982). Effect of moisture content and temperature on the mechanical properties of wood; an analysis of immediate effects. Wood and Fiber, 14 (1). p. 4-36. apud LIMA, J. T.; DELLA LUCIA, R. M.; VITAL, B. R. (1986). Influência do teor de umidade nas propriedades mecânicas de Eucalyptus saligna. Revista Árvore, vol. 10, n. 1, p. 27.43 . 
$\mathrm{f}_{12}=\mathrm{f}_{\mathrm{U} \%}+\alpha \cdot(\mathrm{U} \%-12)$

Onde:

$\mathrm{f}_{12}=$ resistência (ou outra propriedade mecânica), para o teor de umidade de 12\%;

$\mathrm{f}_{\mathrm{U} \%}=$ resistência (ou outra propriedade mecânica), para o teor de umidade U\%;

$\mathrm{U} \%$ = teor de umidade da madeira em \%, e

$\alpha \quad=$ coeficiente. No estudo de MATEUS (1962), para o Pinho Bravo, $\alpha$ assume o valor aproximado de $25 \mathrm{kgf} / \mathrm{cm}^{2}$, para relacionar a resistência à compressão paralela às fibras ao teor de umidade.

KARLSEN et al. (1967) e DESLANDES \& VANDERBERGHE (1959) também utilizam uma expressão linear, eq. (06), para corrigir a resistência ao teor de umidade de 15\%. Esta expressão sugere, para corrigir a resistência para 12\%, o seguinte modelo:

$$
\mathrm{f}_{12}=\mathrm{f}_{\mathrm{U} \%} \cdot[1+\alpha \cdot(\mathrm{U} \%-12)]
$$

Onde:

$\mathrm{f}_{12}=$ resistência a um teor de umidade de $12 \%$;

$\mathrm{f}_{\mathrm{U} \%}=$ resistência a um teor de umidade de $\mathrm{U} \%$;

$\mathrm{U} \%=$ teor de umidade da madeira, em \%, e

$\alpha=$ coeficiente de correção.

A atual norma brasileira NBR 7190/97 adota uma expressão, baseada no modelo apresentado na eq. (26), mas usando a seguinte forma:

$$
\mathrm{f}_{12}=\mathrm{f}_{\mathrm{U} \%} \cdot\left[1+\frac{\alpha \cdot(\mathrm{U} \%-12)}{100}\right]
$$

Onde:

$\mathrm{f}_{12}=$ resistência a um teor de umidade de $12 \%$;

$\mathrm{f}_{\mathrm{U} \%}=$ resistência a um teor de umidade de $\mathrm{U} \%$;

$\mathrm{U} \%=$ teor de umidade da madeira, em \%, e 
$\alpha=$ coeficiente de correção. A NBR 7190/97 adota $\alpha=3$ para a correção da resistência e $\alpha=2$ para correção do módulo de elasticidade.

O ajuste do resultado de ensaio para o teor de umidade de referência é tratado de maneira diferente em outras normas. O EUROCODE 5, da CEN (1993), repassa a responsabilidade desta correção às normas dos países membros. A norma canadense CSA 086.1-94, da CANADIAN STANDARDS ASSOCIATION (1994), tabela diretamente as características da madeira para diversas situações de uso e condições ambientais. A norma francesa, segundo DESLANDES \& VANDERBERGHE (1959), utiliza o modelo da eq. (26) com diferentes valores de $\alpha$, conforme a propriedade a ser ajustada. A norma norte americana, segundo TSOUMIS (1991), utiliza-se da eq. (16), idealizada pelo FOREST PRODUCTS LABORATORY.

TIEMANN $^{37}$ apud LIMA et al. (1986) relacionou a resistência à compressão paralela às fibras com a densidade aparente e o teor de umidade, usando o modelo:

$$
\mathrm{f}_{\mathrm{U} \%}=\rho \cdot\left(\beta_{0}+\beta_{1} \cdot \mathrm{U} \%+\beta_{2} \cdot \mathrm{U} \%{ }^{2}\right)
$$

Onde:

$\mathrm{f}_{12}=$ resistência (ou outra propriedade mecânica), ao teor de umidade $12 \%$;

$\mathrm{f}_{\mathrm{U} \%} \quad=$ resistência (ou outra propriedade mecânica), ao teor de umidade U\%;

$\mathrm{U} \% \quad=$ teor de umidade da madeira;

$\rho \quad=$ densidade aparente, $\mathrm{e}$

$\beta_{0}, \beta_{1}$, e $\beta_{2}=$ constantes (coeficientes da regressão).

PIGOZZO (1982), estudando a influência da umidade e da densidade na resistência à compressão paralela, ajusta suas curvas ao seguinte modelo:

$$
\frac{\log \mathrm{f}_{\mathrm{U} \%}}{\rho}=\beta_{0}+\beta_{1} \cdot \mathrm{U} \%+\beta_{2} \cdot \mathrm{U}^{2}+\frac{\beta_{3}}{\rho}
$$

Onde:

37 TIEMANN, H. D. (1951). Wood technology, constitution, properties, and uses. 3.ed. London, Pitman. 396 p. apud LIMA, J. T.; DELLA LUCIA, R. M.; VITAL, B. R. (1986). Influência do teor de umidade nas propriedades mecânicas de Eucalyptus saligna. Revista Árvore, vol. 10, n. 1, p. 27.43. 
$\mathrm{f}_{\mathrm{U} \%} \quad=$ resistência (ou outra propriedade mecânica), ao teor de umidade U\%;

$\mathrm{U} \%=$ teor de umidade da madeira;

$\rho \quad=$ densidade aparente, $\mathrm{e}$

$\beta_{0} \ldots \beta_{3}=$ constantes (coeficientes da regressão).

TANAAMI (1986), estudando a influência da umidade e da densidade na resistência à flexão, por sua vez, obtém curvas ajustadas ao seguinte modelo:

$$
\mathrm{f}_{\mathrm{U} \%}=\beta_{0}+\beta_{1} \cdot \mathrm{U} \%+\beta_{2} \cdot \rho+\beta_{3} \cdot \mathrm{U} \% \cdot \rho+\beta_{4} \cdot \mathrm{U} \%{ }^{2} \cdot \rho
$$

Onde:

$\mathrm{f}_{\mathrm{U} \%}=$ resistência (ou outra propriedade mecânica), ao teor de umidade U\%;

$\mathrm{U} \% \quad=$ teor de umidade da madeira;

$\rho \quad=$ densidade aparente, $\mathrm{e}$

$\beta_{0} \ldots \beta_{4}=$ constantes (coeficientes da regressão).

Os modelos apresentados nas expressões (13) a (30), para correção da resistência, também poderiam ser utilizados para a correção da rigidez. Para isto basta substituir, nas expressões, os termos $f_{U \%}$ e $f_{12}$ por $E_{U \%}$ e $E_{12}$, respectivamente. Onde $E_{U \%}$ e $E_{12}$ representam os módulos de elasticidade, respectivamente, para os teores de umidade $\mathrm{U} \%$ e $12 \%$.

\subsection{COMENTÁRIOS SOBRE A REVISÃO BIBLIOGRÁFICA REALIZADA}

O estudo da influência do teor de umidade sobre as propriedades da madeira, do ponto de vista histórico, é antigo. KOLLMANN \& COTÉ (1984) fazem referência ao trabalho de BETTS (1919).

No Brasil, exceção feita ao diagrama, reproduzido na figura 01 deste trabalho, contido na versão original de 1940, da NBR 6230 da ABNT (1980), os primeiros trabalhos encontrados são bem mais recentes e envolvem apenas algumas propriedades da madeira. PIGOZZO (1982) e HELLMEISTER (1983) apresentam resultados da influência do teor de umidade sobre a resistência à compressão paralela às fibras, TANAAMI (1986) estuda o efeito da umidade e da densidade sobre a resistência à flexão.

Um estudo mais abrangente, envolvendo várias propriedades da madeira, foi realizado por LIMA et al. (1986), ainda sob a égide da NBR 6230, da ABNT (1980). O trabalho mais recente, apresentado por BALLARIN \& RIBEIRO (1998), se limita ao estudo do efeito 
da umidade sobre a resistência à compressão paralela às fibras, entretanto aproveita seus resultados para verificar a validade do modelo proposto pela atual NBR 7190/97.

De maneira geral os estudos, apresentados nesta revisão bibliográfica, apontam para uma relação resistência-umidade na qual: para teores de umidade acima do ponto de saturação das fibras a resistência se mantém praticamente constante; para teores de umidade abaixo deste ponto a resistência aumenta com o decréscimo do teor de umidade, em geral através de uma exponencial muito suave que pode ser associada, para intervalos limitados de umidade, a linha retas (ver figura 53, alíneas a e c). Para teores de umidade mais baixos, em alguns casos, a relação resistência-umidade pode atingir um ponto de máximo, e em seguida decrescer com o decréscimo do teor de umidade (figura 53, alínea c). Para a rigidez relações semelhantes são observadas. Em alguns casos particulares não existe influência do teor de umidade sobre a propriedade de resistência (figura 53, alínea d), como por exemplo na flexão dinâmica.

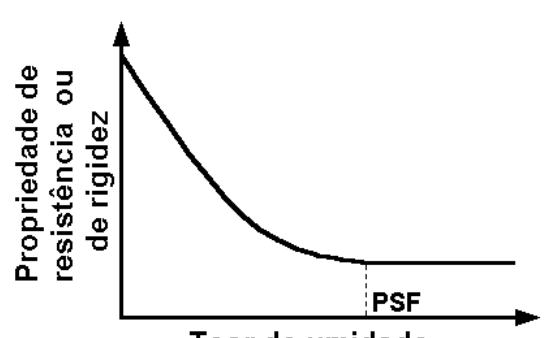

a)



c)

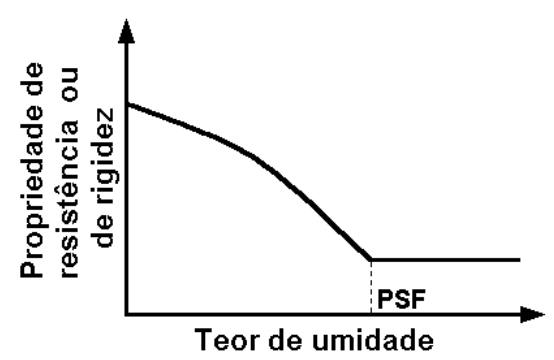

b)

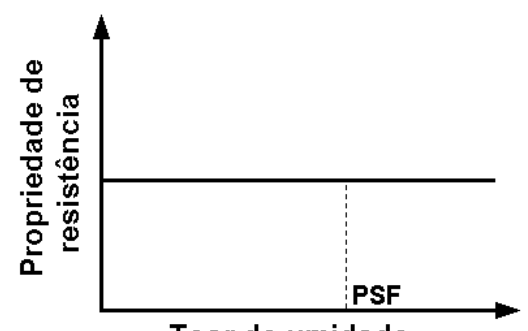

d)

FIGURA 53 - Curvas típicas utilizadas para representar a influência do teor de umidade sobre as propriedades de resistência e rigidez. As curvas "a" e "c" ocorrem com maior freqüência. A curva "b", encontrada por SCHNIEWIND (1962) para a tração normal, foi obtida com metodologia discutível. A não dependência da propriedade de resistência com o teor de umidade é encontrada na flexão dinâmica. 
O modelo de regressão oriundo da expressão adotada pela NBR 7190/97 linearizado no intervalo entre $10 \%$ e $20 \%$ de umidade, aparentemente é consistente, pois tem sido utilizado por outros autores no passado, como DESLANDES \& VANDENBERGHE (1959) e KARLSEN et al. (1967), embora utilizando coeficientes diferentes conforme a propriedade e a espécie em estudo.

Quanto aos resultados existentes para madeiras brasileiras, alguns trabalhos, realizados sob a égide da antiga NBR 6230, da ABNT (1980), não podem ser aproveitados integralmente. O módulo de elasticidade, obtido com as prescrições da NBR 6230, da ABNT (1980), era oriundo do ensaio de flexão e, segundo LAHR (1983), para este ensaio a relação vão/altura do corpo-de-prova era tal que a influência da força cortante na deformação não podia ser desprezada, assim o módulo de elasticidade obtido era apenas um valor aparente. A resistência ao cisalhamento, obtido com as prescrições da NBR 6230, da ABNT (1980), não tinha a orientação do plano de cisalhamento claramente definida, portanto os resultados misturam orientações diferentes, aumentando a variabilidade e diminuindo a confiabilidade dos resultados.

Em resumo, para as madeiras brasileiras, os únicos resultados válidos, de interesse do atual trabalho, se referem aos estudos da influência do teor de umidade sobre a resistência à compressão paralela às fibras, para as seguintes espécies: Peroba Rosa, Aspidosperma peroba (madeira não mais comercializada), Eucalipto Puntacta, Eucalyptus puntacta, Eucalipto Saligna, Eucalyptus saligna e Eucalipto citriodora, Eucalyptus citriodora. Observa-se que as espécies nativas, ainda comercializadas, não estão representadas neste conjunto.

Alguns autores, como GREEN \& PELLERIN (1991) e MADSEN (1992), mostram que a relação resistência-umidade pode ser diferente para propriedades diferentes ou para madeiras de qualidade diferente. A resistência à compressão paralela às fibras é, segundo MADSEN (1992), altamente sensível à variação do teor de umidade, já a resistência à tração paralela às fibras e o módulo de elasticidade são menos sensíveis, enquanto que a resistência à flexão dinâmica, agora segundo KRECH (1960), praticamente não é afetada pela variação do teor de umidade. LIMA et al. (1986) observaram, para o Eucalipto Saligna, Eucalyptus saligna, a não dependência da resistência à tração normal às fibras com a variação do teor de umidade. MADSEN (1992), por sua vez, conclui para o "Southern pine", que as propriedades de tração e compressão normal são altamente sensíveis à variação do teor de umidade.

Estes resultados mostram a importância, no estudo da influência da umidade sobre a resistência e rigidez da madeira, da utilização de algumas propriedades de resistência e rigidez e de algumas espécies em classes de resistência distintas. 
Outro ponto importante a ressaltar diz respeito ao processo de secagem. Processos de secagem mais severos, segundo GREEN \& PELLERIN (1991), causam maiores gradientes de umidade no corpo-de-prova e devem ser evitados. Estes gradientes de umidade podem alterar a relação resistência-umidade, BETTS ${ }^{38}$ apud KOLLMANN \& COTÉ (1984) mostrou que isto é fato para a resistência à flexão.

O ideal, provavelmente, seria utilizar uma câmara (ou sala) de climatização, na qual os corpos-de-prova pudessem ser condicionados, em condições preestabelecidas de temperatura e umidade relativa do ar, até atingir um determinado teor de umidade. Em seguida, o clima da câmara seria alterado, para condicionar os corpos-de-prova a uma umidade menor, e assim sucessivamente até se completar a secagem.

Por outro lado, os estudos de MADSEN (1992) o levaram a concluir que a secagem ao ar, muito mais simples e representativa da rotina laboratorial, produz, no intervalo de interesse deste trabalho, os mesmos resultados da secagem tida como ideal descrita acima.

Quanto a metodologia para seleção da amostra, percebe-se a necessidade de definir comportamento através do indivíduo (um corpo-de-prova). Da impossibilidade deste procedimento, devido a natureza destrutiva dos ensaios de resistência, podem ser utilizados corpos-de-prova muito semelhantes: de uma mesma região da árvore, como fizeram LIMA et al. (1986); de uma única barra, como fez HELLMEISTER (1983); ou subdividindo os resultados de uma amostra muito grande em percentis de resistência, como fizeram GREEN \& PELLERIN (1991).

A utilização de corpos-de-prova não semelhantes pode causar um erro na especificação do modelo adotado. Imagine, a título de exemplo, uma família de curvas que representem a relação resistência-umidade de uma determinada espécie (ou grupo de espécies de mesma classe de resistência), como as curvas quase paralelas apresentadas na figura 54. Retirando-se uma amostra, contendo pontos em diferentes curvas desta família, corre-se o risco de obter uma curva ajustada à amostra que nada tem a ver com o comportamento esperado (ver figura 54).

Muitos dos resultados encontrados nesta revisão bibliográfica são inconsistentes. Alguns por utilizarem metodologia de ensaio inadequada, para os padrões atuais, como a obtenção: do módulo de elasticidade a partir do ensaio de flexão em corpos-de-prova de pequena relação vão/altura, desconsiderando a deformação por força cortante; da resistência ao cisalhamento sem definição prévia da orientação do plano de corte; ou ainda, da resistência à

${ }^{38}$ BETTS, H. S. (1919). Timber, its strength, seasoning and grading. New York, p.31 apud KOLlMANN, F. F. P. \& CÔTÉ, W. A. (1984). Principles of wood science and technology. Vol I Solid Wood. Reprint Berlin, Heidelberg, New York, Tokyo. SpringerVerlag. 1968-1984. 
tração paralela permitindo, nas espécies de anéis de crescimento largos, ensaios da madeira de apenas um dos anéis. Outros por falha de amostragem acarretando erro na especificação do modelo, como se mostrou no parágrafo anterior e na figura 54 .

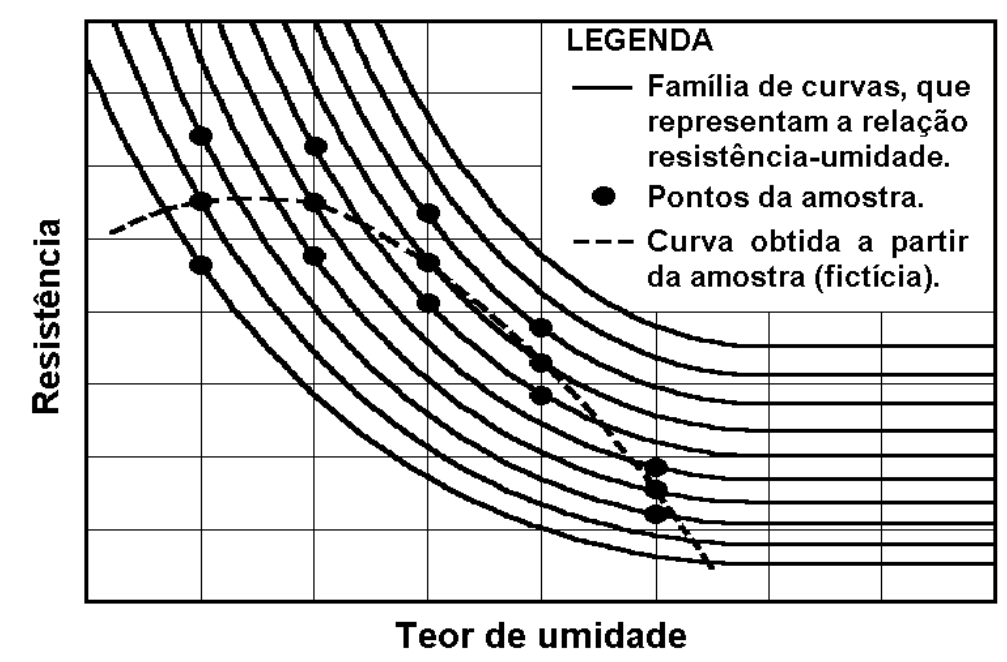

FIGURA 54 - Uma amostra, refletindo a enorme variabilidade da madeira, pode causar um erro de especificação no modelo da relação resistência-umidade. O comportamento depende do indivíduo.

Dessa forma, pode-se concluir que a influência do teor de umidade sobre as propriedades de resistência e rigidez da madeira ainda não está satisfatoriamente estabelecida. Existe a necessidade de aferir esta influência utilizando-se a metodologia de ensaio atual e individualizando o estudo do comportamento com o uso de corpos-de-prova muito semelhantes. É necessário, também, avaliar a influência do teor de umidade sobre as propriedades de resistência e rigidez da madeira de diferentes espécies (ou classes de resistência) e em diferentes propriedades. E, ainda, precisa ser definida uma expressão para o ajuste da densidade aparente, ao teor de umidade de referência. O que mostra a relevância do atual trabalho de tese. 


\section{MATERIAL E MÉTODOS}

\subsection{SELEÇÃO DAS ESPÉCIES}

Com o intuito de tornar o trabalho representativo das sete classes de resistência definidas pela NBR 7190/97, foram selecionadas sete espécies de modo que cada uma representasse uma classe de resistência.

Sabe-se, segundo o anexo F da NBR 7190/97, que para as espécies conhecidas podese aceitar a relação:

$$
\mathrm{f}_{\mathrm{c} 0, \mathrm{k}}=0,70 . \mathrm{f}_{\mathrm{c} 0, \mathrm{~m}}
$$

Onde:

$\mathrm{f}_{\mathrm{c} 0, \mathrm{k}}=$ resistência característica à compressão paralela às fibras;

$\mathrm{f}_{\mathrm{c} 0, \mathrm{~m}}=$ resistência média à compressão paralela às fibras;

Por outro lado, no anexo E da NBR 7190/97, são fornecidos alguns valores médios de espécies nativas e de florestamento. A partir destes valores, aplicando-se a eq. (31), montou-se a tabela 09, na qual são apresentadas as espécies selecionadas e suas respectivas classes de resistência. Outro ponto observado nesta escolha foi a facilidade de obtenção destas espécies na região de São Carlos.

\subsection{MADEIRA E CORPOS-DE-PROVA NECESSÁRIOS}

O pequeno comentário sobre a revisão bibliográfica, apresentado no item 4.12, mostrando que o estudo de um comportamento deve ter origem no indivíduo, serviu de orientação para que fossem utilizados corpos-de-prova semelhantes, retirados ao longo de uma única barra de cada espécie. Considerando-se que o estudo pretende ser abrangente às madeiras e que a variabilidade dos resultados é maior entre as espécies, que entre as árvores de uma mesma espécie, se optou por estudar apenas uma árvore (no caso uma barra) de cada espécie 
e premiar um maior número de espécies (no caso sete, uma para cada classe de resistência, como se apresenta na tabela 09 ).

TABELA 09 - Seleção das espécies

\begin{tabular}{|c|c|c|c|c|}
\hline \multirow[t]{2}{*}{$\begin{array}{c}\text { ESPÉCIE SELECIONADA } \\
\text { (NOME VULGAR) }\end{array}$} & \multirow[t]{2}{*}{$\begin{array}{c}\mathbf{f}_{\mathrm{c} 0, \mathrm{~m}} \\
(\mathrm{MPa})\end{array}$} & \multirow[t]{2}{*}{$\begin{array}{c}\mathbf{f}_{\mathrm{c} 0, \mathrm{k}} \\
(\mathrm{MPa})\end{array}$} & \multicolumn{2}{|c|}{$\begin{array}{l}\text { CLASSE PROVÁVEL } \\
\text { DE RESISTÊNCIA }\end{array}$} \\
\hline & & & CONÍFERAS & DICOTILEDÔNEAS \\
\hline Pinus bahamensis & 32,60 & 22,82 & C 20 & \\
\hline Pinus elliottii & 40,40 & 28,28 & C 25 & \\
\hline Pinus taeda & 44,40 & 31,08 & C 30 & \\
\hline Eucalipto grandis & 40,30 & 28,21 & & C 20 \\
\hline Cupiúba & 54,40 & 38,08 & & C 30 \\
\hline Eucalipto citriodora & 62,00 & 43,40 & & $\mathrm{C} 40$ \\
\hline Jatobá & 93,30 & 65,31 & & $\mathrm{C} 60$ \\
\hline
\end{tabular}

A possibilidade de existência de comportamento diferenciado, conforme a propriedade em estudo, direcionou o trabalho no sentido de se estudar a influência do teor de umidade sobre algumas propriedades da madeira. A madeira possui inúmeras propriedades, seria inviável envolver todas elas neste trabalho. Resolveu-se, portanto, selecionar as propriedades de maior interesse prático para o projeto de estruturas de madeira.

A seleção das propriedades da madeira, a serem abordadas neste trabalho, se baseou no fato da atual NBR 7190/97 definir três níveis de caracterização para as propriedades da madeira: completa, mínima e simplificada.

A caracterização completa da resistência prevê a realização de ensaios de todas as propriedades mecânicas, nas direções paralela e normal às fibras, além das densidades básica e aparente. A caracterização mínima, por sua vez, prevê a realização dos ensaios de compressão, tração e cisalhamento, todos na direção paralela às fibras, além dos ensaios de densidade básica e aparente. Já a caracterização simplificada prevê apenas o ensaio de compressão paralela às fibras.

Por outro lado, as propriedades de resistência da madeira, na direção normal às fibras, podem ser consideradas como de importância secundária no cálculo de estruturas de madeira. $\mathrm{O}$ cisalhamento não acontece na direção normal às fibras. A ocorrência de tração normal às fibras, deve ser evitada, pois a NBR 7190/97, em seu item 7.2.3, recomenda: "A segurança das peças estruturais da madeira em relação a estados limites últimos não devem 
depender diretamente da resistência à tração normal às fibras do material". E a compressão normal às fibras não apresenta ruptura, entendida como a ausência da capacidade de transmitir esforços, tanto que a NBR 7190/97, em seu item B.10.2, define: "A resistência à compressão normal às fibras $\left(f_{\mathrm{wc}, 90}\right.$ ou $\left.\mathrm{f}_{\mathrm{c} 90}\right)$ é o valor convencional determinado pela deformação específica residual de $2 \% "$.

A densidade básica, por sua vez, independe do teor de umidade, pois é definida, no item B.6.2 da NBR 7190/97, por:

$$
\rho_{\text {bas }}=\frac{\mathrm{m}_{0}}{\mathrm{~V}_{\text {sat }}}
$$

Onde:

$\rho_{\text {bas }}=$ densidade básica;

$\mathrm{m}_{0}=$ massa seca da madeira, $\mathrm{e}$

$\mathrm{V}_{\text {sat }}=$ volume da madeira saturada.

Resolveu-se, assim, envolver neste trabalho as seguintes propriedades: compressão paralela às fibras; módulo de elasticidade longitudinal; tração paralela às fibras; cisalhamento paralelo às fibras, e densidade aparente.

O módulo de elasticidade longitudinal e a densidade aparente serão obtidos do ensaio de compressão paralela às fibras.

Considerando que as rupturas por tração paralela e por cisalhamento são frágeis, e que o ensaio de tração paralela é de difícil realização, resolveu-se adotar uma amostra maior para os ensaios de cisalhamento e uma amostra mínima para os ensaios de tração, pois para as duas propriedades se espera um mesmo comportamento da relação resistência-umidade.

Segundo o anexo B da NBR 7190/97 os corpos-de-prova para o ensaio de cisalhamento, são confeccionados com as direções principais bem definidas. Nos ensaios de tração paralela a boa definição das direções principais, dos corpos-de-prova, evita problemas nos ensaios em madeiras com anéis de crescimento largos.

Assim, serão necessárias, para cada espécie em estudo, duas barras: uma para retirar os corpos-de-prova de compressão paralela; e outra, com as direções principais bem definidas, para retirar os corpos-de-prova de tração paralela e cisalhamento.

O comprimento de cada barra limita a quantidade de corpos-de-prova, que devem ser semelhantes e isentos de defeitos, utilizada no trabalho. Para que os corpos-de-prova pudessem ser confeccionados a partir de barras de comprimento usual no comércio (em torno de 
4,00 m), resolveu-se adotar as quantidades de corpos-de-prova indicadas na tabela 10. Devese salientar que não há necessidade de uma amostra muito grande para se realizar uma análise de regressão adequada, bastam alguns resultados no intervalo de umidade entre $10 \%$ e $20 \%$.

TABELA 10 - Quantidade de corpos-de-prova, ou de ensaios, prevista

\begin{tabular}{lccc}
\hline \multicolumn{1}{c}{ PROPRIEDADES } & $\begin{array}{c}\text { NÚMERO DE } \\
\text { CORPOS-DE- } \\
\text { PROVA } \\
\text { POR ESPÉCIE }\end{array}$ & $\begin{array}{c}\text { NÚMERO DE } \\
\text { ESPÉCIES }\end{array}$ & TOTAL \\
& 20 & 7 & 140 \\
\hline $\begin{array}{l}\text { Resistência à compressão paralela } \\
\text { às fibras, módulo de elasticidade } \\
\text { longitudinal e densidade aparente }\end{array}$ & 8 & 7 & 56 \\
$\begin{array}{l}\text { Resistência à tração paralela às fi- } \\
\text { bras }\end{array}$ & 18 & 7 & 126 \\
Resistência ao cisalhamento & 46 & 7 & 322 \\
\hline TOTAIS & & & \\
\hline
\end{tabular}

\subsection{OBTENÇÃO E IDENTIFICAÇÃO DA MADEIRA NECESSÁRIA}

Inicialmente se procurou obter a madeira no comércio de São Carlos e foram encontradas, entre as espécies selecionadas, a Cupiúba e o Jatobá. As demais espécies foram obtidas no Instituto Florestal, da Prefeitura Municipal de Itirapina, que forneceu um toro, com aproximadamente 3,50 $\mathrm{m}$ de comprimento e $40 \mathrm{~cm}$ de diâmetro, para cada uma das espécies solicitadas.

O desdobro dos toros foi orientado no sentido de obter barras, de seção $6 \mathrm{~cm} \times 12 \mathrm{~cm}$, em posições que possibilitassem a retirada de corpos-de-prova, para os ensaios de tração e cisalhamento, com as direções principais bem definidas. As barras adquiridas no comércio de São Carlos foram escolhidas, com a preocupação de apresentarem a posição dos anéis de crescimento equivalentes à situação descrita para as barras retiradas dos toros. A figura 55 apresenta a posição da retirada das barras e a orientação de seus anéis de crescimento, evidentemente as posições diametralmente simétricas também podem ser utilizadas.

Em seguida, pequenos pedaços da madeira e, quando possível, da casca foram encaminhados à Faculdade de Engenharia Florestal, da Universidade Federal de Mato Grosso, 
para identificação das espécies utilizadas. A identificação foi feita pelo Prof. Zenesio Finger $^{39}$, que confirmou as espécies utilizadas. A tabela 11, apresenta a identificação das espécies.

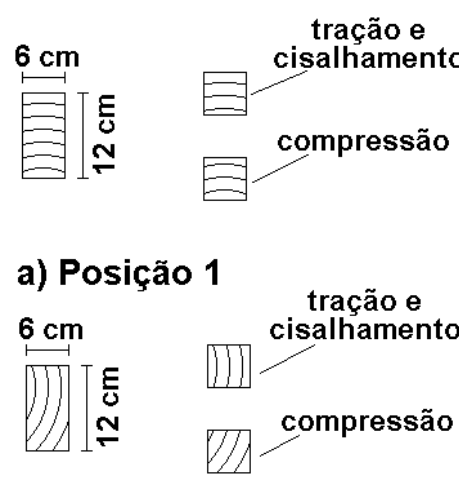

b) Posição 2

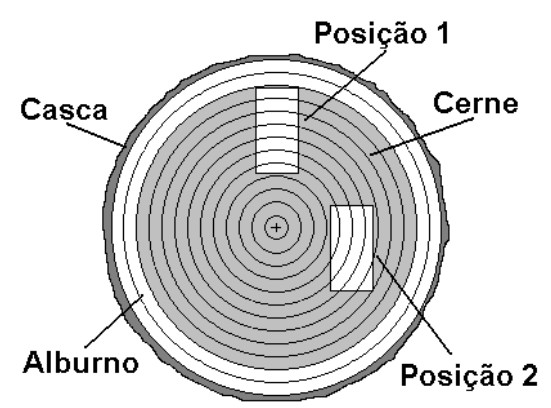

c) Retirada da barra do toro

FIGURA 55 - Posição da retirada das barras e orientação de seus anéis de crescimento.

TABELA 11 - Espécies utilizadas

\begin{tabular}{lll}
\hline & \multicolumn{1}{c}{ ESPÉCIE } & \multirow{2}{*}{ FAMÍLIA } \\
\cline { 1 - 2 } NOME VULGAR & \multicolumn{1}{c}{ NOME CIENTÍFICO } & \\
\hline Pinus bahamensis & $\begin{array}{l}\text { Pinus caribea } \text { Morelet var bahamensis (Griseb) } \\
\text { Barret et Golfari }\end{array}$ & Pinaceae \\
Pinus elliottii & Pinus elliottii Engelm & \\
Pinus taeda & Pinus taeda L. & Pinaceae \\
Eucalipto grandis & Eucalyptus grandis (Hill) Maiden & Pinaceae \\
Cupiúba & Goupia glabra Aubl. & Myrtaceae \\
Eucalipto citriodora & Eucalyptus citriodora Hook & Celastraceae \\
Jatobá & Hymenaeae stilbocarpa Hayne & Myrtaceae \\
\hline
\end{tabular}

\subsection{BREVE DESCRIÇÃO DAS ESPÉCIES UTILIZADAS}

\subsubsection{PINUS BAHAMENSIS}

Pinus caribea Morelet var bahamensis (Griseb) Barret et Golfari

PINACEA

${ }^{39}$ Professor Adjunto da Faculdade de Engenharia Florestal - Universidade Federal de Mato Grosso. Mestre em Ciências Florestais com extensa experiência nas áreas de Dendrologia 
Segundo o Prof. Zenesio Finger ${ }^{40}$, é uma espécie-variedade tropical, originária das ilhas Bahamas, da região do Caribe. Do ponto de vista da auto-ecologia da espécie é muito semelhante ao Pinus oocarpa e pode ser cultivada do centro ao norte do Brasil, entretanto existem poucas informações a respeito desta espécie-variedade e devem ser realizados estudos prévios sobre análise de crescimento e desenvolver tecnologias adequadas de produção, desde a fase de viveiro até a exploração final. Sua madeira, apresentada na figura 56, é muito parecida com a de outros Pinus, como o Pinus elliottii.

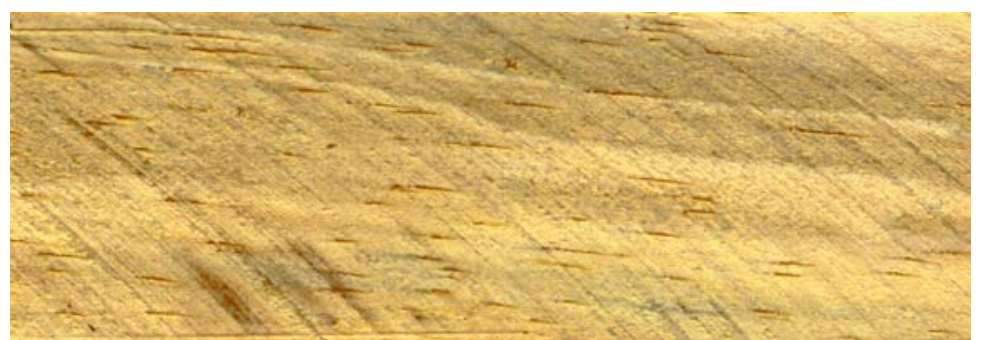

a) Vista longitudinal

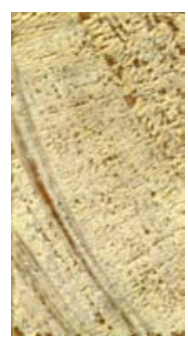

b) Vista transversal

FIGURA 56 - Madeira de Pinus caribea Morelet var bahamensis (Griseb) Barret et Golfari

\subsubsection{PINUS ELLIOTTII}

Pinus elliottii Engelm

PINACEAE

Segundo CORRÊA (1978), é árvore de grande porte, com altura de 15 a $30 \mathrm{~m}$ e diâmetro de 60 a $120 \mathrm{~cm}$, originária da América do Norte e de Cuba. Foi introduzida no Brasil na década de 1960, para reflorestamento, devido à sua rusticidade e rápido crescimento, sendo bem acolhida e intensamente cultivada principalmente no Estado de São Paulo. Na América do Norte é conhecida por "Slash pine". Sua madeira, apresentada na figura 57, é clara e de densidade relativamente baixa.

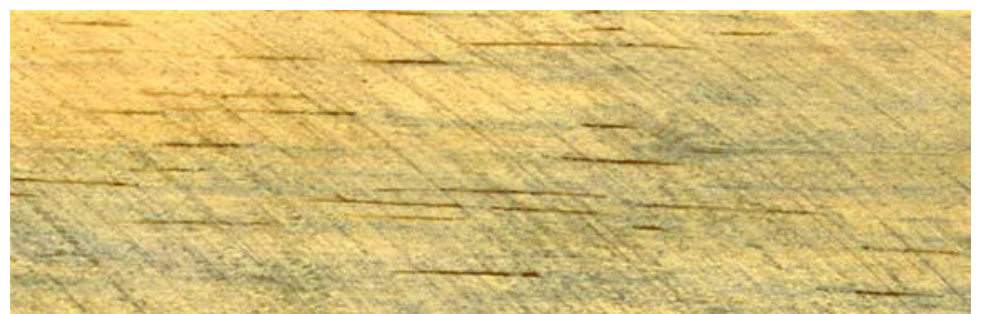

a) Vista longitudinal

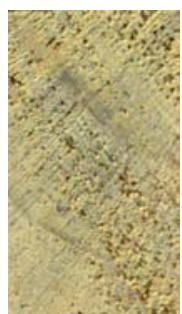

b) Vista transversal

FIGURA 57 - Madeira de Pinus elliottii Engelm

e Anatomia da Madeira.

${ }^{40}$ Professor Adjunto da Faculdade de Engenharia Florestal - Universidade Federal de Mato Grosso. Mestre em Ciências Florestais com extensa experiência nas áreas de Dendrologia e Anatomia da Madeira. 


\subsubsection{PINUS TAEDA}

Pinus taeda L.

PINACEAE

Segundo CORRÊA (1978), é árvore de grande porte, com altura de 20 a 30 m, originária da América do Norte (Flórida e Virgínia). É uma das espécies grande produtora de terebintina. Na Alemanha é conhecida por "Weihranch Kiefer", e na Argentina por "Piño de incienso". Sua madeira é apresentada na figura 58.

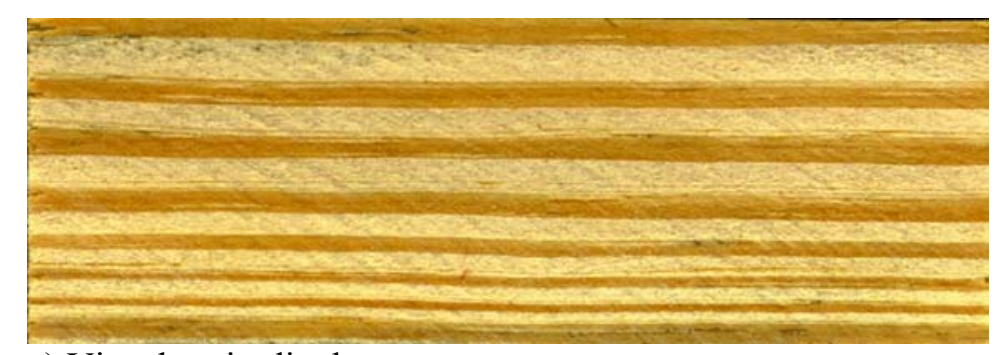

a) Vista longitudinal

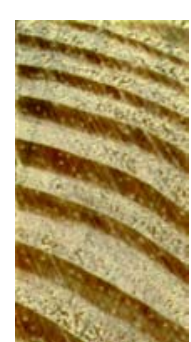

b) Vista transversal

FIGURA 58 - Madeira de Pinus taeda L.

\subsubsection{EUCALIPTO GRANDIS}

Eucalyptus grandis (Hill) Maiden

Segundo RIZZINI (1978), é árvore de grande porte, com altura de 42 a 54 m e diâmetro de 120 a $180 \mathrm{~cm}$. Sua casca é lisa esbranquiçada, cinzenta ou mesmo esverdeada, que se desprende em lâminas. No exterior é conhecida por "Rose Gum", "Toobur", "Flooded Gum". Sua madeira, apresentada na figura 59, é rosa-forte ou vermelho-pardacento-clara, moderadamente dura, de pequena a média densidade e de fácil trabalhabilidade.

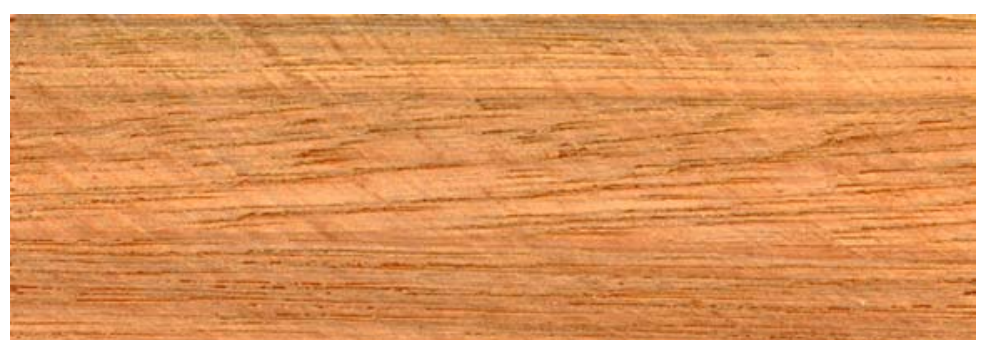

a) Vista longitudinal

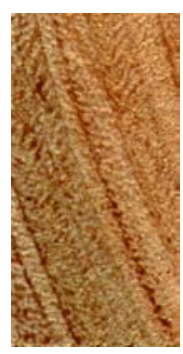

b) Vista transversal

FIGURA 59 - Madeira de Eucalyptus grandis (Hill) Maiden. 


\subsubsection{CUPIÚBA}

Goupia glabra Aubl

CELASTRACEAE

Segundo LOUREIRO \& SILVA (1968), é árvore de grande porte, facilmente reconhecível pela folhagem constante, inconfundível, de cor negra, no momento da caducifólia. É encontrada no Estado do Amazonas, nos arredores de Manaus e no Baixo Amazonas; no Estado do Pará, em todo o Estado e sobretudo nos arredores de Belém; existe em abundância no Estado de Mato Grosso; ocorre ainda nas Guianas, Colômbia e Venezuela. Nas Guianas é conhecida por "Cabacalli", "Copi", "Copie", "Couepi", "Coupi", "Goupi", "Goupil", "Kabukalli", "Kaboekalli", "Koepi" e "Koepie", na Venezuela por "Pilon". Sua madeira, apresentada na figura 60, tem o cerne castanho-amarelo ou bege-claro, levemente rosado, quando recém cortado, passando com o tempo para o castanho-avermelhado. É de fácil trabalhabilidade e aceita acabamento esmerado.

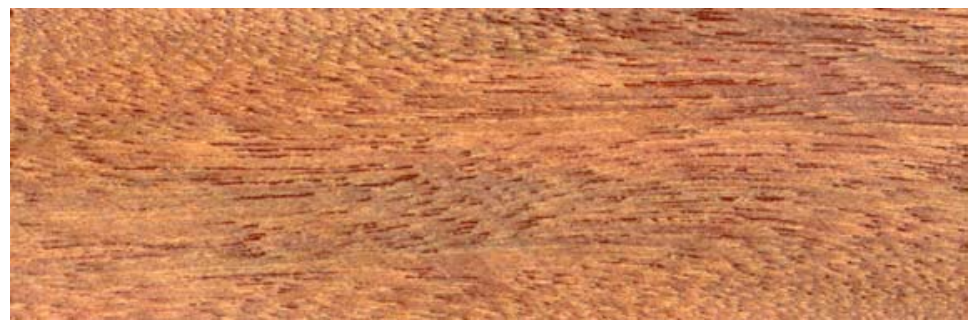

a) Vista longitudinal

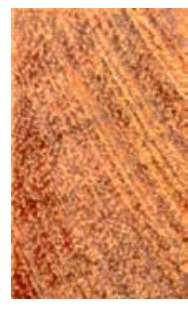

b) Vista transversal

FIGURA 60 - Madeira de Goupia glabra Aubl.

\subsubsection{EUCALIPTO CITRIODORA}

Eucalyptus citriodora Hook

MYRTACEAE

Segundo RIZZINI (1978), é árvore de grande porte, com altura de 24 a 40 m, e diâmetro de 60 a $120 \mathrm{~cm}$. Sua casca é de completa deiscência, lisa, brilhante, brancoacinzentada ou com nuança azulada esmaecida; que cai em pequenas placas (escamas), finas, deixando marcas no local. O cheiro, facilmente reconhecível, de todas as partes desta árvore, recorda o da erva-cidreira. No exterior é conhecida por "Lemmon-scented Gum" e "Lemmon-scented Spotted Gum". Sua madeira, apresentada na figura 61, é: de coloração pardoclara ou pardo-acinzentada; dura; densa e durável. 


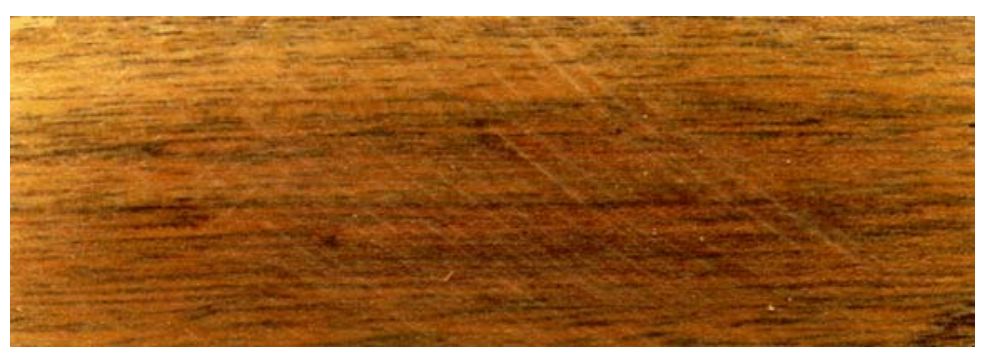

a) Vista longitudinal

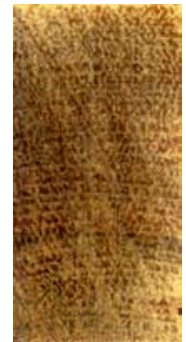

b) Vista transversal

FIGURA 61 - Madeira de Eucalyptus citriodora Hook.

\subsubsection{JATOBÁ}

Hymenaeae stilbocarpa Hayne

LEGUMINOSAE

Segundo HERINGER \& FERREIRA (1975) e RIZZINI (1978), é árvore de grande porte com altura de 12 a $18 \mathrm{~m}$ e diâmetro de 80 a $100 \mathrm{~cm}$, possui fuste reto. Sua casca é áspera, cinzento-clara e sulcada. É encontrada nos Estados do Piauí, Minas Gerais, Bahia, São Paulo, Santa Catarina, Rio Grande do Sul, Goiás e Distrito Federal; ocorre ainda na Argentina e no Paraguai. É conhecida, no Brasil, por: Jatobá, Jutaí, Jataí, Burandá, Castanheiro de Bugre, Courbaril, Farinheira, Jataí-ibá, Jatí, Jataí Amarelo, Jataí Vermelho, e etc.; na Argentina por: "Paqui" e "Copaiba". Sua madeira, apresentada na figura 62, é pardo-avermelhadaescura, uniforme ou com veios mais escuros, é muito densa, dura ao corte, imputrescível quando abrigada, difícil de trabalhar impedindo a penetração de pregos.

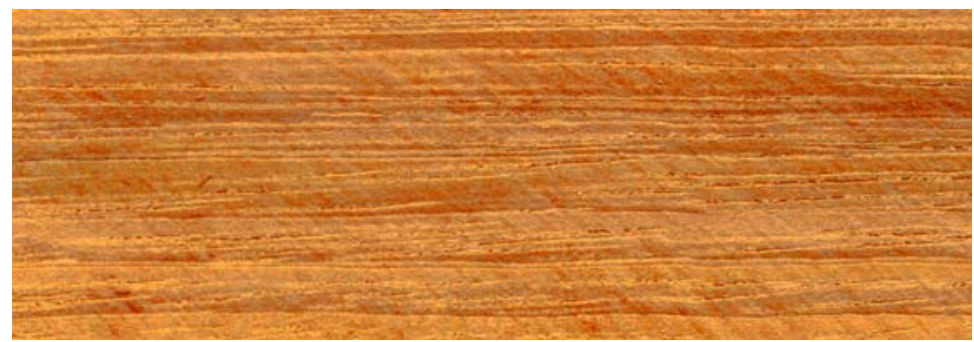

a) Vista longitudinal

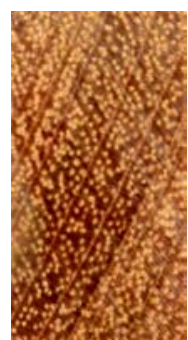

b) Vista transversal

FIGURA 62 - Madeira de Hymenaeae stilbocarpa Hayne.

\subsection{PROCEDIMENTO DE SECAGEM E CONTROLE DO TEOR DE UMI- DADE}

Após a obtenção da madeira necessária, os corpos-de-prova foram confeccionados, em acordo com a NBR 7190/97 e imersos em água destilada, para recuperar o teor de umi- 
dade acima do ponto de saturação das fibras, por aproximadamente dez dias. Os ensaios em Eucalipto grandis foram exceção a esta regra, visto que esta espécie foi utilizada, logo após a árvore ter sido abatida, nos ensaios preliminares deste trabalho, não necessitando de recuperação de umidade.

Utilizou-se água destilada, para recuperação de umidade, por precaução, uma vez que LOGSDON et al. (1998) mostraram, utilizando ensaios de retração e inchamento, que a qualidade da água, inclusive a potável, pode modificar seu fluxo no interior da madeira e em conseqüência as propriedades de retração e inchamento. Para as propriedades mecânicas, não se encontrou estudos deste tipo.

Após este período de imersão, as dimensões e massa de cada corpo-de-prova foram avaliadas e registradas, respectivamente, com sensibilidade de $0,01 \mathrm{~mm}$ e $0,01 \mathrm{~g}$. As massas foram avaliadas em uma balança analítica e as dimensões em um paquímetro digital.

Um primeiro corpo-de-prova, de cada tipo de ensaio (compressão, tração e cisalhamento) e espécie, foi ensaiado e em seguida colocado em uma estufa de esterilização e secagem, a uma temperatura de $103 \pm 2^{\circ} \mathrm{C}$, para a completa secagem e determinação do teor de umidade. A determinação do teor de umidade é análoga à descrita no item B.5 da NBR 7190/97, entretanto utiliza diretamente o corpo-de-prova, do ensaio em avaliação, inteiro.

Os demais corpos-de-prova, foram colocados para secar ao ar, em condições gerais de laboratório.

O teor de umidade, deste primeiro ensaio, foi admitido, por hipótese, como sendo o teor de umidade inicial de todos os corpos-de-prova, para cada tipo de ensaio e de cada espécie, uma vez que suas condições iniciais, após a recuperação da umidade em água destilada, eram, teoricamente, as mesmas. Conhecida a massa inicial, de cada corpo-de-prova, foi possível estimar a massa seca, ver eq. (33 ), e a massa que deveria atingir a um determinado teor de umidade, ver eq. (34).

$$
\begin{aligned}
& \mathrm{U} \%_{\mathrm{i}}=\frac{\mathrm{m}_{\mathrm{i}}-\mathrm{m}_{0}}{\mathrm{~m}_{0}} .100 \Rightarrow \mathrm{m}_{0}=\frac{\mathrm{m}_{\mathrm{i}}}{\left(1+\frac{\mathrm{U} \%_{\mathrm{i}}}{100}\right)} \\
& \mathrm{U} \%=\frac{\mathrm{m}_{\mathrm{U} \%}-\mathrm{m}_{0}}{\mathrm{~m}_{0}} \cdot 100 \Rightarrow \mathrm{m}_{\mathrm{U} \%}=\mathrm{m}_{0} \cdot\left(1+\frac{\mathrm{U} \%}{100}\right) \Rightarrow \mathrm{m}_{\mathrm{U} \%}=\mathrm{m}_{\mathrm{i}} \cdot \frac{\left(1+\frac{\mathrm{U} \%}{100}\right)}{\left(1+\frac{\mathrm{U} \% \mathrm{o}_{\mathrm{i}}}{100}\right)}
\end{aligned}
$$


Onde:

$\mathrm{U} \%_{\mathrm{i}}=$ teor de umidade inicial do corpo-de-prova, adotada por espécie como sendo a umidade do primeiro corpo-de-prova ensaiado, em \%;

$\mathrm{U} \%=$ teor de umidade, que se pretende ensaiar o corpo-de-prova, em \%;

$\mathrm{m}_{0} \quad$ = estimativa da massa seca do corpo-de-prova, com a hipótese de que U\% $\mathrm{i}$ seja a umidade inicial do corpo-de-prova;

$\mathrm{m}_{\mathrm{i}} \quad$ = massa inicial do corpo-de-prova, com a hipótese de ter o teor de umidade $\mathrm{U} \% \mathrm{i}$

$\mathrm{m}_{\mathrm{U} \%}=$ estimativa da massa do corpo-de-prova, quando seu teor de umidade dor $\mathrm{U} \%$;

A partir da eq. (34) foi possível montar uma tabela associando o teor de umidade à massa esperada do corpo-de-prova. O acompanhamento diário da massa de cada corpo-deprova, através de uma balança analítica com $0,01 \mathrm{~g}$ de sensibilidade, a medida em que secavam, permitia estimar o teor de umidade em que se encontrava cada corpo-de-prova e, assim, distribuir o teor de umidade dos ensaios de maneira mais ou menos uniforme.

Procurou-se ensaiar o maior número de corpos-de-prova no intervalo de umidade entre $10 \%$ e $20 \%$, e apenas alguns ensaios com teor de umidade acima do ponto de saturação das fibras e abaixo de $10 \%$.

Uma fixação rígida dos níveis de umidade a serem avaliados não foi possível, pois fatores como a variabilidade natural do teor de umidade inicial dos corpos-de-prova e a disponibilidade de pessoal, ou de equipamento, para realizar os ensaios, principalmente nos feriados, impediam fixar com maior precisão o teor de umidade para realização do ensaio. A estimativa do teor de umidade inicial médio era melhorada, a medida em que eram obtidos novos resultados (massa seca correta do corpo-de-prova), e assim as estimativas da tabela, que associava o teor de umidade à massa esperada do corpo-de-prova, era sistematicamente melhorada.

Depois de aproximadamente quarenta dias, a massa de cada corpo-de-prova praticamente não variava mais (variação diária menor que $0,5 \%$ ). A secagem ao ar foi dada como terminada.

Concluída a secagem ao ar, os corpos-de-prova foram colocados em uma estufa de esterilização e secagem, a um nível de temperatura de $40^{\circ} \mathrm{C}$ por dois dias. A cada dois dias o nível de temperatura era elevado, respectivamente, para $60^{\circ} \mathrm{C}, 80^{\circ} \mathrm{C}$ e $103 \pm 2^{\circ} \mathrm{C}$, até a completa secagem.

Sempre que um corpo-de-prova atingisse um nível de umidade de interesse, durante todo o processo de secagem, ele era ensaiado. 


\subsection{ENSAIO DE COMPRESSÃO PARALELA ÀS FIBRAS}

$\mathrm{O}$ corpo-de-prova e o método de ensaio à compressão paralela às fibras, utilizados neste trabalho, são os descritos no item B.8 da NBR 7190/97.

Foram utilizados, para o ensaio de compressão paralela às fibras, dois relógios comparadores, um paquímetro digital e uma máquina universal. Os relógios comparadores, instalados para avaliar a deformação entre dois pontos do corpo-de-prova, tinham sensibilidade de milésimos de milímetro. O paquímetro digital, utilizado para avaliar as dimensões do corpo-de-prova, tinham sensibilidade de centésimos de milímetro. A máquina universal de ensaios, tinha capacidade de carga de $250 \mathrm{kN}$ e permitia o controle da velocidade de carregamento prevista no ensaio, de $10 \mathrm{MPa} / \mathrm{min}$.

Deste ensaio se obtém a resistência à compressão paralela e o módulo de elasticidade longitudinal. Na figura 63 são apresentadas: a máquina universal, o corpo-de-prova e sua instalação para o ensaio de compressão paralela.

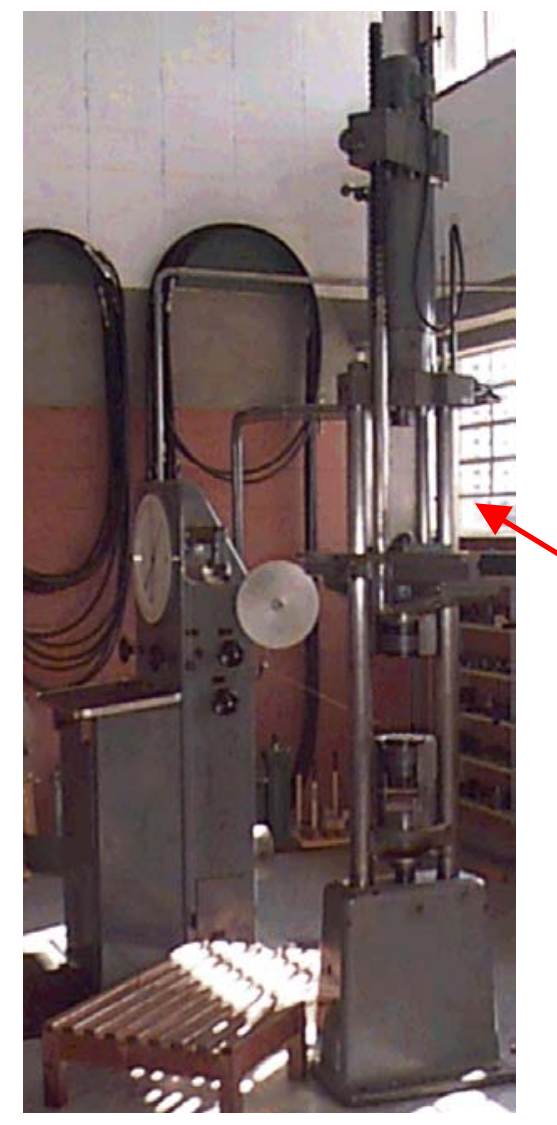

a)

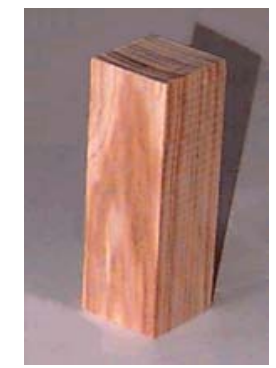

b)

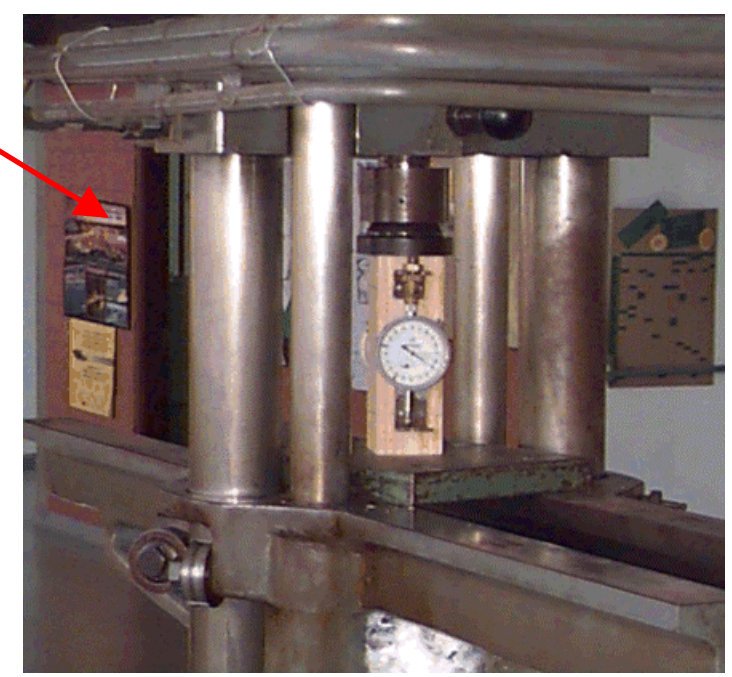

c)

FIGURA 63 - Ensaio de compressão paralela: a) máquina universal, b) corpo-de-prova e c) instalação para o ensaio. 
O corpo-de-prova do ensaio de compressão paralela, também foi usado para avaliar a densidade aparente. O método de ensaio utilizado baseou-se no item B.6 da NBR 7190/97.

A massa e as dimensões, do corpo-de-prova, foram avaliadas no início do ensaio e após a completa secagem do corpo-de-prova. Para avaliar massas foi utilizada uma balança analítica com sensibilidade de $0,01 \mathrm{~g}$. Para avaliar dimensões foi utilizado um paquímetro digital com sensibilidade de centésimos de milímetro.

Para avaliação do volume do corpo-de-prova, as dimensões de sua seção transversal foram obtidas de modo análogo ao ensaio de compressão paralela, já sua altura, por causa do esmagamento na ruptura, foi avaliada apenas no início do ensaio e admitida constante, uma vez que a retração axial é desprezível (ver figura 15). Vale ressaltar que a densidade aparente no instante do ensaio é obtida sem qualquer aproximação. As dimensões do corpo-de-prova seco são estimativas, que permitem obter o coeficiente de retratibilidade volumétrica, apresentado na eq. (09), útil para verificar a validade da eq, (08), que corrige a densidade aparente ao teor de umidade de $12 \%$.

\subsection{ENSAIO DE TRAÇÃO PARALELA ÀS FIBRAS}

O corpo-de-prova e o método de ensaio à tração paralela às fibras, utilizados neste trabalho, são os descritos no item B.9 da NBR 7190/97. Para evitar problemas com as espécies de anéis de crescimento largos, se fez coincidir a direção tangencial com a espessura dos corpos-de-prova.

Foram utilizados, para o ensaio de tração paralela às fibras, um paquímetro digital e uma máquina universal. O paquímetro digital, utilizado para avaliar as dimensões do corpode-prova, tinha sensibilidade de centésimos de milímetro. A máquina universal de ensaios, tinha capacidade de carga de $250 \mathrm{kN}$ e permitia o controle da velocidade de carregamento prevista no ensaio, de $10 \mathrm{MPa} / \mathrm{min}$.

Do ensaio descrito no item B.9 da NBR 7190/97 se obtém a resistência à tração paralela e o módulo de elasticidade longitudinal. Neste trabalho se obteve apenas a resistência à tração paralela às fibras, assim não foi necessário utilizar os relógios comparadores de que trata o item B.9 da NBR 7190/97. Na figura 64 são apresentadas: a máquina universal, o corpo-de-prova e sua instalação para o ensaio de tração paralela. 


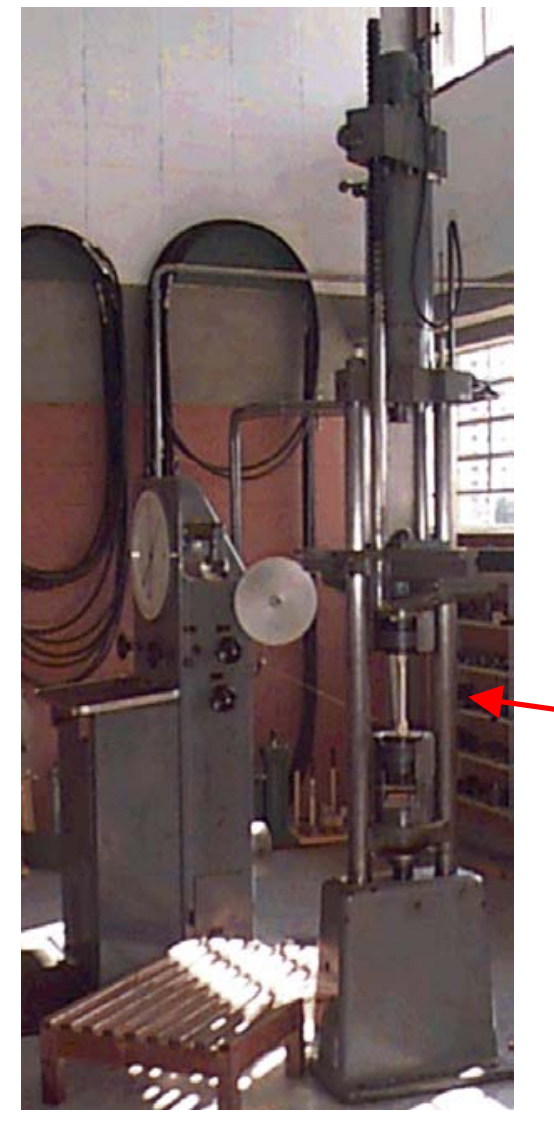

a)

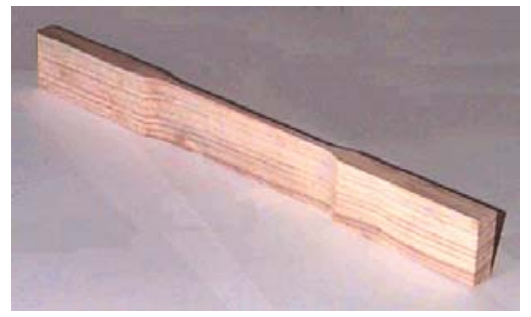

b)

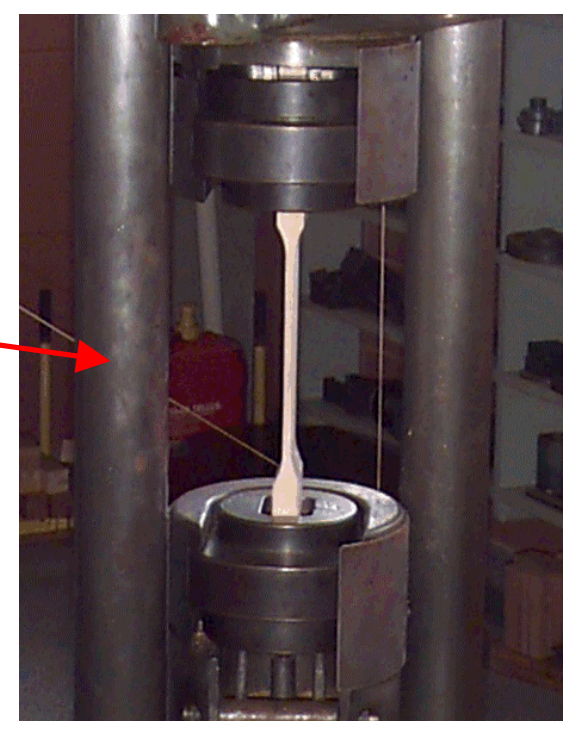

c)

FIGURA 64 - Ensaio de tração paralela: a) máquina universal, b) corpo-de-prova e c) instalação para o ensaio.

\subsection{ENSAIO DE CISALHAMENTO}

O corpo-de-prova, a orientação das direções principais, e o método de ensaio ao cisalhamento, são os descritos no item B.12 da NBR 7190/97.

Foram utilizados, para o ensaio de cisalhamento, um paquímetro digital e uma máquina universal. O paquímetro digital, utilizado para avaliar as dimensões do corpo-deprova, tinha sensibilidade de centésimos de milímetro. A máquina universal de ensaios, tinha capacidade de carga de $250 \mathrm{kN}$ e permitia o controle da velocidade de carregamento prevista no ensaio, de 2,5 MPa/min.

Deste ensaio se obtém a resistência ao cisalhamento. Na figura 65 são apresentadas: a máquina universal, o corpo-de-prova e sua instalação para o ensaio de cisalhamento. 


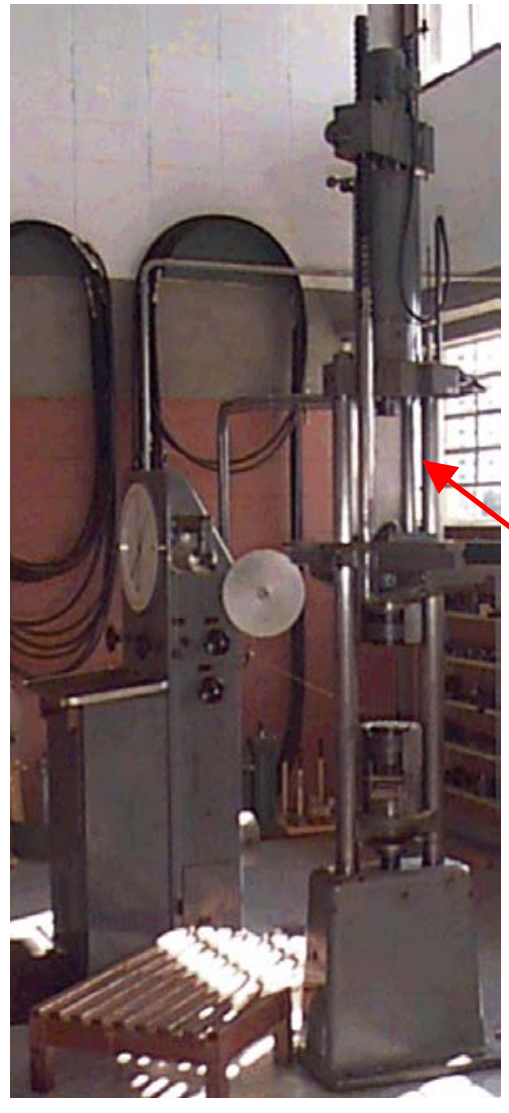

a)

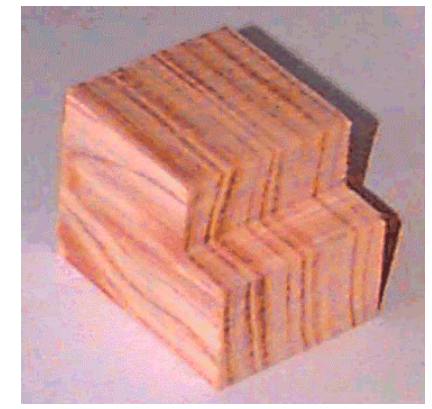

b)

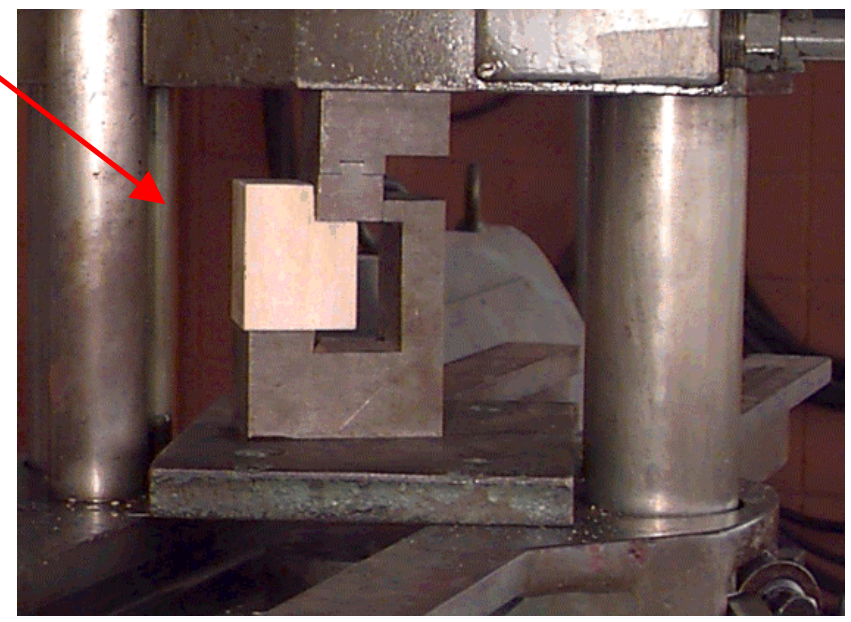

c)

FIGURA 65 - Ensaio de cisalhamento: a) máquina universal, b) corpo-de-prova e c) instalação para o ensaio.

\subsection{ANÁLISE ESTATÍSTICA}

Para a análise estatística foram usados três procedimentos: a análise de regressão, linear simples ou múltipla; um teste de significância, conhecido por "pairing"; e o teste de Tukey.

A análise de regressão, bem apresentada e discutida por FONSECA et al. (1976) e DRAPER \& SMITH (1981), foi utilizada no ajuste dos dados experimentais ao modelo especificado. Inicialmente os dados foram ajustados ao modelo que deu origem à proposta da NBR 7190/97 e como este modelo apresentou bom ajuste não foram testados outros modelos, tendo em vista que o objetivo do trabalho foi aferir o modelo proposto pela NBR 7190.

O modelo que deu origem à proposta da atual norma brasileira NBR 7190/97 é apresentado em seguida: 
$\mathrm{f}_{12}=\mathrm{f}_{\mathrm{U} \%} \cdot\left[1+\frac{\alpha \cdot(\mathrm{U} \%-12)}{100}\right]$

Onde:

$\mathrm{f}_{12}=$ resistência a um teor de umidade de $12 \%$;

$\mathrm{f}_{\mathrm{U} \%}=$ resistência a um teor de umidade de $\mathrm{U} \%$;

$\mathrm{U} \%=$ teor de umidade da madeira, em \%, e

$\alpha=$ coeficiente de correção. A NBR 7190/97 adota $\alpha=3$ para a correção da resistência e $\alpha=2$ para correção do módulo de elasticidade.

Linearizando o modelo apresentado na eq. (35), obtém-se:

$$
\frac{\mathrm{f}_{12}-\mathrm{f}_{\mathrm{U} \%}}{\mathrm{f}_{\mathrm{U} \%}}=\alpha \cdot \frac{\mathrm{U} \%-12}{100}
$$

A eq. (36) representa um modelo para regressão linear simples, que passa pela origem do sistema, nas variáveis:

$$
\mathrm{Y}=\frac{\mathrm{f}_{12}-\mathrm{f}_{\mathrm{U} \%}}{\mathrm{f}_{\mathrm{U} \%}} \quad \text { e } \quad X=\frac{\mathrm{U} \%-12}{100}
$$

Esta regressão linear é de execução muito simples e pode ser feita diretamente em um aplicativo de planilha eletrônica como o Microsoft Excel. Entretanto, o valor de $\mathrm{f}_{12}$ deve ser estimado, pois não se tem garantia de que os resultados dos ensaios forneçam este valor.

Por outro lado, os resultados dos ensaios certamente fornecerão valores próximos a $f_{12}$. Considerando que a curva resistência-umidade é suave e pode ser substituída por linhas retas em pequenos intervalos de umidade, pode-se estimar $\mathrm{f}_{12}$ por interpolação linear de dois resultados do ensaio, com teor de umidade próximo a $12 \%$.

Este procedimento, que também pode ser utilizado para as relações rigidez-umidade e densidade-umidade, fornecerá novos valores para o coeficiente $\alpha$ (a NBR 7190 adota: $\alpha=3$, para a resistência; e $\alpha=2$, para a rigidez). Caso os valores de $\alpha$, obtidos nas diversas espécies e formas de solicitação, sejam próximos pode-se verificar o modelo com coeficiente único, caracterizado pela média dos valores obtidos. 
Conforme o tipo de verificação que se pretende realizar, pode-se utilizar o teste de Tukey ou o teste de "pairing".

O Teste de Tukey, bem apresentado e discutido por GOMES (1982), é utilizado para a comparação de múltiplas médias. Por exemplo, para verificar se dois ou mais modelos, conduzem a um mesmo valor médio de $\mathrm{f}_{12}$.

Este teste será utilizado, no intervalo de umidade entre $10 \%$ e $20 \%$, para verificar se o modelo que deu origem ao proposto pela NBR 7190/97, com um coeficiente único $\alpha=3$ (ou

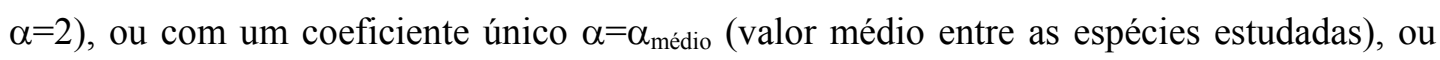
com o coeficiente obtido na regressão de cada caso $\alpha=\alpha_{\text {reg. }}$, conduzem ao valor médio, obtido experimentalmente, de $\mathrm{f}_{12}$. Um programa estatístico será utilizado para fazer este teste, no caso o Statigraphics (Statistical Graphics System), versão 5.0.

O teste de "pairing", utilizado por LAHR (1983), permite a comparação de pares emparelhados, verificando se a média dos desvios pode ser admitida como nula. Por exemplo, para comparar se os dados experimentais se ajustam a um modelo previamente definido.

Este teste ganha mais consistência se utilizado em conjunto com o teste dos desvios, bem apresentado por DRAPER \& SMITH (1981), que verifica se os desvios não apresentam tendenciosidade. O teste de "pairing", associado ao teste dos desvios, será utilizado para verificar se a expressão para obtenção do módulo de elasticidade longitudinal, proposta pela NBR 7190/97, fornece resultado equivalente ao obtido por regressão linear, dos resultados experimentais, no intervalo entre $10 \%$ e $50 \%$ da resistência à compressão. A aplicação deste teste é muito simples e, embora necessite a consulta a uma tabela estatística, pode ser feita em um aplicativo de planilha eletrônica como o Microsoft Excel. 


\section{RESULTADOS E DISCUSSÃO}

\subsection{ENSAIOS DE COMPRESSÃO PARALELA}

\subsubsection{PINUS BAHAMENSIS}

Os ensaios foram realizados em conformidade com a NBR 7190/97 a medida que o corpo-de-prova, em processo de secagem, apresentasse uma estimativa de umidade de interesse para o estudo.

A figura 66, apresenta a planilha de acompanhamento de um destes ensaios. No caso para o corpo-de-prova BAH-16.

O método de ensaio prevê dois ciclos iniciais, com 50\% da carga de ruptura estimada, a fim de ajustar o equipamento de ensaio, e um ciclo final, levado até a ruptura, do qual são obtidos os resultados do ensaio. A estimativa da carga de ruptura, na realidade uma subestimativa, foi obtida de ensaio anterior com maior teor de umidade. Um corpo-de-prova extra foi providenciado para obter esta estimativa para o primeiro corpo-de-prova ensaiado.

A norma brasileira NBR 7190/97 recomenda que, para determinação do módulo de elasticidade, os diagramas tensão x deformação específicas sejam todos construídos. Isto foi feito e, para o corpo-de-prova, cuja folha de acompanhamento é apresentada na figura 66, este diagrama é apresentado na figura 67. Pode-se notar que os resultados experimentais se ajustam razoavelmente bem à expressão para cálculo do módulo de elasticidade, apresentada na planilha da figura 66. Nota-se, também, o acerto do método em realizar dois ciclos iniciais para o ajuste do equipamento.

Uma estimativa, provavelmente mais precisa, do módulo de elasticidade pode ser obtida através de uma regressão linear simples, nas variáveis $X=\varepsilon$ e $Y=\sigma$, no trecho entre $10 \%$ e $50 \%$ da carga de ruptura. O módulo de elasticidade será, com este procedimento, o coeficiente angular da reta obtida na regressão. 


\section{UNIVERSIDADE DE SÃO PAULO \\ ESCOLA DE ENGENHARIA DE SÃO CARLOS \\ DEPARTAMENTO DE ENGENHARIA DE ESTRUTURAS \\ LABORATÓRIO DE MADEIRAS E DE ESTRUTURAS DE MADEIRA ENSAIO DE COMPRESSÃO PARALELA ÀS FIBRAS}

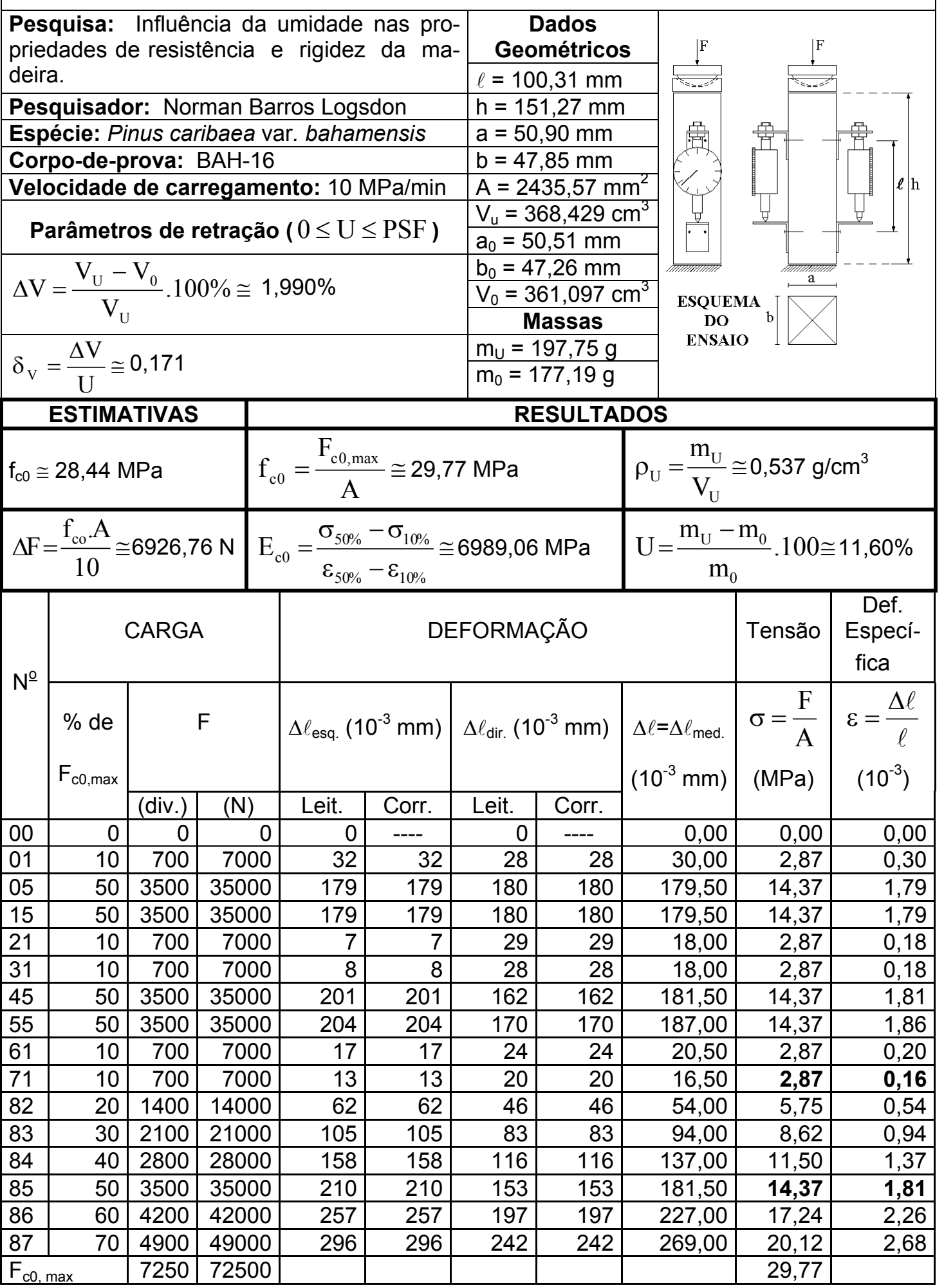

FIGURA 66 - Planilha para acompanhamento do ensaio de compressão paralela às fibras. 


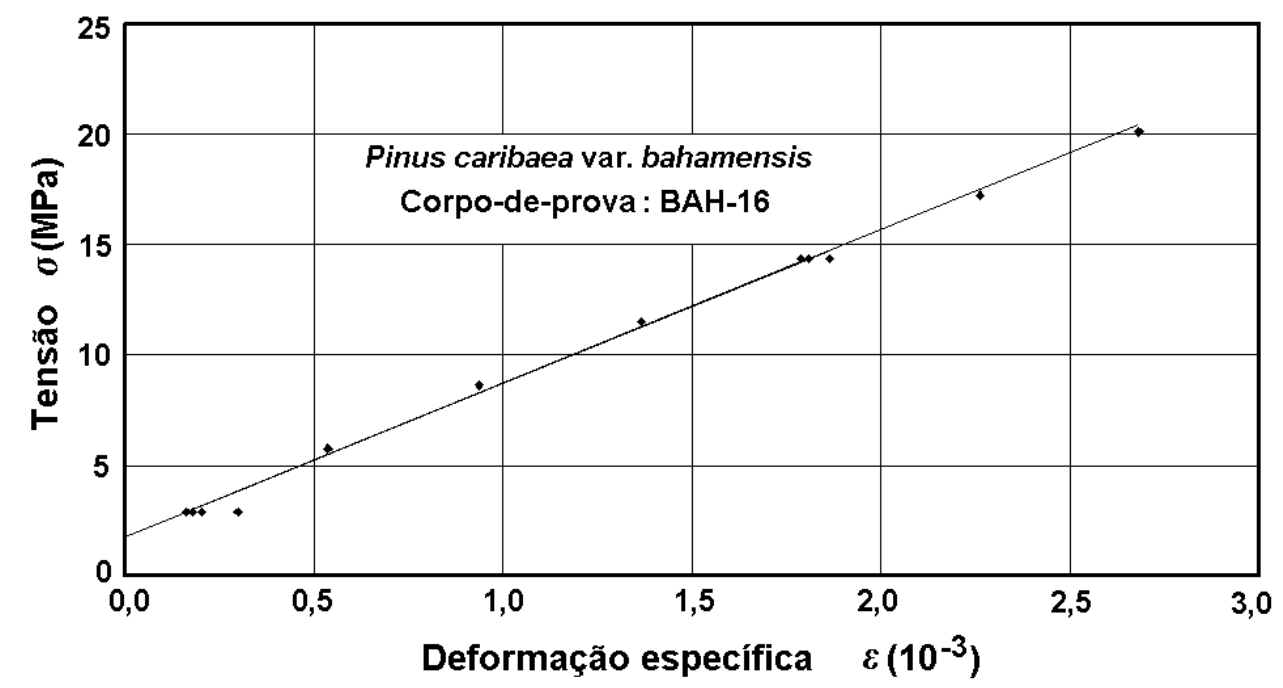

FIGURA 67 - Diagrama tensão x deformação específica para o corpo-de-prova, cuja folha de ensaio é apresentada na figura 66.

Apresentam-se, nas tabelas 12, 13 e 14, os resultados da regressão linear para o corpo-de-prova, cuja folha de acompanhamento é apresentada na figura 66. Nesta análise utilizou-se o aplicativo Microsoft Excel e alguns de seus resultados, de menor interesse, não foram apresentados.

Estes resultados mostram que o valor do módulo de elasticidade obtido na análise de regressão, $\mathrm{E}_{\mathrm{c} 0}=6972,09 \mathrm{MPa}$, praticamente não difere do obtido pela expressão adotada pela NBR 7190/97, $\mathrm{E}_{\mathrm{c} 0}=6987,06 \mathrm{MPa}$. A diferença observada, do valor obtido pela expressão da NBR 7190 em relação ao obtido pela regressão, é inferior a 1\%.

Os resultados obtidos nos demais ensaios de compressão paralela são apresentados na tabela 15 .

TABELA 12 - Estatística e resumo dos resultados da regressão linear $\sigma=\mathrm{A}+\mathrm{B} . \varepsilon$, para o corpo-de-prova BAH-16.

\begin{tabular}{|c|c|c|c|}
\hline \multicolumn{2}{|c|}{ ESTATÍSTICA DE REGRESSÃO } & \multicolumn{2}{|c|}{ RESUMO DOS RESULTADOS } \\
\hline R múltiplo & 0,999390833 & Função especificada & $\sigma=\mathrm{A}+\mathrm{B} \cdot \varepsilon$ \\
\hline R - Quadrado & 0,998782037 & A & 1,908000896 \\
\hline R - Quadrado ajustado & 0,998376050 & $\mathrm{~B} \quad\left(\mathrm{E}_{\mathrm{c} 0}, \mathrm{em} \mathrm{MPa}\right)$ & 6972,093739 \\
\hline Erro padrão & 0,183127963 & $\mathrm{R}^{2}$ & 0,998782037 \\
\hline Observações & 5 & Nível de significância & $1,80467.10^{-5}$ \\
\hline
\end{tabular}


TABELA 13 - Análise de variância da regressão linear $\sigma=\mathrm{A}+\mathrm{B} . \varepsilon$, para o corpo-de-prova BAH-16.

\begin{tabular}{lccccr}
\hline \multicolumn{5}{c}{ ANOVA - ANÁLISE DE VARIÂNCIA } \\
\hline & GL & SQ & MQ & F & F de significação \\
\hline Regressão & 1 & 82,50254664 & 82,50254664 & 2460,129808 & $1,80467.10^{-5}$ \\
Resíduo & 3 & 0,100607553 & 0,033535851 & & \\
Total & 4 & 82,60315419 & & & \\
\hline
\end{tabular}

TABELA 14 - Coeficientes obtidos para a regressão linear $\sigma=\mathrm{A}+\mathrm{B} . \varepsilon$, do corpo-de-prova BAH-16.

\begin{tabular}{lcccc}
\hline \multicolumn{4}{l}{ COEFICIENTES DA REGRESSÃO LINEAR SIMPLES } \\
\hline & \multirow{2}{*}{ Coeficientes } & Erro padrão & \multicolumn{2}{l}{ Intervalo de confiança para os coeficientes } \\
\cline { 4 - 5 } & & & Inferior 95,0\% & \multicolumn{1}{c}{ Superior 95,0\% } \\
\hline Interseção & 1,908000896 & 0,158214277 & 1,404491981 & 2,41150981 \\
Variável X1 & 6972,093739 & 140,5672686 & 6524,745534 & 7419,441943 \\
\hline
\end{tabular}

TABELA 15 - Resultados obtidos nos ensaios de compressão paralela às fibras em Pinus caribaea var. bahamensis

\begin{tabular}{|c|c|c|c|c|c|c|}
\hline \multirow{2}{*}{$\begin{array}{c}\text { Corpo } \\
\text { De } \\
\text { Prova }\end{array}$} & \multirow{2}{*}{$\begin{array}{c}\text { Teor } \\
\text { de } \\
\text { umidade }\end{array}$} & \multirow{2}{*}{$\begin{array}{c}\text { Resistência à } \\
\text { compressão } \\
\text { paralela às } \\
\text { fibras }\end{array}$} & \multicolumn{2}{|c|}{$\begin{array}{c}\text { Módulo de elasticidade } \\
\text { Longitudinal }\end{array}$} & \multirow{3}{*}{$\begin{array}{c}\text { Coeficiente } \\
\text { de } \\
\text { retratibi- } \\
\text { lidade vo- } \\
\text { lumétrica } \\
\text { (estimativa) } \\
\delta_{\mathrm{V}}\end{array}$} & \multirow[t]{2}{*}{$\begin{array}{r}\text { Densidade } \\
\text { aparente }\end{array}$} \\
\hline & & & $\begin{array}{c}\text { Utilizando a } \\
\text { expressão da } \\
\text { NBR } 7190\end{array}$ & $\begin{array}{c}\text { Obtido por } \\
\text { regressão } \\
\text { Linear }\end{array}$ & & \\
\hline C. P. & U (\%) & $\mathrm{f}_{\mathrm{c} 0}(\mathrm{MPa})$ & $\mathrm{E}_{\mathrm{c} 0}(\mathrm{MPa})$ & $\mathrm{E}_{\mathrm{c} 0}(\mathrm{MPa})$ & & $\rho\left(\mathrm{g} / \mathrm{cm}^{3}\right)$ \\
\hline BAH - 02 & 207,10 & 13,06 & 3490 & 3488 & --- & 1,149 \\
\hline BAH - 03 & 214,89 & 13,00 & 3495 & 3494 & --- & 1,148 \\
\hline BAH - 04 & 136,13 & 14,59 & 3606 & 3560 & --- & 1,058 \\
\hline BAH - 05 & 98,68 & 13,25 & 3698 & 3676 & --- & 0,902 \\
\hline BAH - 06 & 38,72 & 17,70 & 4618 & 4616 & --- & 0,634 \\
\hline BAH - 07 & 31,45 & 20,19 & 5211 & 5172 & --- & 0,600 \\
\hline BAH - 08 & 48,27 & 15,32 & 4209 & 4161 & --- & 0,687 \\
\hline
\end{tabular}


TABELA 15 - Resultados obtidos nos ensaios de compressão paralela às fibras em Pinus caribaea var. bahamensis - Continuação.

\begin{tabular}{ccccccc}
\hline C. P. & $\mathrm{U}(\%)$ & $\mathrm{f}_{\mathrm{c} 0}(\mathrm{MPa})$ & $\mathrm{E}_{\mathrm{c} 0}(\mathrm{MPa})^{1}$ & $\mathrm{E}_{\mathrm{c} 0}(\mathrm{MPa})^{2}$ & $\delta_{\mathrm{V}}$ & $\rho\left(\mathrm{g} / \mathrm{cm}^{3}\right)$ \\
\hline BAH - 09 & 41,59 & 16,92 & 4806 & 4856 & --- & 0,641 \\
BAH - 10 & 30,99 & 18,00 & 5009 & 5025 & --- & 0,592 \\
BAH - 11 & 27,15 & 18,66 & 5271 & 5240 & 0,288 & 0,585 \\
BAH - 12 & 20,30 & 23,47 & 5959 & 6032 & 0,274 & 0,563 \\
BAH - 13 & 18,61 & 23,57 & 6282 & 6249 & 0,325 & 0,561 \\
BAH - 14 & 15,60 & 25,53 & 6576 & 6635 & 0,624 & 0,551 \\
BAH - 15 & 12,65 & 28,44 & 6873 & 6872 & 0,448 & 0,540 \\
BAH - 16 & 11,60 & 29,77 & 6989 & 6972 & 0,171 & 0,537 \\
BAH - 17 & 10,24 & 31,19 & 7009 & 7027 & 0,163 & 0,531 \\
BAH - 18 & 8,13 & 34,66 & 7018 & 7021 & 0,394 & 0,528 \\
BAH - 19 & 2,73 & 38,84 & 7289 & 7279 & 0,287 & 0,527 \\
BAH - 20 & 2,82 & 49,99 & 9380 & 9414 & 0,258 & 0,517 \\
\hline OBS.
\end{tabular}

OBS.: ${ }^{1}$ Obtido pela expressão da NBR 7190/97

${ }^{2}$ Obtido por regressão linear no trecho de tensões entre $10 \%$ e $50 \%$ de $\mathrm{f}_{\mathrm{c} 0}$

Devido a enorme semelhança, observada na tabela 15 , entre os resultados do módulo de elasticidade longitudinal, um obtido utilizando a expressão fornecida na NBR 7190/97 e outro pela regressão linear, resolveu-se aplicar o teste de "pairing" com o intuito de verificar se estes dois conjuntos de resultados são estatisticamente equivalentes.

Partindo da hipótese nula: " $\mathrm{H}_{0}=$ os dois conjuntos de dados são equivalentes", então: uma nova variável formada pelos desvios, ou seja, pelas diferenças entre dois valores correspondentes, um de cada conjunto, possuirá média nula e a distribuição dos desvios, ao longo do domínio, não apresentará tendenciosidade.

Utilizando-se esta variável, obtém-se:

- Desvios $\rightarrow \mathrm{d}=\mathrm{E}_{\mathrm{c} 0, \mathrm{NBR}}-\mathrm{E}_{\mathrm{c} 0 \text {,reg. }}$

- Número de elementos $\rightarrow \mathrm{n}=19$

- $\quad$ Média dos desvios $\rightarrow \overline{\mathrm{d}}=-0,13 \mathrm{MPa}$

- Desvio padrão $\rightarrow s_{d}=33,4451 M P a$ 
- $\quad$ Erro padrão de estimativa $\rightarrow \frac{s_{d}}{\sqrt{n}}=7,6660 M P a$

- $\quad$ Graus de liberdade $\rightarrow \phi=n-1=18$

- Valor do estatístico $\rightarrow t(\phi, 95 \%)=2,101$ (extraído de tabela apropriada)

- Intervalo de confiança da média $\rightarrow$

$$
\bar{d}-t(\phi, 95 \%) \cdot \frac{s_{d}}{\sqrt{n}} \leq \mu_{d} \leq \bar{d}+t(\phi, 95 \%) \cdot \frac{s_{d}}{\sqrt{n}} \Rightarrow-16,2370 \leq \mu_{d} \leq 15,9754
$$

Onde:

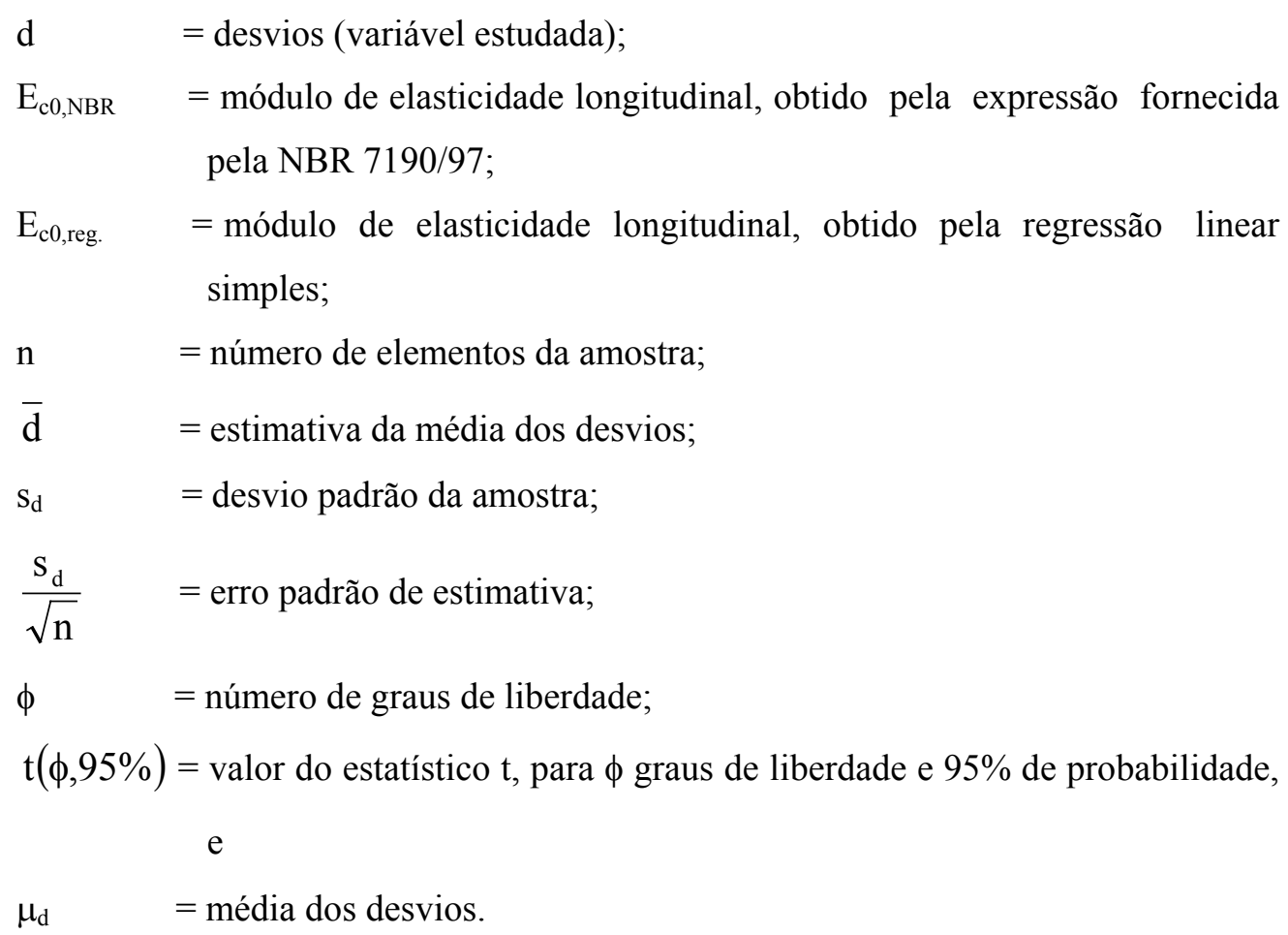

Considerando que o intervalo de confiança da média, eq. (35), contém o zero, portanto a média pode ser nula e o diagrama dos desvios, apresentado na figura 68 , não apresenta tendenciosidade. Conclui-se pela hipótese nula, ou seja, os dois conjuntos de dados são estatisticamente equivalentes.

Na continuidade do trabalho será utilizado o módulo de elasticidade longitudinal obtido pela expressão fornecida pela NBR 7190/97, visto que neste trabalho se procura aferir o modelo proposto pela atual norma brasileira. A menos, é claro, que o resultado da aplicação deste teste às outras espécies, utilizadas no trabalho, o desautorize. 


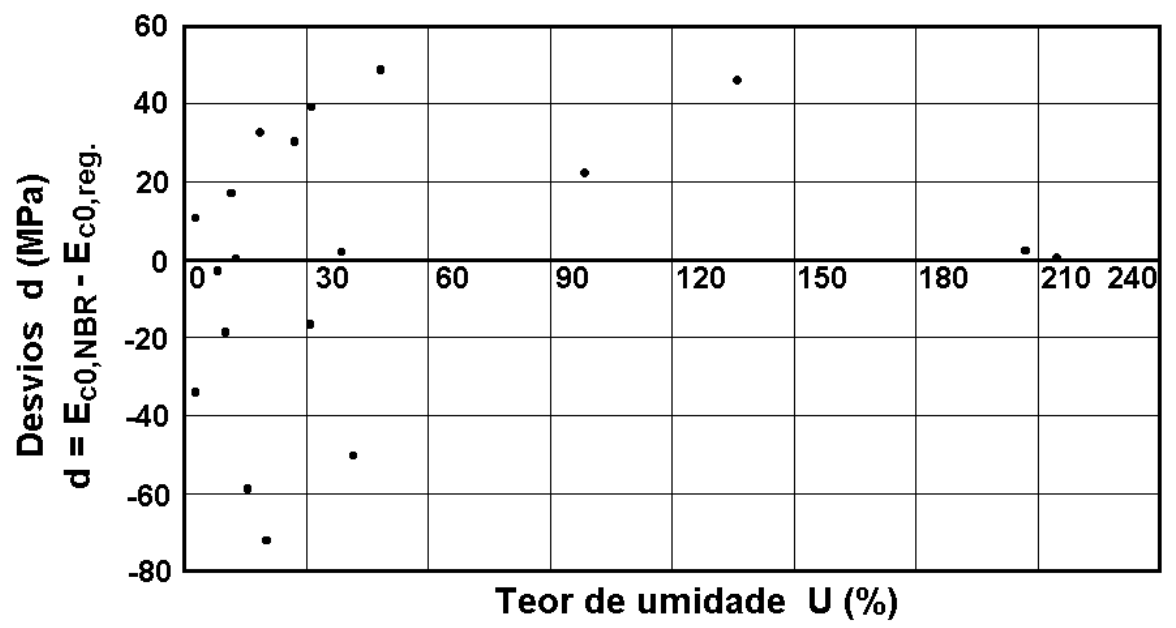

FIGURA 68 - Diagrama de desvios

\subsubsection{PINUS ELLIOTTII}

O mesmo procedimento utilizado para o Pinus bahamensis foi adotado para o Pinus elliottii e forneceu os resultados apresentados, resumidamente, a seguir.

TABELA 16 - Resultados obtidos nos ensaios de compressão paralela às fibras em Pinus elliottii

\begin{tabular}{ccccccc}
\hline C. P. & $\mathrm{U}(\%)$ & $\mathrm{f}_{\mathrm{c} 0}(\mathrm{MPa})$ & $\mathrm{E}_{\mathrm{c} 0}(\mathrm{MPa})^{1}$ & $\mathrm{E}_{\mathrm{c} 0}(\mathrm{MPa})^{2}$ & $\delta_{\mathrm{V}}$ & $\rho\left(\mathrm{g} / \mathrm{cm}^{3}\right)$ \\
\hline ELL - 02 & 97,35 & 18,64 & 6003 & 5969 & --- & 0,915 \\
ELL - 03 & 112,51 & 18,31 & 5825 & 5760 & --- & 0,992 \\
ELL - 04 & 121,87 & 19,40 & 6120 & 6155 & --- & 1,037 \\
ELL - 05 & 67,91 & 16,90 & 6778 & 6734 & --- & 0,788 \\
ELL - 06 & 26,26 & 25,78 & 8615 & 8720 & --- & 0,590 \\
ELL - 07 & 36,08 & 21,52 & 7698 & 7577 & --- & 0,627 \\
ELL - 08 & 55,17 & 18,91 & 7053 & 6968 & --- & 0,720 \\
ELL - 09 & 33,99 & 21,82 & 7834 & 7788 & --- & 0,634 \\
ELL - 10 & 24,35 & 27,05 & 8534 & 8587 & --- & 0,588 \\
ELL - 11 & 22,23 & 28,67 & 8952 & 9036 & --- & 0,586 \\
ELL - 12 & 19,64 & 33,03 & 10285 & 10269 & 0,284 & 0,586 \\
ELL - 13 & 18,91 & 32,40 & 10059 & 10160 & 0,351 & 0,581 \\
ELL - 14 & 18,09 & 34,46 & 10472 & 10499 & 0,309 & 0,580 \\
ELL - 15 & 17,73 & 33,51 & 10239 & 10180 & 0,307 & 0,577
\end{tabular}


TABELA 16 - Resultados obtidos nos ensaios de compressão paralela às fibras em Pinus elliottii - Continuação

\begin{tabular}{ccccccc}
\hline C. P. & $\mathrm{U}(\%)$ & $\mathrm{f}_{\mathrm{c} 0}(\mathrm{MPa})$ & $\mathrm{E}_{\mathrm{c} 0}(\mathrm{MPa})^{1}$ & $\mathrm{E}_{\mathrm{c} 0}(\mathrm{MPa})^{2}$ & $\delta_{\mathrm{V}}$ & $\rho\left(\mathrm{g} / \mathrm{cm}^{3}\right)$ \\
\hline ELL - 16 & 15,28 & 36,81 & 10983 & 10913 & 0,270 & 0,570 \\
ELL - 17 & 12,66 & 40,43 & 11600 & 11800 & 0,246 & 0,561 \\
ELL - 18 & 9,64 & 46,36 & 12198 & 12299 & 0,294 & 0,551 \\
ELL - 19 & 4,78 & 51,07 & 11822 & 12022 & 0,990 & 0,522 \\
ELL - 20 & 3,44 & 54,30 & 12719 & 12605 & 0,118 & 0,552 \\
ELL - 21 & 3,20 & 62,04 & 10966 & 10910 & 0,352 & 0,527 \\
ELL - 22 & 4,40 & 59,36 & 12019 & 11940 & 0,041 & 0,567 \\
\hline
\end{tabular}

OBS.: ${ }^{1}$ Obtido pela expressão da NBR 7190/97

${ }^{2}$ Obtido por regressão linear no trecho de tensões entre $10 \%$ e $50 \%$ de $\mathrm{f}_{\mathrm{c} 0}$

O teste "pairing", comparando os dois módulos de elasticidade apresentados na tabela 16 , fornece, para a média dos desvios $\mu_{\mathrm{d}}$, o intervalo apresentado na eq. (36), que contém o zero. $\mathrm{O}$ correspondente teste de desvios não apresenta tendenciosidade, permitindo aceitar a equivalência estatística entre os dois conjuntos de dados.

$$
-49,3068 \leq \mu_{\mathrm{d}} \leq 38,3642
$$

\subsubsection{PINUS TAEDA}

O mesmo procedimento utilizado para o Pinus bahamensis foi adotado para o Pinus taeda e forneceu os resultados apresentados, resumidamente, a seguir.

TABELA 17 - Resultados obtidos nos ensaios de compressão paralela às fibras em Pinus taeda

\begin{tabular}{ccccccc}
\hline C. P. & $\mathrm{U}(\%)$ & $\mathrm{f}_{\mathrm{c} 0}(\mathrm{MPa})$ & $\mathrm{E}_{\mathrm{c} 0}(\mathrm{MPa})^{1}$ & $\mathrm{E}_{\mathrm{c} 0}(\mathrm{MPa})^{2}$ & $\delta_{\mathrm{V}}$ & $\rho\left(\mathrm{g} / \mathrm{cm}^{3}\right)$ \\
\hline TDA - 01 & 78,54 & 23,94 & 10090 & 9959 & --- & 0,979 \\
TDA - 02 & 53,72 & 24,34 & 9850 & 9935 & --- & 0,876 \\
TDA - 03 & 47,37 & 26,70 & 10054 & 10040 & --- & 0,808 \\
TDA - 04 & 48,53 & 20,10 & 10075 & 9965 & --- & 0,800
\end{tabular}


TABELA 17 - Resultados obtidos nos ensaios de compressão paralela às fibras em Pinus ta$e d a$ - Continuação.

\begin{tabular}{|c|c|c|c|c|c|c|}
\hline C. P. & $\mathrm{U}(\%)$ & $\mathrm{f}_{\mathrm{c} 0}(\mathrm{MPa})$ & $\mathrm{E}_{\mathrm{c} 0}(\mathrm{MPa})^{1}$ & $\mathrm{E}_{\mathrm{c} 0}(\mathrm{MPa})^{2}$ & $\delta_{\mathrm{V}}$ & $\rho\left(\mathrm{g} / \mathrm{cm}^{3}\right)$ \\
\hline TDA - 05 & 27,52 & 31,19 & 10510 & 10626 & 0,342 & 0,685 \\
\hline TDA - 06 & 19,22 & 37,78 & 11663 & 11791 & 0,469 & 0,678 \\
\hline TDA - 07 & 20,50 & 33,00 & 11444 & 11459 & 0,459 & 0,693 \\
\hline TDA - 08 & 20,72 & 35,18 & 11627 & 11562 & 0,469 & 0,671 \\
\hline TDA - 09 & 19,51 & 35,74 & 11072 & 10926 & 0,422 & 0,679 \\
\hline TDA - 10 & 14,01 & 42,80 & 12778 & 12787 & 0,476 & 0,659 \\
\hline TDA - 11 & 11,51 & 46,51 & 13690 & 13641 & 0,245 & 0,650 \\
\hline TDA - 12 & 11,33 & 47,69 & 14070 & 13892 & 0,358 & 0,649 \\
\hline TDA - 13 & 10,75 & 48,83 & 13720 & 13501 & 0,468 & 0,649 \\
\hline TDA - 14 & 10,77 & 46,72 & 13665 & 13614 & 0,409 & 0,647 \\
\hline TDA - 15 & 4,62 & 62,41 & 15738 & 15962 & 0,288 & 0,617 \\
\hline TDA - 16 & 4,48 & 60,58 & 17488 & 17574 & 0,262 & 0,632 \\
\hline TDA - 17 & 3,05 & 62,28 & 15722 & 15800 & --- & 0,649 \\
\hline TDA - 18 & 3,56 & 68,35 & 16432 & 16372 & 0,030 & 0,637 \\
\hline TDA - 19 & 2,52 & 90,12 & 15476 & 15520 & --- & 0,611 \\
\hline TDA - 20 & 1,96 & 73,24 & 15050 & 15031 & --- & 0,637 \\
\hline
\end{tabular}

OBS.: A ruptura dos corpos-de-prova TDA-17, TDA-19 e TDA-20 foi frágil. Os corpos-deprova "explodiram" e praticamente se desagregaram. Isto impediu que as dimensões secas, destes corpos-de-prova, fossem obtidas, mas não a massa. A carga de ruptura exigida pelo corpo-de-prova TDA-19, se fossem mantidas as dimensões iniciais, superaria a capacidade da máquina universal de ensaios. Foi necessário diminuir a área da seção transversal deste corpo-de-prova (aproximadamente dois milímetros em duas das faces).

1 Obtido pela expressão da NBR 7190/97

${ }^{2}$ Obtido por regressão linear no trecho de tensões entre $10 \%$ e $50 \%$ de $\mathrm{f}_{\mathrm{c} 0}$

O teste "pairing", comparando os dois módulos de elasticidade apresentados na tabela 17 , fornece, para a média dos desvios $\mu_{\mathrm{d}}$, o intervalo apresentado na eq. (37), que contém o zero. $\mathrm{O}$ correspondente teste de desvios não apresenta tendenciosidade, permitindo aceitar a equivalência estatística entre os dois conjuntos de dados. 


\subsubsection{EUCALIPTO GRANDIS}

O mesmo procedimento utilizado para o Pinus bahamensis foi adotado para o Eucalipto grandis e forneceu os resultados apresentados, resumidamente, a seguir.

TABELA 18 - Resultados obtidos nos ensaios de compressão paralela às fibras em Eucalyptus grandis

\begin{tabular}{|c|c|c|c|c|c|c|}
\hline C. P. & $\mathrm{U}(\%)$ & $\mathrm{f}_{\mathrm{c} 0}(\mathrm{MPa})$ & $\mathrm{E}_{\mathrm{c} 0}(\mathrm{MPa})^{1}$ & $\mathrm{E}_{\mathrm{c} 0}(\mathrm{MPa})^{2}$ & $\delta_{\mathrm{V}}$ & $\rho\left(\mathrm{g} / \mathrm{cm}^{3}\right)$ \\
\hline GDR-01 & 79,40 & 26,12 & 9770 & 9921 & --- & 0,919 \\
\hline GDR-02 & 57,92 & 28,28 & 9905 & 9908 & --- & 0,876 \\
\hline GDR-03 & 44,30 & 30,49 & 9907 & 9755 & --- & 0,820 \\
\hline GDR-04 & 43,55 & 26,69 & 10182 & 10179 & --- & 0,794 \\
\hline GDR-05 & 37,24 & 30,12 & 10009 & 10181 & --- & 0,782 \\
\hline GDR-06 & 28,28 & 31,87 & 10203 & 10101 & --- & 0,724 \\
\hline GDR-07 & 16,93 & 36,33 & 11595 & 11637 & 0,398 & 0,683 \\
\hline GDR-08 & 19,48 & 34,65 & 11266 & 11214 & 0,409 & 0,692 \\
\hline GDR-09 & 16,29 & 35,53 & 11862 & 11746 & 0,426 & 0,679 \\
\hline GDR-10 & 15,37 & 37,16 & 11684 & 11727 & 0,465 & 0,674 \\
\hline GDR-11 & 14,30 & 39,54 & 12297 & 12120 & 0,512 & 0,673 \\
\hline GDR-12 & 14,93 & 39,02 & 12209 & 12221 & 0,502 & 0,674 \\
\hline GDR-13 & 14,88 & 38,87 & 12194 & 12270 & 0,461 & 0,675 \\
\hline GDR-14 & 15,43 & 39,31 & 11865 & 11887 & 0,320 & 0,679 \\
\hline GDR-15 & 12,98 & 41,28 & 12648 & 12546 & 0,521 & 0,668 \\
\hline GDR-16 & 7,87 & 49,96 & 14315 & 14158 & 0,408 & 0,656 \\
\hline GDR-17 & 7,37 & 48,69 & 13288 & 13145 & 0,392 & 0,631 \\
\hline GDR-18 & 6,22 & 55,19 & 13989 & 14021 & 0,352 & 0,658 \\
\hline GDR-19 & 8,78 & 46,67 & 14015 & 13839 & 0,416 & 0,667 \\
\hline GDR-20 & 2,59 & 64,23 & 13562 & 13508 & & 0,651 \\
\hline GDR-21 & 0,22 & 71,50 & 13277 & 13160 & & 0,631 \\
\hline
\end{tabular}

OBS.: A ruptura dos corpos-de-prova GRD-20 e GRD-21 foi frágil. Os corpos-de-prova "explodiram" e praticamente se desagregaram. Isto impediu que as dimensões secas, destes corpos-de-prova, fossem obtidas, mas não a massa.

${ }^{1}$ Obtido pela expressão da NBR 7190/97

${ }^{2}$ Obtido por regressão linear no trecho de tensões entre $10 \%$ e $50 \%$ de $\mathrm{f}_{\mathrm{c} 0}$ 
O teste "pairing", comparando os dois módulos de elasticidade apresentados na tabela 18 , fornece, para a média dos desvios $\mu_{\mathrm{d}}$, o intervalo apresentado na eq. (38), que contém o zero. O correspondente teste de desvios não apresenta tendenciosidade, permitindo aceitar a equivalência estatística entre os dois conjuntos de dados.

$$
-9,4691 \leq \mu_{d} \leq 85,3624
$$

\subsubsection{CUPIÚBA}

O mesmo procedimento utilizado para o Pinus bahamensis foi adotado para a Cupiúba e forneceu os resultados apresentados, resumidamente, a seguir.

TABELA 19 - Resultados obtidos nos ensaios de compressão paralela às fibras em Goupia

\begin{tabular}{ccccccc}
\multicolumn{7}{c}{ glabra } \\
\hline C. P. & $\mathrm{U}(\%)$ & $\mathrm{f}_{\mathrm{c} 0}(\mathrm{MPa})$ & $\mathrm{E}_{\mathrm{c} 0}(\mathrm{MPa})^{1}$ & $\mathrm{E}_{\mathrm{c} 0}(\mathrm{MPa})^{2}$ & $\delta_{\mathrm{V}}$ & $\rho\left(\mathrm{g} / \mathrm{cm}^{3}\right)$ \\
\hline CUP - 01 & 48,93 & 37,44 & 10396 & 10380 & --- & 1,003 \\
CUP - 02 & 35,29 & 41,27 & 10490 & 10426 & --- & 0,930 \\
CUP - 03 & 30,26 & 41,28 & 10588 & 10462 & --- & 0,873 \\
CUP - 04 & 30,65 & 40,12 & 10431 & 10515 & --- & 0,884 \\
CUP - 05 & 24,31 & 40,17 & 10883 & 10668 & 0,366 & 0,853 \\
CUP - 06 & 18,85 & 43,34 & 12054 & 11811 & 0,556 & 0,814 \\
CUP - 07 & 18,41 & 44,32 & 12324 & 12474 & 0,485 & 0,821 \\
CUP - 08 & 19,89 & 42,06 & 11925 & 11950 & 0,488 & 0,825 \\
CUP - 09 & 13,00 & 51,57 & 14117 & 14260 & 0,401 & 0,805 \\
CUP - 10 & 10,26 & 56,50 & 15199 & 15365 & 0,284 & 0,797 \\
CUP - 11 & 13,67 & 50,03 & 13924 & 14081 & 0,320 & 0,815 \\
CUP - 12 & 11,79 & 53,80 & 14547 & 14494 & 0,420 & 0,801 \\
CUP - 13 & 9,40 & 61,73 & 15450 & 15357 & 0,580 & 0,801 \\
CUP - 15 & 5,12 & 68,47 & 17123 & 17088 & 0,889 & 0,763 \\
CUP - 16 & 8,90 & 58,22 & 15724 & 15716 & 0,425 & 0,804 \\
CUP - 17 & 6,07 & 64,92 & 16640 & 16804 & 0,266 & 0,799 \\
CUP - 18 & 5,90 & 88,71 & 17516 & 17713 & 0,219 & 0,786
\end{tabular}


TABELA 19 - Resultados obtidos nos ensaios de compressão paralela às fibras em Goupia glabra - Continuação

\begin{tabular}{ccccccc}
\hline C. P. & $\mathrm{U}(\%)$ & $\mathrm{f}_{\mathrm{c} 0}(\mathrm{MPa})$ & $\mathrm{E}_{\mathrm{c} 0}(\mathrm{MPa})^{1}$ & $\mathrm{E}_{\mathrm{c} 0}(\mathrm{MPa})^{2}$ & $\delta_{\mathrm{V}}$ & $\rho\left(\mathrm{g} / \mathrm{cm}^{3}\right)$ \\
\hline CUP - 19 & 2,18 & 85,20 & 16008 & 15825 & 0,305 & 0,754 \\
CUP - 20 & 2,85 & 76,94 & 15041 & 15110 & 0,102 & 0,789 \\
\hline
\end{tabular}

OBS.: O corpo-de-prova CUP-14, sofreu um pequeno empenamento, durante o processo de secagem, e apresentou a base ligeiramente retorcida. A forma defeituosa desse corpo-deprova causou sua ruptura na base, por excentricidade de carregamento. Os resultados desse ensaio foram abandonados.

${ }^{1}$ Obtido pela expressão da NBR 7190/97

${ }^{2}$ Obtido por regressão linear no trecho de tensões entre $10 \%$ e $50 \%$ de $\mathrm{f}_{\mathrm{c} 0}$

O teste "pairing", comparando os dois módulos de elasticidade apresentados na tabela 19 , fornece, para a média dos desvios $\mu_{\mathrm{d}}$, o intervalo apresentado na eq. (39), que contém o zero. O correspondente teste de desvios não apresenta tendenciosidade, permitindo aceitar a equivalência estatística entre os dois conjuntos de dados.

$$
-72,9605 \leq \mu_{d} \leq 60,3076
$$

\subsubsection{EUCALIPTO CITRIODORA}

O mesmo procedimento utilizado para o Pinus bahamensis foi adotado para o Eucalipto citriodora e forneceu os resultados apresentados, resumidamente, a seguir.

TABELA 20 - Resultados obtidos nos ensaios de compressão paralela às fibras em Eucalyptus citriodora

\begin{tabular}{ccccccc}
\hline C. P. & $\mathrm{U}(\%)$ & $\mathrm{f}_{\mathrm{c} 0}(\mathrm{MPa})$ & $\mathrm{E}_{\mathrm{c} 0}(\mathrm{MPa})^{1}$ & $\mathrm{E}_{\mathrm{c} 0}(\mathrm{MPa})^{2}$ & $\delta_{\mathrm{V}}$ & $\rho\left(\mathrm{g} / \mathrm{cm}^{3}\right)$ \\
\hline CIT - 01 & 29,42 & 53,08 & 15042 & 14981 & --- & 1,035 \\
CIT - 02 & 21,92 & 53,03 & 15356 & 15224 & 0,243 & 0,976 \\
CIT - 03 & 20,56 & 53,49 & 15248 & 15167 & 0,522 & 0,977 \\
CIT - 04 & 19,58 & 53,65 & 14982 & 14890 & 0,567 & 0,966 \\
CIT - 05 & 21,65 & 54,30 & 15091 & 14938 & 0,375 & 0,982 \\
CIT - 06 & 20,45 & 53,36 & 14883 & 14860 & 0,448 & 0,972
\end{tabular}


TABELA 20 - Resultados obtidos nos ensaios de compressão paralela às fibras em Eucalyptus citriodora - Continuação.

\begin{tabular}{ccccccc}
\hline C. P. & $\mathrm{U}(\%)$ & $\mathrm{f}_{\mathrm{c} 0}(\mathrm{MPa})$ & $\mathrm{E}_{\mathrm{c} 0}(\mathrm{MPa})$ & $\mathrm{E}_{\mathrm{c} 0}(\mathrm{MPa})^{2}$ & $\delta_{\mathrm{V}}$ & $\rho\left(\mathrm{g} / \mathrm{cm}^{3}\right)$ \\
\hline CIT - 07 & 18,10 & 53,30 & 15215 & 15083 & 0,567 & 0,966 \\
CIT - 08 & 15,80 & 58,10 & 16216 & 16298 & 0,531 & 0,963 \\
CIT - 09 & 17,19 & 55,83 & 15848 & 15812 & 0,556 & 0,963 \\
CIT - 10 & 22,20 & 54,00 & 15037 & 15227 & 0,335 & 0,980 \\
CIT - 11 & 16,32 & 56,09 & 15822 & 15929 & 0,568 & 0,961 \\
CIT - 12 & 13,74 & 61,71 & 17222 & 17324 & 0,538 & 0,960 \\
CIT - 13 & 10,97 & 67,43 & 18453 & 18522 & 0,362 & 0,955 \\
CIT - 14 & 16,58 & 58,10 & 15950 & 15987 & 0,492 & 0,962 \\
CIT - 15 & 9,53 & 70,99 & 19876 & 19741 & 0,399 & 0,947 \\
CIT - 16 & 5,22 & 79,24 & 22424 & 22551 & 0,487 & 0,942 \\
CIT - 17 & 4,92 & 77,81 & 21562 & 21492 & 0,698 & 0,953 \\
CIT - 18 & 7,38 & 78,14 & 21050 & 20895 & 0,424 & 0,956 \\
CIT - 19 & 5,60 & 82,86 & 22313 & 22376 & 0,205 & 0,946 \\
CIT - 20 & 4,89 & 84,64 & 22049 & 22149 & 0,501 & 0,943 \\
\hline
\end{tabular}

OBS.: ${ }^{1}$ Obtido pela expressão da NBR 7190/97

${ }^{2}$ Obtido por regressão linear no trecho de tensões entre $10 \%$ e $50 \%$ de $\mathrm{f}_{\mathrm{c} 0}$

O teste "pairing", comparando os dois módulos de elasticidade apresentados na tabela 20 , fornece, para a média dos desvios $\mu_{\mathrm{d}}$, o intervalo apresentado na eq. (40), que contém o zero. O correspondente teste de desvios não apresenta tendenciosidade, permitindo aceitar a equivalência estatística entre os dois conjuntos de dados.

$$
-41,2889 \leq \mu_{d} \leq 60,4512
$$

\subsubsection{JATOBÁ}

O mesmo procedimento utilizado para o Pinus bahamensis foi adotado para o Jatobá e forneceu os resultados apresentados, resumidamente, a seguir. 
TABELA 21 - Resultados obtidos nos ensaios de compressão paralela às fibras em Hymenaea stilbocarpa

\begin{tabular}{|c|c|c|c|c|c|c|}
\hline C. P. & U (\%) & $\mathrm{f}_{\mathrm{c} 0}(\mathrm{MPa})$ & $\mathrm{E}_{\mathrm{c} 0}(\mathrm{MPa})^{1}$ & $\mathrm{E}_{\mathrm{c} 0}(\mathrm{MPa})^{2}$ & $\delta_{\mathrm{V}}$ & $\rho\left(\mathrm{g} / \mathrm{cm}^{3}\right)$ \\
\hline JAT - 01 & 37,58 & 58,41 & 20795 & 20837 & --- & 1,207 \\
\hline JAT - 02 & 29,45 & 65,46 & 21052 & 20838 & --- & 1,102 \\
\hline JAT - 03 & 21,95 & 65,44 & 21018 & 21046 & 0,479 & 1,070 \\
\hline JAT - 04 & 23,31 & 62,35 & 21382 & 21623 & 0,481 & 1,059 \\
\hline JAT - 05 & 19,98 & 67,63 & 21831 & 21727 & 0,481 & 1,045 \\
\hline JAT - 06 & 18,80 & 69,39 & 22363 & 22440 & 0,481 & 1,042 \\
\hline JAT - 07 & 16,39 & 73,79 & 23743 & 23644 & 0,554 & 1,037 \\
\hline JAT - 08 & 14,35 & 78,31 & 25161 & 25254 & 0,491 & 1,035 \\
\hline JAT - 09 & 14,21 & 78,59 & 25156 & 25059 & 0,597 & 1,037 \\
\hline JAT - 10 & 14,43 & 78,26 & 25039 & 24983 & 0,656 & 1,039 \\
\hline JAT - 11 & 10,43 & 88,42 & 27880 & 27917 & 0,341 & 1,034 \\
\hline JAT - 12 & 7,97 & 98,42 & 29172 & 29193 & 0,259 & 1,031 \\
\hline JAT - 13 & 8,09 & 95,24 & 29664 & 29850 & 0,479 & 1,017 \\
\hline JAT - 14 & 9,25 & 97,67 & 28246 & 28147 & --- & 1,026 \\
\hline JAT - 15 & 4,05 & 101,55 & 30633 & 30711 & 0,329 & 1,035 \\
\hline JAT - 16 & 4,37 & 108,06 & 29454 & 29305 & --- & 1,009 \\
\hline JAT - 17 & 2,85 & 115,09 & 28007 & 27818 & --- & 1,033 \\
\hline JAT - 18 & 4,43 & 103,93 & 27020 & 27083 & --- & 1,024 \\
\hline JAT - 19 & 2,83 & 112,60 & 28811 & 28785 & --- & 1,009 \\
\hline JAT - 20 & 3,53 & 106,76 & 28397 & 28201 & --- & 1,018 \\
\hline
\end{tabular}

OBS.: A carga de ruptura exigida pelos corpos-de-prova JAT-14, JAT-16, JAT-17, JAT-18, JAT-19 e JAT-20, se fossem mantidas as dimensões iniciais, superaria a capacidade da máquina universal de ensaios. Foi necessário diminuir a área da seção transversal destes corposde-prova (aproximadamente dois milímetros em duas das faces).

${ }^{1}$ Obtido pela expressão da NBR 7190/97

${ }^{2}$ Obtido por regressão linear no trecho de tensões entre $10 \%$ e $50 \%$ de $\mathrm{f}_{\mathrm{c} 0}$

O teste "pairing", comparando os dois módulos de elasticidade apresentados na tabela 21 , fornece, para a média dos desvios $\mu_{\mathrm{d}}$, o intervalo apresentado na eq. (41), que contém o zero. O correspondente teste de desvios não apresenta tendenciosidade, permitindo aceitar a equivalência estatística entre os dois conjuntos de dados. 


\subsection{ENSAIOS DE TRAÇÃO PARALELA}

\subsubsection{PINUS BAHAMENSIS}

Os ensaios foram realizados em conformidade com a NBR 7190/97 a medida que o corpo-de-prova, em processo de secagem, apresentasse uma estimativa de umidade de interesse para o estudo.

A figura 69, apresenta a planilha de acompanhamento de um destes ensaios. No caso para o corpo-de-prova BAH-04.

Para melhor fixação do corpo-de-prova, às garras da máquina de ensaio, pequenos pregos foram colocados nas "cabeças" do corpo-de-prova, com o intuito de aumentar o atrito. A massa, correspondente a estes pregos, foi descontada nos cálculos, como se pode perceber na planilha apresentada na figura 69. Os resultados obtidos nos demais ensaios de tração paralela são apresentados na tabela 22.

TABELA 22 - Resultados obtidos nos ensaios de tração paralela às fibras em Pinus caribaea var. bahamensis

\begin{tabular}{ccc}
\hline Corpo-de-prova & Teor de umidade & Resistência à tração paralela às fibras \\
\hline C. P. & $\mathrm{U}(\%)$ & $\mathrm{f}_{\mathrm{t} 0}(\mathrm{MPa})$ \\
\hline BAH - 01 & 105,14 & 34,74 \\
BAH - 02 & 74,22 & 35,11 \\
BAH - 03 & 23,71 & 45,79 \\
BAH - 04 & 17,61 & 53,78 \\
BAH - 05 & 19,14 & 51,76 \\
BAH - 06 & 14,30 & 57,95 \\
BAH - 07 & 4,43 & 48,44 \\
BAH - 08 & 3,36 & 43,79 \\
\hline
\end{tabular}






FIGURA 69 - Planilha para acompanhamento do ensaio de tração paralela às fibras.

\subsubsection{PINUS ELLIOTTII}

O mesmo procedimento utilizado para o Pinus bahamensis foi adotado para o Pinus elliottii e forneceu os resultados apresentados, resumidamente, a seguir.

TABELA 23 - Resultados obtidos nos ensaios de tração paralela às fibras em Pinus elliottii

\begin{tabular}{ccc}
\hline C. $P$. & $\mathrm{U}(\%)$ & $\mathrm{f}_{\mathrm{t} 0}(\mathrm{MPa})$ \\
\hline ELL - 01 & 178,30 & 45,29 \\
ELL - 02 & 74,70 & 45,75 \\
ELL - 03 & 19,67 & 58,07 \\
ELL - 04 & 17,58 & 59,64 \\
ELL - 05 & 11,97 & 67,88 \\
ELL - 06 & 6,11 & --- \\
ELL - 07 & 4,21 & 59,78 \\
ELL - 08 & 1,80 & 50,06
\end{tabular}

OBS.: A ruptura do corpo-de-prova ELL-06 ocorreu fora da região esperada, na "cabeça" do corpo-de-prova, por isto se abandonou o ensaio. 


\subsubsection{PINUS TAEDA}

O mesmo procedimento utilizado para o Pinus bahamensis foi adotado para o Pinus taeda e forneceu os resultados apresentados, resumidamente, a seguir.

TABELA 24 - Resultados obtidos nos ensaios de tração paralela às fibras em Pinus taeda

\begin{tabular}{ccc}
\hline C. $\mathrm{P}$. & $\mathrm{U}(\%)$ & $\mathrm{f}_{\mathrm{t} 0}(\mathrm{MPa})$ \\
\hline TDA - 01 & 75,82 & 59,64 \\
TDA - 02 & 51,43 & 60,47 \\
TDA - 03 & 22,18 & 66,90 \\
TDA - 04 & 19,08 & 70,40 \\
TDA - 05 & 14,79 & 77,42 \\
TDA - 06 & 13,16 & 79,81 \\
TDA - 07 & 6,46 & 85,71 \\
TDA - 08 & 3,00 & 80,85 \\
\hline
\end{tabular}

\subsubsection{EUCALIPTO GRANDIS}

O mesmo procedimento utilizado para o Pinus bahamensis foi adotado para o Eucalipto grandis e forneceu os resultados apresentados, resumidamente, a seguir.

TABELA 25 - Resultados obtidos nos ensaios de tração paralela às fibras em Eucalyptus grandis

\begin{tabular}{ccc}
\hline C. P. & $\mathrm{U}(\%)$ & $\mathrm{f}_{\mathrm{t} 0}(\mathrm{MPa})$ \\
\hline GRD-01 & 59,17 & 50,46 \\
GRD-02 & 19,51 & 64,86 \\
GRD-03 & 16,28 & 69,21 \\
GRD-04 & 18,29 & 65,07 \\
GRD-05 & 13,99 & --- \\
GRD-06 & 14,56 & 71,66 \\
GRD-07 & 8,84 & 76,35 \\
GRD-08 & 0,82 & 65,17
\end{tabular}

OBS.: Durante o ensaio do corpo-de-prova GRD-05 ocorreu um importante efeito de torção.

Por causa deste efeito abandonou-se o resultado deste ensaio. 


\subsubsection{CUPIÚBA}

O mesmo procedimento utilizado para o Pinus bahamensis foi adotado para a Cupiúba e forneceu os resultados apresentados, resumidamente, a seguir.

TABELA 26 - Resultados obtidos nos ensaios de tração paralela às fibras em Goupia glabra

\begin{tabular}{ccc}
\hline C. P. & $\mathrm{U}(\%)$ & $\mathrm{f}_{\mathrm{t} 0}(\mathrm{MPa})$ \\
\hline CUP - 01 & 60,34 & 43,94 \\
CUP - 02 & 31,20 & 46,59 \\
CUP - 03 & 19,67 & 53,26 \\
CUP - 04 & 15,09 & 58,35 \\
CUP - 05 & 13,18 & 60,90 \\
CUP - 06 & 18,91 & 53,06 \\
CUP - 07 & 9,13 & 63,33 \\
CUP - 08 & 6,56 & 62,45 \\
\hline
\end{tabular}

\subsubsection{EUCALIPTO CITRIODORA}

O mesmo procedimento utilizado para o Pinus bahamensis foi adotado para o Eucalipto citriodora e forneceu os resultados apresentados, resumidamente, a seguir.

TABELA 27 - Resultados obtidos nos ensaios de tração paralela às fibras em Eucalyptus citriodora

\begin{tabular}{ccc}
\hline C. P. & $\mathrm{U}(\%)$ & $\mathrm{f}_{\mathrm{t} 0}(\mathrm{MPa})$ \\
\hline CIT - 01 & 33,33 & 103,78 \\
CIT - 02 & 19,02 & 116,34 \\
CIT - 03 & 16,61 & 120,06 \\
CIT - 04 & 19,40 & 114,70 \\
CIT - 05 & 15,02 & 124,69 \\
CIT - 06 & 12,20 & 131,97 \\
CIT - 07 & 5,88 & 138,57 \\
CIT - 08 & 4,92 & 137,72 \\
\hline
\end{tabular}

\subsubsection{JATOBÁ}

O mesmo procedimento utilizado para o Pinus bahamensis foi adotado para o Jatobá e forneceu os resultados apresentados, resumidamente, a seguir. 
TABELA 28 - Resultados obtidos nos ensaios de tração paralela às fibras em Hymenaea stilbocarpa

\begin{tabular}{ccc}
\hline C. $P$. & $\mathrm{U}(\%)$ & $\mathrm{f}_{\mathrm{t} 0}(\mathrm{MPa})$ \\
\hline JAT - 01 & 46,40 & 124,16 \\
JAT - 02 & 25,63 & 133,83 \\
JAT - 03 & 17,29 & 149,50 \\
JAT - 04 & 17,89 & 146,58 \\
JAT - 05 & 14,19 & 157,67 \\
JAT - 06 & 11,50 & 166,36 \\
JAT - 07 & 4,09 & 172,18 \\
JAT - 08 & 3,04 & 169,60 \\
\hline
\end{tabular}

\subsection{ENSAIOS DE CISALHAMENTO}

\subsubsection{PINUS BAHAMENSIS}

Os ensaios foram realizados em conformidade com a NBR 7190/97 a medida que o corpo-de-prova, em processo de secagem, apresentasse uma estimativa de umidade de interesse para o estudo.

A figura 70, apresenta a planilha de acompanhamento de um destes ensaios. No caso para o corpo-de-prova BAH-10.

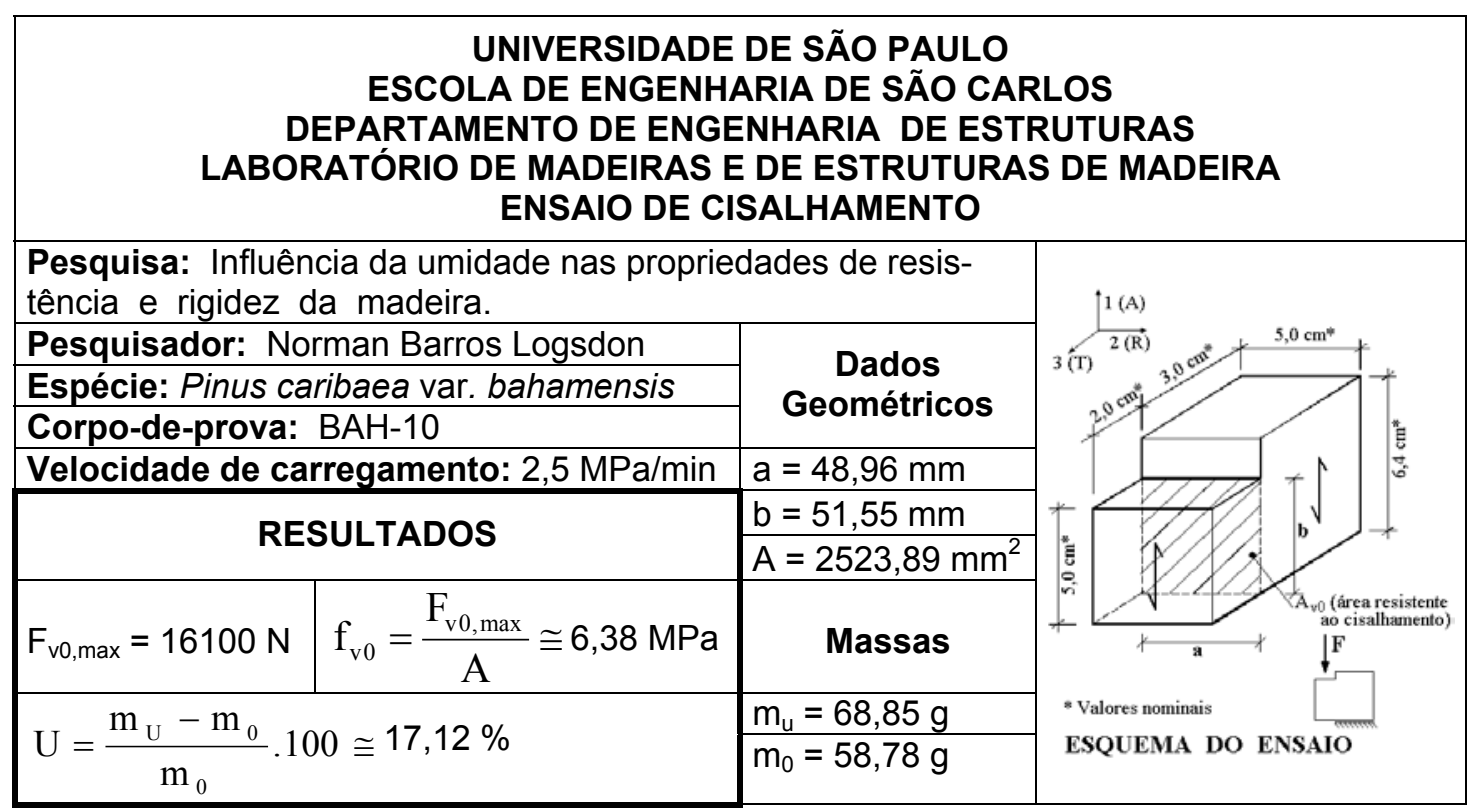

FIGURA 70 - Planilha para acompanhamento do ensaio de cisalhamento. 
Os resultados obtidos nos demais ensaios de cisalhamento são apresentados na tabela 29.

TABELA 29 - Resultados obtidos nos ensaios de cisalhamento em Pinus caribaea var. bahamensis

\begin{tabular}{|c|c|c|}
\hline Corpo-de-prova & Teor de umidade & Resistência ao cisalhamento \\
\hline C. P. & $\mathrm{U}(\%)$ & $\mathrm{f}_{\mathrm{v} 0}(\mathrm{MPa})$ \\
\hline BAH - 01 & 182,37 & 4,56 \\
\hline BAH - 02 & 159,75 & 4,39 \\
\hline BAH - 03 & 157,60 & 4,86 \\
\hline BAH - 04 & 65,80 & 4,63 \\
\hline BAH - 05 & 57,04 & 4,60 \\
\hline BAH - 06 & 28,72 & 4,91 \\
\hline BAH - 07 & 22,19 & 6,03 \\
\hline BAH - 08 & 22,18 & 5,76 \\
\hline BAH - 09 & 18,08 & 6,34 \\
\hline BAH - 10 & 17,12 & 6,38 \\
\hline BAH - 11 & 30,17 & 5,00 \\
\hline BAH - 12 & 16,43 & 6,63 \\
\hline BAH - 13 & 17,78 & 6,28 \\
\hline BAH - 14 & 12,94 & 7,20 \\
\hline BAH - 15 & 10,17 & 7,80 \\
\hline BAH - 16 & 5,20 & 9,46 \\
\hline BAH - 17 & 4,71 & 10,28 \\
\hline BAH - 18 & 4,08 & 10,04 \\
\hline BAH - 19 & 2,82 & 9,69 \\
\hline
\end{tabular}

\subsubsection{PINUS ELLIOTTII}

O mesmo procedimento utilizado para o Pinus bahamensis foi adotado para o Pinus elliottii e forneceu os resultados apresentados, resumidamente, a seguir. 
TABELA 30 - Resultados obtidos nos ensaios de cisalhamento em Pinus elliottii

\begin{tabular}{ccc}
\hline C. $P$. & $\mathrm{U}(\%)$ & $\mathrm{f}_{\mathrm{v} 0}(\mathrm{MPa})$ \\
\hline ELL - 01 & 193,93 & 4,62 \\
ELL - 02 & 170,01 & 5,15 \\
ELL - 03 & 120,79 & 5,31 \\
ELL - 04 & 75,62 & 5,36 \\
ELL - 05 & 46,01 & 5,29 \\
ELL - 06 & 19,75 & 6,42 \\
ELL - 07 & 13,40 & 7,66 \\
ELL - 08 & 15,74 & 7,07 \\
ELL - 09 & 18,05 & 6,95 \\
ELL - 10 & 17,77 & 6,86 \\
ELL - 11 & 18,53 & 6,87 \\
ELL - 12 & 12,04 & 7,95 \\
ELL - 13 & 21,97 & 5,68 \\
ELL - 14 & 15,68 & 7,23 \\
ELL - 15 & 5,20 & 12,68 \\
ELL - 16 & 4,83 & 11,50 \\
ELL - 17 & 3,99 & 12,11 \\
ELL - 18 & 2,63 & 12,74 \\
\hline
\end{tabular}

\subsubsection{PINUS TAEDA}

O mesmo procedimento utilizado para o Pinus bahamensis foi adotado para o Pinus taeda e forneceu os resultados apresentados, resumidamente, a seguir.

TABELA 31 - Resultados obtidos nos ensaios de cisalhamento em Pinus taeda

\begin{tabular}{ccc}
\hline C. $P$. & $\mathrm{U}(\%)$ & $\mathrm{f}_{\mathrm{v} 0}(\mathrm{MPa})$ \\
\hline TDA - 01 & 81,68 & 3,15 \\
TDA - 02 & 51,44 & 2,98 \\
TDA - 03 & 33,48 & 5,09 \\
TDA - 04 & 28,42 & 5,36 \\
TDA - 05 & 28,35 & 5,53
\end{tabular}


TABELA 31 - Resultados obtidos nos ensaios de cisalhamento em Pinus taeda - Continuação.

\begin{tabular}{ccc}
\hline C. $P$. & $\mathrm{U}(\%)$ & $\mathrm{f}_{\mathrm{v} 0}(\mathrm{MPa})$ \\
\hline TDA - 06 & 19,91 & 6,83 \\
TDA - 07 & 16,75 & 7,65 \\
TDA - 08 & 16,96 & 7,61 \\
TDA - 09 & 15,54 & 7,87 \\
TDA - 10 & 13,34 & 8,16 \\
TDA - 11 & 11,54 & 8,73 \\
TDA - 12 & 11,69 & 8,52 \\
TDA - 13 & 10,93 & 8,53 \\
TDA - 14 & 7,82 & 8,83 \\
TDA - 15 & 3,62 & 6,27 \\
TDA - 16 & 3,05 & 5,89 \\
TDA - 17 & 2,82 & 8,49 \\
TDA - 18 & 1,43 & 6,98 \\
\hline
\end{tabular}

\subsubsection{EUCALIPTO GRANDIS}

O mesmo procedimento utilizado para o Pinus bahamensis foi adotado para o Eucalipto grandis e forneceu os resultados apresentados, resumidamente, a seguir.

TABELA 32 - Resultados obtidos nos ensaios de cisalhamento em Eucalyptus grandis

\begin{tabular}{ccc}
\hline C. $P$. & $\mathrm{U}(\%)$ & $\mathrm{f}_{\mathrm{v} 0}(\mathrm{MPa})$ \\
\hline GRD-01 & 61,29 & 3,97 \\
GRD-02 & 24,69 & 5,41 \\
GRD-03 & 20,69 & 5,91 \\
GRD-04 & 18,09 & 6,33 \\
GRD-05 & 16,53 & 6,20 \\
GRD-06 & 15,01 & 6,65 \\
GRD-07 & 14,91 & 6,47 \\
GRD-08 & 12,83 & 7,08 \\
GRD-09 & 12,83 & 7,08
\end{tabular}


TABELA 32 - Resultados obtidos nos ensaios de cisalhamento em Eucalyptus grandis Continuação

\begin{tabular}{ccc}
\hline C. P. & $\mathrm{U}(\%)$ & $\mathrm{f}_{\mathrm{v} 0}(\mathrm{MPa})$ \\
\hline GRD-10 & 13,11 & 7,02 \\
GRD-11 & 12,36 & 7,41 \\
GRD-12 & 12,10 & 7,24 \\
GRD-13 & 11,55 & --- \\
GRD-14 & 11,21 & 7,44 \\
GRD-15 & 10,02 & 7,71 \\
GRD-16 & 5,11 & 7,88 \\
GRD-17 & 2,24 & 7,41 \\
GRD-18 & 1,13 & 6,14 \\
\hline
\end{tabular}

OBS.: O corpo-de-prova GRD-13, por defeito de confecção, apresentou uma ligeira inclinação na face de aplicação de carga. Este defeito causou importante efeito de tração normal. Por causa deste efeito abandonou-se o resultado deste ensaio.

\subsubsection{CUPIÚBA}

O mesmo procedimento utilizado para o Pinus bahamensis foi adotado para a Cupiúba e forneceu os resultados apresentados, resumidamente, a seguir.

TABELA 33 - Resultados obtidos nos ensaios de cisalhamento em Goupia glabra

\begin{tabular}{ccc}
\hline C. P. & $\mathrm{U}(\%)$ & $\mathrm{f}_{\mathrm{v} 0}(\mathrm{MPa})$ \\
\hline CUP - 01 & 53,78 & 7,41 \\
CUP - 02 & 38,58 & 7,36 \\
CUP - 03 & 35,76 & 7,53 \\
CUP - 04 & 34,04 & 7,58 \\
CUP - 05 & 26,62 & 7,58 \\
CUP - 06 & 21,74 & 8,05 \\
CUP - 07 & 17,00 & 8,61 \\
CUP - 08 & 19,77 & 8,17 \\
CUP - 09 & 10,19 & 10,24 \\
CUP - 10 & 12,79 & 9,50 \\
CUP - 11 & 10,94 & 10,03
\end{tabular}


TABELA 33 - Resultados obtidos nos ensaios de cisalhamento em Goupia glabra - Continuação.

\begin{tabular}{ccc}
\hline C. P. & $\mathrm{U}(\%)$ & $\mathrm{f}_{\mathrm{v} 0}(\mathrm{MPa})$ \\
\hline CUP - 12 & 13,91 & 9,15 \\
CUP - 13 & 15,31 & 8,90 \\
CUP - 14 & 5,35 & 10,27 \\
CUP - 15 & 3,20 & 10,17 \\
CUP - 16 & 3,30 & --- \\
CUP - 17 & 6,29 & 10,50 \\
CUP - 18 & 1,75 & 9,84 \\
\hline
\end{tabular}

OBS.: O corpo-de-prova CUP-16, devido às retrações oriundas da secagem, apresentou algumas rachaduras na região próxima ao plano de cisalhamento. Estas rachaduras podem ter causado uma diminuição na área de cisalhamento. Por causa destas rachaduras foi abandonado o resultado deste ensaio.

\subsubsection{EUCALIPTO CITRIODORA}

O mesmo procedimento utilizado para o Pinus bahamensis foi adotado para o Eucalipto citriodora e forneceu os resultados apresentados, resumidamente, a seguir.

TABELA 34 - Resultados obtidos nos ensaios de cisalhamento em Eucalyptus citriodora

\begin{tabular}{ccc}
\hline C. P. & $\mathrm{U}(\%)$ & $\mathrm{f}_{\mathrm{v} 0}(\mathrm{MPa})$ \\
\hline CIT - 01 & 30,99 & 11,01 \\
CIT - 02 & 22,64 & 11,50 \\
CIT - 03 & 18,66 & 11,62 \\
CIT - 04 & 17,60 & 11,89 \\
CIT - 05 & 16,35 & 12,23 \\
CIT - 06 & 16,84 & 12,00 \\
CIT - 07 & 13,46 & 13,08 \\
CIT - 08 & 15,97 & 12,27 \\
CIT - 09 & 15,97 & 12,42 \\
CIT - 10 & 15,02 & 12,70 \\
CIT - 11 & 14,68 & 12,70
\end{tabular}


TABELA 34 - Resultados obtidos nos ensaios de cisalhamento em Eucalyptus citriodora Continuação.

\begin{tabular}{ccc}
\hline C. P. & $\mathrm{U}(\%)$ & $\mathrm{f}_{\mathrm{v} 0}(\mathrm{MPa})$ \\
\hline CIT -12 & 12,74 & 13,31 \\
CIT -13 & 7,54 & 14,09 \\
CIT -14 & 9,77 & 13,87 \\
CIT -15 & 10,22 & 14,21 \\
CIT -16 & 5,30 & 13,71 \\
CIT -17 & 3,39 & 13,50 \\
CIT -18 & 3,20 & 13,03 \\
\hline
\end{tabular}

\subsubsection{JATOBÁ}

O mesmo procedimento utilizado para o Pinus bahamensis foi adotado para o Jatobá e forneceu os resultados apresentados, resumidamente, a seguir.

TABELA 35 - Resultados obtidos nos ensaios de cisalhamento em Hymenaea stilbocarpa

\begin{tabular}{ccc}
\hline C. P. & $\mathrm{U}(\%)$ & $\mathrm{f}_{\mathrm{v} 0}(\mathrm{MPa})$ \\
\hline JAT -01 & 41,05 & 12,04 \\
JAT - 02 & 35,59 & 12,99 \\
JAT - 03 & 21,26 & 13,26 \\
JAT - 04 & 22,08 & 13,20 \\
JAT - 05 & 15,33 & 15,45 \\
JAT - 06 & 14,23 & 15,60 \\
JAT - 07 & 19,21 & 13,75 \\
JAT - 08 & 12,79 & 16,04 \\
JAT - 09 & 13,76 & 15,99 \\
JAT - 10 & 12,07 & 16,33 \\
JAT - 11 & 10,81 & 16,84 \\
JAT - 12 & 5,49 & 17,77 \\
JAT - 13 & 7,52 & 17,70 \\
JAT - 14 & 9,90 & 17,35 \\
JAT - 15 & 6,09 & 17,84 \\
JAT - 16 & 2,24 & 15,32 \\
JAT - 17 & 2,29 & 16,98 \\
JAT - 18 & 1,92 & 14,22 \\
\hline
\end{tabular}




\subsection{REGRESSÕES PARA OBTENÇÃO DAS RELAÇÕES ENTRE O TEOR DE UMIDADE E CADA PROPRIEDADE DA MADEIRA}

\subsubsection{PINUS BAHAMENSIS}

Separando-se, das tabelas 15,22 e 29 , os resultados correspondentes aos teores de umidade no intervalo de $10 \%$ a $20 \%$, utilizando uma interpolação linear para estimar o valor da propriedade a $12 \%$ de umidade, e aplicando uma regressão linear com o modelo:

$$
\frac{\mathrm{p}_{12}-\mathrm{p}_{\mathrm{U} \%}}{\mathrm{p}_{\mathrm{U} \%}}=\alpha \cdot \frac{\mathrm{U} \%-12}{100} \Rightarrow \mathrm{Y}=\alpha . \mathrm{X}, \mathrm{com} \mathrm{Y}=\frac{\mathrm{p}_{12}-\mathrm{p}_{\mathrm{U} \%}}{\mathrm{p}_{\mathrm{U} \%}} \text { e } \mathrm{X}=\frac{\mathrm{U} \%-12}{100}
$$

Onde:

$\mathrm{p}_{12}=$ propriedade estudada ao teor de umidade de $12 \%$;

$\mathrm{p}_{\mathrm{U} \%}=$ propriedade estudada ao teor de umidade $\mathrm{U} \%$;

$\mathrm{U} \%=$ teor de umidade, $\mathrm{em} \%$;

$\mathrm{X}=$ variável independente da regressão linear simples;

$\mathrm{Y}=$ variável dependente da regressão linear simples, e

$\alpha=$ coeficiente angular da regressão linear simples.

Obtém-se os resultados apresentados, resumidamente, nas tabelas 36, 37 e 38 .

TABELA 36 - Resumo dos resultados das regressões para as propriedades de resistência do Pinus caribaea var. bahamensis.

\begin{tabular}{|c|c|c|c|c|c|}
\hline PROPRIEDADE & $\mathbf{n}$ & $\begin{array}{c}\mathbf{p}_{12} \\
(\mathrm{MPa})\end{array}$ & $\alpha$ & $\mathbf{R}^{2}$ & $\begin{array}{c}\text { Nível de } \\
\text { Significância }\end{array}$ \\
\hline $\begin{array}{l}\text { Resistência à compressão } \\
\text { paralela às fibras } \mathrm{f}_{\mathrm{c} 0}(\mathrm{MPa})\end{array}$ & 6 & $\mathrm{f}_{\mathrm{c} 0,12 \%}=29,26$ & 3,7417 & 0,9968 & $2,43025 \cdot 10^{-6}$ \\
\hline $\begin{array}{l}\text { Resistência à tração paralela às } \\
\text { fibras } \mathrm{f}_{\mathrm{t} 0}(\mathrm{MPa})\end{array}$ & 4 & $\mathrm{f}_{\mathrm{t} 0,12 \%}=60,85$ & 2,4000 & 0,9971 & $9,82701 \cdot 10^{-4}$ \\
\hline $\begin{array}{l}\text { Resistência ao cisalhamento } \\
\mathrm{f}_{\mathrm{v} 0}(\mathrm{MPa})\end{array}$ & 7 & $\mathrm{f}_{\mathrm{v} 0,12 \%}=7,40$ & 2,9159 & 0,9905 & $1,89732 \cdot 10^{-6}$ \\
\hline MÉDIA & & & 3,0192 & & \\
\hline
\end{tabular}

OBS.: O número de observações (n) inclui a estimativa da propriedade a 12\% de umidade $\left(\mathrm{p}_{12}\right)$ 
TABELA 37 - Resumo dos resultados da regressão para a rigidez do Pinus caribaea var. bahamensis.

\begin{tabular}{lccccc}
\hline PROPRIEDADE & $\mathbf{n}$ & $\begin{array}{c}\mathbf{E}_{12} \\
(\mathrm{MPa})\end{array}$ & $\alpha$ & $\mathbf{R}^{2}$ & $\begin{array}{c}\text { Nível de } \\
\text { Significância }\end{array}$ \\
\hline
\end{tabular}

Módulo de elasticidade longitudinal $\mathrm{E}_{\mathrm{c} 0}(\mathrm{MPa}) \quad 6 \quad 6944,72 \quad 1,5327 \quad 0,9676 \quad 2,5737.10^{-4}$

OBS.: O número de observações $(\mathrm{n})$ inclui a estimativa da rigidez a $12 \%$ de umidade $\left(\mathrm{E}_{12}\right)$

TABELA 38 - Resumo dos resultados da regressão para a densidade aparente do Pinus caribaea var. bahamensis.

\begin{tabular}{cccccc}
\hline PROPRIEDADE & $\mathbf{n}$ & $\begin{array}{c}\rho_{\mathbf{1 2}} \\
(\mathbf{M P a})\end{array}$ & $\alpha$ & $\mathbf{R}^{2}$ & $\begin{array}{c}\text { Nível de } \\
\text { Significância }\end{array}$ \\
\hline Densidade aparente $\rho\left(\mathrm{g} / \mathrm{cm}^{3}\right)$ & 6 & 0,538 & $-0,6300$ & 0,9962 & $3,4642 \cdot 10^{-6}$ \\
\hline
\end{tabular}

OBS.: O número de observações (n) inclui a estimativa da densidade aparente a $12 \%$ de umidade $\left(\rho_{12}\right)$

A título de ilustração foram construídas as figuras 71 a 75 , a partir dos resultados experimentais.

Os resultados experimentais foram ajustados a três curvas:

- No intervalo de umidade entre $10 \%$ a $20 \%$, à correspondente curva de regressão. Para o intervalo de umidade entre $20 \%$ e o ponto de saturação das fibras, foi mantida a mesma curva obtida para o intervalo de umidade entre $10 \%$ e $20 \%$;

- Para teores de umidade acima do ponto de saturação das fibras, aceito como $28 \%$, ao valor médio da propriedade, e

- Para teores de umidade inferiores a $10 \%$, a uma curva ajustada manualmente..

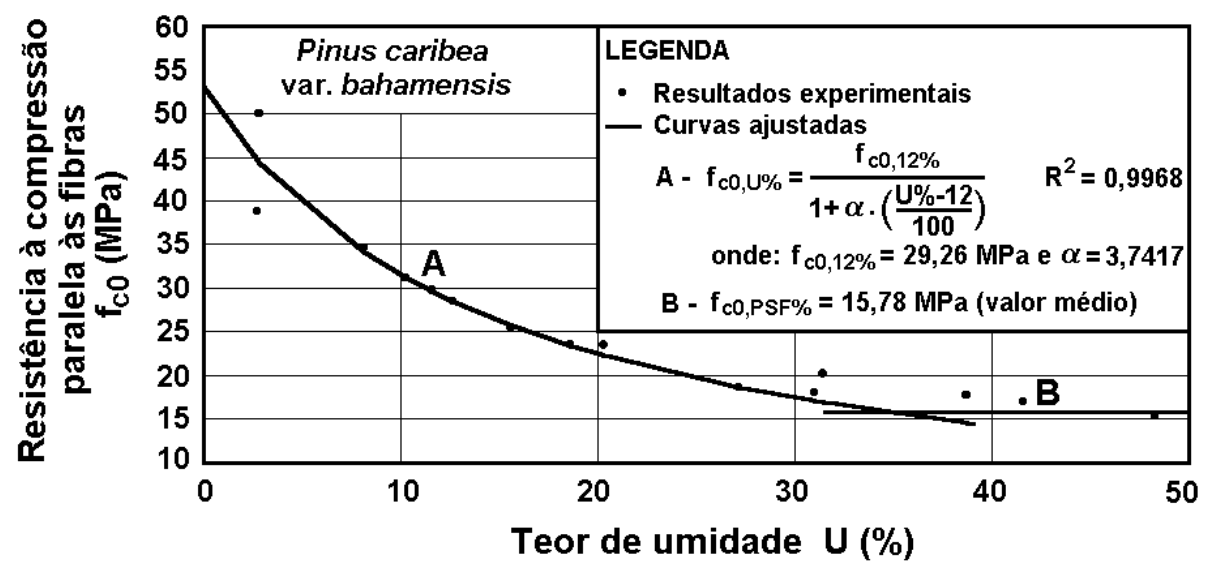

FIGURA 71 - Influência do teor de umidade sobre a resistência à compressão paralela às fibras, para o Pinus caribaea var. bahamensis. 
Para a resistência à compressão paralela (figura 71) não foi necessário o ajuste manual, pois a curva de regressão, obtida para o intervalo de teores de umidade entre $10 \% \mathrm{e}$ $20 \%$, aparentemente pode ser utilizada para menores teores de umidade. Para a densidade aparente (figura 75), que apresenta um coeficiente $\alpha$ negativo, indicando um aumento da densidade aparente com o aumento do teor de umidade, a curva de regressão parece se ajustar bem, exceto para valores muito altos do teor de umidade.

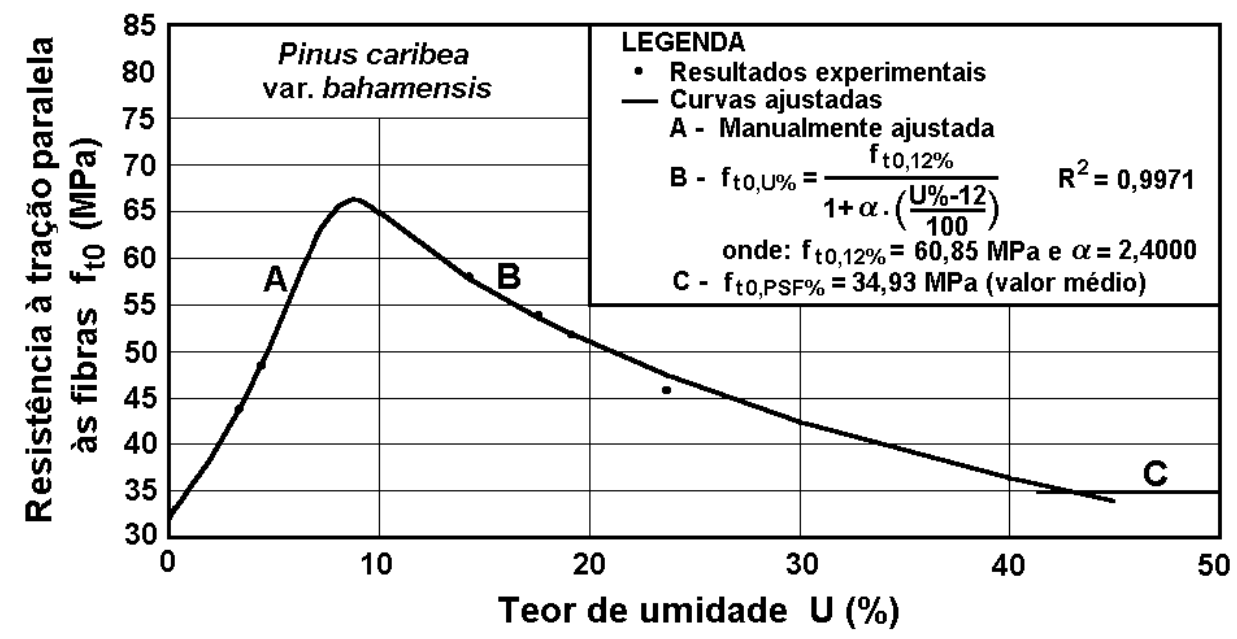

FIGURA 72 - Influência do teor de umidade sobre a resistência à tração paralela às fibras, para o Pinus caribaea var. bahamensis.

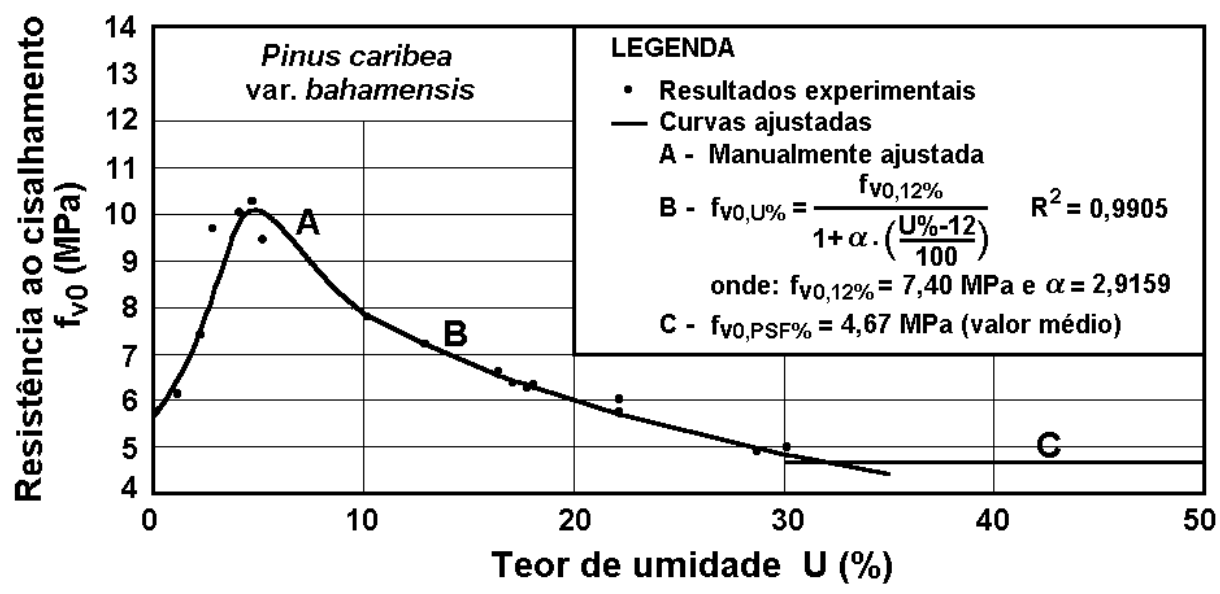

FIGURA 73 - Influência do teor de umidade sobre a resistência cisalhamento, para o Pinus caribaea var. bahamensis. 


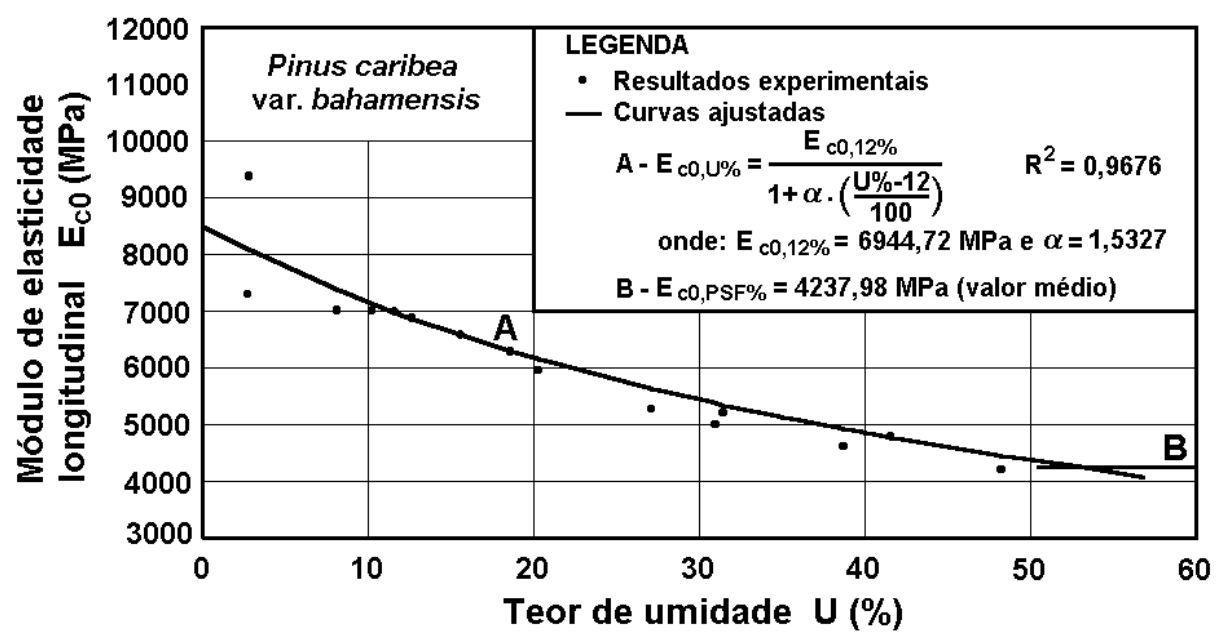

FIGURA 74 - Influência do teor de umidade sobre o módulo de elasticidade longitudinal, para o Pinus caribaea var. bahamensis.

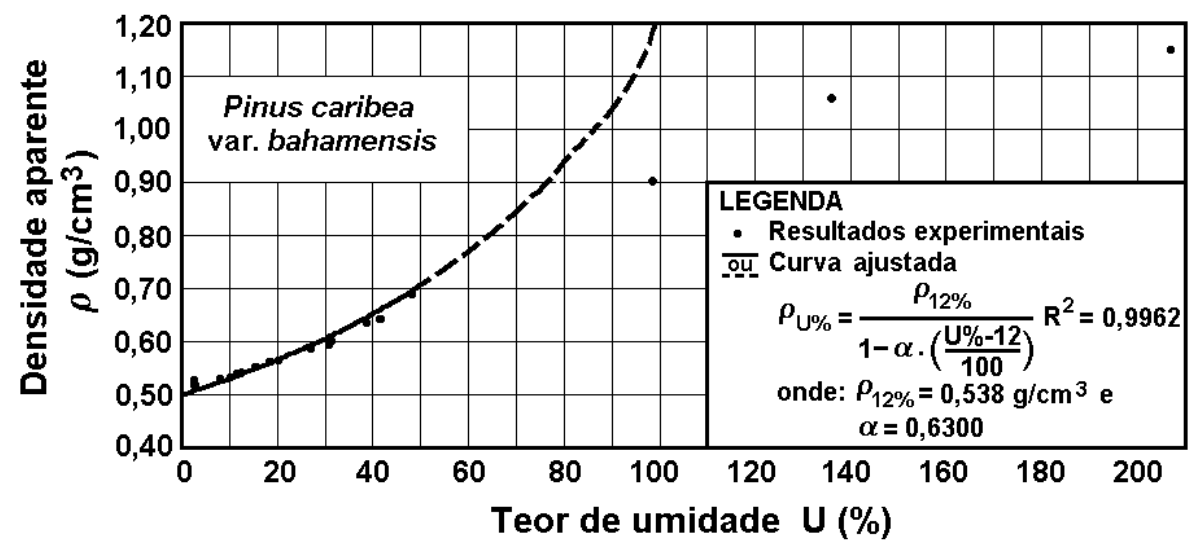

FIGURA 75 - Influência do teor de umidade sobre a densidade aparente, para o Pinus caribaea var. bahamensis.

\subsubsection{PINUS ELLIOTTII}

O mesmo procedimento utilizado para o Pinus bahamensis foi adotado para o Pinus elliottii e forneceu os resultados apresentados, resumidamente, a seguir. 
TABELA 39 - Resumo dos resultados das regressões para as propriedades de resistência do Pinus elliottii.

\begin{tabular}{lccccc}
\hline \multicolumn{1}{c}{ PROPRIEDADE } & $\mathbf{n}$ & $\begin{array}{c}\mathbf{p}_{\mathbf{1 2}} \\
\mathbf{( M P a )}\end{array}$ & $\alpha$ & $\mathbf{R}^{2}$ & $\begin{array}{c}\text { Nível de } \\
\text { Significância }\end{array}$ \\
\hline $\begin{array}{l}\text { Resistência à compressão para- } \\
\text { lela às fibras } \mathrm{f}_{\mathrm{c} 0}(\mathrm{MPa})\end{array}$ & 7 & $\mathrm{f}_{\mathrm{c} 0,12 \%}=41,34$ & 3,6339 & 0,9675 & $4,19905 \cdot 10^{-5}$ \\
$\begin{array}{l}\text { Resistência à tração paralela às } \\
\text { fibras } \mathrm{f}_{\mathrm{t} 0}(\mathrm{MPa})\end{array}$ & 4 & $\mathrm{f}_{\mathrm{t} 0,12 \%}=67,84$ & 2,2861 & 0,9938 & $2,07714 \cdot 10^{-3}$ \\
$\begin{array}{l}\text { Resistência ao cisalhamento } \\
\mathrm{f}_{\mathrm{v} 0}(\mathrm{MPa})\end{array}$ & 9 & $\mathrm{f}_{\mathrm{v} 0,12 \%}=7,96$ & 2,7657 & 0,9594 & $2,54424 \cdot 10^{-6}$ \\
\hline MÉDIA & & & & & \\
\hline
\end{tabular}

OBS.: O número de observações $(\mathrm{n})$ inclui a estimativa da propriedade a $12 \%$ de umidade $\left(\mathrm{p}_{12}\right)$

TABELA 40 - Resumo dos resultados da regressão para a rigidez do Pinus elliottii.

\begin{tabular}{cccccc}
\hline \multicolumn{1}{c}{ PROPRIEDADE } & $\mathbf{n}$ & $\begin{array}{c}\mathbf{E}_{12} \\
\text { (MPa) }\end{array}$ & $\alpha$ & $\mathbf{R}^{2}$ & $\begin{array}{c}\text { Nível de } \\
\text { Significância }\end{array}$ \\
\hline $\begin{array}{l}\text { Módulo de elasticidade longitu- } \\
\text { dinal } \mathrm{E}_{\mathrm{c} 0}(\mathrm{MPa})\end{array}$ & 7 & 11755,76 & 2,1859 & 0,9448 & $1,60463 \cdot 10^{-4}$ \\
\hline
\end{tabular}

OBS.: $\mathrm{O}$ número de observações $(\mathrm{n})$ inclui a estimativa da rigidez a $12 \%$ de umidade $\left(\mathrm{E}_{12}\right)$

TABELA 41 - Resumo dos resultados da regressão para a densidade aparente do Pinus elliottii.

\begin{tabular}{cccccc}
\hline PROPRIEDADE & $\mathbf{n}$ & $\begin{array}{c}\rho_{\mathbf{1 2}} \\
\text { (MPa) }\end{array}$ & $\alpha$ & $\mathbf{R}^{2}$ & $\begin{array}{c}\text { Nível de } \\
\text { Significância }\end{array}$ \\
\hline Densidade aparente $\rho\left(\mathrm{g} / \mathrm{cm}^{3}\right)$ & 7 & 0,559 & $-0,5835$ & 0,9934 & $7,69568 \cdot 10^{-7}$ \\
\hline
\end{tabular}

OBS.: O número de observações (n) inclui a estimativa da densidade aparente a $12 \%$ de umidade $\left(\rho_{12}\right)$ 


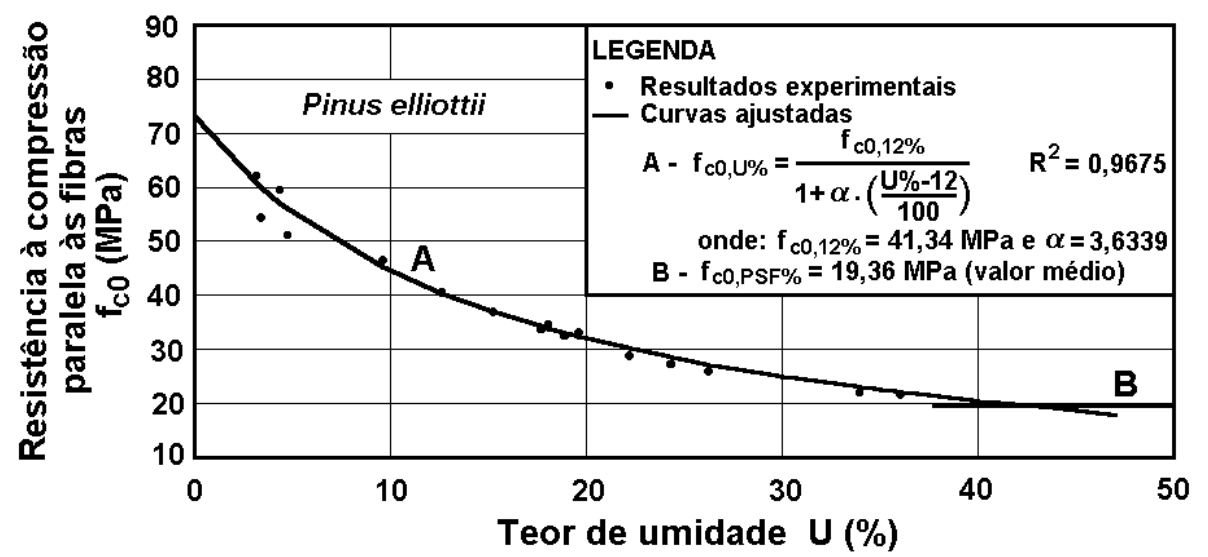

FIGURA 76 - Influência do teor de umidade sobre a resistência à compressão paralela às fibras, para o Pinus elliottii.

Para a resistência à compressão paralela (figura 76) não foi necessário o ajuste manual, pois a curva de regressão, obtida para o intervalo de teores de umidade entre $10 \% \mathrm{e}$ $20 \%$, aparentemente pode ser utilizada para menores teores de umidade. Para a densidade aparente (figura 80 ), que apresenta um coeficiente $\alpha$ negativo, indicando um aumento da densidade aparente com o aumento do teor de umidade, a curva de regressão também parece se ajustar bem, exceto para valores muito altos do teor de umidade.

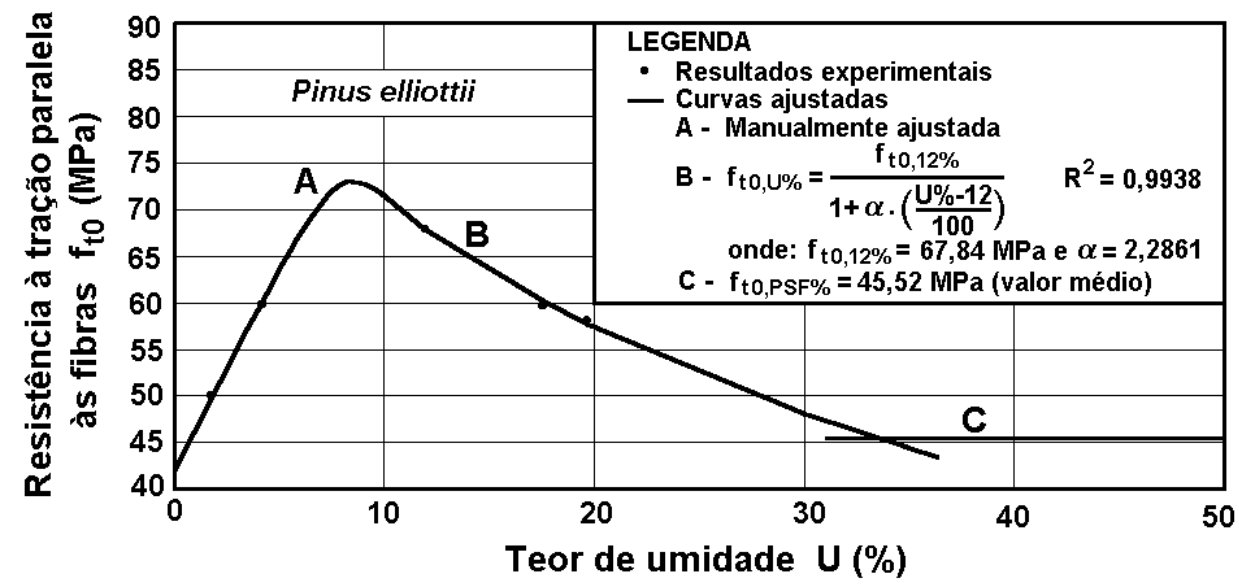

FIGURA 77 - Influência do teor de umidade sobre a resistência à tração paralela às fibras, para o Pinus elliottii. 


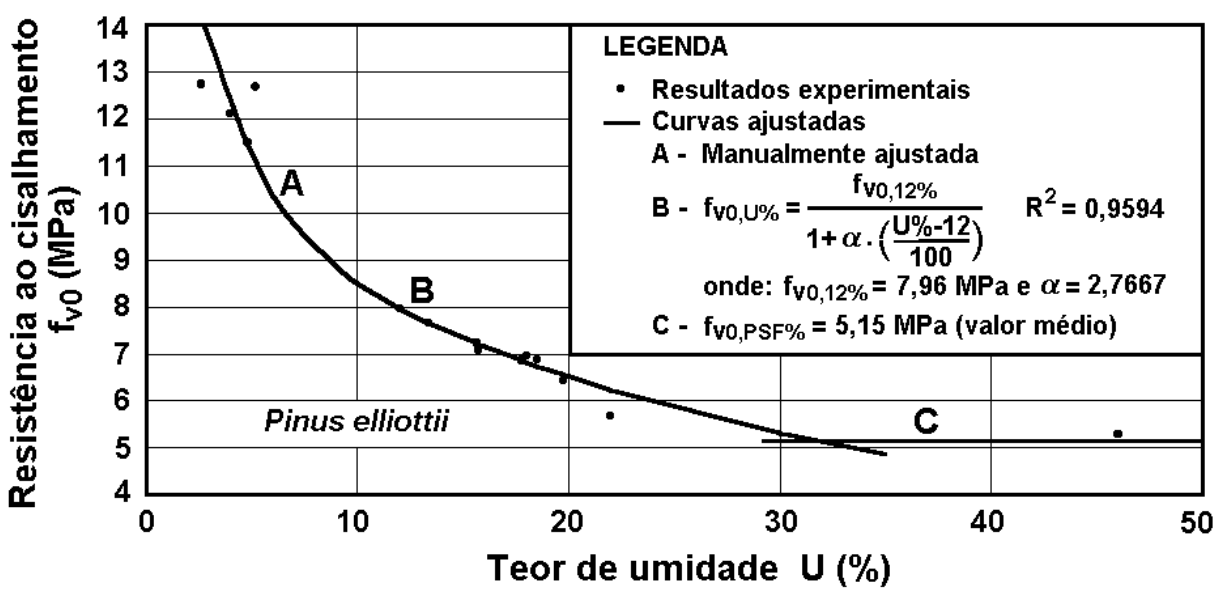

FIGURA 78 - Influência do teor de umidade sobre a resistência cisalhamento, para o Pinus elliottii.

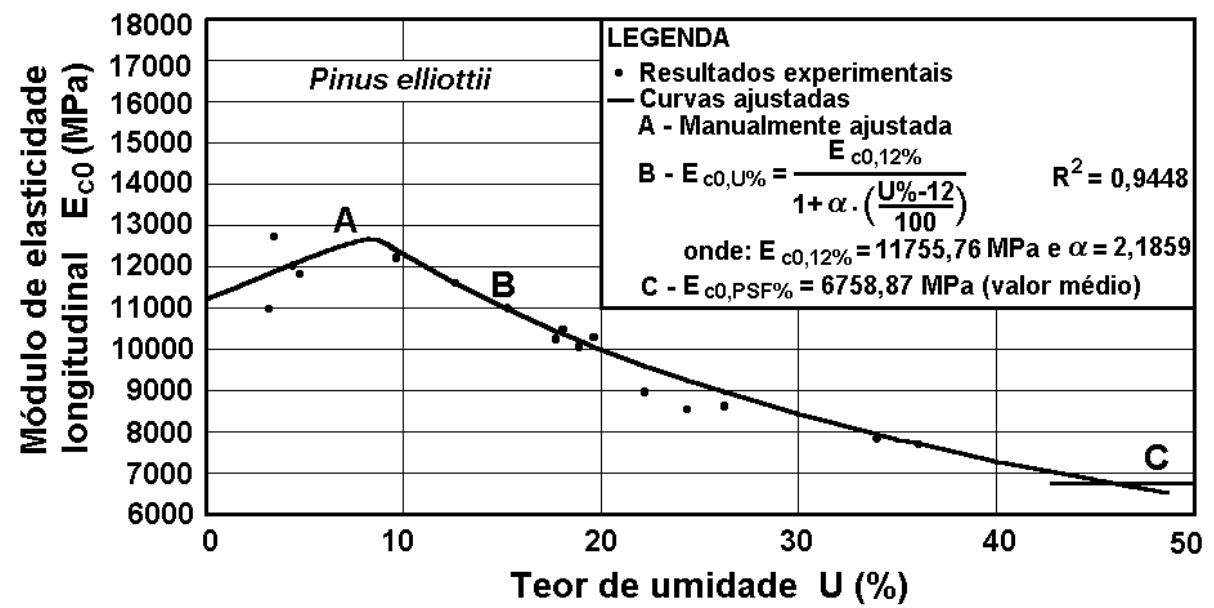

FIGURA 79 - Influência do teor de umidade sobre o módulo de elasticidade longitudinal, para o Pinus elliottii.

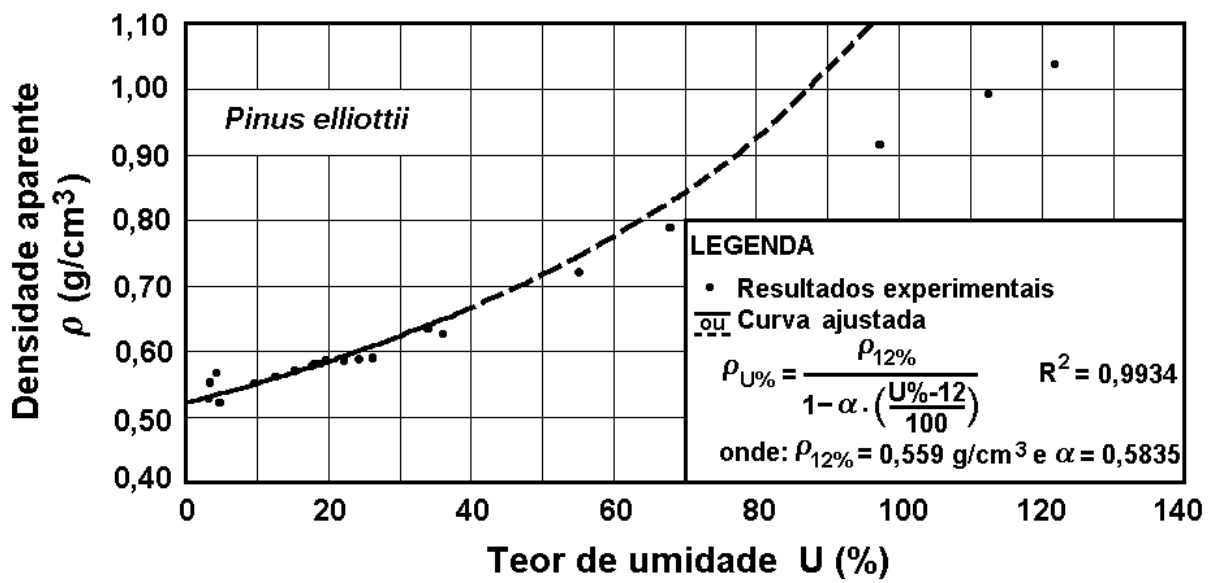

FIGURA 80 - Influência do teor de umidade sobre a densidade aparente, para o Pinus elliottii. 


\subsubsection{PINUS TAEDA}

O mesmo procedimento utilizado para o Pinus bahamensis foi adotado para o Pinus taeda e forneceu os resultados apresentados, resumidamente, a seguir.

TABELA 42 - Resumo dos resultados das regressões para as propriedades de resistência do Pinus taeda.

\begin{tabular}{lccccc}
\hline \multicolumn{1}{c}{ PROPRIEDADE } & $\mathbf{n}$ & $\begin{array}{c}\mathbf{p}_{\mathbf{1 2}} \\
\mathbf{( M P a})\end{array}$ & $\alpha$ & $\mathbf{R}^{\mathbf{2}}$ & $\begin{array}{c}\text { Nível de } \\
\text { Significância }\end{array}$ \\
\hline $\begin{array}{l}\text { Resistência à compressão para- } \\
\text { lela às fibras }\end{array}$ & 8 & $\mathrm{f}_{\mathrm{c} 0,12 \%}(\mathrm{MPa})$ \\
$\begin{array}{l}\text { Resistência à tração paralela às } \\
\text { fibras } \mathrm{f}_{\mathrm{t} 0}(\mathrm{MPa})\end{array}$ & 4 & $\mathrm{f}_{\mathrm{t} 0,12 \%}=81,51$ & 2,1762 & 0,9938 & $2,08243 \cdot 10^{-3}$ \\
$\begin{array}{l}\text { Resistência ao cisalhamento } \\
\mathrm{f}_{\mathrm{v} 0}(\mathrm{MPa})\end{array}$ & 9 & $\mathrm{f}_{\mathrm{v} 0,12 \%}=8,45$ & 2,5997 & 0,9525 & $4,4285 \cdot 10^{-6}$ \\
\hline MÉDIA & & & & & \\
\hline
\end{tabular}

OBS.: O número de observações (n) inclui a estimativa da propriedade a $12 \%$ de umidade $\left(\mathrm{p}_{12}\right)$

TABELA 43 - Resumo dos resultados da regressão para a rigidez do Pinus taeda.

\begin{tabular}{cccccc}
\hline \multicolumn{1}{c}{ PROPRIEDADE } & $\mathbf{n}$ & $\begin{array}{c}\mathbf{E}_{12} \\
(\mathbf{M P a})\end{array}$ & $\alpha$ & $\mathbf{R}^{2}$ & $\begin{array}{c}\text { Nível de } \\
\text { Significância }\end{array}$ \\
\hline $\begin{array}{l}\text { Módulo de elasticidade longitu- } \\
\text { dinal } \mathrm{E}_{\mathrm{c} 0}(\mathrm{MPa})\end{array}$ & 8 & 13511,31 & 2,5614 & 0,9570 & $1,61932 \cdot 10^{-6}$ \\
\hline
\end{tabular}

OBS.: $\mathrm{O}$ número de observações $(\mathrm{n})$ inclui a estimativa da rigidez a $12 \%$ de umidade $\left(\mathrm{E}_{12}\right)$

TABELA 44 - Resumo dos resultados da regressão para a densidade aparente do Pinus tae$d a$.

\begin{tabular}{cccccc}
\hline PROPRIEDADE & $\mathbf{n}$ & $\begin{array}{c}\rho_{12} \\
\text { (MPa) }\end{array}$ & $\alpha$ & $\mathbf{R}^{2}$ & $\begin{array}{c}\text { Nível de } \\
\text { Significância }\end{array}$ \\
\hline Densidade aparente $\rho\left(\mathrm{g} / \mathrm{cm}^{3}\right)$ & 8 & 0,652 & $-0,5340$ & 0,9974 & $3,50574.10^{-9}$ \\
\hline
\end{tabular}

OBS.: O número de observações (n) inclui a estimativa da densidade aparente a $12 \%$ de umidade $\left(\rho_{12}\right)$ 


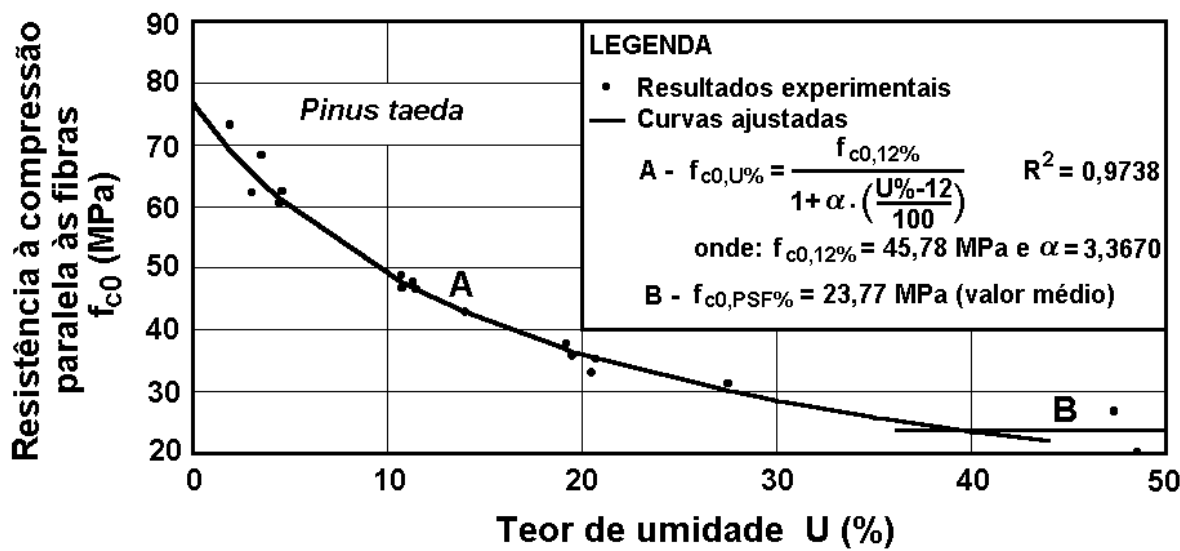

FIGURA 81 - Influência do teor de umidade sobre a resistência à compressão paralela às fibras, para o Pinus taeda.

Para a resistência à compressão paralela (figura 81) não foi necessário o ajuste manual, pois a curva de regressão, obtida para o intervalo de teores de umidade entre $10 \% \mathrm{e}$ $20 \%$, aparentemente pode ser utilizada para menores teores de umidade. Para a densidade aparente (figura 85), que apresenta um coeficiente $\alpha$ negativo, indicando um aumento da densidade aparente com o aumento do teor de umidade, a curva de regressão também parece se ajustar bem, embora com baixa precisão para valores muito altos do teor de umidade.

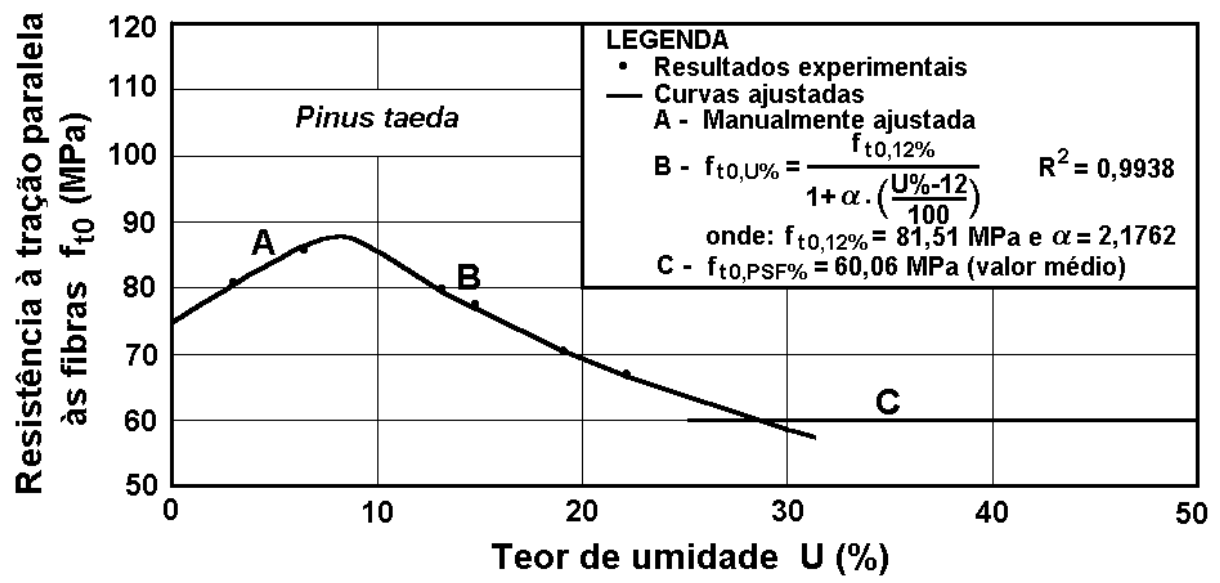

FIGURA 82 - Influência do teor de umidade sobre a resistência à tração paralela às fibras, para o Pinus taeda. 


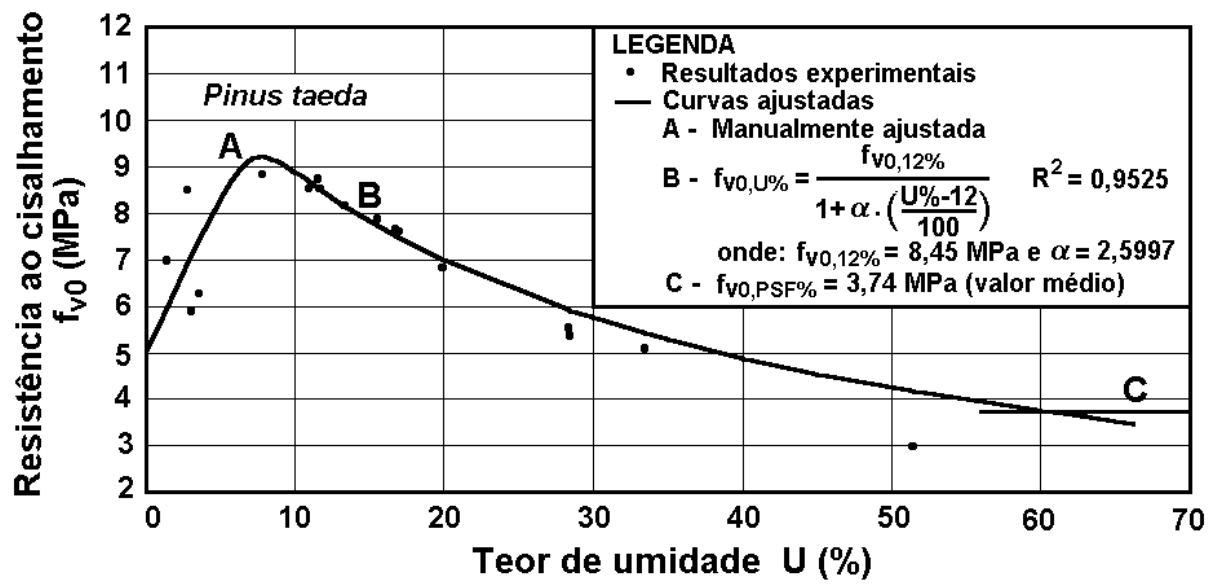

FIGURA 83 - Influência do teor de umidade sobre a resistência cisalhamento, para o Pinus taeda.

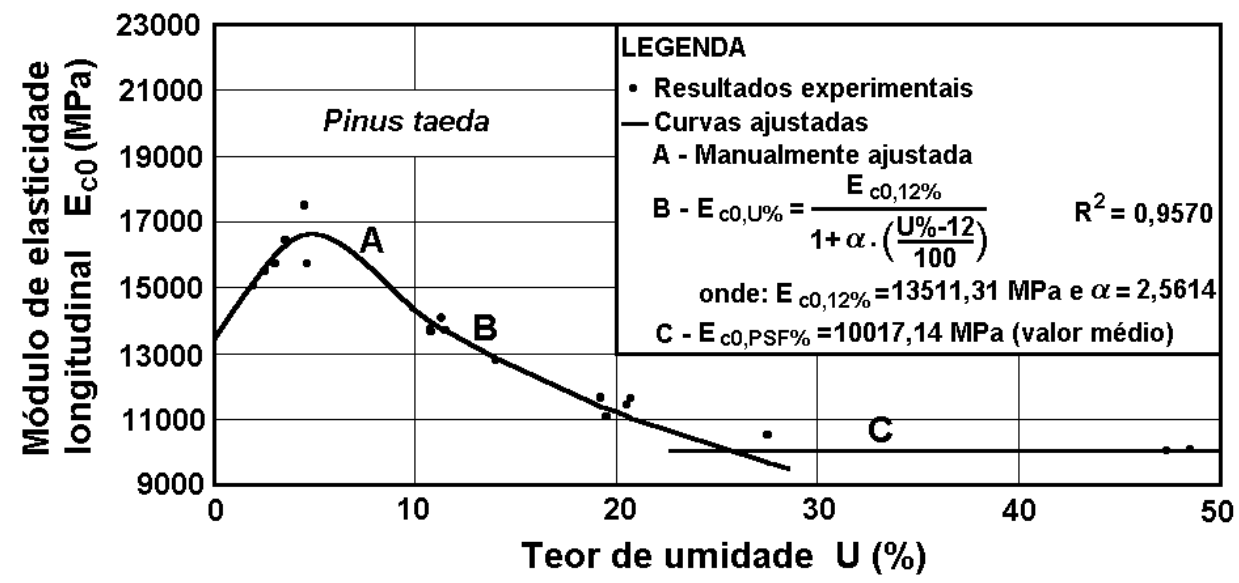

FIGURA 84 - Influência do teor de umidade sobre o módulo de elasticidade longitudinal, para o Pinus taeda.

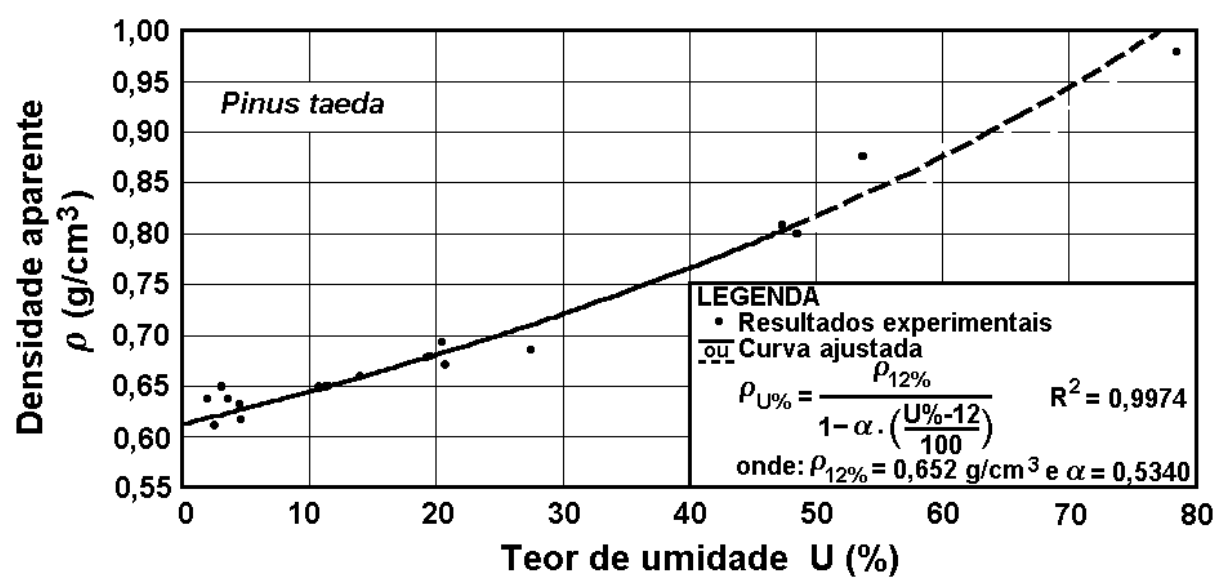

FIGURA 85 - Influência do teor de umidade sobre a densidade aparente, para o Pinus taeda. 


\subsubsection{EUCALIPTO GRANDIS}

O mesmo procedimento utilizado para o Pinus bahamensis foi adotado para o Eucalipto grandis e forneceu os resultados apresentados, resumidamente, a seguir.

TABELA 45 - Resumo dos resultados das regressões para as propriedades de resistência do Eucalyptus grandis.

\begin{tabular}{|c|c|c|c|c|c|}
\hline PROPRIEDADE & $\mathrm{n}$ & $\begin{array}{c}\mathbf{p}_{12} \\
(\mathrm{MPa})\end{array}$ & $\alpha$ & $\mathbf{R}^{2}$ & $\begin{array}{c}\text { Nível de } \\
\text { Significância }\end{array}$ \\
\hline $\begin{array}{l}\text { Resistência à compressão } \\
\text { paralela às fibras } \mathrm{f}_{\mathrm{c} 0}(\mathrm{MPa})\end{array}$ & 10 & $f_{c 0,12 \%}=42,57$ & 3,4026 & 0,8824 & $3,60217 \cdot 10^{-5}$ \\
\hline $\begin{array}{l}\text { Resistência à tração paralela às } \\
\text { fibras } \mathrm{f}_{\mathrm{t} 0}(\mathrm{MPa})\end{array}$ & 5 & $\mathrm{f}_{\mathrm{t} 0,12 \%}=75,31$ & 2,2397 & 0,9780 & $9,13846 \cdot 10^{-4}$ \\
\hline $\begin{array}{l}\text { Resistência ao cisalhamento } \\
\mathrm{f}_{\mathrm{v} 0}(\mathrm{MPa})\end{array}$ & 12 & $\mathrm{f}_{\mathrm{v} 0,12 \%}=7,26$ & 3,0512 & 0,9205 & $5,19750 \cdot 10^{-7}$ \\
\hline MÉDIA & & & 2,8978 & & \\
\hline
\end{tabular}

OBS.: O número de observações (n) inclui a estimativa da propriedade a $12 \%$ de umidade $\left(\mathrm{p}_{12}\right)$

TABELA 46 - Resumo dos resultados da regressão para a rigidez do Eucalyptus grandis.

\begin{tabular}{cccccc}
\hline PROPRIEDADE & $\mathbf{n}$ & $\begin{array}{c}\mathbf{E}_{12} \\
(\mathbf{M P a})\end{array}$ & $\alpha$ & $\mathbf{R}^{2}$ & $\begin{array}{c}\text { Nível de } \\
\text { Significância }\end{array}$ \\
\hline $\begin{array}{l}\text { Módulo de elasticidade longitu- } \\
\text { dinal } \mathrm{E}_{\mathrm{c} 0}(\mathrm{MPa})\end{array}$ & 12909,43 & 2,1779 & 0,9093 & $1,24161.10^{-5}$ \\
\hline
\end{tabular}

OBS.: $\mathrm{O}$ número de observações $(\mathrm{n})$ inclui a estimativa da rigidez a $12 \%$ de umidade $\left(\mathrm{E}_{12}\right)$

TABELA 47 - Resumo dos resultados da regressão para a densidade aparente do Eucalyptus grandis.

\begin{tabular}{cllclc}
\hline PROPRIEDADE & $\mathbf{n}$ & $\begin{array}{c}\rho_{12} \\
(\mathbf{M P a})\end{array}$ & $\alpha$ & $\mathbf{R}^{2}$ & $\begin{array}{c}\text { Nível de } \\
\text { Significância }\end{array}$ \\
\hline Densidade aparente $\rho\left(\mathrm{g} / \mathrm{cm}^{3}\right)$ & 10 & 0,664 & $-0,5338$ & 0,9743 & $7,60491.10^{-8}$ \\
\hline
\end{tabular}

OBS.: O número de observações (n) inclui a estimativa da densidade aparente a $12 \%$ de umidade $\left(\rho_{12}\right)$ 


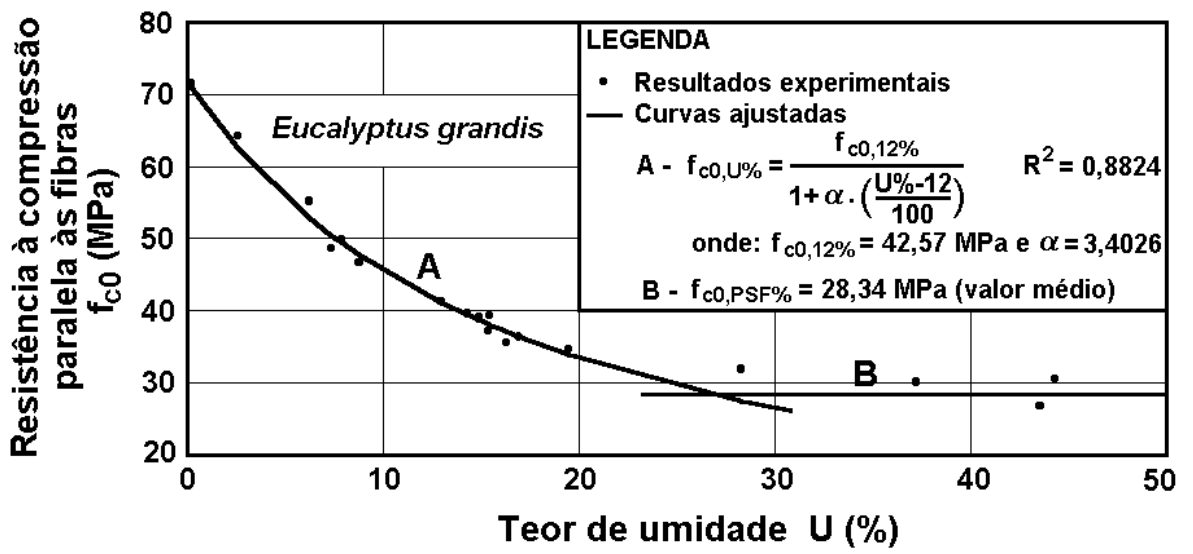

FIGURA 86 - Influência do teor de umidade sobre a resistência à compressão paralela às fibras, para o Eucalyptus grandis.

Para a resistência à compressão paralela (figura 86) não foi necessário o ajuste manual, pois a curva de regressão, obtida para o intervalo de teores de umidade entre $10 \% \mathrm{e}$ $20 \%$, aparentemente pode ser utilizada para menores teores de umidade. Para a densidade aparente (figura 80), que apresenta um coeficiente $\alpha$ negativo, indicando um aumento da densidade aparente com o aumento do teor de umidade, a curva de regressão também parece se ajustar bem, exceto para valores muito altos do teor de umidade.

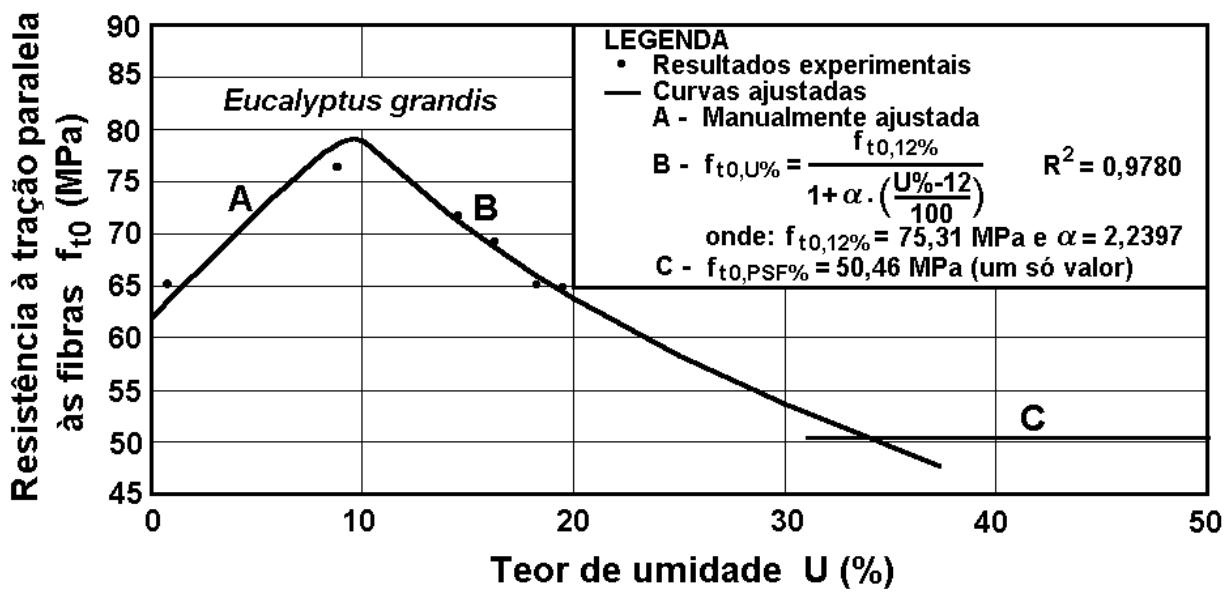

FIGURA 87 - Influência do teor de umidade sobre a resistência à tração paralela às fibras, para o Eucalyptus grandis. 


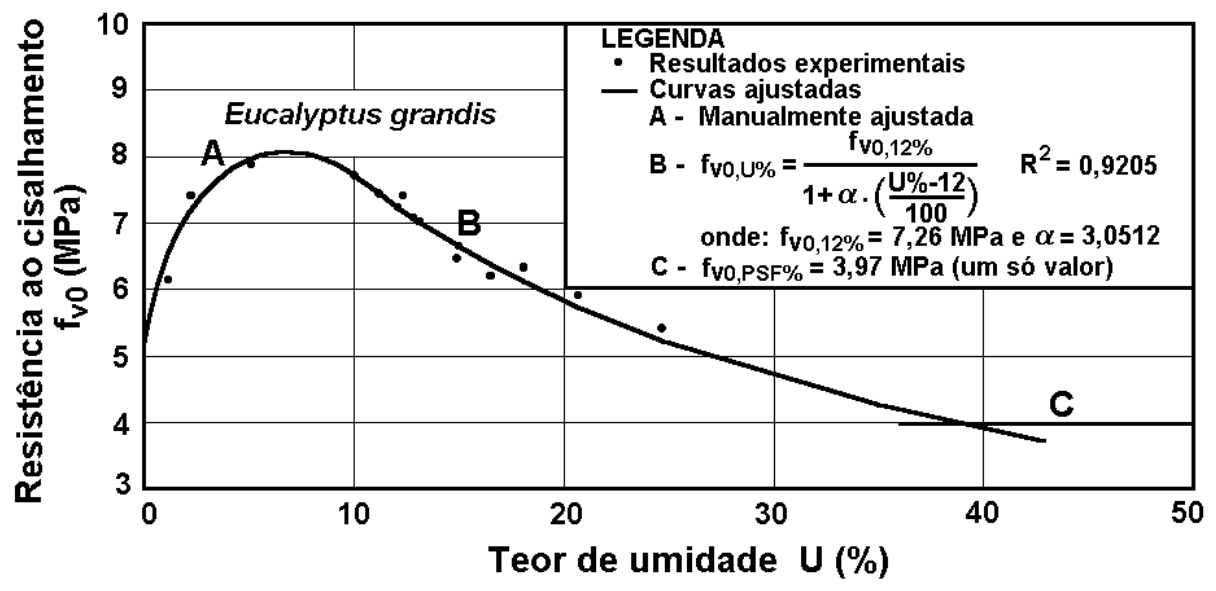

FIGURA 88 - Influência do teor de umidade sobre a resistência cisalhamento, para o $E u$ calyptus grandis.

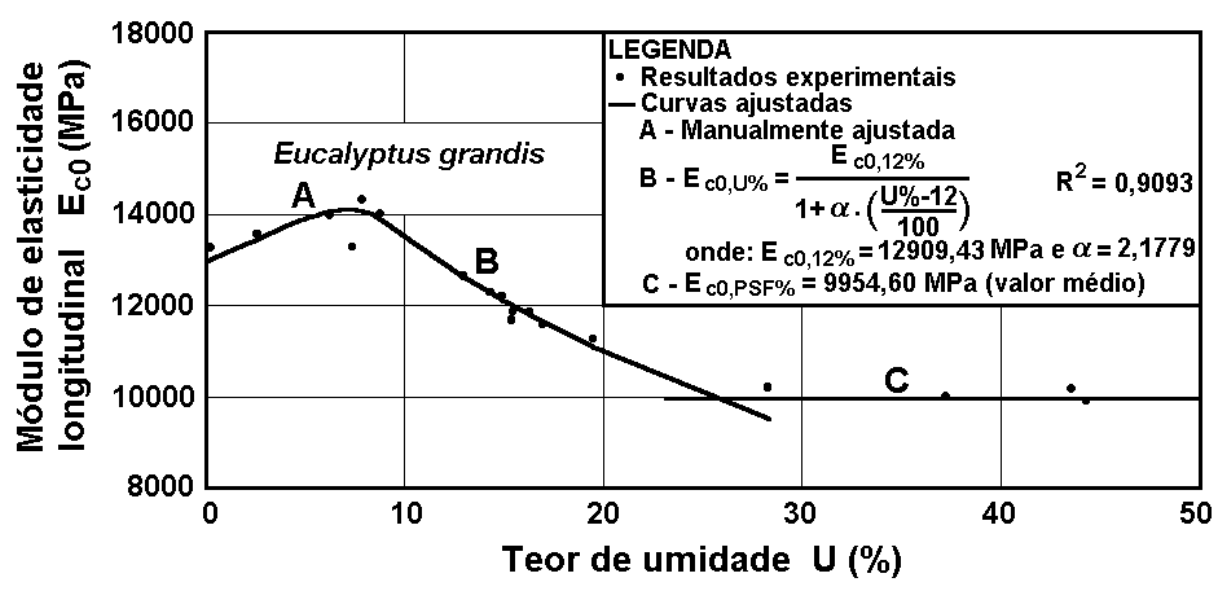

FIGURA 89 - Influência do teor de umidade sobre o módulo de elasticidade longitudinal, para o Eucalyptus grandis.

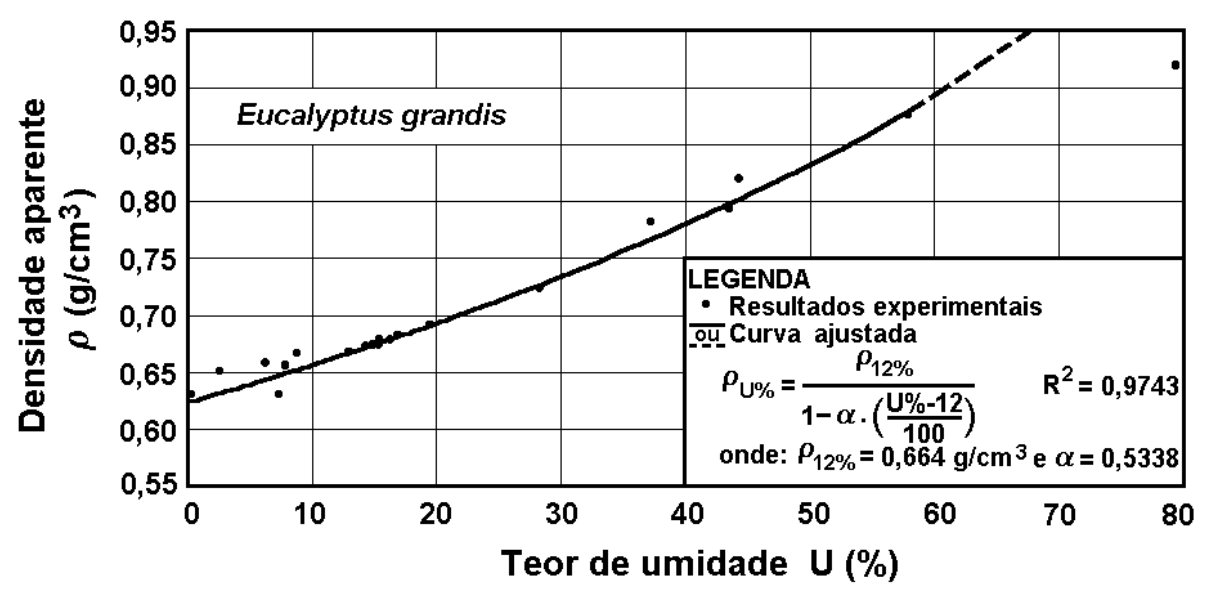

FIGURA 90 - Influência do teor de umidade sobre a densidade aparente, para o Eucalyptus grandis. 


\subsubsection{CUPIÚBA}

O mesmo procedimento utilizado para o Pinus bahamensis foi adotado para a Cupiúba e forneceu os resultados apresentados, resumidamente, a seguir.

TABELA 48 - Resumo dos resultados das regressões para as propriedades de resistência da Goupia glabra.

\begin{tabular}{|c|c|c|c|c|c|}
\hline PROPRIEDADE & $\mathbf{n}$ & $\begin{array}{c}\mathbf{p}_{12} \\
(\mathrm{MPa})\end{array}$ & $\alpha$ & $\mathbf{R}^{2}$ & $\begin{array}{c}\text { Nível de } \\
\text { Significância }\end{array}$ \\
\hline $\begin{array}{l}\text { Resistência à compressão } \\
\text { paralela às fibras } \mathrm{f}_{\mathrm{c} 0}(\mathrm{MPa})\end{array}$ & 8 & $f_{c 0,12 \%}=53,41$ & 3,3618 & 0,9974 & $3,61867 \cdot 10^{-9}$ \\
\hline $\begin{array}{l}\text { Resistência à tração paralela às } \\
\text { fibras } \mathrm{f}_{\mathrm{t} 0}(\mathrm{MPa})\end{array}$ & 5 & $\mathrm{f}_{\mathrm{t} 0,12 \%}=62,48$ & 2,3846 & 0,9900 & $2,78649 \cdot 10^{-4}$ \\
\hline $\begin{array}{l}\text { Resistência ao cisalhamento } \\
\mathrm{f}_{\mathrm{v} 0}(\mathrm{MPa})\end{array}$ & 8 & $\mathrm{f}_{\mathrm{v} 0,12 \%}=9,73$ & 2,5692 & 0,9921 & $9,57821 \cdot 10^{-8}$ \\
\hline MÉDIA & & & 2,7719 & & \\
\hline
\end{tabular}

OBS.: O número de observações (n) inclui a estimativa da propriedade a $12 \%$ de umidade $\left(\mathrm{p}_{12}\right)$

TABELA 49 - Resumo dos resultados da regressão para a rigidez da Goupia glabra.

\begin{tabular}{cccccc}
\hline PROPRIEDADE & $\mathbf{n}$ & $\begin{array}{c}\mathbf{E}_{12} \\
(\mathbf{M P a})\end{array}$ & $\alpha$ & $\mathbf{R}^{2}$ & $\begin{array}{c}\text { Nível de } \\
\text { Significância }\end{array}$ \\
\hline $\begin{array}{l}\text { Módulo de elasticidade longitu- } \\
\text { dinal } \mathrm{E}_{\mathrm{c} 0}(\mathrm{MPa})\end{array}$ & 14472,08 & 2,7697 & 0,9973 & $4,03145 \cdot 10^{-9}$ \\
\hline
\end{tabular}

OBS.: O número de observações (n) inclui a estimativa da rigidez a $12 \%$ de umidade $\left(\mathrm{E}_{12}\right)$

TABELA 50 - Resumo dos resultados da regressão para a densidade aparente da Goupia glabra.

\begin{tabular}{cccccc}
\hline PROPRIEDADE & $\mathbf{n}$ & $\begin{array}{c}\rho_{12} \\
\text { (MPa) }\end{array}$ & $\alpha$ & $\mathbf{R}^{2}$ & $\begin{array}{c}\text { Nível de } \\
\text { Significância }\end{array}$ \\
\hline Densidade aparente $\rho\left(\mathrm{g} / \mathrm{cm}^{3}\right)$ & 8 & 0,802 & $-0,3303$ & 0,8306 & $1,093423 \cdot 10^{-3}$ \\
\hline
\end{tabular}

OBS.: O número de observações (n) inclui a estimativa da densidade aparente a $12 \%$ de umidade $\left(\rho_{12}\right)$ 


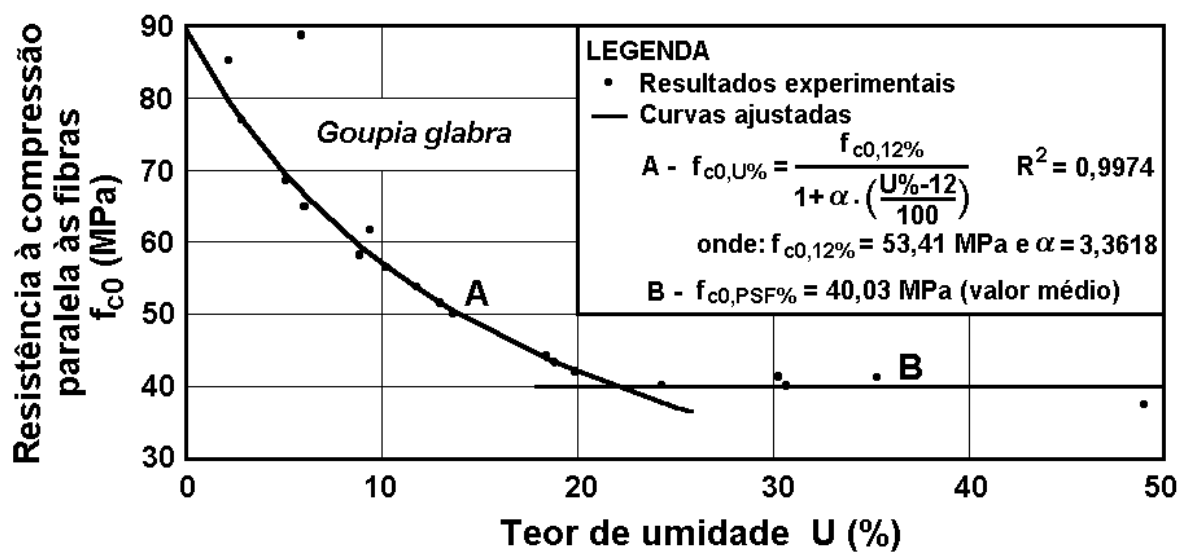

FIGURA 91 - Influência do teor de umidade sobre a resistência à compressão paralela às fibras, para a Goupia glabra.

Para a resistência à compressão paralela (figura 91) não foi necessário o ajuste manual, pois a curva de regressão, obtida para o intervalo de teores de umidade entre $10 \%$ e $20 \%$, aparentemente pode ser utilizada para menores teores de umidade. Para a densidade aparente (figura 95), que apresenta um coeficiente $\alpha$ negativo, indicando um aumento da densidade aparente com o aumento do teor de umidade, a curva de regressão também parece se ajustar bem, exceto para valores muito altos do teor de umidade.

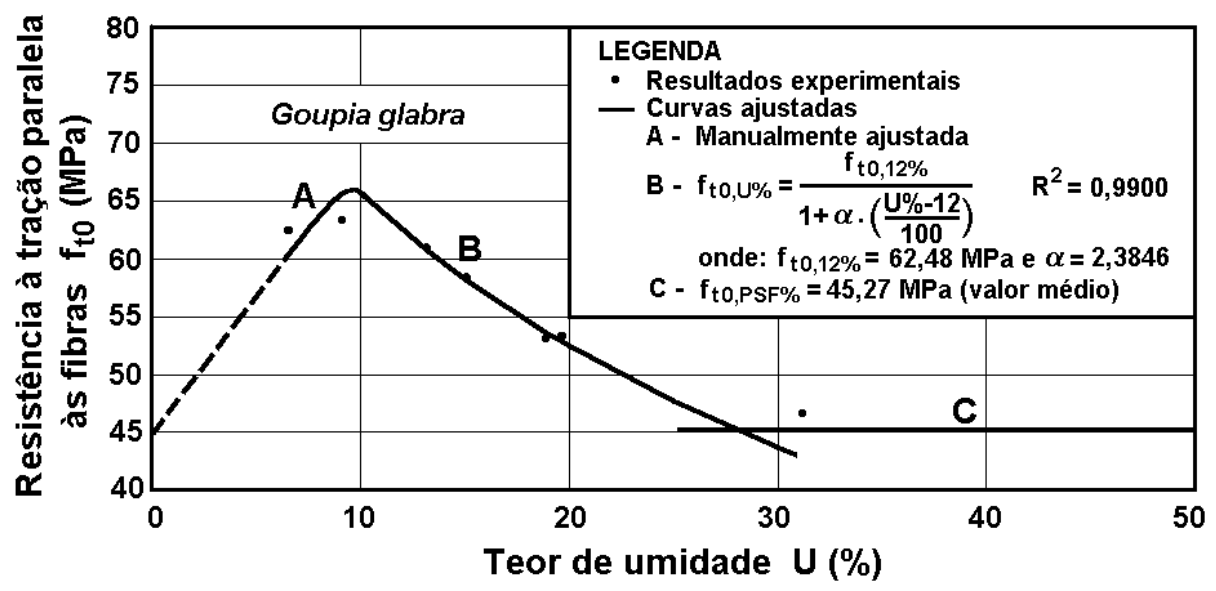

FIGURA 92 - Influência do teor de umidade sobre a resistência à tração paralela às fibras, para a Goupia glabra. 


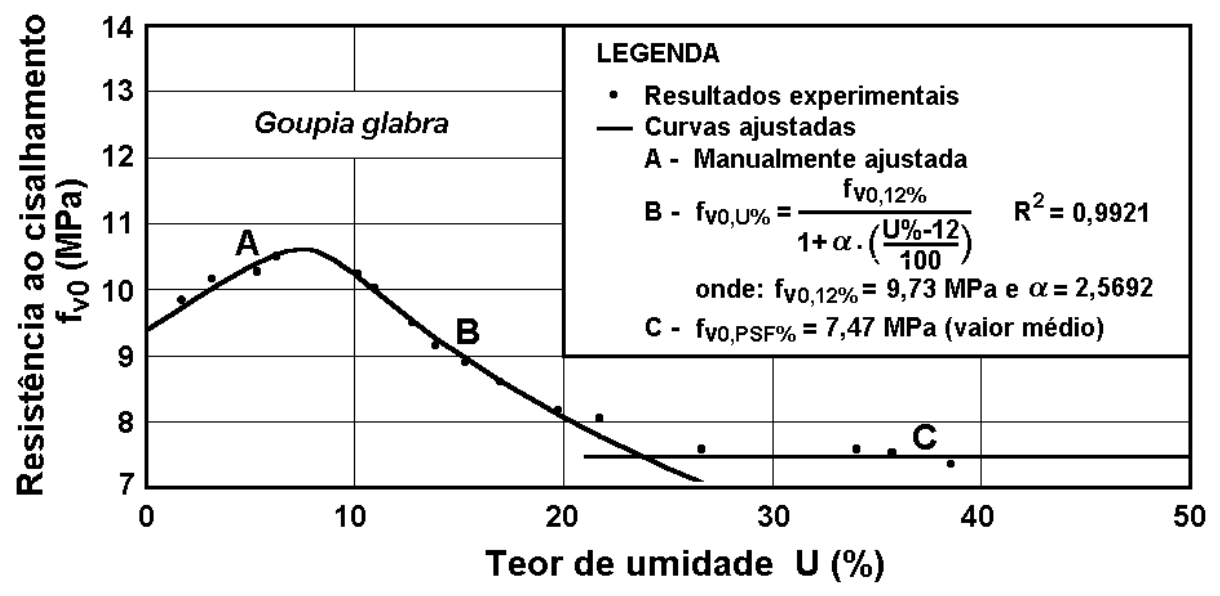

FIGURA 93 - Influência do teor de umidade sobre a resistência cisalhamento, para a Goupia glabra.

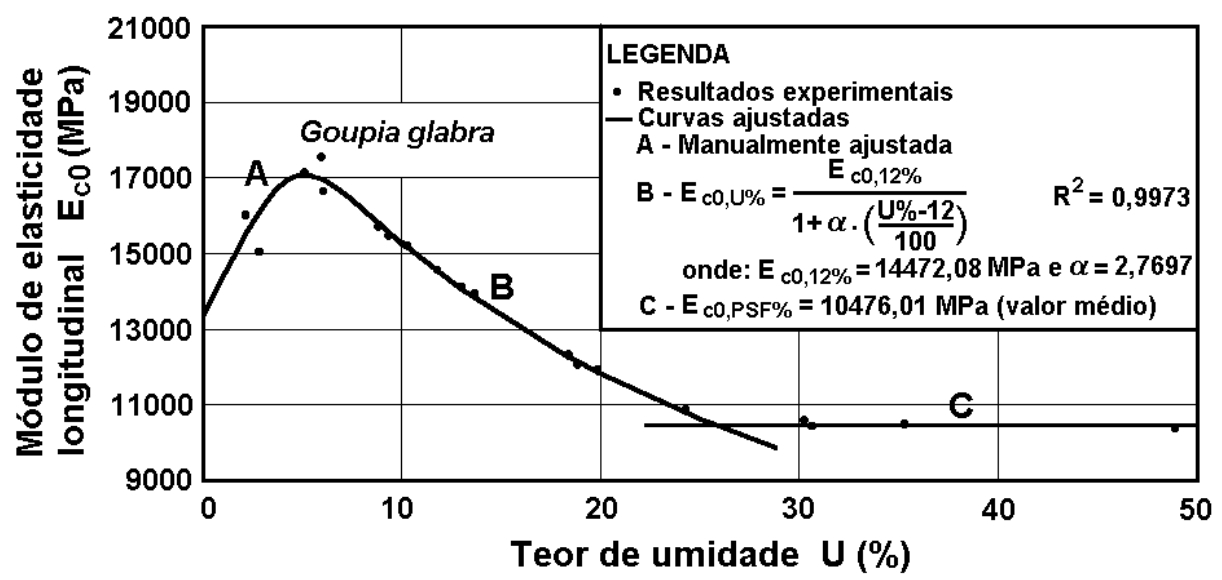

FIGURA 94 - Influência do teor de umidade sobre o módulo de elasticidade longitudinal, para a Goupia glabra.

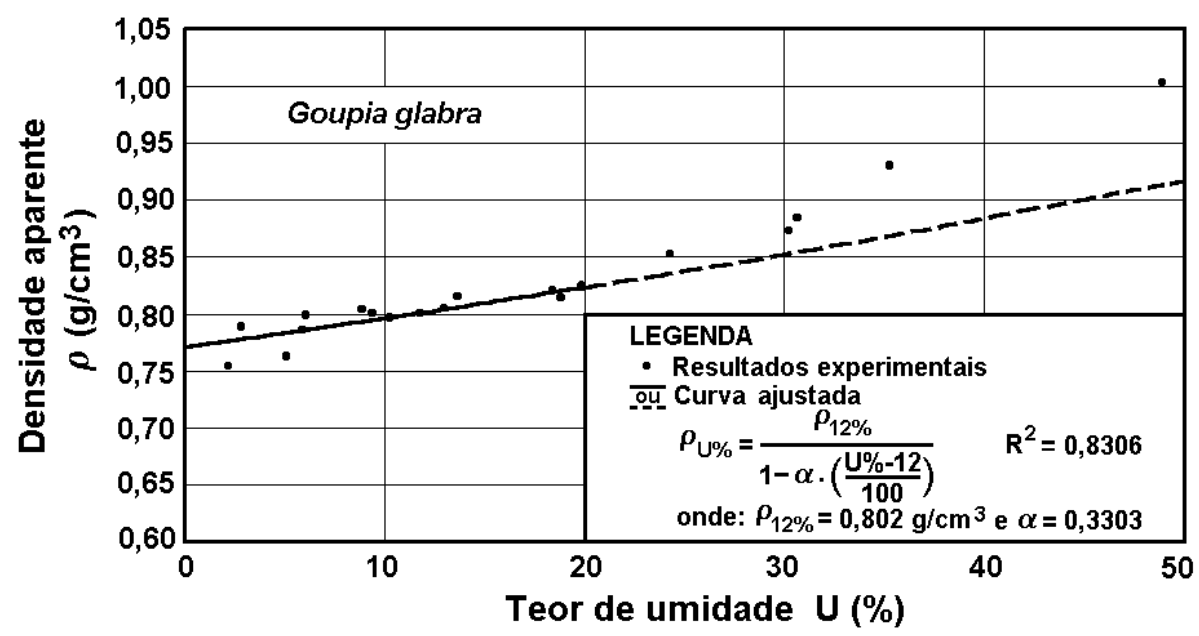

FIGURA 95 - Influência do teor de umidade sobre a densidade aparente, para a Goupia glabra. 


\subsubsection{EUCALIPTO CITRIODORA}

O mesmo procedimento utilizado para o Pinus bahamensis foi adotado para o Eucalipto citriodora e forneceu os resultados apresentados, resumidamente, a seguir.

TABELA 51 - Resumo dos resultados das regressões para as propriedades de resistência do Eucalyptus citriodora.

\begin{tabular}{|c|c|c|c|c|c|}
\hline PROPRIEDADE & $\mathbf{n}$ & $\begin{array}{c}\mathbf{p}_{12} \\
(\mathrm{MPa})\end{array}$ & $\alpha$ & $\mathbf{R}^{2}$ & $\begin{array}{c}\text { Nível de } \\
\text { Significância }\end{array}$ \\
\hline $\begin{array}{l}\text { Resistência à compressão para- } \\
\text { lela às fibras } \mathrm{f}_{\mathrm{c} 0}(\mathrm{MPa})\end{array}$ & 9 & $\mathrm{f}_{\mathrm{c} 0,12 \%}=65,30$ & 3,2169 & 0,9583 & $2,77864 \cdot 10^{-6}$ \\
\hline $\begin{array}{l}\text { Resistência à tração paralela às } \\
\text { fibras } \mathrm{f}_{\mathrm{t} 0}(\mathrm{MPa})\end{array}$ & 6 & $\mathrm{f}_{\mathrm{t} 0,12 \%}=132,49$ & 2,0740 & 0,9950 & $6,10119 \cdot 10^{-6}$ \\
\hline $\begin{array}{l}\text { Resistência ao cisalhamento } \\
\mathrm{f}_{\mathrm{v} 0}(\mathrm{MPa})\end{array}$ & 12 & $\mathrm{f}_{\mathrm{v} 0,12 \%}=13,57$ & 2,5384 & 0,9948 & $6,00465 \cdot 10^{-13}$ \\
\hline MÉDIA & & & 2,6098 & & \\
\hline
\end{tabular}

OBS.: O número de observações (n) inclui a estimativa da propriedade a $12 \%$ de umidade $\left(\mathrm{p}_{12}\right)$

TABELA 52 - Resumo dos resultados da regressão para a rigidez do Eucalyptus citriodora.

\begin{tabular}{cccccc}
\hline \multicolumn{1}{c}{ PROPRIEDADE } & $\mathbf{n}$ & $\begin{array}{c}\mathbf{E}_{\mathbf{1 2}} \\
\text { (MPa) }\end{array}$ & $\alpha$ & $\mathbf{R}^{\mathbf{2}}$ & $\begin{array}{c}\text { Nível de } \\
\text { Significância }\end{array}$ \\
\hline $\begin{array}{l}\text { Módulo de elasticidade longitu- } \\
\text { dinal } \mathrm{E}_{\mathrm{c} 0}(\mathrm{MPa})\end{array}$ & 9 & 17995,27 & 2,8058 & 0,9864 & $5,45463.10^{-8}$ \\
\hline
\end{tabular}

OBS.: $\mathrm{O}$ número de observações $(\mathrm{n})$ inclui a estimativa da rigidez a $12 \%$ de umidade $\left(\mathrm{E}_{12}\right)$

TABELA 53 - Resumo dos resultados da regressão para a densidade aparente do Eucalyptus citriodora.

\begin{tabular}{cccccc}
\hline PROPRIEDADE & $\mathbf{n}$ & $\begin{array}{c}\rho_{12} \\
(\mathbf{M P a})\end{array}$ & $\alpha$ & $\mathbf{R}^{2}$ & $\begin{array}{c}\text { Nível de } \\
\text { Significância }\end{array}$ \\
\hline Densidade aparente $\rho\left(\mathrm{g} / \mathrm{cm}^{3}\right)$ & 9 & 0,957 & $-0,1321$ & 0,9325 & $1,53731.10^{-5}$ \\
\hline
\end{tabular}

OBS.: O número de observações (n) inclui a estimativa da densidade aparente a $12 \%$ de umidade $\left(\rho_{12}\right)$ 


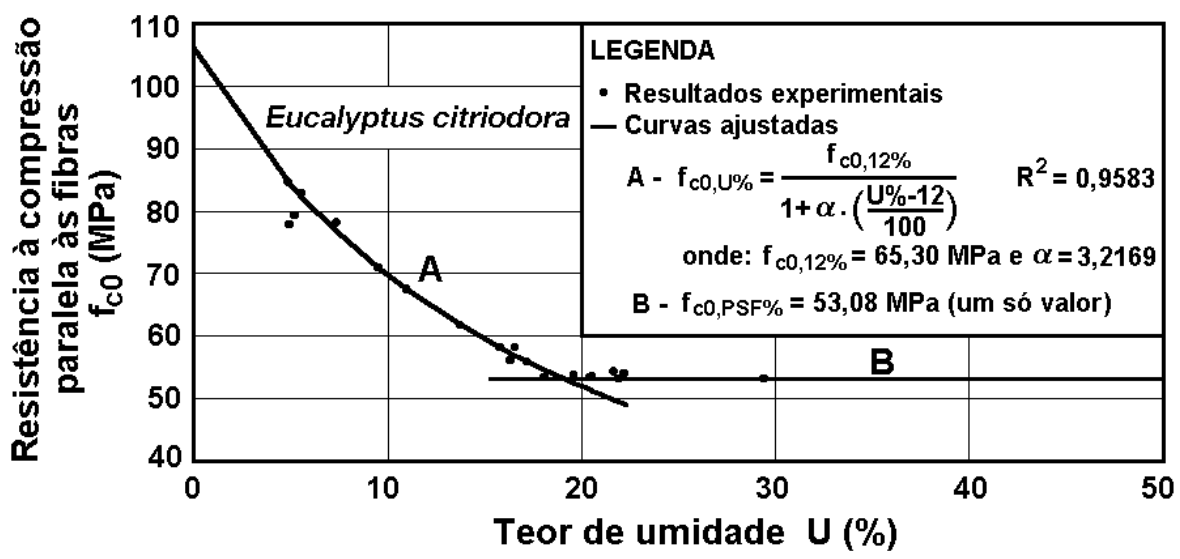

FIGURA 96 - Influência do teor de umidade sobre a resistência à compressão paralela às fibras, para o Eucalyptus citriodora.

Para a resistência à compressão paralela (figura 96) não foi necessário o ajuste manual, pois a curva de regressão, obtida para o intervalo de teores de umidade entre $10 \% \mathrm{e}$ $20 \%$, aparentemente pode ser utilizada para menores teores de umidade. Para a densidade aparente (figura 100), que apresenta um coeficiente $\alpha$ negativo, indicando um aumento da densidade aparente com o aumento do teor de umidade, a curva de regressão também parece se ajustar bem, exceto para valores muito altos do teor de umidade.

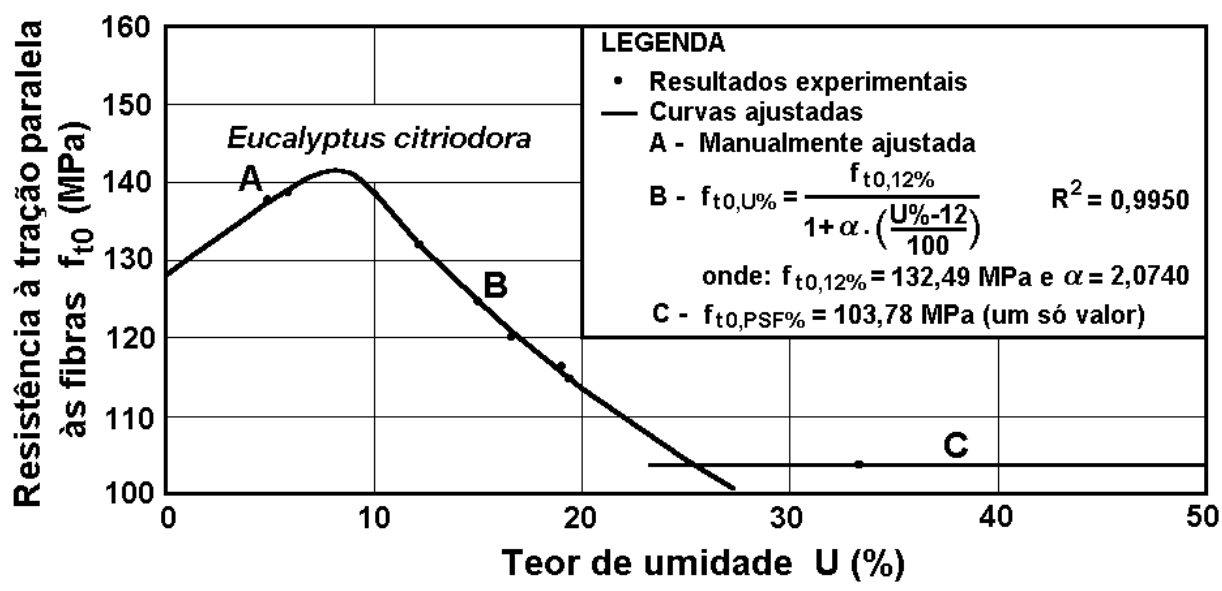

FIGURA 97 - Influência do teor de umidade sobre a resistência à tração paralela às fibras, para o Eucalyptus citriodora. 




FIGURA 98 - Influência do teor de umidade sobre a resistência cisalhamento, para o Eucalyptus citriodora.

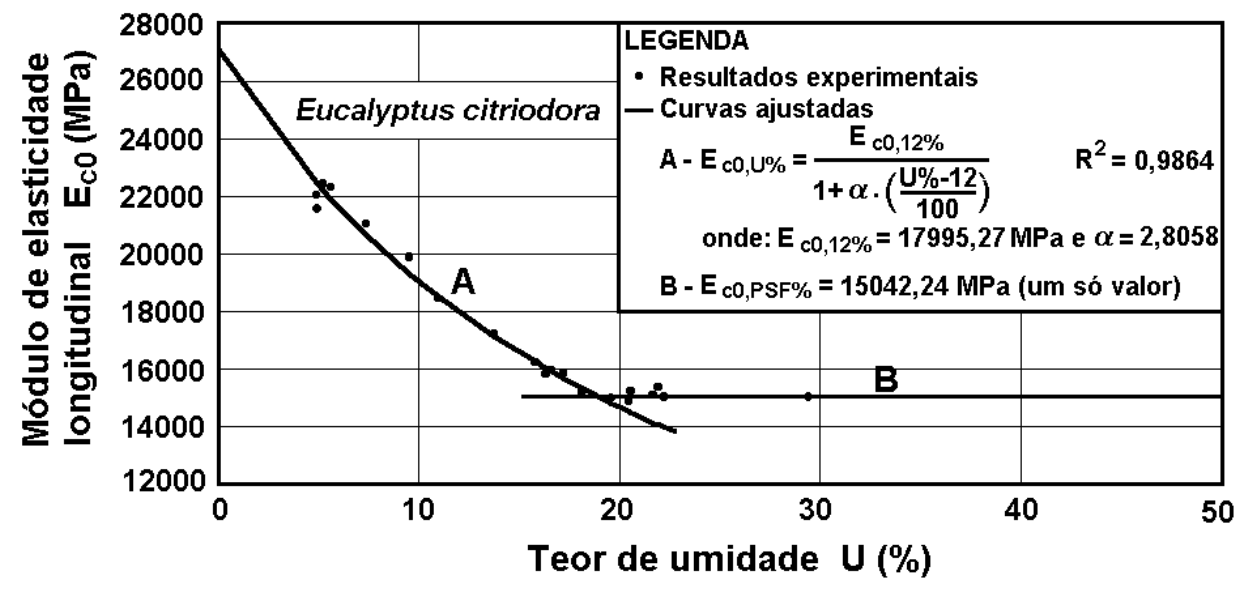

FIGURA 99 - Influência do teor de umidade sobre o módulo de elasticidade longitudinal, para o Eucalyptus citriodora.

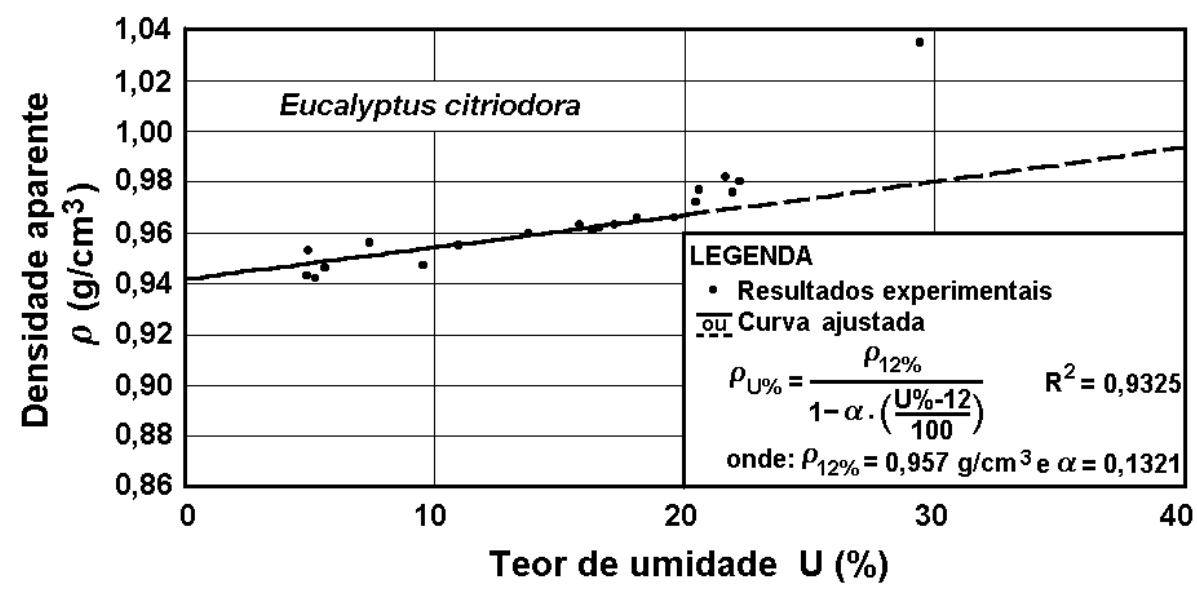

FIGURA 100 - Influência do teor de umidade sobre a densidade aparente, para o Eucalyptus citriodora. 


\subsubsection{JATOBÁ}

O mesmo procedimento utilizado para o Pinus bahamensis foi adotado para o Jatobá e forneceu os resultados apresentados, resumidamente, a seguir.

TABELA 54 - Resumo dos resultados das regressões para as propriedades de resistência do Hymenaea stilbocarpa.

\begin{tabular}{|c|c|c|c|c|c|}
\hline PROPRIEDADE & $\mathbf{n}$ & $\begin{array}{c}\mathbf{p}_{12} \\
(\mathrm{MPa})\end{array}$ & $\alpha$ & $\mathbf{R}^{2}$ & $\begin{array}{c}\text { Nível de } \\
\text { Significância }\end{array}$ \\
\hline $\begin{array}{l}\text { Resistência à compressão } \\
\text { paralela às fibras } f_{c 0}(\mathrm{MPa})\end{array}$ & 8 & $\mathrm{f}_{\mathrm{c} 0,12 \%}=84,34$ & 3,1542 & 0,9989 & $2,39212 \cdot 10^{-10}$ \\
\hline $\begin{array}{l}\text { Resistência à tração paralela às } \\
\text { fibras } \mathrm{f}_{\mathrm{t} 0}(\mathrm{MPa})\end{array}$ & 5 & $\mathrm{f}_{\mathrm{t} 0,12 \%}=164,74$ & 2,0266 & 0,9966 & $5,51099 \cdot 10^{-5}$ \\
\hline $\begin{array}{l}\text { Resistência ao cisalhamento } \\
\mathrm{f}_{\mathrm{v} 0}(\mathrm{MPa})\end{array}$ & 8 & $\mathrm{f}_{\mathrm{v} 0,12 \%}=16,36$ & 2,4079 & 0,9643 & $9,19626 \cdot 10^{-6}$ \\
\hline MÉDIA & & & 2,5296 & & \\
\hline
\end{tabular}

OBS.: O número de observações (n) inclui a estimativa da propriedade a $12 \%$ de umidade $\left(\mathrm{p}_{12}\right)$

TABELA 55 - Resumo dos resultados da regressão para a rigidez do Hymenaea stilbocarpa.

\begin{tabular}{cccccc}
\hline \multicolumn{1}{c}{ PROPRIEDADE } & $\mathbf{n}$ & $\begin{array}{c}\mathbf{E}_{\mathbf{1 2}} \\
\text { (MPa) }\end{array}$ & $\alpha$ & $\mathbf{R}^{\mathbf{2}}$ & $\begin{array}{c}\text { Nível de } \\
\text { Significância }\end{array}$ \\
\hline $\begin{array}{l}\text { Módulo de elasticidade longitu- } \\
\text { dinal } \mathrm{E}_{\mathrm{c} 0}(\mathrm{MPa})\end{array}$ & 8 & 26748,57 & 2,8416 & 0,9992 & $9,14719.10^{-11}$ \\
\hline
\end{tabular}

OBS.: $\mathrm{O}$ número de observações $(\mathrm{n})$ inclui a estimativa da rigidez a $12 \%$ de umidade $\left(\mathrm{E}_{12}\right)$

TABELA 56 - Resumo dos resultados da regressão para a densidade aparente do Hymenaea stilbocarpa.

\begin{tabular}{cccccc}
\hline PROPRIEDADE & $\mathbf{n}$ & $\begin{array}{c}\rho_{12} \\
(\mathbf{M P a})\end{array}$ & $\alpha$ & $\mathbf{R}^{2}$ & $\begin{array}{c}\text { Nível de } \\
\text { Significância }\end{array}$ \\
\hline Densidade aparente $\rho\left(\mathrm{g} / \mathrm{cm}^{3}\right)$ & 8 & 1,035 & $-0,0945$ & 0,8130 & $1,49163 \cdot 10^{-3}$ \\
\hline
\end{tabular}

OBS.: O número de observações (n) inclui a estimativa da densidade aparente a $12 \%$ de umidade $\left(\rho_{12}\right)$ 


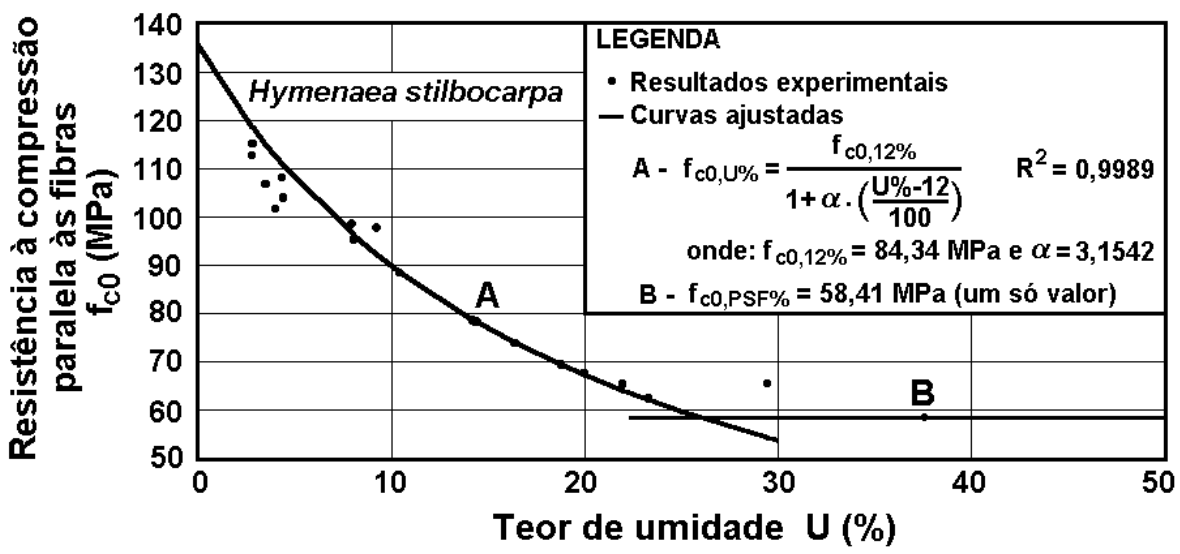

FIGURA 101 - Influência do teor de umidade sobre a resistência à compressão paralela às fibras, para o Hymenaea stilbocarpa.

Para a resistência à compressão paralela (figura 101) não foi necessário o ajuste manual, pois a curva de regressão, obtida para o intervalo de teores de umidade entre $10 \% \mathrm{e}$ $20 \%$, aparentemente pode ser utilizada para menores teores de umidade. Para a densidade aparente (figura 105), que apresenta um coeficiente $\alpha$ negativo, indicando um aumento da densidade aparente com o aumento do teor de umidade, a curva de regressão também parece se ajustar bem, exceto para valores muito altos do teor de umidade.

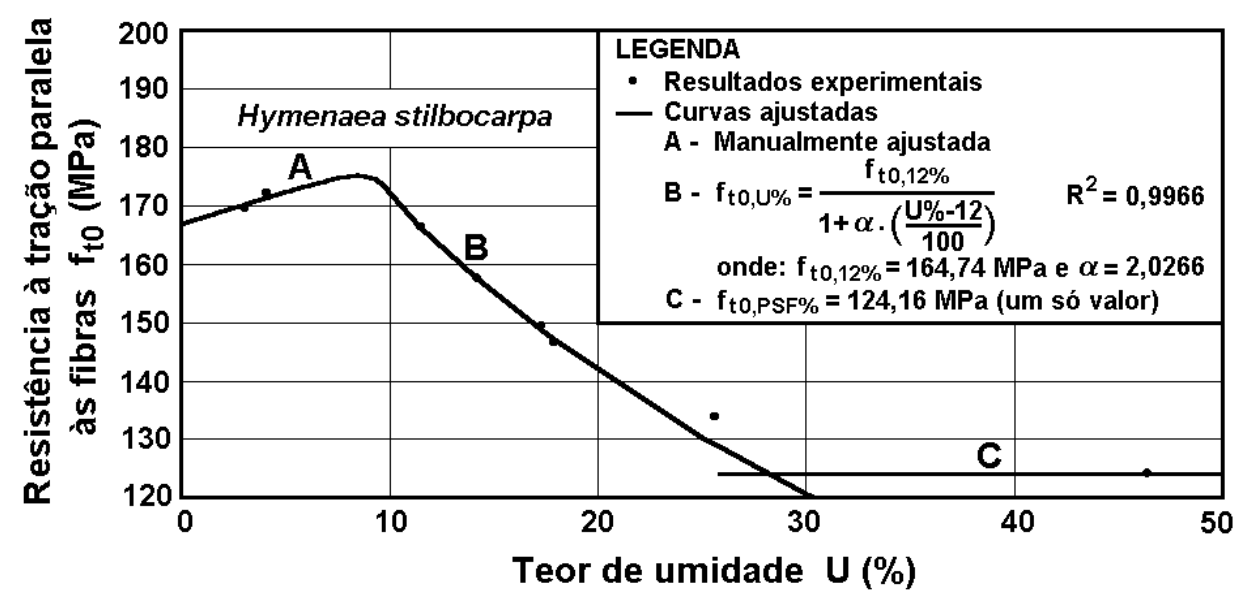

FIGURA 102 - Influência do teor de umidade sobre a resistência à tração paralela às fibras, para o Hymenaea stilbocarpa. 


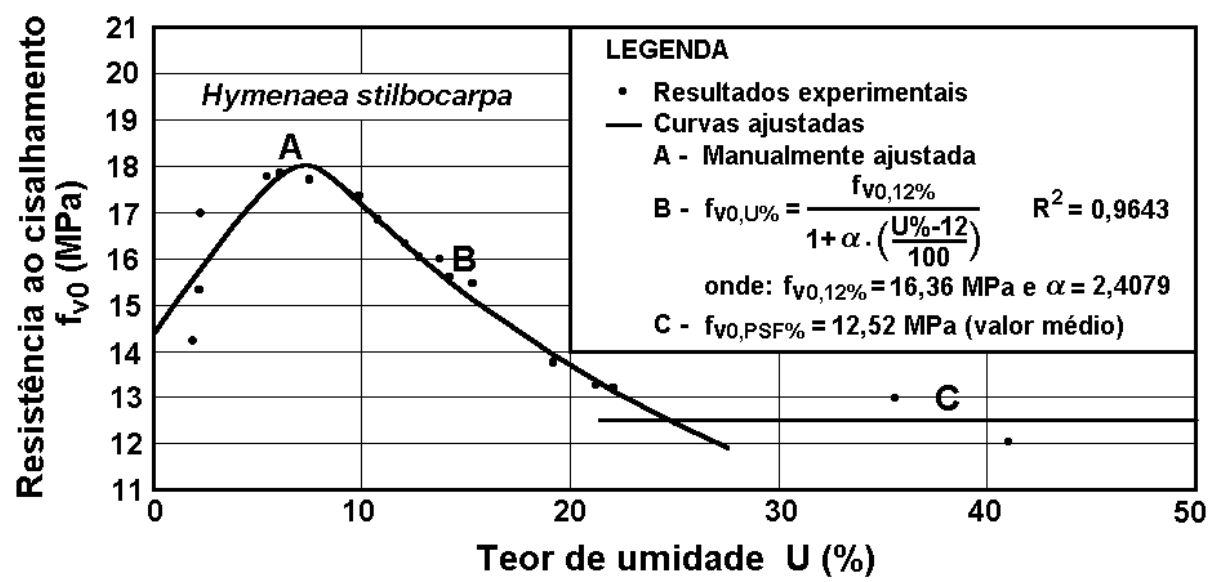

FIGURA 103 - Influência do teor de umidade sobre a resistência cisalhamento, para o $H y$ menaea stilbocarpa.

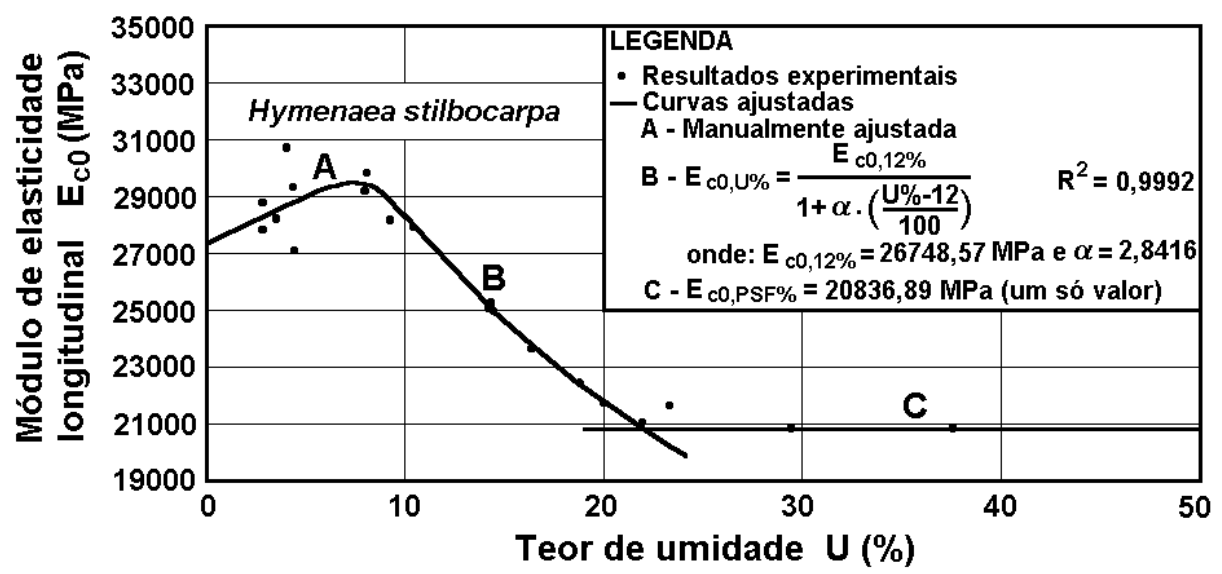

FIGURA 104 - Influência do teor de umidade sobre o módulo de elasticidade longitudinal, para o Hymenaea stilbocarpa.

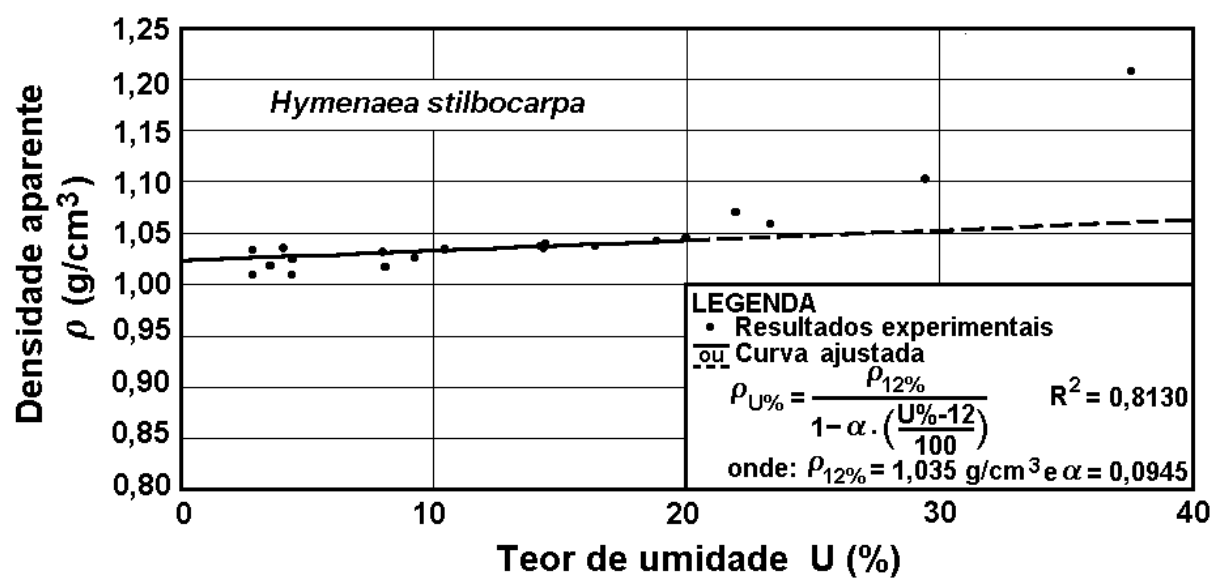

FIGURA 105 - Influência do teor de umidade sobre a densidade aparente, para o Hymenaea stilbocarpa. 


\subsubsection{RESUMO DOS RESULTADOS}

A fim de fornecer uma visão do conjunto dos resultados é apresentada a tabela 57.

TABELA 57 - Resumo dos resultados das regressões.

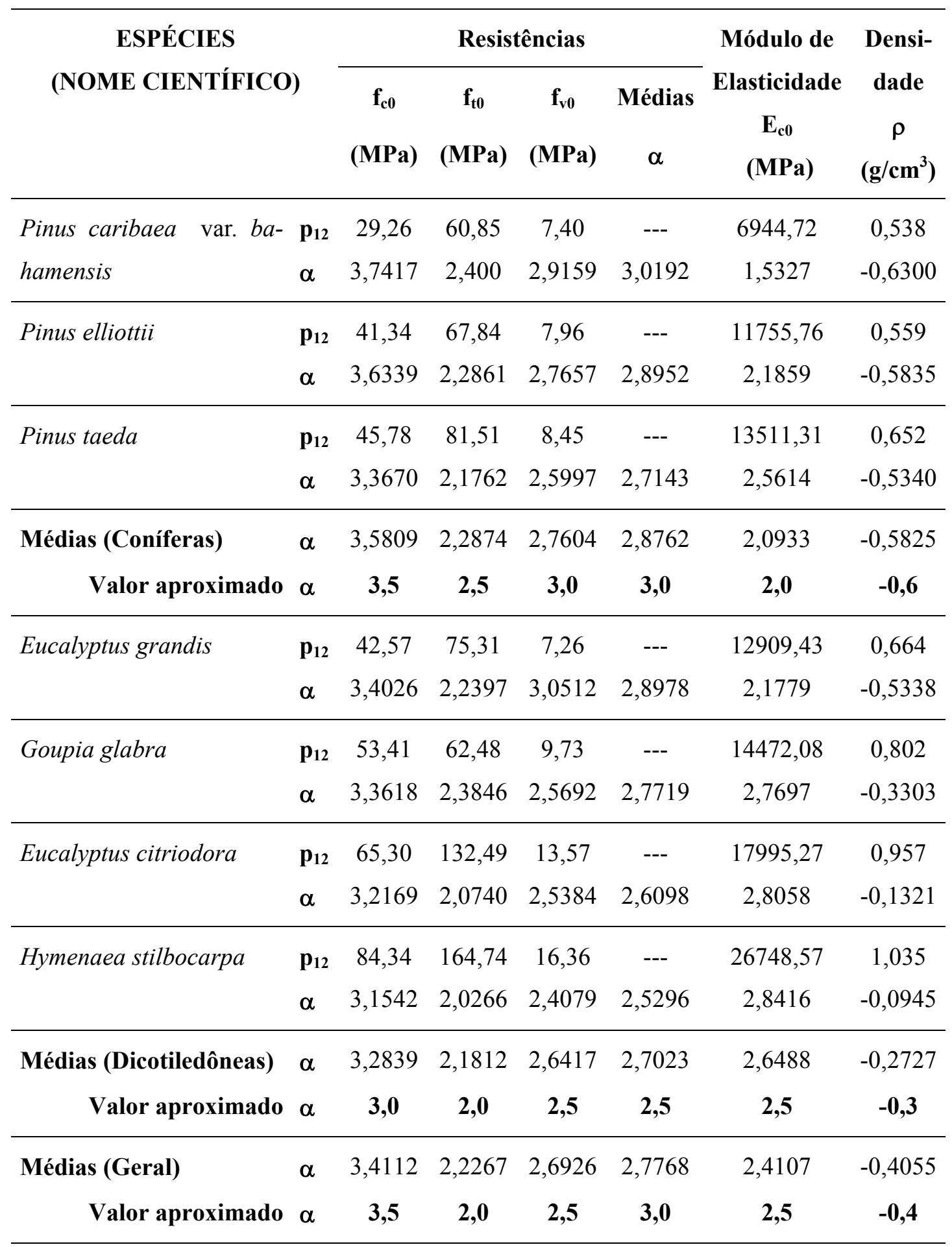




\subsection{VERIFICAÇÃO DA POSSIBILIDADE DE APLICAÇÃO DE ALGUNS MODELOS PARA CORREÇÃO DE DETERMINADA PROPRIEDADE AO TEOR DE UMIDADE DE REFERÊNCIA}

\subsubsection{PINUS BAHAMENSIS}

O modelo de regressão oriundo da expressão adotada pela NBR 7190/97, para correção de uma propriedade de resistência, eq. (43), se ajusta bastante bem aos resultados experimentais obtidos para o Pinus bahamensis.

$$
\mathrm{f}_{12}=\mathrm{f}_{\mathrm{U} \%} \cdot\left[1+\frac{\alpha \cdot(\mathrm{U} \%-12)}{100}\right]
$$

Onde:

$\mathrm{f}_{12}=$ resistência a um teor de umidade de $12 \%$;

$\mathrm{f}_{\mathrm{U} \%}=$ resistência a um teor de umidade de $\mathrm{U} \%$;

$\mathrm{U} \%=$ teor de umidade da madeira, em \%, e

$\alpha=$ coeficiente de correção. A NBR 7190/97 adota $\alpha=3$ para a correção da resistência.

Entretanto, persiste a dúvida se é possível utilizar um coeficiente único, para todas as espécies (ou classes de resistência) e para todas as propriedades de resistência, como adota a NBR 7190/97. Os resultados obtidos mostram pequena diferença destes coeficientes entre as propriedades de resistência das espécies estudadas. Por outro lado, este coeficiente pode ser função da propriedade de resistência, da espécie (ou classe de resistência) e até se a espécie é uma conífera ou uma dicotiledônea.

O resultado corrigido, no entanto, é sempre o valor da propriedade de resistência ao teor de umidade de $12 \%$. Portanto, a comparação dos resultados é a do valor médio de $\mathrm{f}_{12}$, obtida de diversas maneiras (diferentes coeficientes).

A comparação de múltiplas médias pode ser feita utilizando o teste de Tukey. Para escolher um modelo, a ser utilizado na correção das propriedades de resistência, podem ser utilizados os tratamentos definidos na tabela 58. 
TABELA 58 - Tratamentos utilizados no teste de Tukey para o estudo de cada propriedade de resistência.

\begin{tabular}{ll}
\hline TRATA- & DEFINIÇÃO \\
MENTO & \\
\hline
\end{tabular}

$1 \quad \mathrm{O}$ valor de $\mathrm{f}_{12}$ estimado a partir dos resultados experimentais, por interpolação linear de dois resultados com umidade próxima de 12\% (testemunho).

$2 \quad \mathrm{O}$ valor de $\mathrm{f}_{12}$ obtido, através de regressão linear simples, para a propriedade e espécie em questão. Ou seja, um coeficiente $\alpha$ para cada propriedade de resistência de cada espécie (por exemplo, para a resistência à compressão paralela do Pinus caribaea var. bahamensis, conforme a tabela 57, tem-se $\alpha=3,7417$ ).

$3 \quad \mathrm{O}$ valor de $\mathrm{f}_{12}$ obtido através da eq. (43), utilizando para o coeficiente $\alpha$ um valor médio para a espécie (ou classe de resistência) de dicotiledônea (ou conífera), fixada a propriedade de resistência em questão. Ou seja, um coeficiente $\alpha$ para cada propriedade de resistência, mas separando dicotiledôneas de coníferas (por exemplo, para a resistência à compressão paralela do Pinus caribaea var. bahamensis, conforme a tabela 57, tem-se $\alpha=3,5809$ ).

$4 \quad \mathrm{O}$ valor de $\mathrm{f}_{12}$ obtido através da eq. (43), utilizando para o coeficiente $\alpha$ um valor médio para todas as propriedades de resistência da mesma espécie (ou classe de resistência) de dicotiledônea (ou conífera). Ou seja, um coeficiente $\alpha$ único para as propriedades de resistência de cada espécie (por exemplo, para qualquer propriedade de resistência, conforme a tabela 57 usar-se-ia, para o $P i$ nus caribaea var. bahamensis, $\alpha=3,0192$ ).

$5 \quad O$ valor de $f_{12}$ obtido através da eq. (43), utilizando para o coeficiente $\alpha$ um valor médio para todas as propriedades de resistência de todas as espécies (ou classes de resistência) das dicotiledôneas (ou coníferas). Ou seja, um coeficiente $\alpha$ único para as propriedade de resistência, mas separando dicotiledôneas de coníferas (por exemplo, para qualquer propriedade de resistência, conforme a tabela 57 usar-se-ia, para qualquer conífera, $\alpha=2,8762$ ).

$6 \quad \mathrm{O}$ valor de $\mathrm{f}_{12}$ obtido através da eq. (43), utilizando para o coeficiente $\alpha$ um valor médio para todas as espécies (ou classes de resistência) de dicotiledônea (ou conífera), fixada a propriedade de resistência em questão. Ou seja um coeficiente $\alpha$ único para cada propriedade de resistência, independentemente da espécie (por exemplo, para a resistência à compressão paralela, conforme a tabela 57 usar-se-ia, para qualquer espécie, $\alpha=3,4112$ ). 
TABELA 58 - Tratamentos utilizados no teste de Tukey para o estudo de cada propriedade de resistência - Continuação.

\begin{tabular}{cc}
\hline $\begin{array}{c}\text { TRATA- } \\
\text { MENTO }\end{array}$ & DEFINIÇÃo \\
\hline 7 & O valor de $\mathrm{f}_{12}$ obtido através da eq. (43), utilizando para o coeficiente $\alpha$ um va- \\
& lor médio para todas as propriedades de resistência de todas as espécies (ou \\
& classes de resistência), independentemente de ser dicotiledônea ou conífera. Ou \\
& seja um coeficiente $\alpha$ único, independentemente da propriedade de resistência \\
& e da espécie (por exemplo, para qualquer propriedade de resistência, conforme \\
& a tabela 57 usar-se-ia, para qualquer espécie, $\alpha=2,7768)$. \\
& Proposta da NBR 7190/97, com $\alpha=3$. \\
\hline
\end{tabular}

O estudo destes tratamentos, para a resistência à compressão paralela às fibras em Pinus bahamensis, através do teste de Tukey, fornece os resultados apresentados nas tabelas 59 a 61 . O nível de significância superior a 5\%, na análise de variância apresentada na tabela 59, já é indicativo de que não existe diferença significativa entre as médias dos diversos tratamentos. Entretanto GOMES (1982), devido a baixa precisão do teste F, recomenda que o teste de Tukey seja aplicado para se obter os grupos de médias homogêneas. Os resultados obtidos, na tabela 61, indicam não existir diferenças significativas entre as médias (em nenhum dos contrastes) e a média de todos os tratamentos pode ser considerada a mesma.

TABELA 59 - Teste de Tukey - Análise de variância (Resistência à compressão paralela, $\mathrm{f}_{\mathrm{c} 0}$ em MPa - Pinus caribaea var. bahamensis)

\begin{tabular}{lccccc}
\hline Fonte de variação & $\begin{array}{c}\text { Soma dos } \\
\text { quadrados }\end{array}$ & $\begin{array}{c}\text { Graus de } \\
\text { liberdade }\end{array}$ & $\begin{array}{c}\text { Quadrado } \\
\text { médio }\end{array}$ & $\begin{array}{c}\text { Estatístico } \\
\text { F }\end{array}$ & $\begin{array}{c}\text { Nível de } \\
\text { significância }\end{array}$ \\
\hline Tratamentos & 1,0219600 & 7 & 0,1459943 & 0,579 & 0,7674 \\
Resíduos & 8,0642000 & 32 & 0,2520063 & & \\
\hline Total (corrigido) & 9,0861600 & 39 & & & \\
\hline
\end{tabular}

OBS.: Nível de confiança de 95\% 
TABELA 60 - Teste de Tukey - Tabela de médias (Resistência à compressão paralela, $\mathrm{f}_{\mathrm{c} 0} \mathrm{em}$ MPa - Pinus caribaea var. bahamensis)

\begin{tabular}{ccccccc}
\hline \multirow{2}{*}{$\begin{array}{c}\text { Trata- } \\
\text { mento }\end{array}$} & $\begin{array}{c}\text { Quan- } \\
\text { tidade }\end{array}$ & Média & \multicolumn{2}{c}{ Desvio padrão } & \multicolumn{2}{c}{ Intervalo de confiança da média } \\
\cline { 3 - 7 } & & & Interno & Uniformizado & L. inferior & L. superior \\
\hline 1 & 5 & 29,260000 & 0,0000000 & 0,2245022 & 28,745713 & 29,774287 \\
2 & 5 & 29,192000 & 0,0759868 & 0,2245022 & 28,677713 & 29,706287 \\
3 & 5 & 29,126000 & 0,0864639 & 0,2245022 & 28,611713 & 29,640287 \\
4 & 5 & 28,902000 & 0,2668220 & 0,2245022 & 28,387713 & 29,416287 \\
5 & 5 & 28,846000 & 0,3186471 & 0,2245022 & 28,331713 & 29,360287 \\
6 & 5 & 29,060000 & 0,1308052 & 0,2245022 & 28,545713 & 29,574287 \\
7 & 5 & 28,808000 & 0,3547591 & 0,2245022 & 28,293713 & 29,322287 \\
8 & 5 & 28,894000 & 0,2725179 & 0,2245022 & 28,379713 & 29,408287 \\
\hline \multirow{2}{*}{ Total } & 40 & 29,011000 & 0,0793735 & 0,0793735 & 28,829172 & 29,192828 \\
\hline
\end{tabular}

OBS.: Nível de confiança de 95\%

TABELA 61 - Teste de Tukey - Grupos de médias homogêneas (Resistência à compressão paralela, $\mathrm{f}_{\mathrm{c} 0}$ em MPa - Pinus caribaea var. bahamensis)

\begin{tabular}{cccccc}
\hline Tratamento & Quantidade & Média & \multicolumn{2}{c}{ Grupos homogêneos } \\
\hline 7 & 5 & 28,808000 & $\mathrm{X}$ & & \\
5 & 5 & 28,846000 & $\mathrm{X}$ & & \\
8 & 5 & 28,894000 & $\mathrm{X}$ & & \\
4 & 5 & 28,902000 & $\mathrm{X}$ & & \\
6 & 5 & 29,060000 & $\mathrm{X}$ & & \\
3 & 5 & 29,126000 & $\mathrm{X}$ & & \\
2 & 5 & 29,192000 & $\mathrm{X}$ & & Limite \\
1 & 5 & 29,260000 & $\mathrm{X}$ & & 1,02857 \\
\hline Contraste & & & & Diferença & $+/-$ \\
\hline $1-2$ & & & & 0,06800 & 1,02857 \\
$1-3$ & & & & 0,13400 & 1,02857 \\
$1-4$ & & & & 0,35800 & 1,02857 \\
$1-5$ & & & & 0,41400 & 1,02857 \\
$1-6$ & & & &
\end{tabular}


TABELA 61 - Teste de Tukey - Grupos de médias homogêneas (Resistência à compressão paralela, $\mathrm{f}_{\mathrm{c} 0}$ em MPa - Pinus caribaea var. bahamensis) - Continuação

\begin{tabular}{|c|c|c|c|}
\hline Contraste & Diferença & $+/-$ & Limite \\
\hline $1-7$ & 0,45200 & & 1,02857 \\
\hline $1-8$ & 0,36600 & & 1,02857 \\
\hline $2-3$ & 0,06600 & & 1,02857 \\
\hline $2-4$ & 0,29000 & & 1,02857 \\
\hline $2-5$ & 0,34600 & & 1,02857 \\
\hline $2-6$ & 0,13200 & & 1,02857 \\
\hline $2-7$ & 0,38400 & & 1,02857 \\
\hline $2-8$ & 0,29800 & & 1,02857 \\
\hline $3-4$ & 0,22400 & & 1,02857 \\
\hline $3-5$ & 0,28000 & & 1,02857 \\
\hline $3-6$ & 0,06600 & & 1,02857 \\
\hline $3-7$ & 0,31800 & & 1,02857 \\
\hline $3-8$ & 0,23200 & & 1,02857 \\
\hline $4-5$ & 0,05600 & & 1,02857 \\
\hline $4-6$ & $-0,15800$ & & 1,02857 \\
\hline $4-7$ & 0,09400 & & 1,02857 \\
\hline $4-8$ & 0,00800 & & 1,02857 \\
\hline $5-6$ & $-0,21400$ & & 1,02857 \\
\hline $5-7$ & 0,03800 & & 1,02857 \\
\hline $5-8$ & $-0,04800$ & & 1,02857 \\
\hline $6-7$ & 0,25200 & & 1,02857 \\
\hline $6-8$ & 0,16600 & & 1,02857 \\
\hline $7-8$ & $-0,08600$ & & 1,02857 \\
\hline
\end{tabular}

* Denota uma diferença estatisticamente significativa (nível de confiança 95\%).

Procedimento análogo aplicado às outras propriedades de resistência, do Pinus bahamensis, mostram que: para a resistência à tração paralela às fibras existem diferenças significativas entre as médias (ver tabela 62), e se pode considerar três grupos homogêneos, nos quais os tratamentos 4,5 e 8 não são estatisticamente equivalentes aos usados como testemunhos (tratamentos 1 e 2); já para a resistência ao cisalhamento (ver tabela 63) todos os tratamentos podem ser considerados como um grupo homogêneo de mesma média. 
TABELA 62 - Teste de Tukey - Grupos de médias homogêneas (Resistência à tração paralela, $\mathrm{f}_{\mathrm{t} 0} \mathrm{em} \mathrm{MPa} \mathrm{-} \mathrm{Pinus} \mathrm{caribaea} \mathrm{var.} \mathrm{bahamensis)}$

\begin{tabular}{|c|c|c|c|c|c|}
\hline Tratamento & Quantidade & Média & \multicolumn{3}{|c|}{ Grupos homogêneos } \\
\hline 6 & 3 & 60,470000 & $\mathrm{X}$ & & \\
\hline 3 & 3 & 60,630000 & $\mathrm{X}$ & & \\
\hline 1 & 3 & 60,850000 & $\mathrm{XX}$ & & \\
\hline 2 & 3 & 60,933333 & $\mathrm{XX}$ & & \\
\hline 7 & 3 & 61,943333 & $\mathrm{XX}$ & & \\
\hline 5 & 3 & 62,210000 & $\mathrm{X}$ & & \\
\hline 8 & 3 & 62,543333 & $X$ & & \\
\hline 4 & 3 & 62,593333 & $\mathrm{X}$ & & \\
\hline Contraste & & & Diferença & $+/-$ & Limite \\
\hline $1-2$ & & & $-0,08333$ & & 1,10125 \\
\hline $1-3$ & & & 0,22000 & & 1,10125 \\
\hline $1-4$ & & & $-1,74333$ & & $1,10125 *$ \\
\hline $1-5$ & & & $-1,36000$ & & $1,10125 *$ \\
\hline $1-6$ & & & 0,38000 & & 1,10125 \\
\hline $1-7$ & & & $-1,09333$ & & 1,10125 \\
\hline $1-8$ & & & $-1,69333$ & & $1,10125 *$ \\
\hline $2-3$ & & & 0,30333 & & 1,10125 \\
\hline $2-4$ & & & $-1,66000$ & & $1,10125 *$ \\
\hline $2-5$ & & & $-1,27667$ & & $1,10125 *$ \\
\hline $2-6$ & & & 0,46333 & & 1,10125 \\
\hline $2-7$ & & & $-1,01000$ & & 1,10125 \\
\hline $2-8$ & & & $-1,61000$ & & $1,10125 *$ \\
\hline $3-4$ & & & $-1,96333$ & & $1,10125 *$ \\
\hline $3-5$ & & & $-1,58000$ & & $1,10125 *$ \\
\hline $3-6$ & & & 0,16000 & & 1,10125 \\
\hline $3-7$ & & & $-1,31333$ & & $1,10125 *$ \\
\hline $3-8$ & & & $-1,91333$ & & $1,10125 *$ \\
\hline $4-5$ & & & 0,38333 & & 1,10125 \\
\hline $4-6$ & & & 2,12333 & & $1,10125 *$ \\
\hline $4-7$ & & & 0,65000 & & 1,10125 \\
\hline
\end{tabular}


TABELA 62 - Teste de Tukey - Grupos de médias homogêneas (Resistência à tração paralela, $\mathrm{f}_{\mathrm{t} 0}$ em MPa - Pinus caribaea var. bahamensis) - Continuação.

\begin{tabular}{cccc}
\hline Tratamento & Quantidade & Média & \multicolumn{2}{c}{ Grupos homogêneos } \\
\hline $4-8$ & 0,05000 & 1,10125 \\
$5-6$ & 1,74000 & $1,10125^{*}$ \\
$5-7$ & 0,26667 & 1,10125 \\
$5-8$ & $-0,33333$ & 1,10125 \\
$6-7$ & $-1,47333$ & $1,10125^{*}$ \\
$6-8$ & $-2,07333$ & $1,10125^{*}$ \\
$7-8$ & $-0,60000$ & 1,10125 \\
\hline
\end{tabular}

* Denota uma diferença estatisticamente significativa (nível de confiança 95\%).

TABELA 63 - Teste de Tukey - Grupos de médias homogêneas (Resistência ao cisalhamento, $\mathrm{f}_{\mathrm{v} 0} \mathrm{em} \mathrm{MPa} \mathrm{-} \mathrm{Pinus} \mathrm{caribaea} \mathrm{var.} \mathrm{bahamensis)}$

\begin{tabular}{|c|c|c|c|c|c|}
\hline Tratamento & Quantidade & Média & \multicolumn{3}{|c|}{ Grupos homogêneos } \\
\hline 6 & 6 & 7,3533333 & $\mathrm{X}$ & & \\
\hline 3 & 6 & 7,3666667 & $\mathrm{X}$ & & \\
\hline 7 & 6 & 7,3716667 & $\mathrm{X}$ & & \\
\hline 5 & 6 & 7,3900000 & $\mathrm{X}$ & & \\
\hline 1 & 6 & 7,4000000 & $\mathrm{X}$ & & \\
\hline 2 & 6 & 7,4000000 & $\mathrm{X}$ & & \\
\hline 8 & 6 & 7,4183333 & $\mathrm{X}$ & & \\
\hline 4 & 6 & 7,4233333 & $\mathrm{X}$ & & \\
\hline Contraste & & & Diferença & $+/-$ & Limite \\
\hline $1-2$ & & & 0,00000 & & 0,11708 \\
\hline $1-3$ & & & 0,03333 & & 0,11708 \\
\hline $1-4$ & & & $-0,02333$ & & 0,11708 \\
\hline $1-5$ & & & 0,01000 & & 0,11708 \\
\hline $1-6$ & & & 0,04667 & & 0,11708 \\
\hline $1-7$ & & & 0,02833 & & 0,11708 \\
\hline $1-8$ & & & $-0,01833$ & & 0,11708 \\
\hline $2-3$ & & & 0,03333 & & 0,11708 \\
\hline
\end{tabular}


TABELA 63 - Teste de Tukey - Grupos de médias homogêneas (Resistência ao cisalhamento, $\mathrm{f}_{\mathrm{v} 0}$ em MPa - Pinus caribaea var. bahamensis) - Continuação.

\begin{tabular}{ccc}
\hline Contraste & Diferença & + Limite \\
\hline $2-4$ & $-0,02333$ & 0,11708 \\
$2-5$ & 0,01000 & 0,11708 \\
$2-6$ & 0,04667 & 0,11708 \\
$2-7$ & 0,02833 & 0,11708 \\
$2-8$ & $-0,01833$ & 0,11708 \\
$3-4$ & $-0,05667$ & 0,11708 \\
$3-5$ & $-0,02333$ & 0,11708 \\
$3-6$ & 0,01333 & 0,11708 \\
$3-7$ & $-0,00500$ & 0,11708 \\
$3-8$ & $-0,05167$ & 0,11708 \\
$4-5$ & 0,03333 & 0,11708 \\
$4-6$ & 0,07000 & 0,11708 \\
$4-7$ & 0,05167 & 0,11708 \\
$4-8$ & 0,00500 & 0,11708 \\
$5-6$ & 0,03667 & 0,11708 \\
$5-7$ & 0,01833 & 0,11708 \\
$5-8$ & $-0,02833$ & 0,11708 \\
$6-7$ & $-0,01833$ & 0,11708 \\
$6-8$ & $-0,06500$ & 0,11708 \\
$7-8$ & $-0,04667$ & 0,11708 \\
\hline
\end{tabular}

* Denota uma diferença estatisticamente significativa (nível de confiança 95\%).

Para correção do módulo de elasticidade longitudinal, o modelo de regressão oriundo da expressão adotada pela NBR 7190/97, eq. (44), também se ajusta bastante bem aos resultados experimentais do Pinus bahamensis.

$$
\mathrm{E}_{12}=\mathrm{E}_{\mathrm{U} \%} \cdot\left[1+\frac{\alpha \cdot(\mathrm{U} \%-12)}{100}\right]
$$

Onde: 
$\mathrm{E}_{12}=$ rigidez (módulo de elasticidade longitudinal) da madeira a um teor de umidade de $12 \%$;

$\mathrm{E}_{\mathrm{U} \%}=$ rigidez (módulo de elasticidade longitudinal) da madeira a um teor de umidade de $\mathrm{U} \%$;

$\mathrm{U} \%=$ teor de umidade da madeira, em \%, e

$\alpha=$ coeficiente de correção. A NBR 7190/97 adota $\alpha=2$ para correção do módulo de elasticidade.

De maneira análoga ao que foi feito para as propriedades de resistência, a comparação de múltiplas médias no estudo do módulo de elasticidade longitudinal, também utilizando o teste de Tukey, pode utilizar os tratamentos definidos na tabela 64 .

TABELA 64 - Tratamentos utilizados no teste de Tukey para o estudo do módulo de elasticidade longitudinal.

\section{TRATA- \\ DEFINIÇÃO \\ MENTO}

$1 \quad \mathrm{O}$ valor de $\mathrm{E}_{12}$ estimado a partir dos resultados experimentais, por interpolação linear de dois resultados com umidade próxima de 12\% (testemunho).

$2 \mathrm{O}$ valor de $\mathrm{E}_{12}$ obtido, através de regressão linear simples, utilizando o modelo da eq. (44), para a espécie em questão. Ou seja, um coeficiente $\alpha$ para cada espécie (por exemplo, para o Pinus caribaea var. bahamensis, conforme a tabela 57 , tem-se $\alpha=1,5327$ ).

$3 \mathrm{O}$ valor de $\mathrm{E}_{12}$ obtido através da eq. (44), utilizando para o coeficiente $\alpha$ um valor médio para as dicotiledôneas (ou conífera). Ou seja, um coeficiente $\alpha$ para as dicotiledôneas e outro para as coníferas (por exemplo, para o Pinus caribaea var. bahamensis, que é conífera, conforme a tabela 57, tem-se $\alpha=$ 2,0933).

$4 \quad \mathrm{O}$ valor de $\mathrm{E}_{12}$ obtido através da eq. (44), utilizando para o coeficiente $\alpha$ um valor médio para todas as espécies. Ou seja um coeficiente $\alpha$ único, independentemente da espécie (por exemplo, para qualquer espécie, conforme a tabela 57, usar-se-ia $\alpha=2,4107)$.

5 Proposta da NBR 7190/97, com $\alpha=2$. 
Aplicando-se o teste de Tukey, para o módulo de elasticidade longitudinal, verificase que, com estes tratamentos, não se encontram diferenças significativas entre as médias, ver tabela 65 , e se pode considerar que os diversos tratamentos fornecem a mesma média.

TABELA 65 - Teste de Tukey - Grupos de médias homogêneas (Módulo de elasticidade longitudinal, $\mathrm{E}_{\mathrm{c} 0}$ em MPa - Pinus caribaea var. bahamensis)

\begin{tabular}{|c|c|c|c|c|c|}
\hline Tratamento & Quantidade & Média & \multicolumn{3}{|c|}{ Grupos homogêneos } \\
\hline 2 & 5 & 6912,8520 & $\mathrm{X}$ & & \\
\hline 1 & 5 & 6944,7200 & $\mathrm{X}$ & & \\
\hline 5 & 5 & 6963,8200 & $\mathrm{X}$ & & \\
\hline 3 & 5 & 6973,9940 & $\mathrm{X}$ & & \\
\hline 4 & 5 & 7008,6140 & $\mathrm{X}$ & & \\
\hline Contraste & & & Diferença & $+/-$ & Limite \\
\hline $1-2$ & & & 31,8680 & & 256,204 \\
\hline $1-3$ & & & $-29,2740$ & & 256,204 \\
\hline $1-4$ & & & $-63,8940$ & & 256,204 \\
\hline $1-5$ & & & $-19,1000$ & & 256,204 \\
\hline $2-3$ & & & $-61,1420$ & & 256,204 \\
\hline $2-4$ & & & $-95,7620$ & & 256,204 \\
\hline $2-5$ & & & $-50,9680$ & & 256,204 \\
\hline $3-4$ & & & $-34,6200$ & & 256,204 \\
\hline $3-5$ & & & 10,1740 & & 256,204 \\
\hline $4-5$ & & & 44,7940 & & 256,204 \\
\hline
\end{tabular}

* Denota uma diferença estatisticamente significativa (nível de confiança 95\%).

Para correção da densidade aparente, a NBR 7190/97 não apresenta modelo. O modelo de regressão oriundo da expressão adotada pela NBR 7190/97, para correção das propriedades de resistência e rigidez, pode ser estendido e testado para a densidade aparente, eq. (45). BROCHARD (1960) apresenta um modelo bastante simples, eq. (46), e LOGSDON (1992) utilizou outro modelo, eq. (47), que também podem ser utilizados. 
$\rho_{12}=\rho_{\mathrm{U} \%} \cdot\left[1+\frac{\alpha \cdot(\mathrm{U} \%-12)}{100}\right]$

$\rho_{12}=\rho_{\mathrm{U} \%} \cdot \frac{(1+12 / 100)}{(1+\mathrm{U} \% / 100)}$

$\rho_{12}=\rho_{\mathrm{U} \%}+\rho_{\mathrm{U} \%}\left[\left(1-\delta_{\mathrm{V}}\right) \cdot \frac{(12-\mathrm{U} \%)}{100}\right], \operatorname{com} \delta_{\mathrm{V}}=\frac{\Delta \mathrm{V}}{\mathrm{U} \%}$ e $\Delta \mathrm{V}=\frac{\mathrm{V}_{\mathrm{U} \%}-\mathrm{V}_{\text {seca }}}{\mathrm{V}_{\text {seca }}} \cdot 100 \%$

Onde:

$\rho_{12}=$ densidade aparente ao teor de umidade de $12 \%$;

$\rho_{\mathrm{U} \%}=$ densidade aparente ao teor de umidade $\mathrm{U} \%$;

$\mathrm{U} \%=$ teor de umidade da madeira, no instante do ensaio, em \%;

$\alpha=$ coeficiente de correção;

$\delta_{\mathrm{V}} \quad=$ coeficiente de retratibilidade volumétrica;

$\Delta \mathrm{V}=$ retração volumétrica, para a variação de umidade entre $\mathrm{U} \%$ e $0 \%$, em \%;

$\mathrm{V}_{\mathrm{U} \%}=$ volume, do corpo-de-prova, ao teor de umidade $\mathrm{U} \%$, e

$\mathrm{V}_{\text {seca }}=$ volume, do corpo-de-prova, para a madeira seca $\mathrm{U}=0 \%$.

De maneira análoga ao que foi feito para as propriedades de resistência e de rigidez, a comparação de múltiplas médias no estudo da densidade aparente, para o Pinus bahamensis, também utilizando o teste de Tukey, pode utilizar os tratamentos definidos na tabela 66.

TABELA 66 - Tratamentos utilizados no teste de Tukey para o estudo da densidade aparente.

\section{TRATA-}

DEFINIÇÃO

\section{MENTO}

1 O valor de $\rho_{12}$ estimado a partir dos resultados experimentais, por interpolação linear de dois resultados com umidade próxima de 12\% (testemunho).

2 O valor de $\rho_{12}$ obtido, através de regressão linear simples, com o modelo da eq, (45), para a espécie em questão. Ou seja, um coeficiente $\alpha$ para cada espécie (por exemplo, para o Pinus caribaea var. bahamensis, conforme a tabela 57, tem-se $\alpha=-0,6300)$. 
TABELA 66 - Tratamentos utilizados no teste de Tukey para o estudo da densidade aparente - Continuação.

\begin{tabular}{cl}
\hline $\begin{array}{c}\text { TRATA- } \\
\text { MENTO }\end{array}$ & DEFINIÇÃO \\
\hline 3 & O valor de $\rho_{12}$ obtido através da eq. (46). \\
4 & O valor de $\rho_{12}$ obtido através da eq. (47). \\
5 & O valor de $\rho_{12}$ obtido através da eq. (45), utilizando para o coeficiente $\alpha$ um \\
& valor médio para as dicotiledôneas (ou conífera). Ou seja, um coeficiente $\alpha$ pa- \\
& ra as dicotiledôneas e outro para as coníferas (por exemplo, para o Pinus cari- \\
& baea var. bahamensis, que é conífera, conforme a tabela 57, tem-se $\alpha=-$ \\
& 0,5825). \\
& O valor de $\rho_{12}$ obtido através da eq. (45), utilizando para o coeficiente $\alpha$ um \\
& valor médio para todas as espécies. Ou seja um coeficiente $\alpha$ único, indepen- \\
& dentemente da espécie (por exemplo, para qualquer espécie usar-se-ia, confor- \\
& me a tabela $57, \alpha=-0,4055)$.
\end{tabular}

Aplicando-se o teste de Tukey, para a densidade aparente, verifica-se que, com estes tratamentos, não se encontram diferenças significativas (ver tabela 67) entre as médias, e se pode considerar que os diversos tratamentos fornecem a mesma média.

TABELA 67 - Teste de Tukey - Grupos de médias homogêneas (Densidade aparente, $\rho$ em $\mathrm{g} / \mathrm{cm}^{3}$ - Pinus caribaea var. bahamensis)

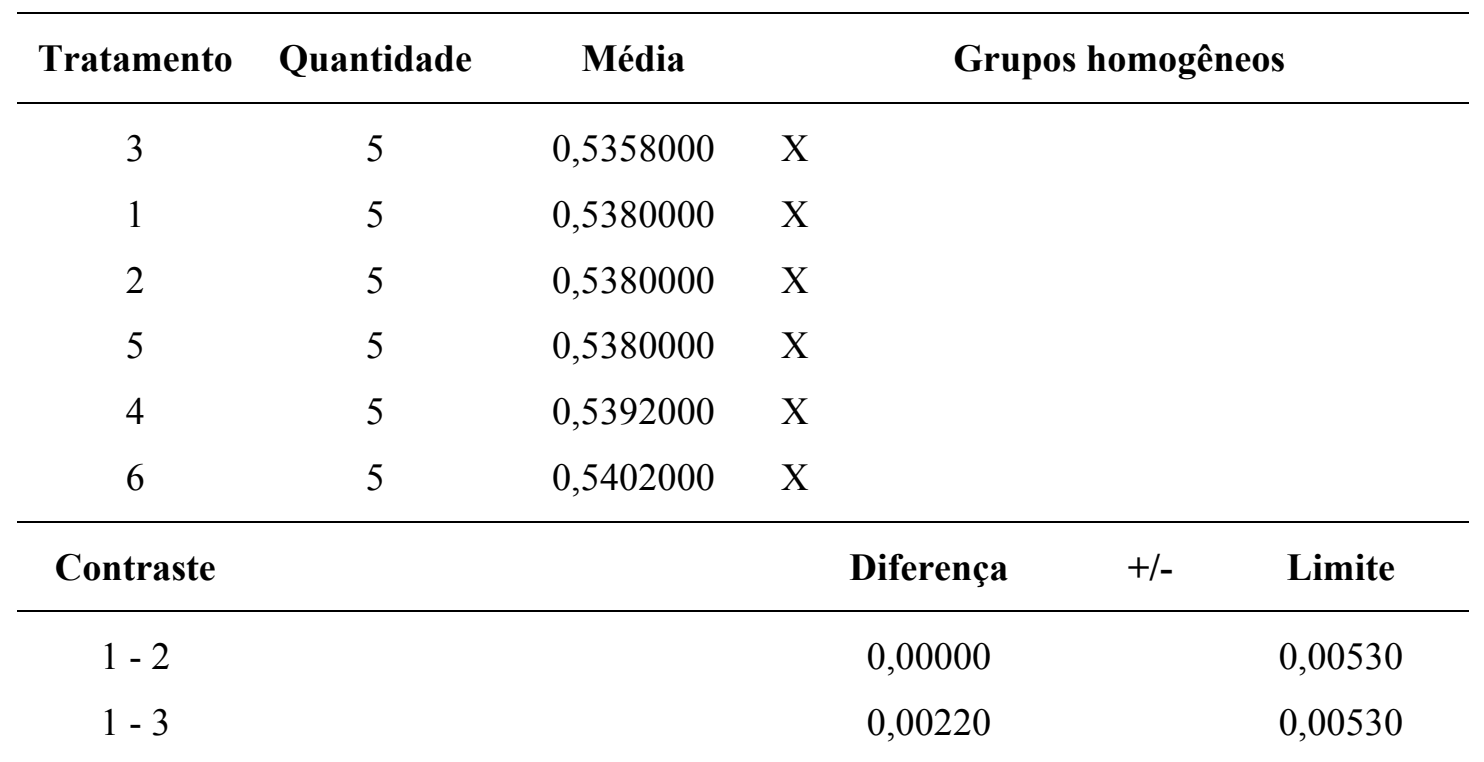


TABELA 67 - Teste de Tukey - Grupos de médias homogêneas (Densidade aparente, $\rho$ em $\mathrm{g} / \mathrm{cm}^{3}$ - Pinus caribaea var. bahamensis) - Continuação.

\begin{tabular}{|c|c|c|c|}
\hline Contraste & Diferença & $+/-$ & Limite \\
\hline $1-4$ & $-0,00120$ & & 0,00530 \\
\hline $1-5$ & 0,00000 & & 0,00530 \\
\hline $1-6$ & $-0,00220$ & & 0,00530 \\
\hline $2-3$ & 0,00220 & & 0,00530 \\
\hline $2-4$ & $-0,00120$ & & 0,00530 \\
\hline $2-5$ & 0,00000 & & 0,00530 \\
\hline $2-6$ & $-0,00220$ & & 0,00530 \\
\hline $3-4$ & $-0,00340$ & & 0,00530 \\
\hline $3-5$ & $-0,00220$ & & 0,00530 \\
\hline $3-6$ & $-0,00440$ & & 0,00530 \\
\hline $4-5$ & 0,00120 & & 0,00530 \\
\hline $4-6$ & $-0,00100$ & & 0,00530 \\
\hline $5-6$ & $-0,00220$ & & 0,00530 \\
\hline
\end{tabular}

* Denota uma diferença estatisticamente significativa (nível de confiança 95\%).

\subsubsection{PINUS ELLIOTTII}

O mesmo procedimento utilizado para o Pinus bahamensis foi adotado para o Pinus elliottii e forneceu os resultados apresentados, resumidamente, a seguir.

A aplicação de testes de Tukey, com os tratamentos definidos na tabela 58, para as propriedades de resistência, no Pinus elliottii, fornece os resultados apresentados, de forma simplificada, nas tabelas 68,69 e 70 .

A análise dos resultados, apresentados nas tabelas 68, 69 e 70, mostra que: para a resistência à compressão paralela às fibras são identificados dois grupos homogêneos, e apenas o tratamento 7 não é estatisticamente equivalente aos testemunhos (tratamentos 1 e 2); para a resistência à tração paralela às fibras e para o cisalhamento não foram detectadas diferenças significativas entre as médias. 
TABELA 68 - Teste de Tukey - Grupos de médias homogêneas (Resistência à compressão paralela, $\mathrm{f}_{\mathrm{c} 0} \mathrm{em} \mathrm{MPa}-$ Pinus elliottii)

\begin{tabular}{cccll}
\hline Tratamento & Quantidade & Média & & Grupos homogêneos \\
\hline 7 & 6 & 39,853333 & X & \\
5 & 6 & 40,023333 & X X \\
4 & 6 & 40,056667 & X X \\
8 & 6 & 40,235000 & X X \\
6 & 6 & 40,938333 & X X \\
3 & 6 & 41,228333 & X X \\
2 & 6 & 41,320000 & $X$ \\
1 & 6 & 41,340000 & $X$ \\
\hline
\end{tabular}

Diferenças, entre médias, não significativas (nível de confiança 95\%) $= \pm 1,44219$.

TABELA 69 - Teste de Tukey - Grupos de médias homogêneas (Resistência à tração paralela, $\mathrm{f}_{\mathrm{t} 0} \mathrm{em} \mathrm{MPa}-$ Pinus elliottii)

\begin{tabular}{cccll}
\hline Tratamento & Quantidade & Média & & Grupos homogêneos \\
\hline 6 & 3 & 67,623333 & $\mathrm{X}$ & \\
2 & 3 & 67,776667 & $\mathrm{X}$ & \\
3 & 3 & 67,780000 & $\mathrm{X}$ \\
1 & 3 & 67,840000 & $\mathrm{X}$ \\
7 & 3 & 69,046667 & $\mathrm{X}$ \\
5 & 3 & 69,303333 & $\mathrm{X}$ \\
4 & 3 & 69,353333 & $\mathrm{X}$ \\
8 & 3 & 69,623333 & $\mathrm{X}$ \\
\hline
\end{tabular}

Diferenças, entre médias, não significativas (nível de confiança 95\%) $= \pm 3,25373$. 
TABELA 70 - Teste de Tukey - Grupos de médias homogêneas (Resistência ao cisalhamento, $\mathrm{f}_{\mathrm{v} 0} \mathrm{em} \mathrm{MPa} \mathrm{-} \mathrm{Pinus} \mathrm{elliottii)}$

\begin{tabular}{cccll}
\hline Tratamento & Quantidade & Média & & Grupos homogêneos \\
\hline 6 & 8 & 7,9362500 & $\mathrm{X}$ & \\
3 & 8 & 7,9550000 & $\mathrm{X}$ & \\
2 & 8 & 7,9575000 & $\mathrm{X}$ & \\
1 & 8 & 7,9600000 & $\mathrm{X}$ \\
7 & 8 & 7,9612500 & $\mathrm{X}$ \\
5 & 8 & 7,9912500 & $\mathrm{X}$ \\
4 & 8 & 7,9975000 & $\mathrm{X}$ \\
8 & 8 & 8,0275000 & $\mathrm{X}$ \\
\hline
\end{tabular}

Diferenças, entre médias, não significativas (nível de confiança 95\%) = $\pm 0,17920$.

A comparação de múltiplas médias no estudo do módulo de elasticidade longitudinal, utilizando o teste de Tukey, com os tratamentos definidos na tabela 64, fornece os resultados apresentados na tabela 71. Analisando-se estes resultados não se encontram diferenças significativas entre as médias, portanto os diversos tratamentos fornecem a mesma média.

TABELA 71 - Teste de Tukey - Grupos de médias homogêneas (Módulo de elasticidade longitudinal, $\mathrm{E}_{\mathrm{c} 0}$ em MPa - Pinus elliottii)

\begin{tabular}{cccll}
\hline Tratamento & Quantidade & Média & & Grupos homogêneos \\
\hline 5 & 6 & 11653,887 & $\mathrm{X}$ & \\
3 & 6 & 11702,752 & $\mathrm{X}$ & \\
2 & 6 & 11751,242 & $\mathrm{X}$ & \\
1 & 6 & 11755,760 & $\mathrm{X}$ \\
4 & 6 & 11868,967 & $\mathrm{X}$ \\
\hline
\end{tabular}

Diferenças, entre médias, não significativas (nível de confiança 95\%) = $\pm 277,252$.

Aplicando-se o teste de Tukey, com os tratamentos definidos na tabela 66, para a densidade aparente, obtém-se os resultados apresentados na tabela 72. Analisando-se estes resultados são identificados três grupos homogêneos, nos quais os tratamentos 3 e 6 não fornecem resultados estatisticamente equivalentes aos usados como testemunhos (tratamentos 1 e 2). 
TABELA 72 - Teste de Tukey - Grupos de médias homogêneas (Densidade aparente, $\rho$ em $\mathrm{g} / \mathrm{cm}^{3}-$ Pinus elliottii)

\begin{tabular}{ccccc}
\hline Tratamento & Quantidade & Média & & Grupos homogêneos \\
\hline 3 & 6 & 0,5511667 & $\mathrm{X}$ & \\
4 & 6 & 0,5555000 & $\mathrm{X}$ & \\
2 & 6 & 0,5588333 & $\mathrm{X}$ & \\
5 & 6 & 0,5588333 & $\mathrm{X}$ & \\
1 & 6 & 0,5590000 & $\mathrm{X}$ & \\
6 & 6 & 0,5640000 & \multicolumn{2}{c}{$\mathrm{X}$} \\
\hline
\end{tabular}

Diferenças, entre médias, não significativas (nível de confiança 95\%) = 0,00393 .

\subsubsection{PINUS TAEDA}

O mesmo procedimento utilizado para o Pinus bahamensis foi adotado para o Pinus taeda e forneceu os resultados apresentados, resumidamente, a seguir.

A aplicação de testes de Tukey, com os tratamentos definidos na tabela 58, para as propriedades de resistência, no Pinus taeda, fornece os resultados apresentados nas tabelas 73,74 e 75 .

TABELA 73 - Teste de Tukey - Grupos de médias homogêneas (Resistência à compressão paralela, $\mathrm{f}_{\mathrm{c} 0}$ em MPa - Pinus taeda)

\begin{tabular}{cccll}
\hline Tratamento & Quantidade & Média & & Grupos homogêneos \\
\hline 4 & 7 & 45,484286 & $\mathrm{X}$ & \\
7 & 7 & 45,524286 & $\mathrm{X}$ & \\
5 & 7 & 45,588571 & $\mathrm{X}$ & \\
8 & 7 & 45,670000 & $\mathrm{X}$ \\
1 & 7 & 45,780000 & $\mathrm{X}$ \\
2 & 7 & 45,907143 & $\mathrm{X}$ \\
6 & 7 & 45,935714 & $\mathrm{X}$ \\
3 & 7 & 46,045714 & $\mathrm{X}$ \\
\hline
\end{tabular}

Diferenças, entre médias, não significativas (nível de confiança 95\%) = $\pm 1,76619$. 
TABELA 74 - Teste de Tukey - Grupos de médias homogêneas (Resistência à tração paralela, $\mathrm{f}_{\mathrm{t} 0} \mathrm{em}$ MPa - Pinus taeda)

\begin{tabular}{cccll}
\hline Tratamento & Quantidade & Média & & Grupos homogêneos \\
\hline 1 & 3 & 81,510000 & $\mathrm{X}$ & \\
2 & 3 & 81,730000 & $\mathrm{X}$ & \\
6 & 3 & 81,866667 & $\mathrm{XX}$ & \\
3 & 3 & 82,030000 & $\mathrm{XX}$ \\
4 & 3 & 83,176667 & $\mathrm{XX}$ \\
7 & 3 & 83,346667 & $\mathrm{XX}$ \\
5 & 3 & 83,613333 & $\mathrm{XX}$ \\
8 & 3 & 83,946667 & $\mathrm{X}$ \\
\hline
\end{tabular}

Diferenças, entre médias, não significativas (nível de confiança 95\%) $= \pm 2,26544$.

TABELA 75 - Teste de Tukey - Grupos de médias homogêneas (Resistência ao cisalhamento, $\mathrm{f}_{\mathrm{v} 0}$ em MPa - Pinus taeda)

\begin{tabular}{cccll}
\hline Tratamento & Quantidade & Média & & Grupos homogêneos \\
\hline 1 & 8 & 8,4500000 & $\mathrm{X}$ & \\
2 & 8 & 8,4762500 & $\mathrm{X}$ & \\
6 & 8 & 8,4950000 & $\mathrm{X}$ & \\
4 & 8 & 8,5012500 & $\mathrm{X}$ \\
3 & 8 & 8,5087500 & $\mathrm{X}$ \\
7 & 8 & 8,5125000 & $\mathrm{X}$ \\
5 & 8 & 8,5300000 & $\mathrm{X}$ \\
8 & 8 & 8,5550000 & $\mathrm{X}$ \\
\hline
\end{tabular}

Diferenças, entre médias, não significativas (nível de confiança 95\%) = 0,23136.

A análise dos resultados, apresentados nas tabelas 73, 74 e 75, mostra que: para a resistência à compressão paralela às fibras não existem diferenças significativas entre as médias, portanto todos os tratamentos podem ser considerados estatisticamente equivalentes aos usados como testemunhos (tratamentos 1 e 2); para a resistência à tração paralela às fibras existem diferenças significativas entre as médias, e se pode considerar dois grupos homogêneos, nos quais o tratamento 8 não é estatisticamente equivalente aos usados como testemu- 
nhos (tratamentos 1 e 2); já para a resistência ao cisalhamento todos os tratamentos podem ser considerados como um grupo homogêneo de mesma média.

A comparação de múltiplas médias no estudo do módulo de elasticidade longitudinal, utilizando o teste de Tukey, com os tratamentos definidos na tabela 64, fornece os resultados apresentados na tabela 76. Analisando-se estes resultados não se encontram diferenças significativas entre as médias, portanto os diversos tratamentos fornecem a mesma média.

TABELA 76 - Teste de Tukey - Grupos de médias homogêneas (Módulo de elasticidade longitudinal, $\mathrm{E}_{\mathrm{c} 0}$ em MPa - Pinus taeda)

\begin{tabular}{cccll}
\hline Tratamento & Quantidade & Média & & Grupos homogêneos \\
\hline 5 & 7 & 13359,630 & $\mathrm{X}$ & \\
3 & 7 & 13378,683 & $\mathrm{X}$ & \\
4 & 7 & 13443,501 & $\mathrm{X}$ \\
2 & 7 & 13474,277 & $\mathrm{X}$ \\
1 & 7 & 13511,310 & $\mathrm{X}$ \\
\hline
\end{tabular}

Diferenças, entre médias, não significativas (nível de confiança 95\%)= = 414,796.

Aplicando-se o teste de Tukey, com os tratamentos definidos na tabela 66, para a densidade aparente, obtém-se os resultados apresentados na tabela 77. Analisando-se estes resultados, não se encontram diferenças significativas entre as médias, portanto os diversos tratamentos fornecem a mesma média.

TABELA 77 - Teste de Tukey - Grupos de médias homogêneas (Densidade aparente, $\rho$ em $\mathrm{g} / \mathrm{cm}^{3}-$ Pinus taeda)

\begin{tabular}{cccll}
\hline Tratamento & Quantidade & Média & & Grupos homogêneos \\
\hline 3 & 7 & 0,6480000 & $\mathrm{X}$ & \\
5 & 7 & 0,6512857 & $\mathrm{X}$ & \\
2 & 7 & 0,6518571 & $\mathrm{X}$ & \\
4 & 7 & 0,6518571 & $\mathrm{X}$ \\
1 & 7 & 0,6520000 & $\mathrm{X}$ \\
6 & 7 & 0,6534286 & $\mathrm{X}$ \\
\hline
\end{tabular}

Diferenças, entre médias, não significativas (nível de confiança 95\%) = $\pm 0,00606$. 
O mesmo procedimento utilizado para o Pinus bahamensis foi adotado para o Eucalipto grandis e forneceu os resultados apresentados, resumidamente, a seguir.

A aplicação de testes de Tukey, com os tratamentos definidos na tabela 58, para as propriedades de resistência, no Eucalipto grandis, fornece os resultados apresentados nas tabelas 78,79 e 80 .

TABELA 78 - Teste de Tukey - Grupos de médias homogêneas (Resistência à compressão paralela, $\mathrm{f}_{\mathrm{c} 0} \mathrm{em} \mathrm{MPa} \mathrm{-} \mathrm{Eucalyptus} \mathrm{grandis)}$

\begin{tabular}{cccll}
\hline Tratamento & Quantidade & Média & & Grupos homogêneos \\
\hline 5 & 9 & 41.593333 & $\mathrm{X}$ & \\
7 & 9 & 41.693333 & $\mathrm{X}$ & \\
4 & 9 & 41.856667 & $\mathrm{X}$ & \\
8 & 9 & 41.993333 & $\mathrm{X}$ \\
3 & 9 & 42.375556 & $\mathrm{X}$ \\
2 & 9 & 42.534444 & $\mathrm{X}$ \\
6 & 9 & 42.545556 & $\mathrm{X}$ \\
1 & 9 & 42.570000 & $\mathrm{X}$ \\
\hline
\end{tabular}

Diferenças, entre médias, não significativas (nível de confiança 95\%)= $\pm 1,34708$.

TABELA 79 - Teste de Tukey - Grupos de médias homogêneas (Resistência à tração paralela, $\mathrm{f}_{\mathrm{t} 0}$ em MPa - Eucalyptus grandis)

\begin{tabular}{cccll}
\hline Tratamento & Quantidade & Média & & Grupos homogêneos \\
\hline 3 & 4 & 75,202500 & $\mathrm{X}$ & \\
1 & 4 & 75,310000 & $\mathrm{X}$ & \\
6 & 4 & 75,360000 & $\mathrm{XX}$ & \\
2 & 4 & 75,405000 & $\mathrm{XX}$ \\
5 & 4 & 76,995000 & $\mathrm{XXX}$ \\
7 & 4 & 77,255000 & $\mathrm{XX}$ \\
4 & 4 & 77,670000 & $\mathrm{X}$ \\
8 & 4 & 78,020000 & $\mathrm{X}$ \\
\hline
\end{tabular}

Diferenças, entre médias, não significativas (nível de confiança 95\%) = $\pm 1,90680$. 
TABELA 80 - Teste de Tukey - Grupos de médias homogêneas (Resistência ao cisalhamento, $\mathrm{f}_{\mathrm{v} 0}$ em MPa - Eucalyptus grandis)

\begin{tabular}{cccll}
\hline Tratamento & Quantidade & Média & & Grupos homogêneos \\
\hline 3 & 11 & 7,2254545 & $\mathrm{X}$ & \\
5 & 11 & 7,2300000 & $\mathrm{X}$ & \\
6 & 11 & 7,2300000 & $\mathrm{X}$ \\
7 & 11 & 7,2372727 & $\mathrm{X}$ \\
4 & 11 & 7,2500000 & $\mathrm{X}$ \\
8 & 11 & 7,2581818 & $\mathrm{X}$ \\
1 & 11 & 7,2600000 & $\mathrm{X}$ \\
2 & 11 & 7,2636364 & $\mathrm{X}$ \\
\hline
\end{tabular}

Diferenças, entre médias, não significativas (nível de confiança 95\%) $= \pm 0,18388$.

A análise dos resultados, apresentados nas tabelas 78, 79 e 80, mostra que: para a resistência à compressão paralela às fibras não existem diferenças significativas entre as médias, portanto todos os tratamentos podem ser considerados estatisticamente equivalentes aos usados como testemunhos (tratamentos 1 e 2); para a resistência à tração paralela às fibras existem diferenças significativas entre as médias, e se pode considerar três grupos homogêneos, nos quais os tratamentos 4,7 e 8 não são estatisticamente equivalentes aos usados como testemunhos (tratamentos 1 e 2); já para a resistência ao cisalhamento todos os tratamentos podem ser considerados como um grupo homogêneo de mesma média.

A comparação de múltiplas médias no estudo do módulo de elasticidade longitudinal, utilizando o teste de Tukey, com os tratamentos definidos na tabela 64, fornece os resultados apresentados na tabela 81. Analisando-se estes resultados observam-se dois grupos homogêneos, entretanto todos os tratamentos podem ser considerados estatisticamente equivalentes aos usados como testemunhos (tratamentos 1 e 2).

TABELA 81 - Teste de Tukey - Grupos de médias homogêneas (Módulo de elasticidade longitudinal, $\mathrm{E}_{\mathrm{c} 0} \mathrm{em} \mathrm{MPa}$ - Eucalyptus grandis) 


\begin{tabular}{cccll}
\hline Tratamento & Quantidade & Média & & Grupos homogêneos \\
\hline 5 & 9 & 12811,030 & X & \\
2 & 9 & 12886,926 & X X & \\
1 & 9 & 12909,430 & X X & \\
4 & 9 & 12986,243 & X X \\
3 & 9 & 13087,822 & X \\
\hline
\end{tabular}

Diferenças, entre médias, não significativas (nível de confiança 95\%) = $\pm 215,381$.

Aplicando-se o teste de Tukey, com os tratamentos definidos na tabela 66, para a densidade aparente, obtém-se os resultados apresentados na tabela 82. Analisando-se estes resultados observam-se quatro grupos homogêneos, nos quais os tratamentos 3 e 5 não fornecem resultados estatisticamente equivalentes aos testemunhos (tratamentos 1 e 2).

TABELA 82 - Teste de Tukey - Grupos de médias homogêneas (Densidade aparente, $\rho$ em $\mathrm{g} / \mathrm{cm}^{3}-$ Eucalyptus grandis)

\begin{tabular}{ccrc}
\hline Tratamento & Quantidade & Média & \multicolumn{2}{c}{ Grupos homogêneos } \\
\hline 3 & 9 & 0,6562222 & X \\
4 & 9 & 0,6633333 & X \\
1 & 9 & 0,6640000 & X X \\
2 & 9 & 0,6643333 & X X \\
6 & 9 & 0,6674444 & X X \\
5 & 9 & 0,6708889 & X \\
\hline
\end{tabular}

Diferenças, entre médias, não significativas (nível de confiança 95\%) = $\pm 0,00348$.

\subsubsection{CUPIÚBA}

O mesmo procedimento utilizado para o Pinus bahamensis foi adotado para a Cupiúba e forneceu os resultados apresentados, resumidamente, a seguir.

A aplicação de testes de Tukey, com os tratamentos definidos na tabela 58, para as propriedades de resistência, na Cupiúba, fornece os resultados apresentados nas tabelas 83 , 84 e 85.

TABELA 83 - Teste de Tukey - Grupos de médias homogêneas (Resistência à compressão paralela, $\mathrm{f}_{\mathrm{c} 0}$ em MPa - Goupia glabra) 


\begin{tabular}{cccll}
\hline Tratamento & Quantidade & Média & & Grupos homogêneos \\
\hline 5 & 7 & 52,424286 & $\mathrm{X}$ & \\
4 & 7 & 52,518571 & $\mathrm{X}$ & \\
7 & 7 & 52,524286 & $\mathrm{X}$ & \\
8 & 7 & 52,825714 & $\mathrm{X}$ \\
3 & 7 & 53,204286 & $\mathrm{X}$ \\
2 & 7 & 53,310000 & $\mathrm{X}$ \\
6 & 7 & 53,375714 & $\mathrm{X}$ \\
1 & 7 & 53,410000 & $\mathrm{X}$ \\
\hline
\end{tabular}

Diferenças, entre médias, não significativas (nível de confiança 95\%) = $\pm 1,12666$.

TABELA 84 - Teste de Tukey - Grupos de médias homogêneas (Resistência à tração paralela, $\mathrm{f}_{\mathrm{t} 0}$ em MPa - Goupia glabra)

\begin{tabular}{cccll}
\hline Tratamento & Quantidade & Média & & Grupos homogêneos \\
\hline 3 & 4 & 61,995000 & $\mathrm{X}$ & \\
6 & 4 & 62,110000 & $\mathrm{X}$ & \\
1 & 4 & 62,480000 & $\mathrm{X}$ & \\
2 & 4 & 62,515000 & $\mathrm{X}$ \\
5 & 4 & 63,332500 & $\mathrm{XX}$ \\
4 & 4 & 63,510000 & $\mathrm{XX}$ \\
7 & 4 & 63,525000 & $\mathrm{XX}$ \\
8 & 4 & 64,100000 & $\mathrm{X}$ \\
\hline
\end{tabular}

Diferenças, entre médias, não significativas (nível de confiança 95\%) = \pm 1,57755.

A análise dos resultados, apresentados nas tabelas 83,84 e 85 , mostra que: para a resistência à compressão paralela às fibras não existem diferenças significativas entre as médias, portanto todos os tratamentos podem ser considerados estatisticamente equivalentes aos usados como testemunhos (tratamentos 1 e 2); para a resistência à tração paralela às fibras existem diferenças significativas entre as médias, e se pode considerar dois grupos homogêneos, nos quais o tratamento 8 não é estatisticamente equivalente aos tratamentos usados como testemunhos (tratamentos 1 e 2); já para a resistência ao cisalhamento todos os tratamentos podem ser considerados como um grupo homogêneo de mesma média. 
TABELA 85 - Teste de Tukey - Grupos de médias homogêneas (Resistência ao cisalhamento, $\mathrm{f}_{\mathrm{v} 0}$ em MPa - Goupia glabra)

\begin{tabular}{cccll}
\hline Tratamento & Quantidade & Média & & Grupos homogêneos \\
\hline 2 & 7 & 9,7128571 & $\mathrm{X}$ & \\
3 & 7 & 9,7271429 & $\mathrm{X}$ & \\
1 & 7 & 9,7300000 & $\mathrm{X}$ & \\
6 & 7 & 9,7342857 & $\mathrm{X}$ \\
5 & 7 & 9,7371429 & $\mathrm{X}$ \\
4 & 7 & 9,7514286 & $\mathrm{X}$ \\
7 & 7 & 9,7528571 & $\mathrm{X}$ & \\
8 & 7 & 9,7914286 & $\mathrm{X}$ \\
\hline
\end{tabular}

Diferenças, entre médias, não significativas (nível de confiança 95\%) $= \pm 0,14908$.

A comparação de múltiplas médias no estudo do módulo de elasticidade longitudinal, utilizando o teste de Tukey, com os tratamentos definidos na tabela 64, fornece os resultados apresentados na tabela 86. Analisando-se estes resultados não se encontram diferenças significativas entre as médias, portanto os diversos tratamentos fornecem a mesma média.

TABELA 86 - Teste de Tukey - Grupos de médias homogêneas (Módulo de elasticidade longitudinal, $\mathrm{E}_{\mathrm{c} 0}$ em MPa - Goupia glabra)

\begin{tabular}{cccll}
\hline Tratamento & Quantidade & Média & & Grupos homogêneos \\
\hline 5 & 7 & 14194,317 & $\mathrm{X}$ & \\
4 & 7 & 14348,931 & $\mathrm{X}$ & \\
3 & 7 & 14438,567 & $\mathrm{X}$ & \\
1 & 7 & 14472,080 & $\mathrm{X}$ \\
2 & 7 & 14484,080 & $\mathrm{X}$ \\
\hline
\end{tabular}

Diferenças, entre médias, não significativas (nível de confiança 95\%) = $\pm 306,943$.

Aplicando-se o teste de Tukey, com os tratamentos definidos na tabela 66, para a densidade aparente, obtém-se os resultados apresentados na tabela 87. Analisando-se estes resultados são encontradas diferenças significativas entre as médias dos tratamentos 3 e 5 , observam-se dois grupos homogêneos, mas todos os tratamentos fornecem resultados estatisticamente equivalentes aos testemunhos (tratamentos $1 \mathrm{e} 2$ ). 
TABELA 87 - Teste de Tukey - Grupos de médias homogêneas (Densidade aparente, $\rho$ em $\mathrm{g} / \mathrm{cm}^{3}$ - Goupia glabra)

\begin{tabular}{cccll}
\hline Tratamento & Quantidade & Média & & Grupos homogêneos \\
\hline 3 & 7 & 0,7898571 & X & \\
4 & 7 & 0,7985714 & X X & \\
6 & 7 & 0,8008571 & X X & \\
1 & 7 & 0,8020000 & X X & \\
2 & 7 & 0,8028571 & X X & \\
5 & 7 & 0,8041429 & $X$ & \\
\hline
\end{tabular}

Diferenças, entre médias, não significativas (nível de confiança 95\%) $= \pm 0,01356$.

\subsubsection{EUCALIPTO CITRIODORA}

O mesmo procedimento utilizado para o Pinus bahamensis foi adotado para o Eucalipto citriodora e forneceu os resultados apresentados, resumidamente, a seguir.

A aplicação de testes de Tukey, com os tratamentos definidos na tabela 58, para as propriedades de resistência, no Eucalipto citriodora, fornece os resultados apresentados nas tabelas 88,89 e 90 .

TABELA 88 - Teste de Tukey - Grupos de médias homogêneas (Resistência à compressão paralela, $\mathrm{f}_{\mathrm{c} 0} \mathrm{em} \mathrm{MPa}$ - Eucalyptus citriodora)

\begin{tabular}{cccll}
\hline Tratamento & Quantidade & Média & & Grupos homogêneos \\
\hline 4 & 8 & 63,860000 & X & \\
5 & 8 & 64,068750 & X X & \\
7 & 8 & 64,235000 & X X \\
8 & 8 & 64,732500 & X X \\
2 & 8 & 65,217500 & X X
\end{tabular}

TABELA 88 - Teste de Tukey - Grupos de médias homogêneas (Resistência à compressão paralela, $\mathrm{f}_{\mathrm{c} 0} \mathrm{em} \mathrm{MPa} \mathrm{-} \mathrm{Eucalyptus} \mathrm{citriodora)} \mathrm{-} \mathrm{Continuação.}$

\begin{tabular}{ccccc}
\hline Tratamento & Quantidade & Média & & Grupos homogêneos \\
\hline 1 & 8 & 65,300000 & X X
\end{tabular}




$\begin{array}{rrrr}3 & 8 & 65,370000 & \text { X X } \\ 6 & 8 & 65,652500 & \text { X }\end{array}$

Diferenças, entre médias, não significativas (nível de confiança 95\%) = $\pm 1,71369$.

TABELA 89 - Teste de Tukey - Grupos de médias homogêneas (Resistência à tração paralela, $\mathrm{f}_{\mathrm{t} 0}$ em MPa - Eucalyptus citriodora)

\begin{tabular}{cccll}
\hline Tratamento & Quantidade & Média & & Grupos homogêneos \\
\hline 1 & 4 & 132,49000 & $\mathrm{X}$ & \\
3 & 4 & 132,93250 & $\mathrm{X}$ & \\
2 & 4 & 133,05000 & $\mathrm{X}$ & \\
6 & 4 & 133,13500 & $\mathrm{X}$ & \\
4 & 4 & 134,83250 & $\mathrm{X}$ \\
5 & 4 & 135,24500 & $\mathrm{X}$ \\
7 & 4 & 135,57500 & $\mathrm{X}$ \\
8 & 4 & 136,56250 & $\mathrm{X}$ & \\
\hline
\end{tabular}

Diferenças, entre médias, não significativas (nível de confiança 95\%) $= \pm 4,55591$.

TABELA 90 - Teste de Tukey - Grupos de médias homogêneas (Resistência ao cisalhamento, $\mathrm{f}_{\mathrm{v} 0}$ em MPa - Eucalyptus citriodora)

\begin{tabular}{cccll}
\hline Tratamento & Quantidade & Média & & Grupos homogêneos \\
\hline 1 & 11 & 13,570000 & $\mathrm{X}$ & \\
2 & 11 & 13,573636 & $\mathrm{X}$ & \\
4 & 11 & 13,604545 & $\mathrm{X}$ & \\
3 & 11 & 13,614545 & $\mathrm{X}$ & \\
6 & 11 & 13,634545 & $\mathrm{X}$ \\
5 & 11 & 13,640909 & $\mathrm{X}$ \\
7 & 11 & 13,669091 & $\mathrm{X} \mathrm{X}$ \\
8 & 11 & 13,755455 & $\mathrm{X}$ & \\
\hline
\end{tabular}

Diferenças, entre médias, não significativas (nível de confiança 95\%) $= \pm 4,55591$.

A análise dos resultados, apresentados nas tabelas 88,89 e 90 , mostra que: para a resistência à compressão paralela às fibras existem diferenças significativas entre as médias, observam-se dois grupos homogêneos, entretanto os resultados de todos os tratamentos podem ser considerados estatisticamente equivalentes aos usados como testemunhos (tratamen- 
tos 1 e 2); para a resistência à tração paralela às fibras não existem diferenças significativas entre as médias, portanto todos os tratamentos fornecem resultados estatisticamente equivalentes aos testemunhos (tratamentos 1 e 2); já para a resistência ao cisalhamento observam-se diferenças significativas entre as médias formando dois grupos homogêneos, onde apenas o tratamento 8 não fornece resultados estatisticamente equivalentes aos testemunhos (tratamentos 1 e 2).

A comparação de múltiplas médias no estudo do módulo de elasticidade longitudinal, utilizando o teste de Tukey, com os tratamentos definidos na tabela 64, fornece os resultados apresentados na tabela 91. Analisando-se estes resultados observam-se diferenças significativas entre as médias formando dois grupos homogêneos, onde apenas o tratamento 5 não fornece resultados estatisticamente equivalentes aos testemunhos (tratamentos 1 e 2).

TABELA 91 - Teste de Tukey - Grupos de médias homogêneas (Módulo de elasticidade longitudinal, $\mathrm{E}_{\mathrm{c} 0} \mathrm{em} \mathrm{MPa}$ - Eucalyptus citriodora)

\begin{tabular}{cccll}
\hline Tratamento & Quantidade & \multicolumn{1}{c}{ Média } & & Grupos homogêneos \\
\hline 5 & 8 & 17469,950 & $\mathrm{X}$ & \\
4 & 8 & 17727,973 & $\mathrm{XX}$ & \\
3 & 8 & 17877,563 & $\mathrm{X}$ & \\
2 & 8 & 17976,198 & $\mathrm{X}$ \\
1 & 8 & 17995,270 & $\mathrm{X}$ & \\
\hline
\end{tabular}

Diferenças, entre médias, não significativas (nível de confiança 95\%) $= \pm 284,562$.

Aplicando-se o teste de Tukey, com os tratamentos definidos na tabela 66, para a densidade aparente, obtém-se os resultados apresentados na tabela 92. Analisando-se estes resultados são encontradas diferenças significativas entre as médias e observam-se dois grupos homogêneos, nos quais o tratamento 3 não fornece resultados estatisticamente equivalentes aos testemunhos (tratamentos 1 e 2).

TABELA 92 - Teste de Tukey - Grupos de médias homogêneas (Densidade aparente, $\rho$ em $\mathrm{g} / \mathrm{cm}^{3}$ - Eucalyptus citriodora)

\begin{tabular}{lll}
\hline Tratamento & Quantidade & Média \\
\hline
\end{tabular}




\begin{tabular}{llll}
3 & 8 & 0,9287500 & $\mathrm{X}$ \\
4 & 8 & 0,9446250 & $\mathrm{X}$ \\
6 & 8 & 0,9461250 & $\mathrm{X}$ \\
5 & 8 & 0,9513750 & $\mathrm{X}$ \\
2 & 8 & 0,9567500 & $\mathrm{X}$ \\
1 & 8 & 0,9570000 & $\mathrm{X}$ \\
\hline
\end{tabular}

Diferenças, entre médias, não significativas (nível de confiança 95\%) = $\pm 0,01325$.

\subsubsection{JАTOBÁ}

O mesmo procedimento utilizado para o Pinus bahamensis foi adotado para o Jatobá e forneceu os resultados apresentados, resumidamente, a seguir.

A aplicação de testes de Tukey, com os tratamentos definidos na tabela 58, para as propriedades de resistência, no Jatobá, fornece os resultados apresentados nas tabelas 93, 94 e 95.

TABELA 93 - Teste de Tukey - Grupos de médias homogêneas (Resistência à compressão paralela, $\mathrm{f}_{\mathrm{c} 0}$ em MPa - Hymenaea stilbocarpa)

\begin{tabular}{cccl}
\hline Tratamento & Quantidade & Média & \multicolumn{1}{c}{ Grupos homogêneos } \\
\hline 4 & 7 & 82,645714 & X \\
5 & 7 & 83,074286 & X X \\
7 & 7 & 83,262857 & X X X \\
8 & 7 & 83,820000 & X X X \\
2 & 7 & 84,201429 & X X X \\
1 & 7 & 84,340000 & X X \\
3 & 7 & 84,525714 & X \\
6 & 7 & 84,842857 & X \\
\hline
\end{tabular}

Diferenças, entre médias, não significativas (nível de confiança 95\%) = $\pm 1,16456$.

TABELA 94 - Teste de Tukey - Grupos de médias homogêneas (Resistência à tração paralela, $\mathrm{f}_{\mathrm{t} 0}$ em MPa - Hymenaea stilbocarpa)

\begin{tabular}{ccccc}
\hline Tratamento & Quantidade & Média & Grupos homogêneos \\
\hline 2 & 4 & 164,73750 & $\mathrm{X}$
\end{tabular}




$\begin{array}{llll}1 & 4 & 164,74000 & \mathrm{X} \\ 3 & 4 & 165,47750 & \mathrm{X} \\ 6 & 4 & 165,69500 & \mathrm{X} \\ 4 & 4 & 167,14750 & \mathrm{X} \\ 5 & 4 & 167,97250 & \mathrm{X} \\ 7 & 4 & 168,33000 & \mathrm{X} \\ 8 & 4 & 169,40000 & \mathrm{X}\end{array}$

Diferenças, entre médias, não significativas (nível de confiança 95\%) $= \pm 5,70124$.

TABELA 95 - Teste de Tukey - Grupos de médias homogêneas (Resistência ao cisalhamento, $\mathrm{f}_{\mathrm{v} 0}$ em MPa - Hymenaea stilbocarpa)

\begin{tabular}{cccll}
\hline Tratamento & Quantidade & Média & & Grupos homogêneos \\
\hline 1 & 7 & 16,360000 & $\mathrm{X}$ & \\
2 & 7 & 16,430000 & $\mathrm{X}$ & \\
4 & 7 & 16,462857 & $\mathrm{X}$ & \\
3 & 7 & 16,495714 & $\mathrm{X}$ \\
6 & 7 & 16,512857 & $\mathrm{X}$ \\
5 & 7 & 16,514286 & $\mathrm{X}$ \\
7 & 7 & 16,535714 & $\mathrm{X}$ & \\
8 & 7 & 16,600000 & $\mathrm{X}$ & \\
\hline
\end{tabular}

Diferenças, entre médias, não significativas (nível de confiança 95\%) $= \pm 0,33991$.

A análise dos resultados, apresentados nas tabelas 93, 94 e 95, mostra que: para a resistência à compressão paralela às fibras existem diferenças significativas entre as médias formando quatro grupos homogêneos, nos quais os tratamentos 4 e 5 não podem ser considerados estatisticamente equivalentes aos usados como testemunhos (tratamentos 1 e 2); já para as resistências à tração paralela às fibras e ao cisalhamento todos os tratamentos podem ser considerados como um grupo homogêneo de mesma média.

A comparação de múltiplas médias no estudo do módulo de elasticidade longitudinal, utilizando o teste de Tukey, com os tratamentos definidos na tabela 64, fornece os resultados apresentados na tabela 96. Analisando-se estes resultados observam-se dois grupos homogêneos, nos quais o tratamento 5 não fornece resultados estatisticamente equivalentes aos testemunhos (tratamentos 1 e 2). 
TABELA 96 - Teste de Tukey - Grupos de médias homogêneas (Módulo de elasticidade longitudinal, $\mathrm{E}_{\mathrm{c} 0}$ em MPa - Hymenaea stilbocarpa)

\begin{tabular}{ccccc}
\hline Tratamento & Quantidade & Média & & Grupos homogêneos \\
\hline 5 & 7 & 26059,883 & $\mathrm{X}$ & \\
4 & 7 & 26389,797 & $\mathrm{X} \mathrm{X}$ & \\
3 & 7 & 26581,060 & $\mathrm{X}$ & \\
2 & 7 & 26735,936 & $\mathrm{X}$ & \\
1 & 7 & 26748,570 & $\mathrm{X}$ & \\
\hline
\end{tabular}

Diferenças, entre médias, não significativas (nível de confiança 95\%) $= \pm 470,421$.

Aplicando-se o teste de Tukey, com os tratamentos definidos na tabela 66, para a densidade aparente, obtém-se os resultados apresentados na tabela 97. Analisando-se estes resultados são encontradas diferenças significativas, que originam dois grupos homogêneos, nos quais o tratamento 3 não fornece resultados estatisticamente equivalentes aos testemunhos (tratamentos 1 e 2).

TABELA 97 - Teste de Tukey - Grupos de médias homogêneas (Densidade aparente, $\rho$ em $\mathrm{g} / \mathrm{cm}^{3}$ - Hymenaea stilbocarpa)

\begin{tabular}{cccll}
\hline Tratamento & Quantidade & Média & & Grupos homogêneos \\
\hline 3 & 7 & 1,0074286 & $\mathrm{X}$ & \\
4 & 7 & 1,0214286 & $\mathrm{X} \mathrm{X}$ & \\
6 & 7 & 1,0237143 & $\mathrm{X} \mathrm{X}$ & \\
5 & 7 & 1,0284286 & $\mathrm{X}$ \\
1 & 7 & 1,0350000 & $\mathrm{X}$ \\
2 & 7 & 1,0351429 & $\mathrm{X}$ & \\
\hline
\end{tabular}

Diferenças, entre médias, não significativas (nível de confiança 95\%) = $\pm 0,02066$.

\subsubsection{RESUMO DOS TESTES DE TUKEY}

A fim de fornecer uma visão do conjunto dos testes de Tukey são apresentadas as tabelas 98,99 e 100, nas quais se pode identificar os tratamentos que fornecem resultados equivalentes aos experimentais para todas as espécies. 
TABELA 98 - Tratamentos estatisticamente equivalentes aos resultados experimentais (Densidade aparente)

\begin{tabular}{|c|c|c|c|c|c|c|c|}
\hline \multirow[t]{2}{*}{ PROPRIEDADE } & \multirow{2}{*}{$\begin{array}{c}\text { ESPÉCIE } \\
\text { (NOME CIENTÍFICO) }\end{array}$} & \multicolumn{6}{|c|}{ TRATAMENTOS } \\
\hline & & 1 & 2 & 3 & 4 & 5 & 6 \\
\hline \multirow[t]{7}{*}{ Densidade aparente $(\rho)$} & Pinus caribaea var. bahamensis & $\mathrm{X}$ & $\mathrm{X}$ & $\mathrm{X}$ & $\mathrm{X}$ & $\mathrm{X}$ & $\mathrm{X}$ \\
\hline & Pinus elliottii & $\mathrm{X}$ & $\mathrm{X}$ & & $\mathrm{X}$ & $\mathrm{X}$ & \\
\hline & Pinus taeda & $\mathrm{X}$ & $\mathrm{X}$ & $\mathrm{X}$ & $\mathrm{X}$ & $\mathrm{X}$ & $\mathrm{X}$ \\
\hline & Eucalipto grandis & $\mathrm{X}$ & $\mathrm{X}$ & & $\mathrm{X}$ & & $\mathrm{X}$ \\
\hline & Goupia glabra & $\mathrm{X}$ & $\mathrm{X}$ & $\mathrm{X}$ & $\mathrm{X}$ & $\mathrm{X}$ & $\mathrm{X}$ \\
\hline & Eucalipto citriodora & $\mathrm{X}$ & $\mathrm{X}$ & & $\mathrm{X}$ & $\mathrm{X}$ & $\mathrm{X}$ \\
\hline & Hymenaea stilbocarpa & $\mathrm{X}$ & $\mathrm{X}$ & & $\mathrm{X}$ & $\mathrm{X}$ & $\mathrm{X}$ \\
\hline
\end{tabular}

OBS.: Os tratamentos 1, 2 e 4 são válidos para a densidade aparente. Os outros tratamentos não são equivalentes aos tratamentos usados como testemunhos em algumas das espécies estudadas.

TABELA 99 - Tratamentos estatisticamente equivalentes aos resultados experimentais (Módulo de elasticidade longitudinal)

\begin{tabular}{|c|c|c|c|c|c|c|}
\hline \multirow[t]{2}{*}{ PROPRIEDADE } & \multirow{2}{*}{$\begin{array}{c}\text { ESPÉCIE } \\
\text { (NOME CIENTÍFICO) }\end{array}$} & \multicolumn{5}{|c|}{ TRATAMENTOS } \\
\hline & & 1 & 2 & 3 & 4 & 5 \\
\hline \multirow{7}{*}{$\begin{array}{l}\text { Módulo de elasticidade longitudinal } \\
\left(\mathrm{E}_{\mathrm{c} 0}\right)\end{array}$} & Pinus caribaea var. bahamensis & $\mathrm{X}$ & $\mathrm{X}$ & $\mathrm{X}$ & $\mathrm{X}$ & $\mathrm{X}$ \\
\hline & Pinus elliottii & $\mathrm{X}$ & $\mathrm{X}$ & $\mathrm{X}$ & $\mathrm{X}$ & $\mathrm{X}$ \\
\hline & Pinus taeda & $X$ & $\mathrm{X}$ & $\mathrm{X}$ & $\mathrm{X}$ & $\mathrm{X}$ \\
\hline & Eucalipto grandis & $\mathrm{X}$ & $\mathrm{X}$ & $\mathrm{X}$ & $\mathrm{X}$ & $\mathrm{X}$ \\
\hline & Goupia glabra & $\mathrm{X}$ & $\mathrm{X}$ & $\mathrm{X}$ & $\mathrm{X}$ & $\mathrm{X}$ \\
\hline & Eucalipto citriodora & $\mathrm{X}$ & $\mathrm{X}$ & $\mathrm{X}$ & $\mathrm{X}$ & \\
\hline & Hymenaea stilbocarpa & $\mathrm{X}$ & $\mathrm{X}$ & $\mathrm{X}$ & $\mathrm{X}$ & \\
\hline
\end{tabular}

OBS.: Os tratamentos 1, 2, 3 e 4 são válidos para o módulo de elasticidade longitudinal. O tratamento 5, adotado pela NBR 7190/97, não fornece resultados equivalentes, em algumas das espécies estudadas, aos experimentais.

TABELA 100 - Tratamentos estatisticamente equivalentes aos resultados experimentais (Propriedades de resistência) 


\begin{tabular}{|c|c|c|c|c|c|c|c|c|}
\hline $\begin{array}{l}\text { Resistência à compres- } \\
\text { são paralela às fibras }\end{array}$ & $\begin{array}{l}\text { Pinus caribaea var. bahamensis } \\
\text { Pinus elliottii }\end{array}$ & $\begin{array}{l}X \\
X\end{array}$ & $\begin{array}{l}X \\
X\end{array}$ & $\begin{array}{l}X \\
X\end{array}$ & $\begin{array}{l}X \\
X\end{array}$ & $\begin{array}{l}X \\
X\end{array}$ & $\begin{array}{l}X \\
X\end{array}$ & 2 \\
\hline$\left(\mathrm{f}_{\mathrm{c} 0}\right)$ & Pinus taeda & $\mathrm{X}$ & $\mathrm{X}$ & $\mathrm{X}$ & $\mathrm{X}$ & $\mathrm{X}$ & $\mathrm{X}$ & $\mathrm{X}$ \\
\hline & Eucalipto grandis & $\mathrm{X}$ & $\mathrm{X}$ & $\mathrm{X}$ & $\mathrm{X}$ & $X$ & $X$ & $\mathrm{X}$ \\
\hline & Goupia glabra & $\mathrm{X}$ & $\mathrm{X}$ & $\mathrm{X}$ & $\mathrm{X}$ & $\mathrm{X}$ & $\mathrm{X}$ & $\mathrm{X}$ \\
\hline & Eucalipto citriodora & $\mathrm{X}$ & $\mathrm{X}$ & $\mathrm{X}$ & $\mathrm{X}$ & $\mathrm{X}$ & $\mathrm{X}$ & $\mathrm{X}$ \\
\hline & Hymenaea stilbocarpa & $\mathrm{X}$ & $\mathrm{X}$ & $\mathrm{X}$ & & & $\mathrm{X}$ & $\mathrm{X}$ \\
\hline Resistência à tração pa- & Pinus caribaea var. bahamensis & $\mathrm{X}$ & $\mathrm{X}$ & $\mathrm{X}$ & & & $\mathrm{X}$ & $\mathrm{X}$ \\
\hline ralela às fibras $\left(f_{t 0}\right)$ & Pinus elliottii & $\mathrm{X}$ & $\mathrm{X}$ & $\mathrm{X}$ & $\mathrm{X}$ & $\mathrm{X}$ & $\mathrm{X}$ & $\mathrm{X}$ \\
\hline & Pinus taeda & $\mathrm{X}$ & $\mathrm{X}$ & $\mathrm{X}$ & $\mathrm{X}$ & $\mathrm{X}$ & $\mathrm{X}$ & $\mathrm{X}$ \\
\hline & Eucalipto grandis & $\mathrm{X}$ & $\mathrm{X}$ & $\mathrm{X}$ & & $\mathrm{X}$ & $\mathrm{X}$ & \\
\hline & Goupia glabra & $\mathrm{X}$ & $\mathrm{X}$ & $\mathrm{X}$ & $\mathrm{X}$ & $\mathrm{X}$ & $\mathrm{X}$ & $\mathrm{X}$ \\
\hline & Eucalipto citriodora & $\mathrm{X}$ & $\mathrm{X}$ & $\mathrm{X}$ & $\mathrm{X}$ & $\mathrm{X}$ & $\mathrm{X}$ & $\mathrm{X}$ \\
\hline & Hymenaea stilbocarpa & $\mathrm{X}$ & $X$ & $\mathrm{X}$ & $\mathrm{X}$ & $X$ & $X$ & $\mathrm{X}$ \\
\hline Resistência ao cisalha- & Pinus caribaea var. bahamensis & $\mathrm{X}$ & $\mathrm{X}$ & $\mathrm{X}$ & $\mathrm{X}$ & $\mathrm{X}$ & $\mathrm{X}$ & $\mathrm{X}$ \\
\hline mento paralelo às fibras, & Pinus elliottii & $\mathrm{X}$ & $\mathrm{X}$ & $\mathrm{X}$ & $\mathrm{X}$ & $\mathrm{X}$ & $\mathrm{X}$ & $\mathrm{X}$ \\
\hline plano radial-longitudinal & Pinus taeda & $\mathrm{X}$ & $\mathrm{X}$ & $\mathrm{X}$ & $\mathrm{X}$ & $\mathrm{X}$ & $\mathrm{X}$ & $\mathrm{X}$ \\
\hline$\left(f_{\mathrm{v} 0}\right)$ & Eucalipto grandis & $\mathrm{X}$ & $\mathrm{X}$ & $\mathrm{X}$ & $\mathrm{X}$ & $\mathrm{X}$ & $\mathrm{X}$ & $\mathrm{X}$ \\
\hline & Goupia glabra & $\mathrm{X}$ & $\mathrm{X}$ & $\mathrm{X}$ & $\mathrm{X}$ & $\mathrm{X}$ & $\mathrm{X}$ & $\mathrm{X}$ \\
\hline & Eucalipto citriodora & $\mathrm{X}$ & $\mathrm{X}$ & $\mathrm{X}$ & $\mathrm{X}$ & $\mathrm{X}$ & $\mathrm{X}$ & $\mathrm{X}$ \\
\hline & Hymenaea stilbocarpa & $X$ & $\mathrm{X}$ & $\mathrm{X}$ & $\mathrm{X}$ & $X$ & $\mathrm{X}$ & $\mathrm{X}$ \\
\hline
\end{tabular}

OBS.: Os tratamentos 1, 2, 3 e 6 são válidos para todas as propriedades de resistência. $\mathrm{O}$ tratamento 8, adotado pela NBR 7190/97, é válido para a resistência à compressão paralela, mas não fornece resultados estatisticamente equivalentes, em algumas das espécies estudadas, aos experimentais nos casos de tração paralela ou cisalhamento.

Percebe-se, ao observar a tabela 98 , a validade do tratamento 4, e portanto para reportar a densidade aparente, ao teor de umidade de $12 \%$, pode-se utilizar a seguinte expressão:

$$
\rho_{12}=\rho_{\mathrm{U} \%}+\rho_{\mathrm{U} \%} \cdot\left[\left(1-\delta_{\mathrm{V}}\right) \cdot \frac{(12-\mathrm{U} \%)}{100}\right], \text { com } \delta_{\mathrm{V}}=\frac{\Delta \mathrm{V}}{\mathrm{U} \%} \text { e } \Delta \mathrm{V}=\frac{\mathrm{V}_{\mathrm{U} \%}-\mathrm{V}_{\text {seca }}}{\mathrm{V}_{\text {seca }}} .10 \% \%
$$

Onde:

$\rho_{12}=$ densidade aparente ao teor de umidade de $12 \%$; 
$\rho_{\mathrm{U} \%}=$ densidade aparente ao teor de umidade $\mathrm{U} \%$;

$\mathrm{U} \%=$ teor de umidade da madeira, no instante do ensaio, em \%;

$\delta_{\mathrm{V}}=$ coeficiente de retratibilidade volumétrica;

$\Delta \mathrm{V}=$ retração volumétrica, para a variação de umidade entre $\mathrm{U} \%$ e $0 \%$, em \%;

$\mathrm{V}_{\mathrm{U} \%}=$ volume, do corpo-de-prova, ao teor de umidade $\mathrm{U} \%$, e

$\mathrm{V}_{\text {seca }}=$ volume, do corpo-de-prova, para a madeira seca $\mathrm{U}=0 \%$.

Para reportar uma propriedade de resistência ou de rigidez, ao teor de umidade de $12 \%$, percebe-se observando as tabelas 99 e 100 , pode-se utilizar: um coeficiente de correção, $\alpha$, único (valor médio) para cada propriedade, independentemente da espécie (tratamento 6, para as propriedades de resistência, e 4 para o módulo de elasticidade); ou, um coeficiente de correção, $\alpha$, único (valor médio) para cada propriedade, mas separando coníferas de dicotiledôneas (tratamento 3, nos dois casos). Evidentemente, aplicando este coeficiente nas seguintes expressões:

$$
\begin{aligned}
& \mathrm{f}_{12}=\mathrm{f}_{\mathrm{U} \%} \cdot\left[1+\frac{\alpha \cdot(\mathrm{U} \%-12)}{100}\right] \\
& \mathrm{E}_{12}=\mathrm{E}_{\mathrm{U} \%} \cdot\left[1+\frac{\alpha \cdot(\mathrm{U} \%-12)}{100}\right]
\end{aligned}
$$

Onde:

$\mathrm{f}_{12}=$ resistência, à determinada solicitação, a um teor de umidade de $12 \%$;

$\mathrm{f}_{\mathrm{U} \%}=$ resistência, à determinada solicitação, a um teor de umidade de U\%;

$\mathrm{E}_{12}=$ módulo de elasticidade longitudinal, a um teor de umidade de $12 \%$;

$\mathrm{E}_{\mathrm{U} \%}=$ módulo de elasticidade longitudinal, a um teor de umidade de $\mathrm{U} \%$;

$\mathrm{U} \%=$ teor de umidade da madeira, em \%, e

$\alpha=$ coeficiente de correção. Pode ser utilizado: um valor de $\alpha$ para cada propriedade de resistência ou rigidez, separando coníferas de dicotiledôneas; ou, um valor de $\alpha$ para cada propriedade de resistência ou rigidez, independentemente da espécie. 
Os valores do coeficiente de correção, $\alpha$, validados até o momento, são os valores médios constantes na tabela 57, do item 6.4.8. Estes valores são de difícil memorização e em conseqüência de pouca aceitação no meio técnico. Por este motivo foram refeitos os testes de Tukey utilizando os valores aproximados destes coeficientes, também apresentados na tabela 57, do item 6.4.8. Os resultados obtidos, nestes testes, também validam os coeficientes aproximados.

Um estudo do erro relativo, em relação aos valores experimentais, da utilização destes dois modelos, com coeficientes aproximados, mostrou uma distribuição muito semelhante, com erros máximos de 5,80\% (separando coníferas de dicotiledôneas) e 5,40\% (sem separar as espécies). 


\section{CONCLUSÕES}

Os resultados mostram que o modelo de regressão, que deu origem à proposta da NBR 7190/97, para reportar as propriedades de resistência e rigidez ao teor de umidade de $12 \%$, se ajusta bem aos resultados experimentais, mas fornece resultados ligeiramente diferentes dos coeficientes adotados pela norma.

O modelo proposto, para reportar as propriedades de resistência ao teor de umidade de referência, pela NBR 7190/97, é bastante razoável para a correção da resistência à compressão paralela às fibras e foi validado para as sete espécies estudadas, apesar disto o coeficiente adotado pela norma é uma aproximação grosseira do valor médio encontrado e pode

ser melhorado. Para as outras propriedades de resistência, entretanto, este modelo não se mostrou válido: para a resistência à tração paralela às fibras, o modelo forneceu resultados estatisticamente diferentes dos experimentais em quatro das sete espécies estudadas; para a resistência ao cisalhamento paralelo às fibras, no plano radial-longitudinal, o modelo forneceu resultados estatisticamente diferentes dos experimentais em uma das sete espécies estudadas.

O modelo proposto, para reportar as propriedades de rigidez ao teor de umidade de referência, pela NBR 7190/97, também não foi validado. Para o módulo de elasticidade longitudinal, este modelo, forneceu resultados estatisticamente diferentes dos experimentais em duas das sete espécies estudadas.

Por outro lado, os resultados mostram, que pode-se utilizar expressão semelhante à proposta pela NBR 7190/97, mas com coeficientes diferentes para cada propriedade de resistência ou rigidez. Ou seja, a correção de uma propriedade de resistência, para o teor de umidade de $12 \%$, pode ser feita utilizando-se a seguinte expressão:

$$
\mathrm{f}_{12}=\mathrm{f}_{\mathrm{U} \%} \cdot\left[1+\frac{\alpha \cdot(\mathrm{U} \%-12)}{100}\right]
$$

Onde:

$\mathrm{f}_{12}=$ resistência, à determinada solicitação, a um teor de umidade de $12 \%$; 
$\mathrm{f}_{\mathrm{U} \%}=$ resistência, à determinada solicitação, a um teor de umidade de $\mathrm{U} \%$;

$\mathrm{U} \%=$ teor de umidade da madeira, em $\%$, e

$\alpha=$ coeficiente de correção, fornecido na tabela 101.

Já, a correção do módulo de elasticidade longitudinal, para o teor de umidade de $12 \%$, pode ser feita utilizando-se a seguinte expressão:

$$
\mathrm{E}_{12}=\mathrm{E}_{\mathrm{U} \%} \cdot\left[1+\frac{\alpha \cdot(\mathrm{U} \%-12)}{100}\right]
$$

Onde:

$\mathrm{E}_{12}=$ módulo de elasticidade longitudinal, a um teor de umidade de $12 \%$;

$\mathrm{E}_{\mathrm{U} \%}=$ módulo de elasticidade longitudinal, a um teor de umidade de $\mathrm{U} \%$;

$\mathrm{U} \%=$ teor de umidade da madeira, em \%, e

$\alpha=$ coeficiente de correção, fornecido na tabela 101.

TABELA 101 - Valores do coeficiente de correção, $\alpha$

PROPRIEDADE DE RESISTÊNCIA OU RIGIDEZ

PROPRIEDADE DE RESISTENCIA OU RIGIDEZ

COEFICIENTE DE

CORREÇÃO, $\alpha$

\begin{tabular}{ll}
\hline Resistência à compressão paralela às fibras, $\mathrm{f}_{\mathrm{c} 0}$ & 3,5 \\
Resistência à tração paralela às fibras, $\mathrm{f}_{\mathrm{t} 0}$ & 2,0 \\
Resistência ao cisalhamento paralelo às fibras, $\mathrm{f}_{\mathrm{v} 0}$ & 2,5 \\
Módulo de elasticidade longitudinal, $\mathrm{E}_{\mathrm{c} 0}$ & 2,5 \\
\hline
\end{tabular}

Os resultados também apontam para a possibilidade de tratar separadamente coníferas e dicotiledôneas, entretanto a distribuição e a magnitude do erro relativo são tão semelhantes à da proposta apresentada acima, que, do ponto de vista prático, não justifica esta separação.

A correção da densidade aparente, para o teor de umidade de $12 \%$, não foi mencionada pela NBR 7190/97. Um modelo semelhante ao das propriedades de resistência e rigidez também foi avaliado, mas não se mostrou adequado.

Por outro lado, os resultados mostram que, para corrigir a densidade aparente ao teor de umidade de referência, pode-se utilizar a seguinte expressão: 
$\rho_{12}=\rho_{\mathrm{U} \%}+\rho_{\mathrm{U} \%}\left[\left(1-\delta_{\mathrm{V}}\right) \cdot \frac{(12-\mathrm{U} \%)}{100}\right], \operatorname{com} \delta_{\mathrm{V}}=\frac{\Delta \mathrm{V}}{\mathrm{U} \%}$ e $\Delta \mathrm{V}=\frac{\mathrm{V}_{\mathrm{U} \%}-\mathrm{V}_{\text {seca }}}{\mathrm{V}_{\text {seca }}} \cdot 10 \% \%$

Onde:

$\rho_{12}=$ densidade aparente ao teor de umidade de $12 \%$;

$\rho_{\mathrm{U} \%}=$ densidade aparente ao teor de umidade $\mathrm{U} \%$;

$\mathrm{U} \%=$ teor de umidade da madeira, no instante do ensaio, em \%;

$\delta_{\mathrm{V}}=$ coeficiente de retratibilidade volumétrica;

$\Delta \mathrm{V}=$ retração volumétrica, para a variação de umidade entre $\mathrm{U} \%$ e $0 \%$;

$\mathrm{V}_{\mathrm{U} \%}=$ volume, do corpo-de-prova, ao teor de umidade $\mathrm{U} \%$, e

$\mathrm{V}_{\text {seca }}=$ volume, do corpo-de-prova, para a madeira seca $\mathrm{U}=0 \%$.

Os resultados obtidos neste trabalho indicam a necessidade de outros estudos e a reavaliação de alguns pontos da atual NBR 7190/97, além das expressões para reportar as propriedades de resistência, rigidez e densidade aparente ao teor de umidade de referência.

No tocante à reavaliação da NBR 7190/97, pode-se chamar a atenção para os métodos de ensaios sobre estabilidade dimensional e densidade da madeira, descritos no anexo B da NBR 7190/97, que omitem a definição do coeficiente de retratibilidade volumétrica, necessário à correção da densidade aparente ao teor de umidade de referência pela eq. (53).

Outro ponto importante diz respeito ao coeficiente de modificação, que considera o teor de umidade da madeira em serviço, $\mathrm{k}_{\text {mod,2. }}$. Os resultados obtidos neste trabalho indicam a necessidade de reavaliar os valores desse coeficiente e, talvez, redefinir as classes de umidade estabelecidas na NBR 7190/97.

As relações entre as propriedades de resistência, quando se utiliza a caracterização simplificada da resistência da madeira serrada, definidas no item 6.3.3, da NBR 7190/97, também merece estudo complementar. Os resultados, obtidos neste trabalho, indicam relações diferentes das adotadas pela norma. 


\section{REFERÊNCIAS BIBLIOGRÁFICAS}

ANDREWS, H. J. (1967). An introduction to timber engineering. Oxford, Pergamon.

ASSOCIAÇÃO BRASILEIRA DE NORMAS TÉCNICAS (1980). NBR 6230 - Ensaios Fisicos e Mecânicos de Madeiras. Rio de Janeiro.

ASSOCIAÇÃO BRASILEIRA DE NORMAS TÉCNICAS (1982). NBR 7190 - Cálculo e Execução de estruturas de Madeira. Rio de Janeiro.

ASSOCIAÇÃO BRASILEIRA DE NORMAS TÉCNICAS (1997). NBR 7190 - Projeto de Estruturas de Madeiras. Rio de Janeiro.

BALLARIN, A. W.; RIBEIRO, A. B. (1998). Variação da resistência à compressão paralela às fibras da madeira de E. citriodora com a umidade. In: Encontro Brasileiro em Madeiras e Estruturas de Madeira, 6., Florianópolis, SC. 1998. Anais. Florianópolis, v. 3, p. 231-40.

BENTDTSEN, A.; GALLIGAN, W. L. (1967). Deriving allowable properties of lumber: a practical guide for interpretation of ASTM standards. Mad., Wis., USDA - FS - FPL, S.D. (General Technical Report, FPL 20).

BETTS, H. S. (1919). Timber, its strength, seasoning and grading. New York, 31 p.

BODIG, J. (1966). Stress-strain relationship of wood in transverse compression. J. Mat. 1 (3). p. 645-66.

BODIG, J.; JAYNE, B. A. (1992). Mechanics of Wood and Wood Composites. New York. Van Nostrand Reinhold Company Inc. 712 p.

BROCHARD, F. X. (1960). Bois et charpente em bois (Le matériau et son utilisation).Collection de L'Institut Technique du Batiment et des Travaux Publics. Paris. Éditions Eyrolles.

CANADIAN STANDARDS ASSOCIATION (1994). CSA O86.1-94. Engineering Design in Wood (Limit States Design). Etobicoke, Ontario, Canada.

CARRINGTON, H. (1922). The elastic constants of spruce as affected by moisture content. Aeronautical Journal, 26, 462. 
CORRÊA, M. P. (1978). Dicionário das Plantas Úteis do Brasil e das Exóticas Cultivadas. Instituto Brasileiro de Desenvolvimento Florestal (IBDF). Ministério da Agricultura. v. V. Rio de Janeiro, IBDF.

COVINGTON, S. A.; FEWELL, A. R. (1975). The effect of change in moisture content on the geometrical properties, modulus of elasticity and stiffness of timber. Garston, Building Research Establishment Department of the Environment, Feb. 1975 (Current Paper 21/75).

DESLANDES, F.; VANDENBERGHE, L. (1959). Le bois (Caractéristiques-usinage utilizations diverses). Paris. Editions Eyrolles.

DINWOODIE, J. M. (1981). Timber its nature and behavior. Princes Risborough Laboratory. Building Research Establishment. New York. USA. Van Nostrand Reinhold Company Ltd.

DRAPER, N.; SMITH, H. (1981). Applied regression analysis. 2.ed. New York. John Wiley \& Son Inc.

EUROPEAN COMMITTES FOR STANDARDIZATION (1993). EUROCODE 5 - Design of timber structures - Part 1-1: General rules and rules for buildings. Brussels.

FONSECA, J. S.; MARTINS, G. A.; TOLEDO, G. L. (1976). Estatística aplicada. 1.ed. São Paulo, Atlas.

FOREST PRODUCTS LABORATORY. (1974). Wood Handbook. USDA Handbook. No. 72, rev., Washington. DC.

GEHARDS, C. C. (1982). Effect of moisture content and temperature on the mechanical properties of wood; an analysis of immediate effects. Wood and Fiber, 14 (1). p. 4-36.

GOMES, F. P. (1982). Curso de estatística experimental. 10. Ed. Piracicaba. Escola Superior de Agricultura Luiz de Queiroz. Universidade de São Paulo.

GREEN, D. W.; EVANS, J. W.; PELLERIN, R. (1991). Moisture content and the flexural properties of lumber: species differences. In: International Timber Engineering Conference London. Anais. London, England.

HAYGREEN, J. G.; BOWER, J. L. (1982). Forest products and wood science. Iowa State University. Press: Ames.

HELLMEISTER, J. C. (1983). Madeiras e suas características. In: Encontro Brasileiro em Madeiras e Estruturas de Madeira, 1., São Carlos, SP. 1983. Anais. São Carlos, USPEESC-SET-LaMEM. Características.

HERINGER, E. P.; FERREIRA, M. B. (1975). Árvores úteis da região geoeconômica do Distrito Federal: Dendrologia, o gênero Hymenaea - Jatobás, Jataís, Jutaís, etc.. Cerrado, ano VII, n. 27, p 27-29, mar. 
KARLSEN, G. G.; BOLSHAKOV, V. V.; KAGAN, M. Y.; SVENTSITSKY, G. V.; ALEKSANDROVSKY, K. V.; BOCHKARYOV, I. V.; FOLOMIN, A. I. (1967). Wooden Structures. Moscow. Mir Publishers. 638 p.

KOLLMANN, F. (1934). Holzgewicht und Feuchtigkeit. Z. VDI 78: 1399

KOLlMANN, F. (1951). Technologie des Holzes und der Holzwerkstoffe, Vol. I, 2.ed.. Berlin - Göttingen - Heidelberg. Springer-Verlag.

KOLLMANN, F. and KRECH, H. (1960). Dynamische Messungen der elastischen Holzeigenschaften und der Dämpfung. Holz als Roh und Werkstoff, 18, p. 41-54.

KOLLMANN, F. F. P.; CÔTÉ, W. A. (1984). Principles of wood science and technology. vol. I Solid Wood. Reprint. Berlin, Heidelberg, New York, Tokyo. Springer-Verlag: 1968-1984.

KRECH, H. (1960). Größe und zeitlicher Ablauf von Kraft und Durchbiegung beim Schlagbiegeversuch na Holz und ihr Zusammenhang mit der Bruchschlagarbeit.

KRETSCHMANN, D.; GREEN, D. (1994). Strength properties of low moisture content Southern Pine. In: Pacific Timber Engineering Conference. Gold Coast. Australia. 1994. Anais. Gold Coast. PTEC 94. v. 1. p. 731-39.

KRPAN, J. (1954). Untersuchungen über den Fasersättigungspunkt des Buchen. Eichen. Tannen und Fichtenholzes. Holz Roh Werkst. 12. (3). p. 84-91.

KÜCH, W. (1943). Der Einflu $\beta$ des Feuchtigkeisgehalts auf die Festigkeit von Voll und Schichtholz. Holz als Roh und Werkstoff, 6. p. 157-61.

LAHR, F. A. R. (1983). Sobre a determinação de propriedades de elasticidade da madeira. São Carlos. 216 p. Tese (Doutorado) - Escola de Engenharia de São Carlos, Universidade de São Paulo

LIMA, J. T.; DELLA LUCIA, R. M.; VITAL, B. R. (1986). Influência do teor de umidade nas propriedades mecânicas de Eucalyptus saligna. Revista Árvore, vol. 10, n. 1, p. $27-43$.

LOGSDON, N. B. (1992). Estudo comparativo sobre a maneira de obter a densidade aparente a $12 \%$ de umidade. In: Encontro Brasileiro em Madeiras e Estruturas de Madeira, 4 , São Carlos, SP. 1992. Anais. São Carlos, LaMEM/EESC/USP. v. 4, p. 31-42.

LOGSDON, N. B. (1995). Variação da tensão resistente ao cisalhamento paralelo às fibras em uma peça de dimensões comerciais de AMESCLA, Trattinickia burserifolia (Mart.) Wild.. In: Encontro Brasileiro em Madeiras e Estruturas de Madeira, 5., Belo Horizonte, MG. 1995. Anais. Belo Horizonte, v. 2, p. 235-44. 
LOGSDON, N. B. (1998). Principais características físicas de algumas espécies florestais do Estado de Mato Grosso. In: Encontro Brasileiro em Madeiras e Estruturas de Madeira, 6, Florianópolis, SC. 1998. Anais. Florianópolis, v. 3, p. 195-204.

LOGSDON, N. B.; ALMEIDA, A. S. DE; ALMEIDA, B. C. DE; SOUZA, H. DE A.; SOARES, M. M. F.; FERREIRA, M. A. C. (1998). Estudo comparativo sobre a utilização de água destilada ou potável no ensaio de retratibilidade. In: Encontro Brasileiro em Madeiras e Estruturas de Madeira, 6, Florianópolis, SC. 1998. Anais. Florianópolis, v. 1, p. 101-07.

LOUREIRO, A. A.; SILVA, M. F. (1968). Catálogo das Madeiras da Amazônia. Superintend6encia do Desenvolvimento da Amazônia (SUDAM). Ministério do Interior. v. 2. Belém, SUDAM.

MADSEN, B. (1992). Structural Behaviour of Timber. North Vancouver, British Columbia. Canada. Timber Engineering Ltd.

MARWARDT, L. J.; WILSON, T. R. C. (1935). Strength and related properties of woods grown in the United States. U. S. Dep. Agr. Tech. Bull. Washington, D.C., No. 479, $67 \mathrm{p}$.

MATEJAK, M.; STARECKA, D. (1971). Effect of freezing of wood on its compression strength. (In German.) Holztechnol. 12 (3). p. 144-46

MATEUS, T. J. E. (1961).Bases para o dimensionamento de estruturas de madeira. Lisboa. 312 p. Dissertação (Investigador do Laboratório Nacional de Engenharia Civil) - Laboratório Nacional de Engenharia Civil, Ministério das Obras Públicas.

MCLAIN, T.E.; DEBONIS, A. L.; GREEN, D. W.; WILSON, F. J.; LINK, C. (1986). The Influence of Moisture Content on the Flexural! Properties of Southern Pine Dimension Lumber. Res. Pap. FPL-447, Madison, WI. U.S. Department of Agriculture, Forest Service, Forest Products Laboratory.

MONNIN, M. (1932). L'essai des bois. Kongreßbuch Zürich Int. Verb. Materialprüfung. $85 \mathrm{p}$.

PEIRCE, F. T. (1929). A two-phase theory of the absorption of water vapor by cotton cellulose. Journal of Textile, 20. p. 133-150.

PIGOZZO, J. C. (1982). Influência da umidade e da densidade na resistência à compressão da madeira. São Carlos. 141 p. Dissertação (Mestrado) - Escola de Engenharia de São Carlos, Universidade de São Paulo.

RIZZINI, C. T. (1978). Plantas do Brasil: Árvores e Madeiras Úteis do Brasil - Manual de Dendrologia Brasileira. São Paulo. Edgard Blücher 
SCHLYTER, R.; WINBERG, G. (1929). Svenskt furuvirkes háafasthetsegenskaper och deras beroende av fuktighetahalt och volymvikt. Stat. Provningsanst. Medd. 42. Stockholm.

SCHMIDT, U. (1995). Wood movement. GOSHEN Timber Frames. http://timberframemag.com/hardwoods/moisture.html (28/05/98)

SCHNIEWIND, A. P. (1962). Tensile strength, perpendicular to grain as a function of moisture content in California black oak. For. Prod. J. 12 (5). p. 249-52.

SIIMES, F. E. (1967). The effects of specific gravity, moisture content, temperature and heating time on the tension and compression strength and elasticity properties perpendicular to the grain of Finnish pine, spruce and birch wood and the significance of these factors on the checking of timber at kiln drying. VTT Report 84, Helsinki.

SKAAR, C. (1984). Wood-Water Relationships. In: The Chemistry of Solid Wood. Washington, DC. American Chemical Society.

SMITH, P. (1998). Black spruce, $\underline{\underline{\text { Picea }}} \underline{\underline{\text { mariana }}}$ (Mill.) B. $\quad$ S. $\quad$ P. http://forestry.auburn.edu/coops/sfnmc/class/bspruce.html (22/06/98)

SVENSSON, S. (1998). Internal Stresses in Wood Caused by Climate Variations. Lecture Hall V. A. School of Civil Engineering. Lund University. $15^{\text {th }}$ January 1998 (PHD. Thesis). http://thse.kstr.lhtse/ staffan/thesis.htm (28/05/98)

TANAAMI, R. G. (1986). Influência da umidade e da densidade na resistência à flexão de peças de madeira. In: Encontro Brasileiro em Madeiras e Estruturas de Madeira ,2., São Carlos, SP. 1986. Anais. São Carlos, USP - EESC - SET - LaMEM. Características. p.126-52.

TIEMANN, H. D. (1951). Wood technology, constitution, properties, and uses. 3.ed. London, Pitman. 396 p.

TSOUMIS, G. (1991). Science and technology of wood - Structure, properties, utilization. New York. Van Nostrand Reinhold.

WIANDY, J. E.; ROWELL, R. M. (1984). The Chemistry of Wood Strength. In: The Chemistry of Solid Wood. Washington, D.C. American Chemical Society.

WILSON, T. R. C. (1932). Strength-moisture relations for wood. U. S. Dep. Agr. Tech. Bull. Washington, D.C., No. 282, 88 p.

ZIMMERMAN, M. H.; BROWN, C. L. (1971). Trees-Structure and Function. New York. Springer-Verlag. 